\title{
Digital Saviours: Digitally Able Secondary School Teachers in their First Year of Teaching
}

\author{
By
}

\section{Louise Starkey}

\author{
A thesis \\ submitted to the Victoria University of Wellington \\ in fulfilment of the requirements for the degree of \\ Doctor of Philosophy \\ in Education
}

Victoria University of Wellington

2010 


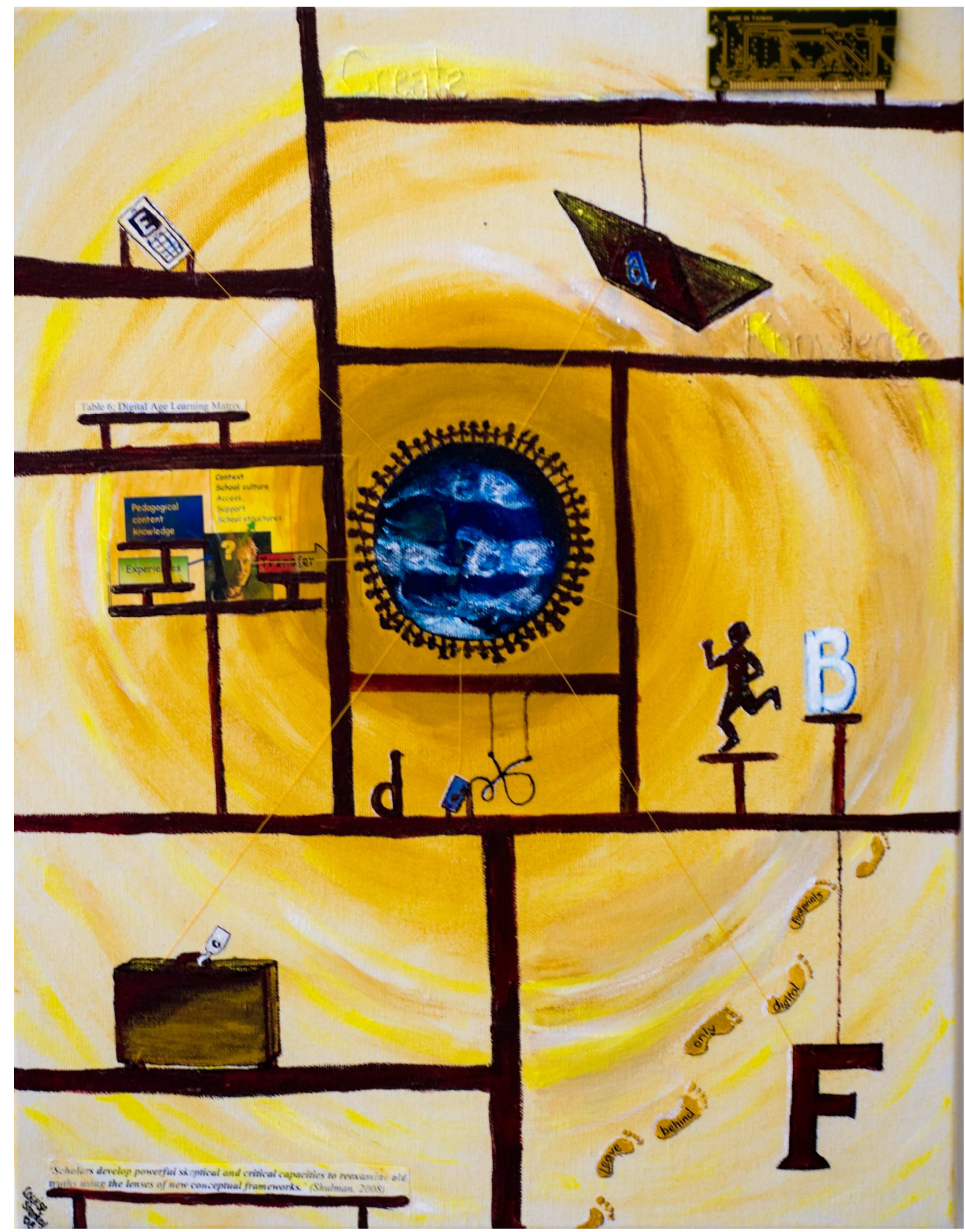

Case studies in a connected world: a pictorial representation of the $\mathrm{PhD}$ thesis. 


\section{Abstract}

The digital era is a time when available technology enables access to information, ideas and people from a range of locations, at anytime. Young graduating teachers have grown up using digital technologies and some educators see this generation as digital saviours who will sweep into schools, able to teach the digital generation in relevant ways. This thesis examines the experiences of digitally able beginning secondary school teachers as they attempted to transfer their knowledge of digital technologies to the teaching context.

The methodological approach taken in this research was a multiple case study underpinned by a complexity theory conceptual framework. Six digitally confident teachers volunteered to be examined through interviews and observation during their first year of secondary teaching to identify how they used digital technologies in their teaching practice, the learning that occurred, and the barriers and enablers experienced while attempting to integrate digital technologies into teaching praxis. A digital age learning matrix was developed as a research tool based on connectivist learning theory to measure the types of learning activities used by the teachers. Student think alouds were used to ascertain the learning that was occurring in the classroom.

During the year, each of the teachers transferred their knowledge of digital technologies while facing challenges and accessing support from within and beyond the schooling context in which they were teaching. Using generic inductive qualitative analysis, the barriers and enablers were coded to five categories based on patterns identified from the interviews including: access, experience, support, school structures and knowledge. It was found that teachers with strong pedagogical content knowledge, that included the use of subject specific digital technologies or applications, were more likely to include knowledge creation in their learning activities.

The teachers drew on their base knowledge when making pedagogical decisions. This appeared to restrict the opportunities to include knowledge creation. Web 2.0 features, such as connecting with others, collaboratively developing ideas and understandings within teacher networks or classrooms by the teachers or students, aspects of connectivist learning theory in the design of learning activities were notably absent. 
The findings from this research identified knowledge, experiences and support that could influence how beginning teachers use digital technologies within their teaching practice. The beginning teachers in this study were more likely to use digital technologies to enhance student learning when they were: (a) familiar with teaching students using a 'trial and error, ask a friend' approach to learning, (b) experienced in the use of digital technologies in specific subject specialist areas, (c) supported by mentors with pedagogical content expertise, (d) given a sense of agency, (e) given access to digital technologies, and (f) able to apply digital age learning theories and models to their teaching praxis. Digital age learning theories and models include complexity theory, connectivism, pedagogical reasoning and action for the digital age, and the digital age learning matrix. The latter two models were developed within this thesis and reflect an important development in teacher professional learning. 


\section{Acknowledgements}

I would like to acknowledge the people who have helped make the completion of this thesis possible. The data collection that was undertaken between July 2007 and June 2008 involved six beginning teachers, all of whom were adapting to the reality of teaching teenagers and working within complex secondary school settings. These teachers willingly and reflectively shared their experiences, setting aside time in their busy schedules. Without the help of the people who are referred to as Ana, Barry, Cath, Dayna, Erina and Fiona, the insights and consequential theoretical models would not have been possible.

The principals of the schools in which the teachers were based supported the research, as did the students who were interviewed and their parents. The students who enthusiastically and thoughtfully shared their thinking as they were using digital technologies helped give insight into the reality of learning processes, which proved valuable to the development of the digital age learning matrix.

Throughout the process I have been supported by Lex McDonald and Ken Stevens who supervised the development of the thesis, giving valuable advice and guidance. Janice Wearmouth also provided supervisory support during the early stages. Brenda Morrison and Susan Kaiser kindly provided editorial expertise for which I am grateful. Colleagues at Victoria University of Wellington Faculty of Education have offered support through academic discussions and encouragement during the phases of study. It is through these connections, my experiences, and ideas from academics whose work I have read, that the emerging knowledge in this thesis has been developed. The faculty, as an employer, has been generous with support of time, study leave, workshops and access to expertise.

My family and friends have always been supportive of my academic endeavours and believed in my ability to succeed. I would like to acknowledge their support and understanding as discussions often included the research I was working on, or the thesis was taken along to social events to be worked on during spare moments. In particular I would like to thank my parents, Aileen and Fred, and my son, Tana.

Lastly I would like to thank the coffee producers of the world. 


\section{Contents}

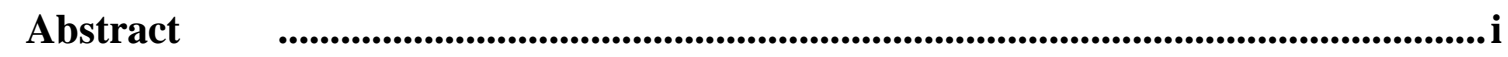

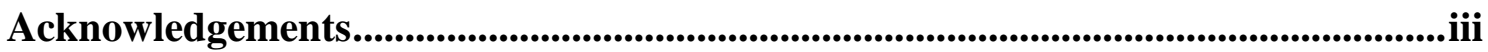

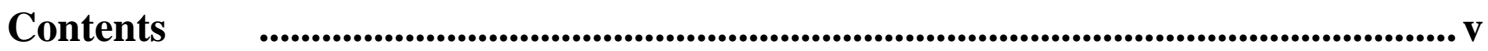

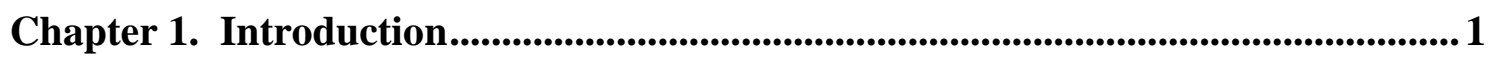

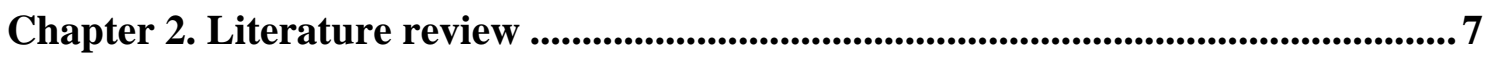

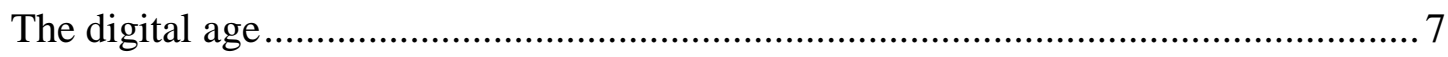

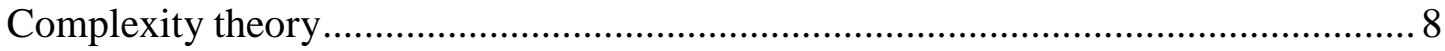

Connectivism - a learning theory for the digital age ....................................... 12

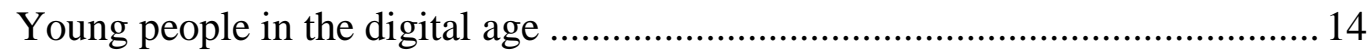

Young people using digital technologies ........................................................ 16

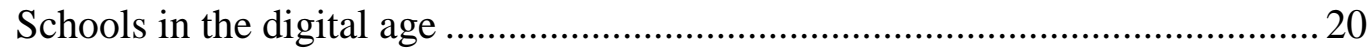

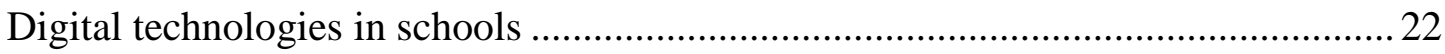

Barriers and enablers teachers face when using digital technologies.....................25

How digital technologies are used in secondary schools .................................. 33

Impact digital technology has on teaching ....................................................... 38

Impact digital technology use has on learning .................................................. 39

The problem with measuring effectiveness................................................... 42

Measuring effective use of digital technologies in the digital age..................... 45

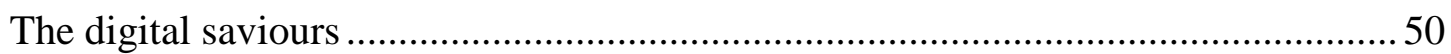

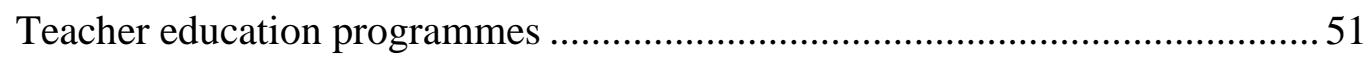

The reality of the first year of teaching ............................................................. 53

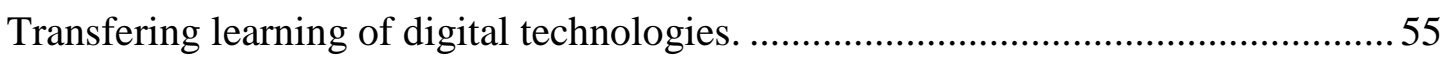

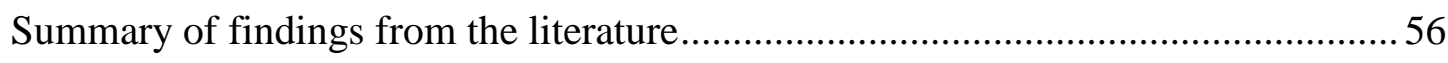

Chapter 3. Methodology and research design ......................................................6 61

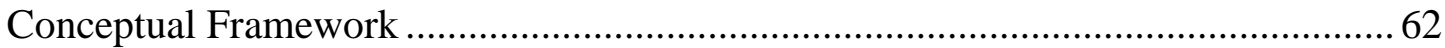

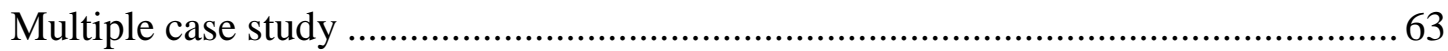

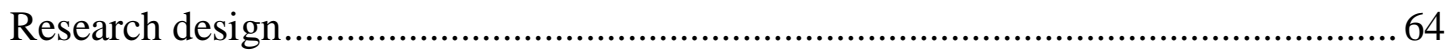

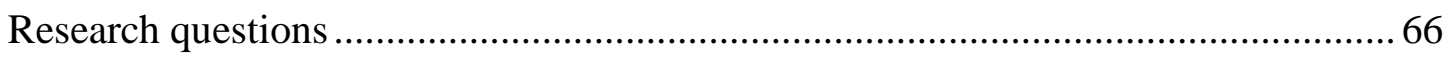

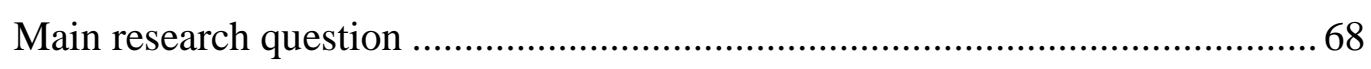

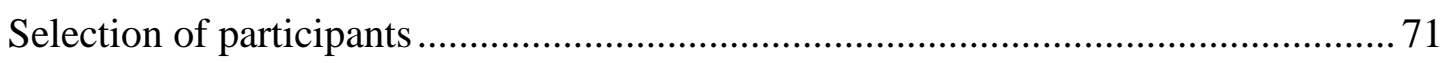

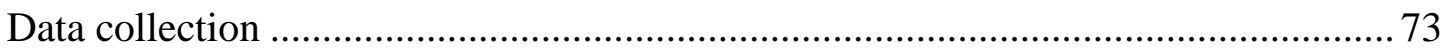

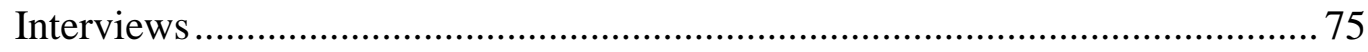

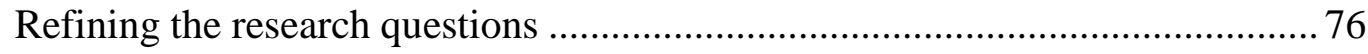

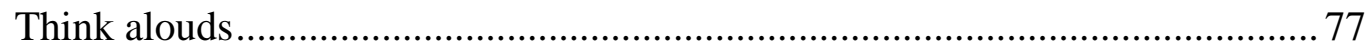




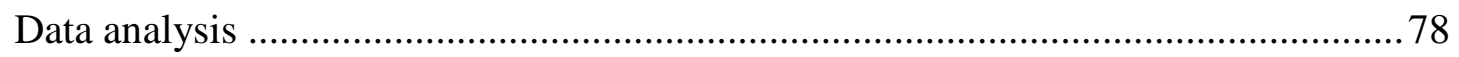

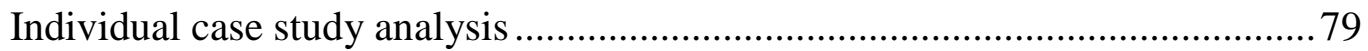

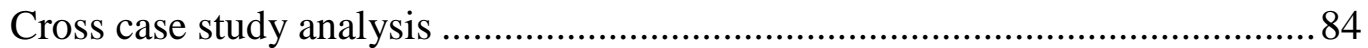

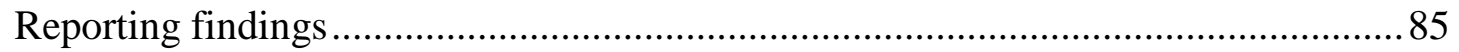

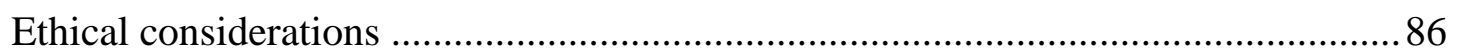

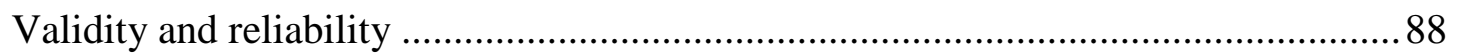

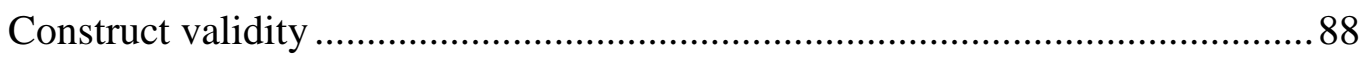

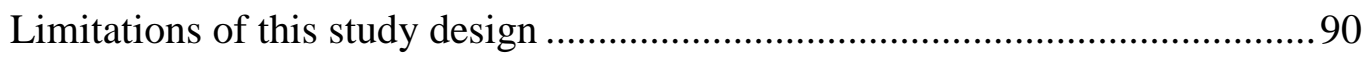

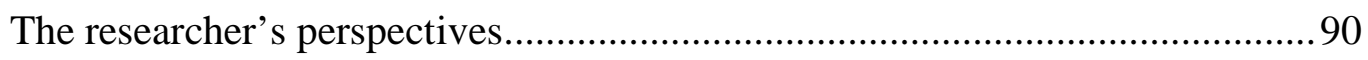

Chapter 4. Case Study Descriptions ................................................................93

Case study A ......................................................................................................................95

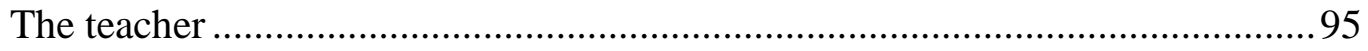

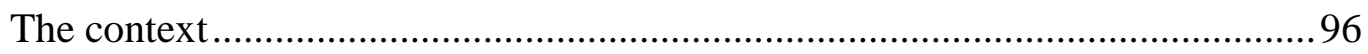

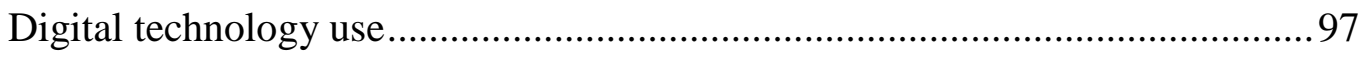

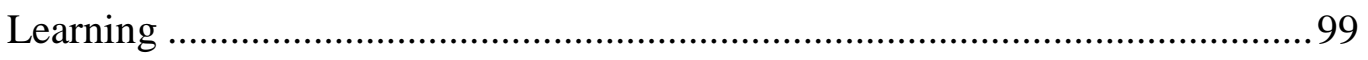

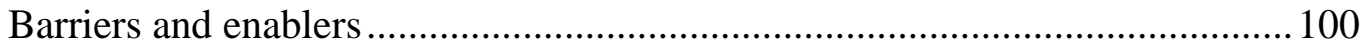

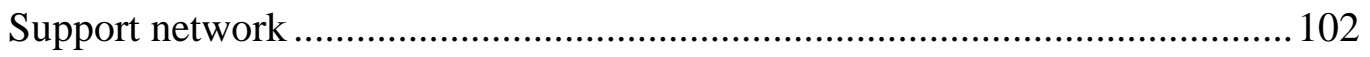

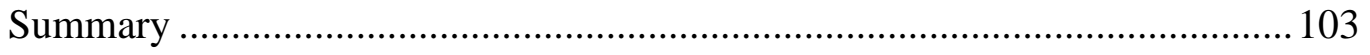

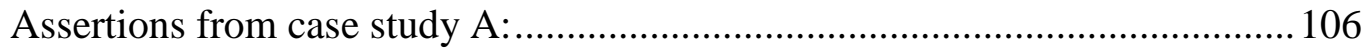

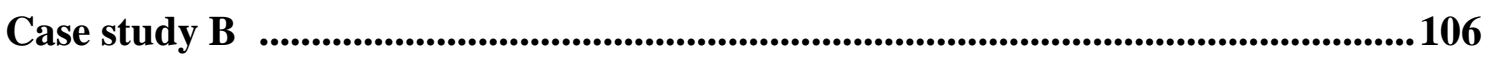

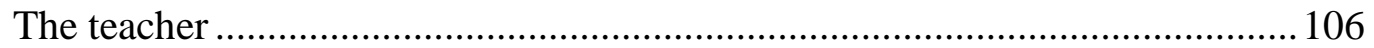

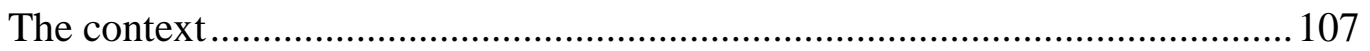

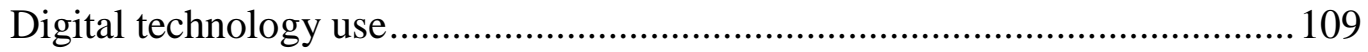

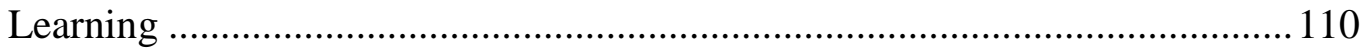

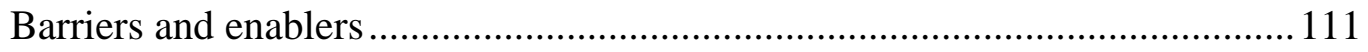

Specific example - anatomy and physiology ............................................... 113

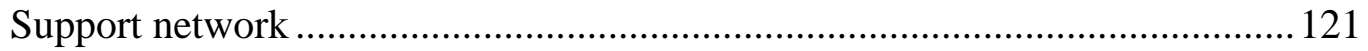

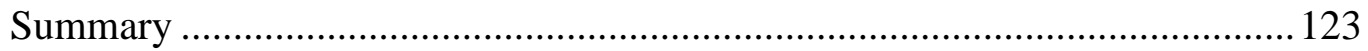

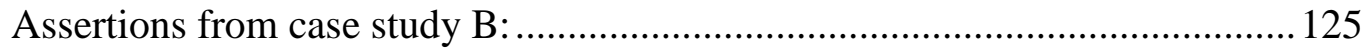

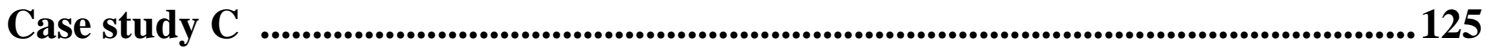

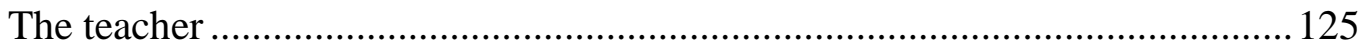

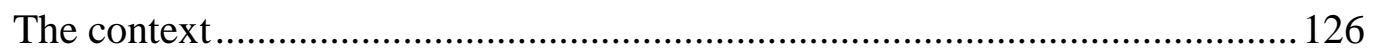

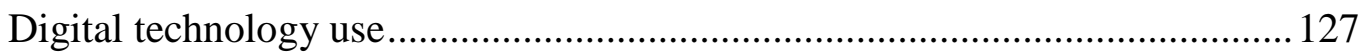

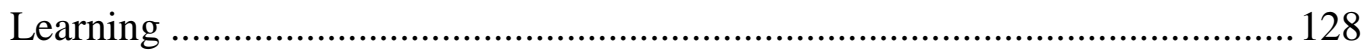

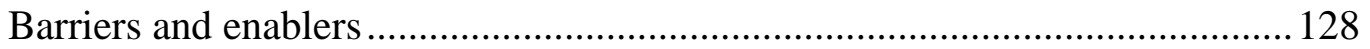

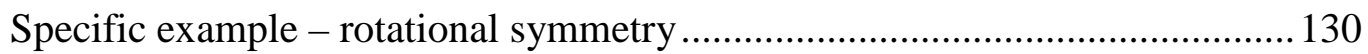




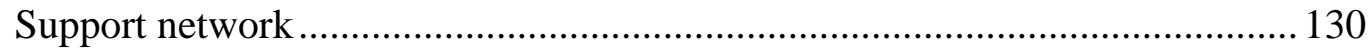

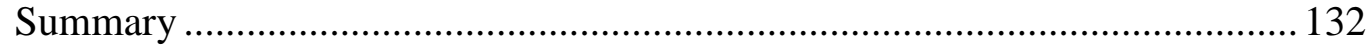

Assertion from case study C ..................................................................... 133

Case study $D$.................................................................................................................................. 134

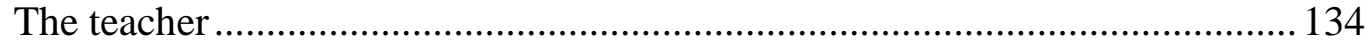

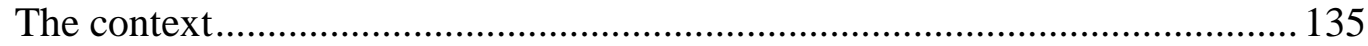

Digital technology use .................................................................................. 135

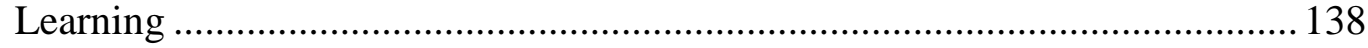

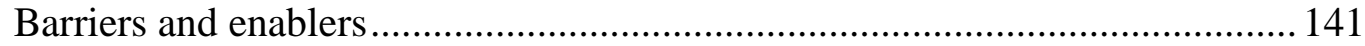

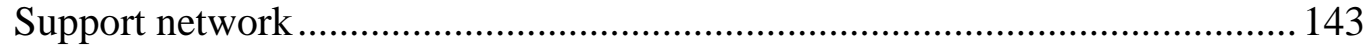

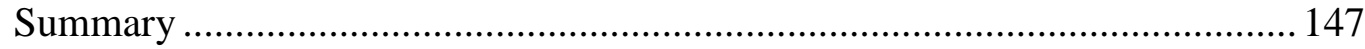

Assertions from case study D:.................................................................... 148

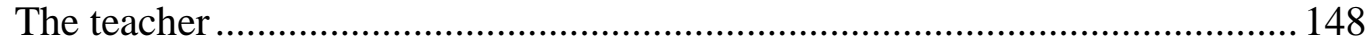

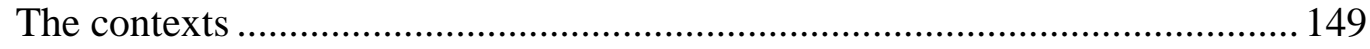

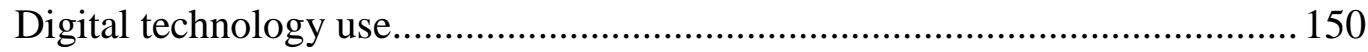

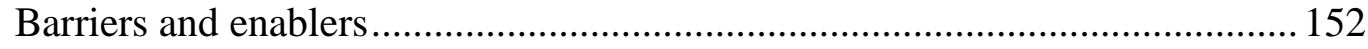

Specific example - body image …............................................................ 154

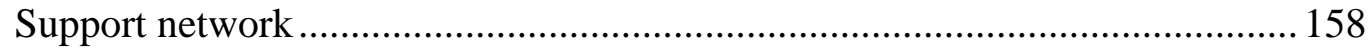

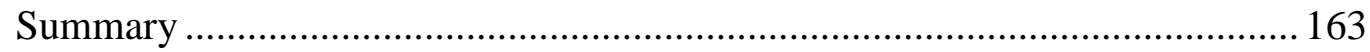

Assertions from case study E: ……......................................................... 164

Case study $F$

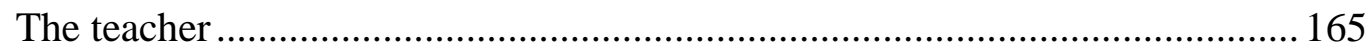

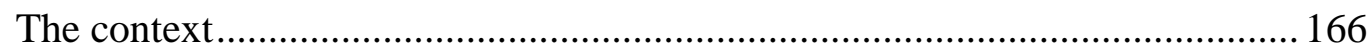

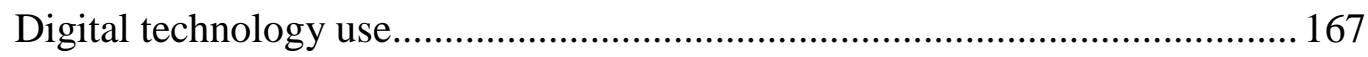

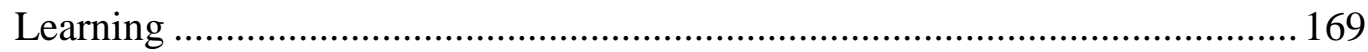

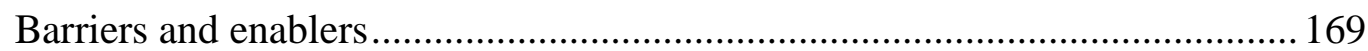

Specific example - using symbols to communicate clearly........................... 172

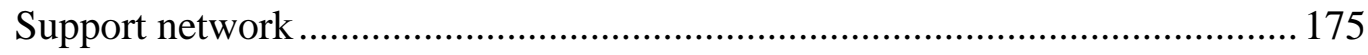

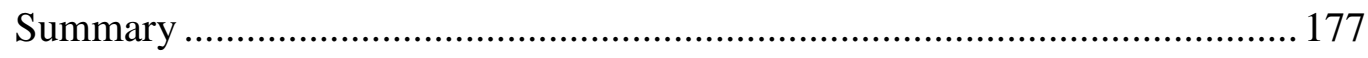

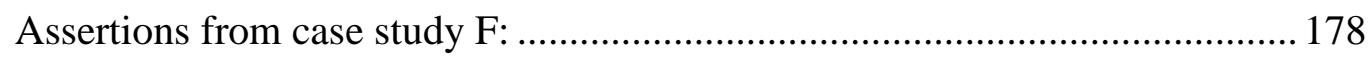

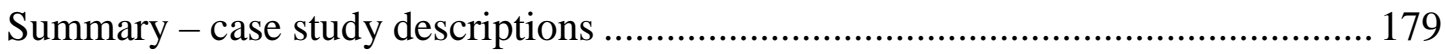

Chapter 5. Analysis and findings across the case studies....................................... 180

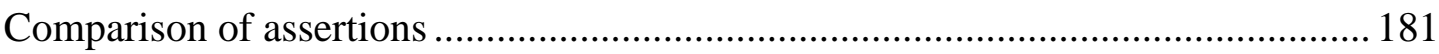

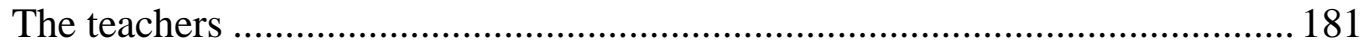

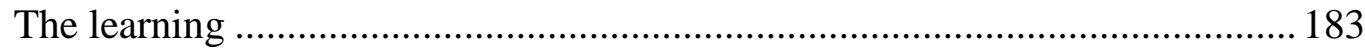

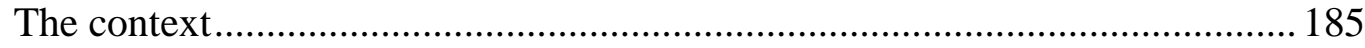


The research questions

How do digitally able beginning teachers use digital technologies for teaching and learning?

What factors impede or encourage the use of digital technologies by

beginning teachers?

How do beginning teachers connect and collaborate in their teaching and professional learning?

What learning occurs in a beginning teacher's classroom as students use

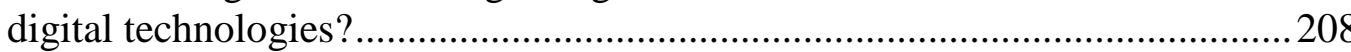

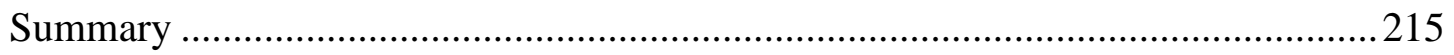

Chapter 6. Discussion ..............................................................................................2 217

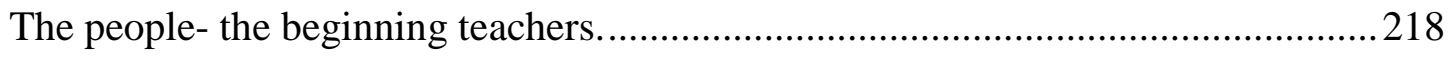

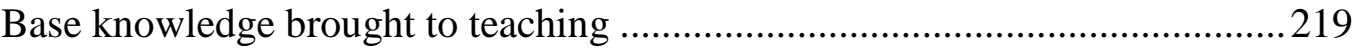

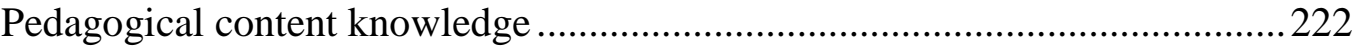

Transferring base knowledge to the school context........................................224

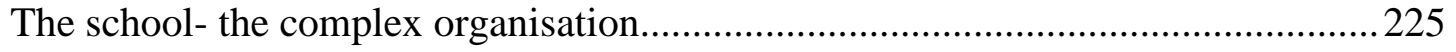

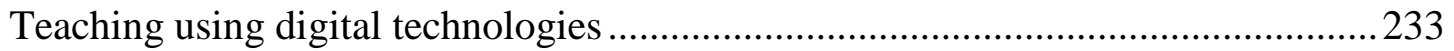

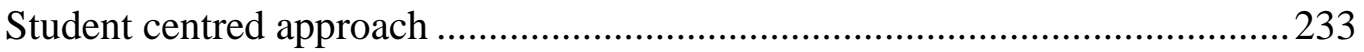

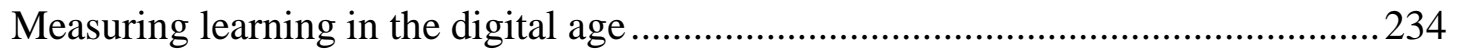

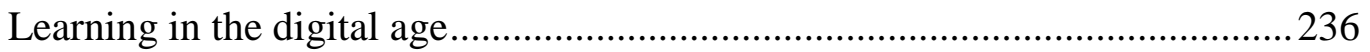

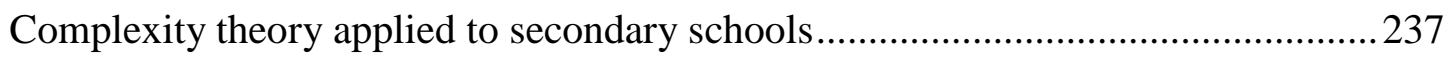

Using complexity theory as a conceptual framework. .................................. 240

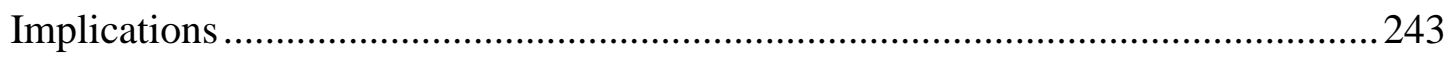

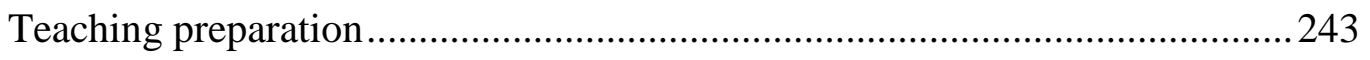

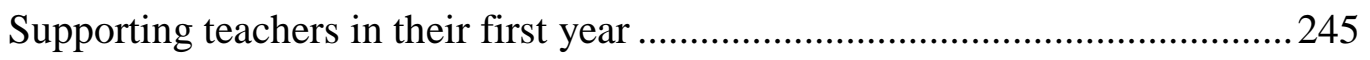

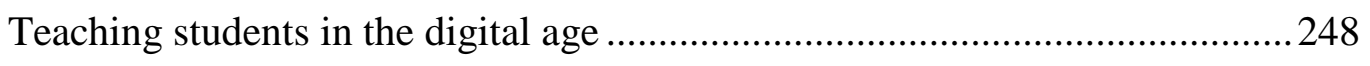

Phases of First-Year Teaching ….............................................................. 249

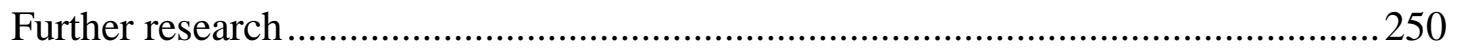

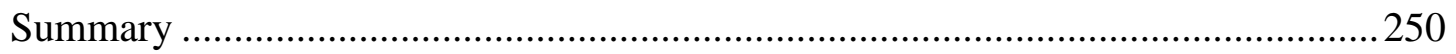

Chapter 7. Conclusion.............................................................................................................. 253

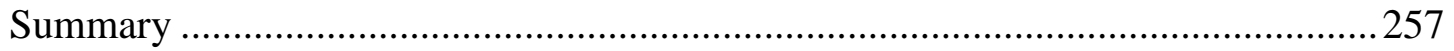

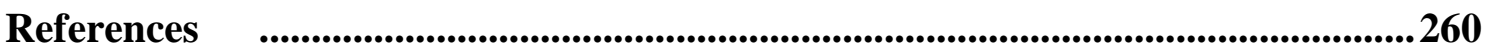

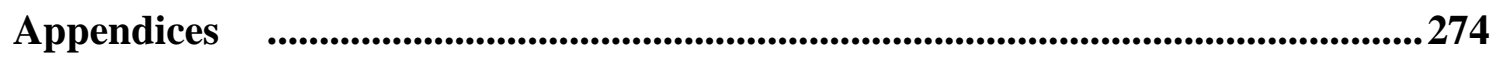

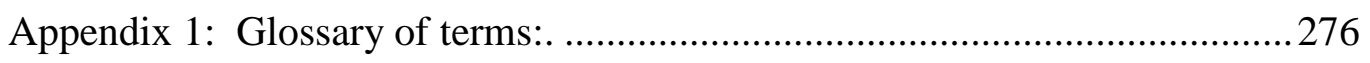

Appendix 2: Information sheet for participants. .......................................2276

Appendix 3: Information about the "Digital beginning teachers" research project for parents/ caregivers of students aged 15 and over. 
Appendix 4: Consent form "Digital beginning teachers" research project

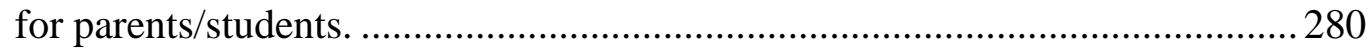

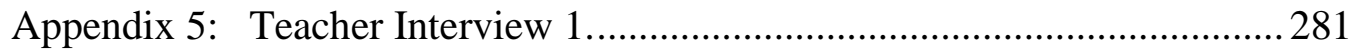

Appendix 6a: Interview 2 - observation of teaching using digital technologies. 283

Appendix 6b: Student think aloud 284

Appendix 7: Interview 3 -after teaching using digital technologies/ end of

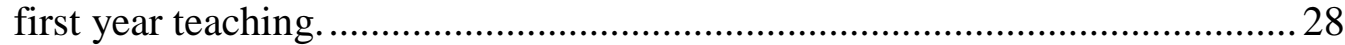

Appendix 8: Refining the research questions after initial research stage. .... 286

Appendix 9: Cross case synthesis - the purpose of reported digital technology use across the case studies.

Appendix 10: General inductive qualitative analysis. Theme: purpose or reasons given for using digital technologies. 


\section{List of illustrations}

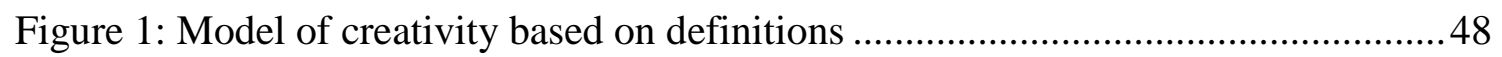

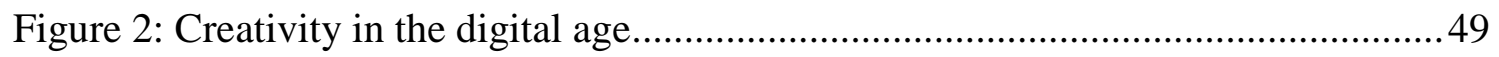

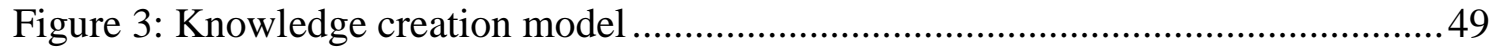

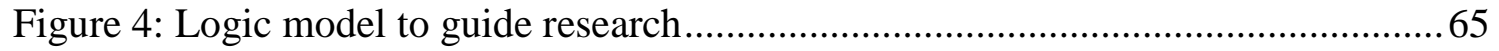

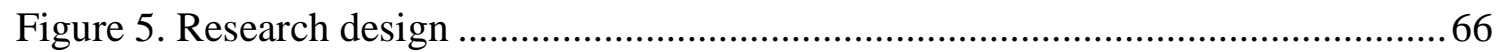

Figure 6: The relationship between the research questions......................................... 72

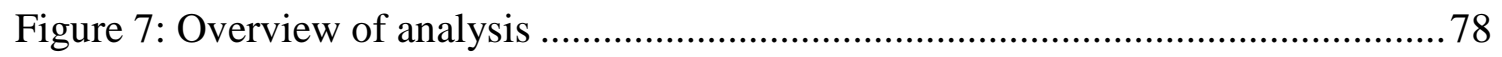

Figure 8: Generic logic model of digital technology use within a single case study ......79

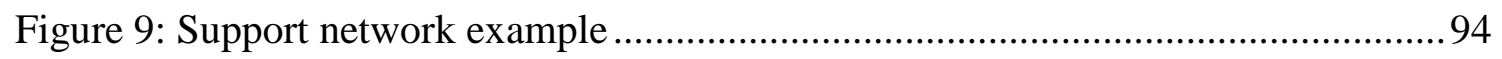

Figure 10: A generic logic model of digital technology use in teaching ......................95

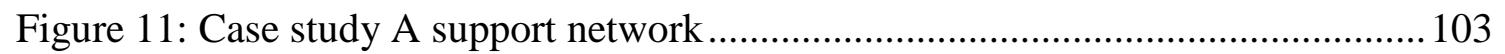

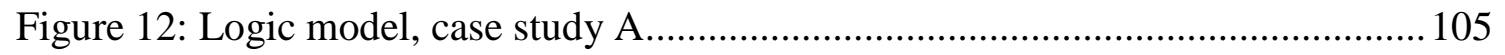

Figure 13: Case study B protopage with links to keep students focussed..................... 114

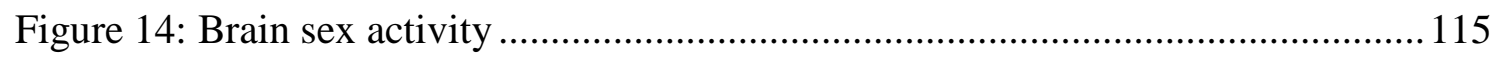

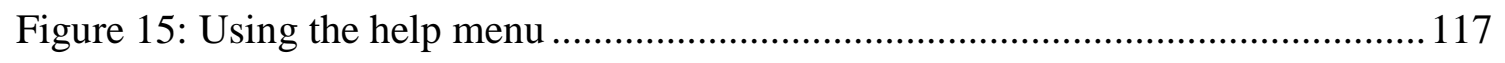

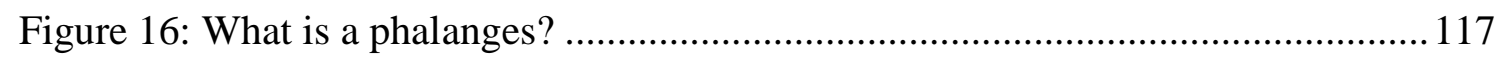

Figure 17: Case study B anatomy and physiology logic model ................................... 119

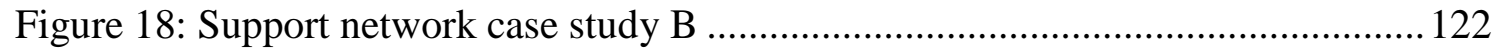

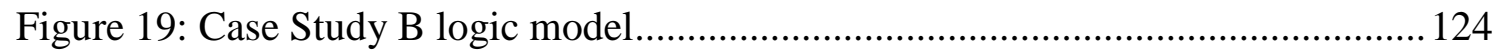

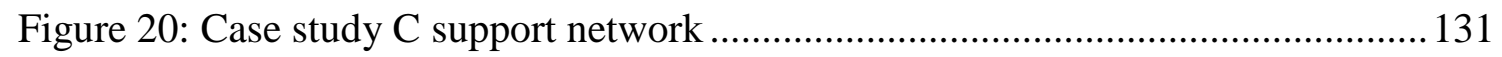

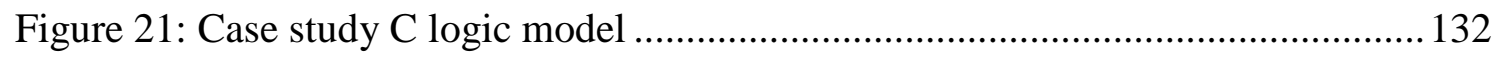

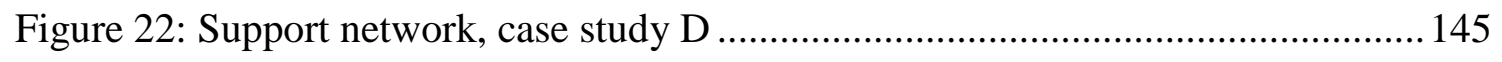

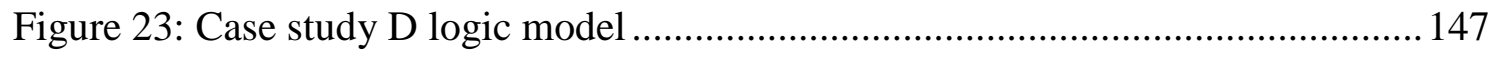

Figure 24: Body image learning activity logic model............................................... 158

Figure 25: Support network case study E, first school............................................... 159

Figure 26: Support network case study E second school ........................................... 161

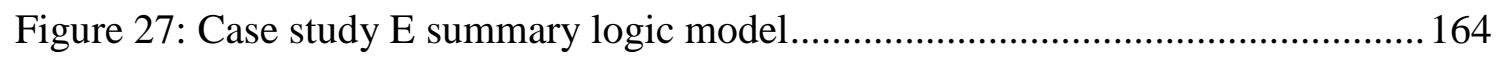

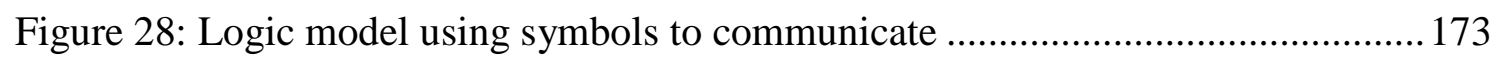

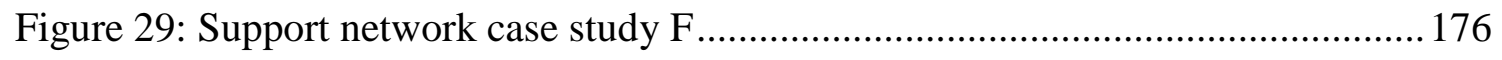

Figure 30: Summary logic model, Case study F ...................................................... 178

Figure 31: Model of ambiguously bound complex system with connections within

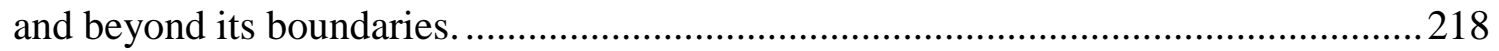

Figure 32: Transferring learning: considering whether to use digital technologies......219

Figure 33: Base knowledge for cognitive transfer of learning ......................................220 
Figure 34: Complexity of transferring knowledge. 224

Figure 35: Complex cognitive transfer of learning, case study B. 225

Figure 36: Partial representation of the complex phenomenon of secondary schooling240 Figure 37: Model of teacher pedagogical reasoning and action for the digital age ...... 245

Figure 38: The pathway towards digital technology use for beginning teachers 254

\section{List of Tables}

Table 1: How digital technologies are used in teaching and learning............................ 34

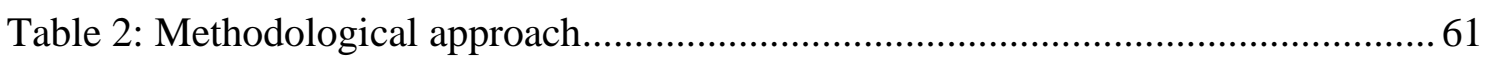

Table 3: Data sources, research questions and variables of interest. ............................ 74

Table 4: Planning for interviews using Kvale's guidelines. ........................................ 76

Table 5: Comparison of levels of learning on the digital age learning matrix with the

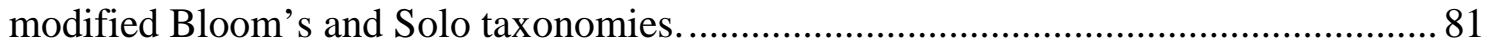

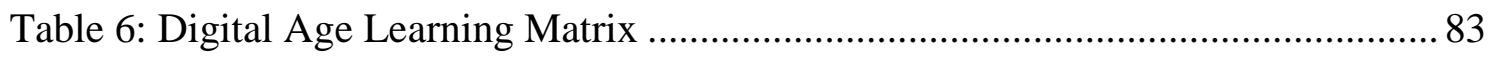

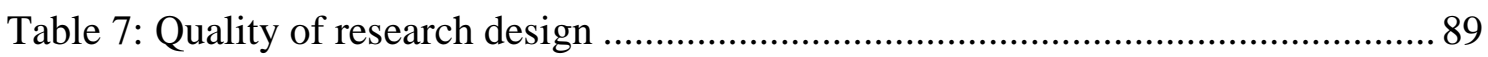

Table 8: Digital age learning matrix applied to learning activities in case study A. .... 100

Table 9: Digital age learning matrix applied to case study B ................................... 111

Table 10: Digital age learning matrix applied to case study C .................................. 129

Table 11: Digital age learning matrix applied to case study D.................................. 139

Table 12: Digital age learning matrix applied to case study E .................................. 153

Table 13: Barriers and solutions during one teaching example .................................. 155

Table 14: Digital age learning matrix applied to case study F.................................... 170

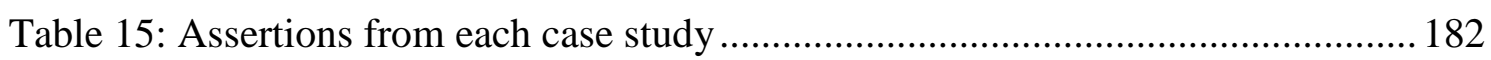

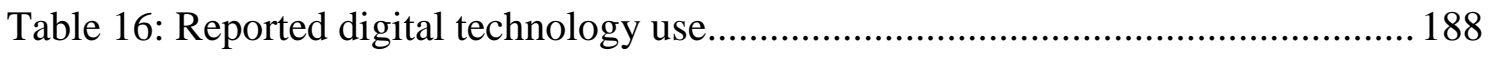

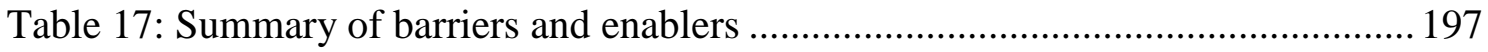

Table 18: Level of support reported across case studies ........................................... 202

Table 19: Summary of learning activities using digital technologies ..........................209

Table 20: Comparison of Becker's enabling factors with findings from this research. 226

Table 21: Contextual factors that help beginning teachers integrate digital technologies. 229

Table 22. Complexity theory conceptual framework................................................. 241 



\title{
Chapter 1. Introduction
}

\author{
Ka pū te rūhā, ka hao te rangatahi.
}

The old net is cast aside, while the new net goes fishing.

The current generation of young graduating teachers has been called the digital saviours (Cowie et al., 2008; Karsenti, Brodeur, Deaudelin, Larose, \& Tardif, 2002). They have grown up with digital technologies more so than any beginning teachers in the past: most had cell phones as teenagers, Google for information, and keep in constant contact with friends through Facebook and texting or instant messaging. It is possible that this generation of teachers will revolutionise the teaching profession at a time when baby boomer generation teachers are retiring. In the words of the whakatauki (proverb), ka pū te rūhā, ka hao te rangatahi: the old net can be cast aside while the new net goes fishing - or can it?

The introduction of digital technologies in society is influencing teaching and learning in schools in two ways. The first is through the re-examination of the concept of knowledge, the constructs of which underpin teaching and learning theories. A fundamental change in society during the digital age has been the way knowledge is developed:

Half of what is known today was not known 10 years ago. The amount of knowledge in the world has doubled in the past 10 years and is doubling every 18 months according to the American Society of Training and Documentation (ASTD). (Gonzalez, 2004, p. 5)

Knowledge can be developed and ideas shared anywhere, anytime through the internet. Web 2.0 is also known as the interactive web where participants not only access information (as with Web 1.0), but are able to comment, present their own ideas and information, and collaborate online through self-selected networks without needing to know computer-based languages. This has led to debate in educational research about the way that knowledge is conceptualised in the digital age (examples include: Bereiter, 2002; Gilbert, 2005) and as ideas about knowledge underpin learning theory and pedagogical practice this has had an effect on teaching and learning in secondary schools. Digital technologies have a ubiquitous presence in society today and consequently their widespread use is causing the second influence on teaching and 
learning in secondary schools through being available for teenagers and teachers to use both within school and in their lives beyond school.

While there is a growing body of research that examines how teachers are integrating digital technologies into their existing practice (for example: Levin \& Wadmany, 2005; Slaouti \& Barton, 2007; Somekh et al., 2007; Webb \& Cox, 2004), there is limited research into the experiences of digitally able individuals entering the teaching profession or how, and if, they integrate their knowledge of digital technologies into their teaching practice. This thesis aims to achieve an insight into the reality for beginning teachers during their first year of teaching.

Complexity theory suggests that complex systems evolve at the edge of chaos where they face constant irreversible change and draw on their history as they adapt while retaining systemic integrity (Buchanan, 2000, Davis and Sumara, 2007; Morrison, 2002). The introduction of digital technologies to society is a change which is irreversible and causing schools (which are complex systems) to adapt while retaining systemic integrity. The digitally able are a diverse new generation of teachers, some of whom are entering the profession confident and adaptable in their use of a range of technologies to communicate, problem solve, access and share information, compete, play and learn. They are joining schools and becoming part of the interconnected complex system and thus contributing to the emerging knowledge and understanding of teaching in the digital age. Complexity theory underpins this study as a conceptual framework.

The thesis first examines a selection of literature available up to 2008 which focused on digital technologies (including ICT, cell phones, computers, interactive whiteboards and subject specific software or hardware), their use in and beyond secondary schools. The literature reviewed reflects the time in which it is written and the beliefs of the researchers, thus the review aims to provide a historical context to situate the thesis. The literature findings also informed the methodological approach and variables of interest within the study.

A multiple case study which acknowledged the complex context of New Zealand secondary schooling was the methodological approach taken in this research. Six young (23-35 years old) and digitally able teachers (confidently using a range of cell phone and computer applications on a daily basis) were examined during their first year of teaching to explore how they used digital technologies, and how elements of 
the teaching context influenced them and prior learning or experiences were drawn upon. To enable the measurement of learning activities a 'digital age learning matrix' was designed, tested and applied, and a logic model was used to guide the case study data collection. This approach allowed an in-depth analysis of the experiences of a group of digitally able beginning teachers. Data was analysed in three ways; through individual cases and across cases by comparing assertions arising from individual cases, through attributing data directly to the research questions and through examining the data using a generic inductive qualitative analysis (Hood, 2006).

The teachers in the study used a range of digital technologies for teaching, administration and student learning. The motivation for using digital technologies included engaging students in learning, accessing information, preparing students for a digital world beyond school, efficiency, teacher professional leaning, saving money, minimising their carbon footprint, as well as for administration or management purposes. Digital technologies were found to be used within professional learning networks for exchanging information and organisational purposes. Digital technologies in this study included the range identified in the literature and by the participants in the research. This broad definition was deliberately chosen to reflect the emerging range of functionality that exist in cell phones and other devices such as the ability to use web2.0, SMS, MMS, text message, video conference, take a video clip or photo, calculator and voice communication.

Pedagogical content knowledge influenced the learning activities that the beginning teachers designed that incorporated digital technologies. Where the teachers reported having strong pedagogical content knowledge they were more likely to have students creating, critiquing and evaluating knowledge and personalising learning. Where the teacher was teaching in a subject where they felt their pedagogical content knowledge was not strong, student learning activities focused on understanding concepts and skills. While professional support was appreciated by all the case study teachers, the support that was most useful to the beginning teachers was from teachers in the same subject area who were able to help with the development of pedagogical content knowledge.

The context in which the teacher was situated influenced their access to digital technologies and the support they received. The relative wealth of a school 
community did not appear to correlate with the beginning teachers' use of digital technologies; more relevant were policies, school culture, leadership and the technical and pedagogical support available. A teacher's sense of agency (their belief in their ability to actively participate in school based decisions) had an impact on his or her ability to access digital technologies and support. The sense of agency was increased when the teacher was included in professional discussions about pedagogy and about the use of digital technologies in the department or school in which they were located. The teacher's unique disposition influenced the support they received and their sense of agency within their teaching context.

The approach that the beginning teachers took when considering the use of digital technologies in their teaching practice was different to that of experienced teachers. The beginning teachers used a cognitive approach as they applied their pedagogical content knowledge and experiences of using digital technologies to their classroom practice.

A selection of students were invited to talk about their learning as they were using digital technologies and reported on how they engaged in learning, the personalised nature of the activities, their use of multimedia, and the support in the learning activities they received. The approach the students took to learning was similar to their informal learning style and included a trial and error approach, checking online menus and asking a friend or peer. The use of digital technologies by the beginning teachers appeared to have a positive effect on their students' learning.

The beginning teachers in the sample were entering the profession with varying levels of understanding of how specific digital technologies are used in their subject area. Where the beginning teachers had extensive pedagogical content knowledge they were personalising their teaching approaches to align with the learning needs of the particular students and they expected their students to be creating and critiquing knowledge. The teachers did not expect students to be sharing knowledge through connections (a key aspect of learning in the digital age and connectivist learning theory). There was a gap between the educational tools being used and the conceptual understanding of learning and knowledge creation in the digital age. This gap between theoretical models and the reality in classrooms could be attributable to the time lag between the development of theoretical models and their subsequent uptake and integration into the complex system of secondary schooling and teacher 
education programmes. The beginning teachers in this study were working from theoretical models that predate the digital era. Connectivism (Siemens, 2004), the digital age learning matrix (Starkey, 2008) and a modified version of Shulman's (1987) model of pedagogical reasoning and action which reflects teaching in the digital age could be useful to beginning teachers and teacher educators in the digital age.

The focus of the research and the findings presented were interpreted through a lens influenced by the researcher's experiences and beliefs. This included a philosophy similar to Dewey's (1920) belief that the purpose of secondary schooling is to educate young people to become knowledgeable and to be able to effectively participate in the society in which they live. This means maintaining an enthusiasm for ongoing learning and contributing to the growing and evolving knowledge base in society. The researcher believes that in the digital age this includes being able to create, share and critique knowledge to actively participate in society.

This thesis was undertaken within the period of 2005-2008; the timing of the research should be considered as readers contemplate the findings. The digital world was evolving and secondary schooling was responding in its complex way. Web 2.0 applications were in the early stages of general uptake with social networking sites such as Facebook and Bebo being the main examples used, Twitter was new to the market. Cell phones, computers, gaming consoles and music players were ubiquitous household or personal items. Secondary schools in New Zealand had broadband access, teacher use of laptops, suites of computers, a growing number of data projectors and interactive whiteboards. Co-ordinated professional learning programmes under the leadership of an e-principal, focussing on the ways that digital technologies could be integrated into teaching was taking place in clusters of schools that had applied for government support. A national curriculum was launched in 2007, which allowed for a more flexible school-based curriculum, cognisant of the digital age (Ministry of Education, 2007). The dominant learning theory named and discussed in the context of professional learning was constructivism.

Young people who have grown up with computers in their homes and cell phones in their pockets are joining the teaching profession. While there has been research into the way that experienced teachers in schools are learning and using (or not using) digital technologies (for example: Auld et al., 2008; Becker, 1999; Becta, 2007; M 
Brown, 2004; Christensen \& Knezek, 2001; Cowie et al., 2008; Cuban, 2001; Hernández-Ramos, 2005), there is limited research exploring how beginning teachers are using digital technologies in their teaching practice (Clifford, Friesen, \& Lock, 2005). A semi-structured qualitative case study methodological approach was used to explore the purposes of using digital technologies in teaching, pedagogical decision making and analysing the resulting learning within the complex phenomenon of schooling, with the results presented with adequate detail to allow future readers to draw their own interpretations. 


\section{Chapter 2. Literature review}

Scholars develop powerful skeptical and critical capacities to reexamine old truths using the lenses of new conceptual frameworks. (Shulman, 2008, p.7)

The literature was examined through a complexity theory perspective to identify the emerging knowledge of teaching and learning in secondary schools in the digital age, the context in which beginning teachers work. This review begins with an overview of the digital age and complexity theory to situate the study. This is followed with an exploration of literature on learning theories appropriate for this digital age, including research exploring digital technologies in schools, teaching and learning with digital technologies, measuring effectiveness, and beginning teaching in the digital age, emerging knowledge which informed the focus and approach of this thesis. There was limited research found which explicitly examined the beginning teacher in the digital age or how students are learning while using digital technologies.

\section{The digital age}

The digital age could be said to be putting a focus on a 'knowledge economy' and impacting on global influences. Friedman (2006) proposed that the impact of digital technologies and the internet has flattened the world, equalising the opportunities to participate in the global market and across the world. Friedman's argument has a strong American perspective, focusing on the success of a few multinational companies, suggesting that developing countries are able to compete with developed countries in the business and commercial arenas and therefore schools in the United States of America need to make sure that its school graduates are prepared for this flexible knowledge economy. Friedman's underpinning rationale for including digital technologies in schools is the economic fear of being left behind - of losing market dominance - in a global economy.

Tapscott and Williams (2006) focus on the way that people participate in the market by using weapons of mass collaboration (Web 2.0 tools). In their book, Wikinomics, they explore and speculate on what happens when masses of people and organisations collaborate openly to drive innovation and growth in their industries. They note that people can be producers rather than just consumers of information and ideas, and some global entities such as the pharmaceutical industry, marketing and 
scientific organisations are using this to boost their knowledge base and potentiate innovations. The idea that access to the internet can result in individuals collectively contributing to the global knowledge base has implications for schooling and pedagogical beliefs.

The potential for individuals to collaborate through global connections available through digital technology and the internet is enabling geographically diverse people to form like-minded groups. Anderson (2006) examined the impact of the internet on sales and marketing of products which would not be viable in a small geographically bound community. He found that in a global community the market for special interest products such as a particular type of music or book can become profitable and accessible, hence the success of Amazon books. He called this phenomenon the long tail. When the long tail is applied to learning rather than the market situation, it means that through the World Wide Web, learners and knowledge creators are able to connect with others in the world with similar interests, to critique and give feedback. These connections were not available prior to the development of social software or Web 2.0. The long tail can be applied to secondary school age learning, where young people can connect with other like-minded people to enhance the personalisation of learning environments.

\section{Complexity theory}

In 2000 Stephen Hawking said that: the next century would be the century of complexity (Chui, 2000). Complexity theory has emerged from the physical sciences over the last 50 years where the cause and effect of a deterministic universe is being replaced with theories to explain how communities of organisms evolve (Morrison, 2002). Complexity theory is non-deterministic and does not predict the future (Prigogin, 1997). The emergence of complexity theory shows a domain between deterministic order and randomness which is complex. This is referred as the edge of chaos (Cilliers, 1998). Complexity theory reflects the multi-dimensional and dissipative nature of societies (Waldrop, 1992). Hence the theory has become transdisciplinary (Davis and Sumara, 2006), being applied to the social sciences to examine how complex systems (such as organisations or economies) evolve over time (Morrison, 2002).

Complexity theory has a number of defining constructs, the details of which are debatable and appear to vary across disciplines. To date there is limited literature 
specific to education or schooling in this emerging field. Davis and Sumara (2006) appear to have made a significant contribution to the application of complexity theory to the educational setting to date, their ideas, which build on other complexity theorists, are discussed, critiqued, and applied in this thesis. Radford (2008) has considered how research in a complexity paradigm may need to avoid a prediction and control methodological approach.

A complex system or organisation consists of a number of levels, with each level having a recognisable open boundary (Davis and Sumara, 2006). For example, the complexity of secondary schooling can be examined at a national, regional, school, or classroom level. Between each there are connections where knowledge can be exchanged and developed. Thus the systems are open in that exchanges occur beyond their boundaries such as through regional or national subject association teacher networks. Davis and Sumara note that matter or energy is exchanged in an open system, in this thesis the exchange or development of knowledge rather than matter or energy is the important feature when looking at how knowledge emerges within a system. Davis and Sumara's definition is an example of how details or interpretations of a construct may not align when the context is changed.

The different levels of a system or organisation could be viewed as a nested structure. Davis and Sumara (2006) note that having a nested structure is a key construct within complexity theory, though the researchers drew on the idea of fractals to explain how nested structures are self-similar. This aspect may be applied to the sciences or mathematical modelling, but when complexity theory is applied to the social sciences the complex nature of the different nested structures makes it hard to align them to be self-similar or have the same patterns repeated at different levels (which is how Davis and Sumara describe nested structures). Therefore applying complexity theory to schooling or education should acknowledge the differing scales that exist without expecting similar characteristics as seen in fractals.

A further construct of complexity theory is the decentralised control or bottom up emergent knowledge (Davis and Sumara, 2006). While schools, education systems, and classrooms appear to be driven top-down, there is research that reflects how the relationships, history, and culture within each level and from the bottom up influences and informally controls the changes which occur in a classroom (Bishop 
and Glynn, 1999; Senge et al, 2000; Wink, 2000). Thus emerging knowledge within schools is influenced by the parts, participants and processes within the system.

The emergence of knowledge within organisations occurs through the connections between the parts or participants in a system (Davis and Sumara, 2006). In the case of schooling this could include conversations between teachers in a school or department, discussions with parents, reading of research, examining data, and meetings, online information exchange with other educationalists, or conversations in the classroom setting.

A complex system is not static; it faces constant change in its structures, participants, parts, processes and knowledge. New knowledge will emerge based on history and while the system or organisation remains in tact, the structure, knowledge or systemic processes may change. The type and nature of the resulting change or emerging knowledge is not predictable (Prigogin, 1997). Therefore the impact of the introduction of digital technologies into societies and of the digitally able beginning teachers joining the schooling system is unknown.

The concept of redundancy and diversity resulting in emerging knowledge is a key component of complexity theory when applied to education or schooling (Davis and Sumara, 2006). Within a complex organisation (such as a school) innovations and ideas are introduced or emerge, with some being developed and trialled creating diversity in practices or beliefs. Like the Darwinian theory of survival of the fittest (Darwin, 1871), some innovations and longstanding practices or ideas become redundant and are discontinued or replaced. The process and decisions are likely to be unique to each specific context dependent on their history, culture and other variables such as the preferences and experiences of the teachers and the learning community and resourcing available. Through this process of diversity and redundancy knowledge emerges through connections in complex organisations.

Through the connections, complex systems or organisations draw on their history to evolve over time (Buchanan, 2000). The emerging knowledge within a complex system is informed by its history. In a schooling context this could include how the process of change has occurred in the past or the particular culture or values that have developed over time within an organisation. Each school has unique culture that has developed over time (Senge, Cambron-McCabe, Lucus, Smith, Dutton \& Kleiner, 2000). The historical component is not examined by Davis and Sumara 
(2006) even though it is a key aspect, drawn upon as knowledge emerges within education and schooling.

Complexity theory has been applied to organisations and schools. Morrison (2002) examined complexity theory within the context of schools and school leadership. He noted that by limiting research of schools to the individual parts, the whole picture can be misunderstood. He proposed that it is impossible to predict what the outcomes of one aspect of change will be in a school as there are so many factors that will influence the response. Stacey (2001) noted that human relations lie at the heart of complexity theory where the agency and mutual influence of individuals and groups create a responsive process, responding to events. It is through the networks and responses to events that new knowledge emerges; this could be applied to networks across schools, a network of learners or networks within schools. This thesis examines an aspect of emerging knowledge in the digital age applying a complexity theory conceptual framework.

To summarise, the conceptual framework in this thesis is underpinned by the following constructs which are central to complexity theory:

- A complex system is multileveled, ambiguously bound and can not be examined as isolated parts (Waldrop, 1992)

- The connections between the parts of a system are where knowledge emerges. Human relationships are an important connection in an education context (Stacey, 2001)

- Knowledge emerges through a process of redundancy and diversity within a complex system (Davis and Sumara, 2006).

- Change is not predictable (Prigogin, 1997), but the balance between randomness and deterministic order (Cilliers, 1998) influenced by historical experiences (Buchanan, 2000).

These constructs are reflected in the underpinning assumptions of schooling and teaching throughout this thesis. From a complexity theory perspective, each school, region, department and network of teachers has the characteristics of a complex system with unique variables or parts such as its' history, culture, community, leadership, students, policies, communication networks, structures, resources and 
teachers. Knowledge emerges as new and diverse ideas, resources, processes or practices are introduced while some existing beliefs, policies or practices, and new innovations are modified or become redundant. It is through this process of diversity and redundancy, controlled collectively by the parts of the system that new knowledge emerges which will be unique in some way to the context (or system). The nature and extent of the change is not linear or predictable. Change in a policy or practice will lead to further change and the emerging knowledge is dynamic, influenced by the parts, participants and processes within the system. This thesis focuses on an aspect of change occurring in secondary schooling as a sample of digitally able beginning teachers join the teaching profession.

Complexity theory constructs influenced the methodological approach to the research. Radford (2008) outlined how a complexity paradigm is different to the dominant discourse in research which he describes as the 'prediction/control' paradigm. To adopt the complexity paradigm requires a reorientation of the approach and expectations of research. When using complexity theory as a conceptual framework in education, the methodological approach should aim to avoid reductionism and acknowledge the complexities that exist as knowledge emerges. The literature review in such a framework will thus examine the historical developments relevant to the emerging knowledge at the focus of the research. A case study methodological approach allows for the close examination of a complex system (or aspects of the system) with variables of interest and frameworks or models to guide research. Findings which go beyond descriptive observations and analysis are likely to be in the form of flexible models, frameworks, and considerations for practitioners, policymakers, and future researchers to consider within their context.

\section{Connectivism - a learning theory for the digital age}

Bereiter (2002) called for a new way of thinking about knowledge and the mind. He advocated a move away from the idea of the mind as a container which he sees as a 'two dimensional world of folk theory' (p.461) to a three dimensional world better suited to the knowledge era. Jane Gilbert (2005) calls for knowledge to become a verb rather than a noun. Both authors point to the importance of collaboration and connections in the knowledge building process and knowledge not being held in the heads of individuals. This way of examining knowledge in the digital era has implications for teaching and learning. A teacher's conception of knowledge 
underpins their pedagogical approach, as knowledge in the digital age is redefined as a new theory of learning, or development of current theories appears to be required.

Gilbert (2005) proposed that learning is not the same as knowledge building. Bereiter (2002) makes a similar distinction between acquiring knowledge and creating knowledge. Learning involves mastering an understanding or skills; knowledge building takes place through connections with other people or through connecting information, ideas or processes in new ways. Gilbert notes that the significant use of digital technologies in schools of the future will be to develop relationships or connections between people, instead of the replicating of existing practice.

The abundance of information and ideas available at an individual's fingertips through the internet can be overwhelming. A learning theory for this digital era currently would consider learning as a continual process within a complex environment rather than an event. Connectivism aims to provide a basis for examining how multiple aspects of information creation interact and evolve. Siemens (2004) developed 'connectivism' as a learning theory for the digital era. The theory considers how people, organisations and technology work collaboratively to construct knowledge, building on ideas that have emerged since the introduction of widespread interaction and access to information through the internet. Siemens (2004) describes connectivism as:

The integration of principles explored by chaos, network, and complexity and self-organization theories. Learning is a process that occurs within nebulous environments of shifting core elements - not entirely under the control of the individual. Learning (defined as actionable knowledge) can reside outside of ourselves (within an organization or a database), is focused on connecting specialized information sets, and the connections that enable us to learn more are more important than our current state of knowing. (paragraph 21)

This description aligns closely with a construct of emerging knowledge within a complexity thinking conceptual framework. The connections within a complex structure occur between the core elements, which in the example of schools could include teachers, community, history and culture of the organisation, information available, processes and structures.

Scardamalia and Bereiter (2006) noted a paradox in existing theories of learning:

If learners construct their own knowledge, how is it possible for them to create a cognitive structure more complex than the one they already possess? (p. 103) 
A central idea in the learning theory of connectivism is the continual expansion of knowledge as new and novel connections open new interpretations and understandings to create knew knowledge. There is a strong link between complexity theory and connectivism- both recognizing the importance of the relationships and the knowledge that can emerge through interactions or connections. (Siemens, 2004)

Connectivism as a learning theory is relatively new, hence the literature and research is somewhat limited. The theory development itself and has been debated and clarified in the blogosphere with a variety of educationalists connecting through open online networks, which has in turn, contributed to its emerging form (Downes, 2008a; Hook, 2008; Sessums, 2007) and through organised learning opportunities such as the connectivism and connective knowledge online course (Downes, 2008b). The development of the theory has been collaborative and open to anyone to contribute. This use of digital technologies to construct and develop knowledge (in this case theory) aligns with complexity theory.

Discussion around theories of learning for the digital age has also taken place in more traditional academic forums such as through journals and conferences. For example, Brown (2006) proposed that the focus in the knowledge era should be on how to navigate the information and knowledge available through digital technologies rather than creating knowledge. He described navigationism as a broader concept than connectivism, as creating knowledge should have less emphasis than navigating through knowledge. He argued that there was a need to move from content driven teaching to a focus on information navigation skills, which he saw as essential skills for students to learn in the future, noting that they are unlikely to be constructing new knowledge. His ideas differed from Siemens (2004), reflecting a different view of learning. Brown placed emphasis on students accessing existing knowledge, Siemens emphasised connecting existing knowledge to create new interpretations or understandings.

\section{Young people in the digital age}

Young people are an integral part of the schooling system and therefore contribute to the emerging knowledge within the complex organisations in which they belong. To evaluate the use of digital technologies in the process of learning, current models of professional development would suggest that the learning that students experience is an important measure (Guskey, 2000; Kirkpatrick, 1994). 
Digital technologies have been affecting the lives of the young - with programmes designed for preschoolers, children and youth, gaming and mobile communication devices all becoming ubiquitous items. The effect this is having on teenagers and the implications for education have been speculated on and researched to varying degrees in the literature.

Literature about young people in the digital age is divided into three areas: speculations about the generation, how teenagers use digital technologies, and research concerning what they say about the effect of technology on learning and school. Young people who have had access to digital technologies have been labelled as the net-generation or N-gen (Tapscott, 1998), digital natives (Prensky, 2001), the Google generation and generation C (Dye, 2007), the underpinning idea being that they are different to previous generations in the way they live and learn due to technological developments.

Tapscott (1998) introduced the term N-gen, a shortening of net generation, as a description of the youth of the time he says grew up with internet access. In 1998 the young people might have had access to the internet for a few years; they would be unlikely to have had access since their toddler years. Naming youth in 1998 as the net generation appears premature. The research appears to be based on young people Tapscott had spoken with on a small sample of websites. While the author notes that this generation of young people has greater access to information so life will be different for them, the book was ostensibly an interesting opinion-based dissertation which raised the idea of a generation that is living in differing times and gaining different skills through the use of the internet. The beginning teachers in the study would be categorised as N-Gen by Tapscott's definition.

Three years after Tapscott's publication, Prensky (2001) introduced the idea of the digital native to describe people who have grown up with access to digital technologies not knowing a life without them. He likens it to a first language; hence, digital immigrants are like second language learners. He hypothesised that digital native youths switch off at school as they are not being taught in a way that fits with their multi-tasking gaming, internet and instant messaging worlds (Prensky, 2005a, 2005b). While the idea of digital natives and digital immigrants has been a widely accepted metaphor it appears to lack a basis in research. 
A third commonly used term for the young digital technology using people is the Google generation, defined by Wikipedia as those born after 1993 that use search engines as their first port of call. Rosa, Cantrell, Hawk and Wilson (2005) interviewed 396 college students in six countries during 2005 and found that $89 \%$ of college students used search engines to begin an information search. The report noted that professors are also likely to use internet searches as a starting point, so maybe rather than a Google generation it is a Google era or time.

A recent name for the current digital generation is Generation C (Dye, 2007) with the C representing content; the author noted that it could also stand for creativity, consumption or connected the latter three giving a Web 2.0 and connectivist flavour to the term. The labels given to youth have changed over time to align with developments and usage of digital technologies. The school students and beginning teachers in this research could align with characteristics of the $\mathrm{N}$-gen, digital native, Google generation and/ or generation $\mathrm{C}$.

\section{Young people using digital technologies}

How young people (secondary school student age) use and respond to digital technologies has been the subject of research. In a 2006 study of 935 12-17 year-olds and their parents in the USA, Lenhart, Madden, Macgill, and Smith (2007) found that $93 \%$ of the teens surveyed were using the internet with increasing numbers using Web 2.0 functions. This included $39 \%$ of online teens sharing their artistic creations online (artwork, photos, stories, or videos), 28\% blogging, and 26\% mashing content they found online into their own creations. These figures show an increase from an earlier similar survey taken in 2004 (Lenhart \& Madden, 2005) which found teenagers accessing tools to remix and create media, and half of the teenagers in the study were found to be content creators, blogging remixing or creating their own digital products. The extent to which the content being shared was new knowledge was not examined in this research. This growth in sharing digital creativity reflects the increasing use of Web 2.0 amongst American secondary school students. If similar studies were conducted in New Zealand they would be likely to show a similar growth trend of online interactions. Analysis of the same data set found that $89 \%$ of the teens thought that digital technologies made their life easier (Macgill, 2007) which would be a motivation for ongoing use. 
Research into the use of mobile digital technologies such as mobile phones is relevant to this research as this is the more obvious digital technology used by teenagers. Ten group interviews were undertaken in 1999 in Norway to gather information on the way that teenagers used cell phones. Ling and Yttri (2002) found that cell phones were used for micro-coordination: organising meetings, transport arrangements etc with family and friends. In a later article using the same data (Ling \& Yttri, 2003), they reported that power relationships with teenagers and parents altered with the introduction of mobile phones. Complexity theory would suggest that this is unlikely to be a simple causeeffect.

A UK study of mobile phone use amongst 11-16 year-olds reported that students tended to get phones when they began secondary school (Vincent, 2004). The mobile phone was a 'coming of age' symbol, used as an organiser and for communications with family and friends. There are differences between the situation in UK and in New Zealand. The pricing plans available explain different types of mobile phone use in different settings. New Zealand teenagers tend to text friends using text language, rarely using their phone to talk to their friends, which contrasts with UK teenagers who use voice calls. The year the data were gathered was not found in the research report. Mobile phones are an important digital technology to teenagers, and how beginning teachers used or did not include this in their teaching practice was of interest in this research as cell phone technology has not been included in a lot of the literature on the use of digital technologies in schools or learning apart from some innovative pilot schemes (for example, Attewell, 2004).

Research into youth use of search engines found critical skills in accessing and evaluating information to be poorly developed. Though put into context, the research also found this was not only a feature of young people, but that professors also lacked the tenacity and skills for effective online searches (Jenkins, Clinton, Purushotma, Robinson, \& Weigel, 2007). Assumptions made about the Google generation were found to be not necessarily true. Many beginning teachers and the students they teach are part of this so-called next generation; students' and young people's voices as they use digital technologies should be included in research to avoid incorrect assumptions being made. There is emerging research that encompasses young people's perspectives, including a number of studies by the Pew Internet and American Life Project (Lenhart, Hitlin, \& Madden, 2005; Lenhart \& Madden, 2007b; Lenhart et al., 2007). 
In a New Zealand study, Bolstad, Gilbert, Vaughan, Darr and Cooper (2006) asked young people to present their ideas about learning in the digital age. While a novel research method was employed which involved the students making a digital presentation, the students did not articulate their ideas about learning as the researchers had hoped, reflecting that the connection between participants in a complex system does not always lead to emerging knowledge. The researchers did report on the diversity amongst the students in the type, way and frequency of technology use and noted that where digital leaders go, others may not follow. The findings align with a study of 4000 random telephone interviews in the USA funded by the Pew Internet and American Life Project which found diversity amongst users, including age, as a factor in technology use. The researchers designed a typology of digital technology users to reflect their diversity (Horrigan, 2007). The diversity amongst students and beginning teachers was a consideration in this research.

There appears to be a lack of research that examines how students learn while using digital technologies. The Zilda research (Bolstad et al., 2006) has, however, done some introductory investigations into how students learn while using digital technologies. Further research would help to get a picture of the connection between students using digital technologies in a formal setting and their learning.

Not all young people have access to digital technologies. Research has been carried out in communities where digital technologies are not commonly accessible. Mitra (Mitra, Dangwal, Chatterjee, Jha, Bisht \& Kapur, 2005) led what is known as the hole in the wall experiments in India in the late 1990s. This involved placing a computer in a poor neighbourhood in India and monitoring what happened. He found that children gathered around the computer, learning how to operate it including the necessary English language. He postulated that a curriculum needs three things: a teacher, someone who is more knowledgeable than the learner, and a peer group. The postulations appear to ignore the key findings of the experiment - which the students managed to learn without a teacher or some expert on hand who knew more than they did as a group. The learning that occurred appears to reinforce the complexity/ connectivist concept of knowledge emerging through connections of people, ideas and/or information. It also reinforces ideas embedded in socio-cultural theory about the influences of the group and global culture. Unfortunately the experiments were carried out before Web 2.0 applications were available, between 1998 and 2000 and therefore the students in the experiment were unlikely to have had the opportunity to connect online with other people. 
While there is no evidence that the current generation of students are homogenous, there is evidence that they are heterogeneous. There is no evidence that their brains are wired differently or that they have less concentration than previous generations. Research being carried out in Australian universities to examine students' use of digital technologies found diversity amongst the students and found a selection of tools and technologies for which use and access border on being both universal and uniform (Kennedy, Judd, Churchward, Gray, \& Krause, 2008). The university students relied heavily on digital technologies for study, listening to music, for keeping in touch with friends through calling and texting, and for information gathering. In a 2005 study of children from the United Kingdom, which included surveys and interviews, four categories of digital technology users were identified: digital pioneers, creative producers, everyday communicators and information gatherers (Green \& Hannon, 2007). These results reflect some diversity amongst users and the report acknowledges that not all young people are digital enthusiasts, despite the ubiquitous use of cell phones and digital music players. It is possible that a number of young people in New Zealand would identify with more than one of these categories.

Research from the Pew Internet and American Life Project concluded that the digital divide was not access to hardware, but to knowledge (Levin, Arafeh, Lenhart, \& Rainie, 2002). Though in the era of Web 2.0 perhaps not being able to create and share knowledge through connecting online disadvantages those without adequate access.

Concern has been raised about the effects of a digital divide within the school community, a nation and globally (Brown, 2005; infoDev, 2005; Somekh et al., 2007). A report funded by the MacArthur Foundation et al., (2007) aimed to shift the focus of the conversation about the digital divide from access to technology to developing the cultural competencies and social skills to enable participation in a Web 2.0 environment, and noting that school was the logical place to provide this. Access could be considered to include the competencies that are required to participate in the global online environment.

Having access to broadband influences how the internet is used and how much young people will contribute to the online environment (Lenhart et al., 2005). In a study of teenagers in the USA in 2005 it was found that half had access to broadband, $74 \%$ 
accessed the internet mainly from home and $51 \%$ were going online daily. This indicates that in 2005 the internet was part of the daily lives of US teens.

From this research into youth use of digital technologies, it was assumed that New Zealand secondary school-aged students and beginning teachers in 2007 were familiar with the internet, diverse in their attitudes to digital technologies, and that the majority owned the youth-identifying mobile phone to keep in touch frequently with friends and family. Some were connecting online for gaming, instant chat or social networking, finding information, downloading music or sharing creative products with others. Then they went to school...

\section{Schools in the digital age}

A beginning teacher works within complex structures including a school, the educational system and regional networks. The introduction of digital technologies into society has included the introduction into schools and the education system which is a catalyst for the development of new understandings and knowledge about schooling, teaching and learning in the digital age.

The current generation of secondary school students use a range of digital technologies in their lives. Students join social networks such as Bebo where they share information online, they take part in online gaming and are in constant contact with peers through cell phone technologies (Lenhart et al., 2005). The use of interactive digital technologies is not necessarily limited to learning and interacting beyond school. All secondary schools in New Zealand have broadband that gives students and teachers the potential to interact and exchange ideas or information through the internet using Web 2.0 applications (Johnson, Kazakov \& Švehla, 2005).

There is an evolving range of literature since the introduction of digital technologies into secondary schools. The literature is written within the epistemological beliefs of the researcher and reflects their pedagogical beliefs and the events of the time in which they are writing (Scott \& Usher, 1996). Research reports from the late 1990s frequently focussed on the ratio of students to computers, reflecting the quasi market system underpinning secondary education in New Zealand at the time.

The 1989 Education Act changed the way that schools were governed. There was increased community and local decision making and less central control. Decisions 
about the use of a bulk grant for curriculum and learning support to schools was devolved which meant that decisions about the purchase of digital technologies, support for the technologies and teacher professional learning became a function of the boards of trustees who governed individual schools (Jesson, 1997). This change coincided with an era of a quasi-market schooling system (Gordon, 1997) where marketing and the image of schools became a priority for some boards of trustees and the ratio of computers to students was included in marketing information as a desirable feature of a school. In New Zealand, the 1990s became a time when secondary schools were very image aware, marketing themselves and conscious of the ratio of computers to students, figures which could be misleading if administration computers were included.

Towards the end of the 1990s a growing tension about the value of using computers in schools is found in the literature. The policy and assumptions about the benefits of computers in schools was being questioned by educational writers such as Oppenheimer (1997) and Cuban (2001).

Oppenheimer (1997) expressed concern in the 1990s at the US government's desire to increase computer ratios and computer use in schools at the expense of learning arts and physical education. He noted that in examples of research which reported improved student achievement and innovative use of computers, the studies themselves were anecdotal rather than research based and that it was the teachers' pedagogical approach that was behind improved student learning rather than the use of the digital technologies.

Cuban (2001) summised that the teachers in his study adapted computer use to fit with their traditional practices rather than adapting the way they teach to take account of the opportunities offered by computers (as had been hoped by policy makers and some proponents of information communication technologies). When he compared the introduction of computers in schools with previous innovations, he found that the process of change in schools can be intergenerational, taking decades rather than a few months or years. Research in the early 2000s tended to focus on if teachers were using digital technologies in their teaching and the factors that were helping or preventing their use of them. Student learning as a result of the use was not examined, perhaps due to a lack of frameworks to measure learning. Engagement was examined (Passey, Rogers, Machell, \& McHugh, 2004), a focus that aligns with 
constructivist perspective which was the dominant learning theory and research discourse of the time.

The Pew Internet and American Life Project commissioned research into how the internet is being used by American 12-17 year-olds. The researchers surveyed 136 students in 2002 and found that internet using students relied on the internet to help them navigate their way through school, to juggle school assignments and extracurricular activities. The research identified five metaphors for the way that students used the internet: the internet as a virtual textbook, virtual tutor, virtual study group, virtual guidance counsellor and virtual locker or notebook (Levin et al., 2002). This research reflects a time when students were starting to use the internet to collaborate and learn informally beyond school. The students reported that schools did not integrate this use into the teaching and learning programmes. This was prior to Web 2.0 technologies being widely available so the internet was a source of information and storage and the dominant teaching and learning focus was on students learning existing knowledge by accumulating information.

Cox et al. (2004) reviewed studies on the use of digital technologies and student attainment and concluded that digital technologies only enhance student achievement when it is combined with effective teaching practices. This review reflects the changing focus in the literature at the time on how aspects of secondary schooling influence student learning, in this case how digital technologies are being used to enhance student learning. Schools have been accumulating digital technologies since the 1990s and the focus in the literature has turned to examine how teachers are using these digital technologies in their teaching practice and the outcomes for students.

In summary, a number of studies on the use of digital technologies in secondary schools report on whether teachers are using digital technologies, the barriers and enablers for teachers using digital technologies and/or how digital technologies are being used. Debate around the implications for learning processes appeared to be a gap in the literature. The focus of research into digital technologies in schools has changed over time.

\section{Digital technologies in schools}

The introduction of digital technologies into society and into schools is a change that has an affect the complex systems of schooling and education, the extent of this as 
reported in research to date is examined in this review. Complexity theory suggests that through the experiences and connections of the participants within and beyond the schools, the digital technologies are integrated or rejected and the schools continue to operate.

Digital technologies such as computers and calculators have been used in schools since the 1970s (Cuban, 2001). The digital technologies and software that are available for use in schools are of three types: those that are designed for the business world then used in schools, those which have a subject specific application, and those that are designed specifically for use in schools. Particular digital technologies will reflect the socio-cultural norms for the users they were designed for (Sutherland et al., 2004). PowerPoint for example was designed for business presentations and computers were designed to sit on office desks. Thus at the start of the digital age the digital technologies that are available and accessible to schools may not be ideal for the socio-cultural context of a classroom. As young people and educators have input into the development of technologies and software, a greater range more suited to learning at secondary school and in the digital age is beginning to emerge such as Web 2.0 tools and networks.

In a study of computer use in two schools in Silicon Valley (USA) during 1998-99, it was concluded that the cost of investing in computers (in both time and money) had not been educationally worthwhile (Cuban, Kirkpatrick, \& Peck, 2001). The researchers had assumed that by studying schools in Silicon Valley they were likely to see computers being used to enhance learning. They found very little use with less than $5 \%$ of teachers integrating computer technology into their teaching practice. It was about this time that the focus in the literature moved from ratios of computers to students in schools to if schools were using the digital technologies that were in the schools. Later studies started to look at the learning associated with digital technology use.

Cuban (2001), in finding that teachers were not getting their students to use the computers which had been put in schools in Silicon Valley, rejected the most common response from critics of the schools in the 1990s, what he called the "blame and train" approach where technophobic teachers must be forced to learn how to use computers. This is still one approach. For example Muir-Herzig (2004) found no significant improvement in achievement when digital technologies were introduced 
to at-risk students' classes and concluded that the technology training was needed for the teachers.

Christensen and Knezek developed stages of adoption of technology to measure ICT use and then carried out research using these as a measure. The stages identified included:

Stage 1: awareness,

Stage 2: learning the process,

Stage 3: understanding and application of the process,

Stage 4: familiarity and confidence,

Stage 5: adaptation to other contexts and

Stage 6: creative application to new contexts

(Christensen \& Knezek, 2001; Knezek \& Christensen, 1999)

This model which can be applied to experienced teachers learning a specific function, infers that learning is neat and ordered and the teacher needs to be the technical expert. When Web 2.0 applications and complexity theory is applied it becomes apparent that the stages suggested by Christensen and Knezek are unlikely to be sequential or present when teachers of the future adopt new technologies. For example, a teacher becomes aware of podcasting, and decides that this has potential as a way for students to peer critique speeches. The teacher shares this with the students who then develop a way of podcasting. Perhaps someone in the class who is experienced in podcasting is appointed to be the producer or trainer (or the teacher works with colleagues to figure it out or goes online to Google or asks in an ed-tech forum). The class develops podcasts, critiques them, and modifies then shares with a broader online community where further feedback may lead to further development of the speeches. The model is unlikely to be relevant to beginning teachers confident in a range of digital technologies and beginning to develop knowledge of how to teach. These teachers may be at stage 2-6 but lack the awareness of when and how to apply their knowledge of digital technologies.

The model developed by Knezek and Christensen (1999) was applied by Johnson et al. (2005) in a study of the use of ICTs in New Zealand schools in 2005. Principals from 138 secondary schools rated their teaching staff with $84 \%$ of teachers being rated at stage 4 or above. This reflects a perception by the principals taking part that their teachers were familiar and confident in the use of ICTs in 2005. In the same 
study (Johnson et al., 2005), secondary school principals were asked if the integration of ICT was making major improvements to the quality of curriculum delivery in their school to which $76 \%$ of the 138 respondents stated that it was. The question was very broad and likely to be interpreted in different ways by different principals, and as those responding to the questionnaire are likely to have supported the financing and use of computers in their school, there was likely to be some bias in the answers. The researchers included results from a similar survey carried out in 2001 in which $52 \%$ of secondary school principals had said that ICT was making major improvements to the quality of curriculum delivery; the change in the results over time may negate the bias caused by the vested interest. This study did not examine how teachers were using digital technologies and did not attempt to evaluate the effectiveness beyond reporting on principals' perceptions and students per computer ratios (4 in 2005 and 10 in 1995).

The study of digital technologies on school wide or regional basis has to date focussed on whether they are present in schools, followed by whether they were being used in schools.

\section{Barriers and enablers teachers face when using digital technologies}

Research into the integrated use of digital technologies in teaching and learning has centred on experienced teachers with established pedagogical practices. There are a number of studies which identify barriers or enablers that these teachers report which prevent, inhibit, enable or encourage the use of digital technologies in their teaching practice for student learning. The studies examined here informed the research design and analysis of the examination of beginning teachers as they seek to use digital technologies in their teaching practice.

Becker (1999) carried out research to identify factors that facilitate greater levels of internet use by teachers. He identified eight factors (listed in order of significance):

high levels of classroom connectivity; (meaning internet connection) computer expertise; constructivist pedagogy; participation in staff development; high frequency of informal contacts with other teachers; involvement in professional leadership activities; 
being a young teacher; and

not being a mathematics teacher.

These could have been grouped under the broader themes of context (including access), beliefs, support and experience. If the study was about the use of digital technologies rather than internet use, some of the results may have differed. For example, mathematics teachers in 1999 may have been using digital technologies for specific mathematics functions such as logo programming. Becker's research examined teachers' perceptions of the value of using the internet, whether they used it, and whether they had their students using it for either research or projects. Because the research was undertaken 10 years ago it did not examine whether students or teachers used the internet to make connections and to learn collaboratively as the main use in education in 1999 was for accessing or presenting information. The nature of internet use in society and the potential in schools has changed since this research was conducted.

In New Zealand, a number of barriers to teachers using digital technologies have been identified including the school and work culture, the leadership and management of the school, professional development opportunities and technical support and access to hardware (Lai, 2005). Lai focused on beliefs about ICT rather than pedagogical beliefs about learning and teaching. The two beliefs are likely to be linked, underpinned by conceptions of knowledge, learning and teenage motivation.

Sime and Priestley (2005) identified four categories of factors that predict whether teachers will integrate digital technologies into their teaching. These included: resources available (access), experience of digital technology, beliefs, and the context (including available support). These categories encompass the findings of other researchers, and became 'variables of interest' in this study.

Access to reliable digital technologies was a barrier to use, particularly in the 1990s. If a technology was believed to be unreliable, secondary teachers with 25 to 30 students to keep engaged with limited time would not choose to use it (Cuban, 2001).

In 2005, 100\% of New Zealand secondary schools had internet access and 93\% of them had broadband access (Johnson et al., 2005). Thus the levels of classroom connectivity should be decreasing as a perceived barrier to teachers. The research by Johnson et al., did not explore how, or if, the computers in New Zealand schools 
were being used. Teachers in 2008 have access to laptops (Cowie et al., 2008) and all secondary schools have computers students can access, digital video cameras and data projectors. There is a difference between schools having digital hardware and teachers being able to use these with their students.

Teachers were undertaking professional development in how to use different computer programmes during the late 1990s. Cuban (2001) found little evidence of resistance by teachers to using digital technology. He found that many used it extensively to prepare their work, communicate with parents and maintain records, and carry out research; they did not have students using digital technologies extensively or in a way that showed a change in the way that students were learning. Access, however, was not the most important factor that limited students' use of digital technologies in school. He found that where teachers were using digital technologies it was to enhance their existing teaching practices; therefore teachers would only consider using digital technologies which they perceived as enhancing their existing or desired teaching practice. For example if a teacher believed that the purpose of secondary education was to transmit content knowledge to the students so that they could present the same material back when examined, using presentation software to transmit ideas through a variety of media would be a useful teaching tool and likely to be used.

Teacher values and beliefs have been found to be important factors for the effective use of digital technologies for learning (Goos, Galbraith, Renshaw, \& Geiger, 2003; Moseley et al., 1999). The pedagogical beliefs of the teacher have been reported as being strongly linked to the way that they will use digital technologies in teaching and their professional lives. Papert (2004) described the introduction of digital technologies into conventional schooling, where the underpinning belief about knowledge is that it is something to be handed out to students as 'strapping the jet engine to the horse and buggy'.

Becker and Riel (2000) found that teachers with constructivist beliefs were more likely to network with other teachers and use digital technologies and the internet in a constructivist compatible way compared to teachers who identify their practice within a transmission model of teaching and learning. They used survey questions to determine whether the teachers had constructivist beliefs, such as encouraging student input into learning activities and being flexible in their approach. 
Identifying teachers as teaching in a constructivist or transmission/ traditional way can be problematic as there are overlapping definitions of what this means. Clifford et al. (2005) reported finding that some teachers who identified themselves as teaching to encourage constructivist learning were in fact using weak approaches to teaching and learning with digital technology. These weak approaches included what Scardamalia and Bereiter (2006) termed shallow constructivism - where students focus on a process of what they are doing, rather than the concepts or ideas which underpin a learning activity. Student teachers and experienced teachers aimed to add digital technologies to their existing practice, whatever pedagogical approach they were using (Clifford et al., 2005).

Some research is underpinned by beliefs that digital technologies should be a tool that is added to the teachers' current practice, a belief that should be considered when examining how the research findings are discussed. For example, Becker (2000) wrote a list of conditions that allow computers to become a valuable and wellfunctioning instructional 'tool', where computer activities flow seamlessly alongside other learning activities. A teacher in 2008 who is aiming to have students creating knowledge through connections is likely to see the computer as a place to build connections and develop knowledge, integral to a learning activity rather than as an additional part to the learning.

Students of teachers whose educational beliefs and classroom practices radically changed and which reflected a 'constructivist approach' to learning regarded learning as a process of engaging with complex, context-related tasks requiring multiple viewpoints, whereas students whose teachers had a transmission approach saw technology-assisted learning as learning with technical tools (Levin \& Wadmany, 2005). This study indicated a reciprocal rather than unidirectional relationship between teacher classroom practice and changes in teacher educational beliefs and knowledge restructuring process.

Studies have shown that teachers' beliefs and values underpin the way that they use digital technologies in the teaching process (Ertmer, 2005; Goos et al., 2003; Moseley et al., 1999). Beliefs and experiences are closely linked in that they influence each other. Research by Slaouti and Barton (2007) found that experiences brought to teaching by newly qualified teachers were important as to whether they used digital technologies or not. The examination of teachers' own beliefs that 
underpin teaching decisions has been identified as an important aspect of teacher reflection during professional learning (Ertmer, 2005; Glassett, 2008).

Researching teacher beliefs is problematic due to varying interpretations and understanding of different pedagogies..A 2004 study of teachers' use of technology carried out in Silicon Valley (USA) involved surveying teachers at 61 schools to find out about their use of digital technology in their classes (Hernández-Ramos, 2005). It was found that the teachers used technology at a similar rate to other teachers in the USA. This research looked at the constructivist beliefs of teachers based on a range of statements that focussed on project-based learning which appeared to be a particular interpretation of constructivist beliefs. The finding that teachers who used technology more frequently had stronger constructivist beliefs could be misleading due to lack of clarity around what the researchers meant by constructivist beliefs.

The dominant teaching and learning theories underpinning preservice teacher education in 2007 were social learning theory, constructivism and behaviourism. Social learning theory is founded on a complex model of triadic reciprocal causation in which contextual events, behavioural and cognitive factors operate in a social environment resulting in emerging cognitive understandings. The theory recognises self-efficacy, self-regulative, and self-reflective processes in socio-cognitive functioning (Bandura, 1977). The importance of the social context of the classroom and teacher networks is closely linked with behaviourism and motivational theory. Beginning teachers in 2007 were also familiar with constructivist learning theory. The way that learners build knowledge to develop an understanding of the world has been applied to both students and teachers as learners. How teachers decide which resources they will use and the teaching method has been explained in teacher education through applying Shulman's (1987) model of pedagogical reasoning, which is comprised of the actions that a teacher undergoes during the teaching process. The model includes six aspects; (a) comprehension of the subject knowledge, (b) transformation of subject knowledge into teachable representations, (c) instruction, (d) evaluation of students' learning and teacher's performance, (e) reflection, and (f) new comprehensions.

Shulman's (1987) model of pedagogical reasoning is appropriate for the digital age thinking about knowledge development in that it recognises that the teacher and students will be gaining new comprehensions or understandings which could include 
creating knowledge as a result of the teaching and learning process. Shulman also acknowledges the diversity that exists within teaching, noting that the actions are not a fixed sequence and sometimes some may not occur which fits with complexity theory. However, it may not be appropriate for the digital age as it appears to be underpinned by the belief that teaching is about the transmission of information.

Building on the ideas of Shulman, the idea of technological pedagogical content knowledge has been proposed (Mishra \& Koehler, 2008). This framework acknowledges three types of knowledge - pedagogical, content and technological. Such a model may be relevant to existing teachers who are learning about digital technology to integrate it into their teaching. For beginning teachers and teachers of the future who have joined secondary teaching with knowledge of digital technologies within their subject area, this is part of their content knowledge, therefore subsumed by pedagogical content knowledge (or, according to Shulman, curriculum knowledge). The knowledge of how to use a microscope, a heart rate monitor or a text book within a teaching context is a subset of pedagogical content knowledge for teachers; the same will apply to digital technologies in the future.

Webb and Cox (2004) noted that changes in teachers' beliefs and values are necessary to ensure a change in pedagogical practices to maximise the benefits of using digital technologies with students. This assumes that if teachers say they believe that students learn in a certain way, they will try to teach to enable that way of learning. An in-depth study of teachers in Taiwan (Chen, 2008) found that most teachers surveyed identified with constructivist beliefs (which had been a government focus) but when observed teaching they tended to use digital technologies within a transmission practice rather than teach to encourage constructivist learning. The researcher concluded that the teachers had inadequate understanding about the theoretical concepts and/or how to incorporate the concepts into their teaching, noting that teacher beliefs are different to teacher knowledge. When national policy makes changes to education there can be lag time between policy dissemination and teacher understanding and implementing the practice within the contexts of their classrooms and their schools (Starkey et al., 2008). Applying complexity theory, the emerging knowledge about learning and teaching using digital technologies will emerge from the connections being made by the teachers and the researchers. This knowledge is not yet available due to the lag time between innovation and change in practice; hence the researcher was not able to locate 
research focussing on the pedagogical beliefs of teachers seeking to integrate Web 2.0 (collaborative web-based technologies) into their students' learning activities.

Support has been identified as enabling teachers who seek to use digital technologies in their teaching practice (Cowie et al., 2008; Lowther, Strahl, Inan, \& Ross, 2008; Slaouti $\&$ Barton, 2007; Tearle, 2003). In a study of teacher use of laptops in New Zealand, it was found that support was an important enabler for teachers using digital technologies (Cowie et al., 2008). Support ranges from messages given by the principal about the value of digital technologies in the teaching and learning process, professional learning available, collegial support, whole school processes to just in time technical support.

Becker and Riel (2000) examined professional engagement in teachers. They measured professional engagement by the communications with teachers within and beyond their own school and being involved in peer leadership activities. The teachers that they identified as professionally engaged were more likely to have teaching philosophies and teach in ways compatible with constructivist learning theory, and less likely to focus on transmission teaching, and (hence) likely to use computers in more exemplary ways. Although the exemplary ways focussed on teaching practice rather than student learning. This suggests that teachers with strong professional connections or network support are likely to be less transmission oriented. Being less transmission oriented in this instance meant that the teacher focuses on students' active engagement in learning.

A study of six first year language teachers who were interested in using digital technologies, found a range of factors which enhanced or prevented their use of digital technologies in 2004/2005 (Slaouti \& Barton, 2007). This included access issues such as bookability or reliability, key personnel varied, induction to the school systems were lacking, there was great variation in department and schools' commitment to ICT and espoused commitment varied from observed commitment. This research examined whether beginning teachers are using digital technologies and the barriers or enablers to the use. It did not examine how the beginning teachers were using digital technologies. It did find that the teachers were resourceful in achieving their aims; they were able to overcome a number of barriers. It was found that the context in which the beginning teachers found themselves was important in their decisions on whether to use digital technologies. 
Funding and support were put in place to negate identified barriers to technology integration in Tennessee (USA) schools. Mixed methods research was carried out in 54 schools involving 28,735 students and 1,746 teachers to evaluate the effectiveness of digital technology integration once the barriers to implementation had been removed (Lowther et al., 2008) Programme effectiveness was measured by direct classroom observations, surveys, student performance assessments, focus groups, and student achievement analysis. The barriers which had been identified included availability and access to computers, availability of curriculum materials, teacher beliefs, demographic characteristic of teachers, teachers' technological and content knowledge and technical, administrative and peer support. To overcome these barriers funding was provided to schools that were committed to developing their use of digital technologies which was used to improve access to computers, provide technical coaching and support, on-site, one on one, small group and just in time professional support. The researchers found that the students at the schools with the extra support performed as well as or better than those at schools without the support, in most but not all the measures used.

Tearle (2003) examined a secondary school that was deemed to be successfully integrating digital technologies across the curriculum and found that teachers in the school had not changed the way they taught because they were using computers. She noted that the context, the whole school culture of support and professional learning were key aspects of the success as a school.

Learners and colleagues are part of the schooling context. Students' understanding of the teaching and learning process influences the impact that digital technology use has on learning. A study of a teacher who aimed to use digital technologies to help students learn in a constructivist way found that while the teacher was designing collaborative knowledge construction activities the students were acculturated in a transmission style of learning, thereby creating a barrier to a new way of approaching their learning (Starkey \& McCarthy, 2008). While this study was small in scale, a similar finding was included in research by Chen (2008). Complexity theory and research suggests that the school context and the students' experiences and expectations of learning will influence the learning environment (Wink, 2000).

The barriers and enablers for teachers wanting to use digital technologies to help students learn have changed over the past 10 years. Access to computers or the internet and teachers' computer skills were initially identified as barriers. As the research focus 
moved to how digital technologies were being used, pedagogical beliefs were seen as a barrier or enabler for teachers using digital technologies effectively.

\section{How digital technologies are used in secondary schools}

Growing numbers of teachers are overcoming barriers and making the most of the support and access they have to use digital technologies for teaching and learning (Johnson et al., 2005; Kitchen, Finch, \& Sinclair, 2007). This has led to an increasing focus on the way that teachers use digital technologies in their practice. Digital technologies have evolved and developed over time which has influenced the attitudes to their use and the knowledge and skills to be able to utilise their functionality in an educational setting.

Brown (2004) developed a metaphor for the changes in computer use over time. $\mathrm{He}$ identified four waves of computer use in schools, each wave washing over the previous one, with teachers jumping onto the wave to ride with it. The four waves he identified included:

The instructional wave (1975-85) - where the computer was the instructional tutor The problem solving wave (1980-90) - students teach the computer

The mind tool wave (1985-95) - the computer is a tool

The media wave (1995-present) - learning from the information available on the internet.

During the instructional, problem solving and mind tool waves, which were prior to the widespread use of the internet, digital technologies were used within specific subject areas, particularly in mathematics, science and computing. The mind tool wave teachers were starting to use presentation software as a teaching tool. The media wave saw the introduction of access to information through the internet in schools and hence inquiry learning with differing degrees of teacher control over the content and direction.

The media wave in Brown's thesis looks at the notion of computers being connected within a classroom and to the internet. The above model does not take into account the ability to collaborate beyond the classroom to build knowledge through the use of digital technologies. Starkey and Stevens (2007) summarised the stages of the introduction of digital technologies in schools in New Zealand, hypothesising that the emerging use of Web 2.0 and social software since 2004 has seen the beginning of a connectivism wave. The implications of integrating Web 2.0 into teaching and 
learning programmes has yet to be explored in the literature and offers a new way of using digital technologies in schools.

Digital technologies examined in this research include any digital technology that was identified in the literature or by participants. The decision to take a wide definition was made due to the increasingly integrated nature of technologies such as cell phones which include web2.0, video, photo, SMS, voice messaging, video calling and calculator functions, all of which can be used within a teaching and learning context.

The use of digital technologies in schools can be divided into four categories based on the technologies and applications reported in the literature as being used for learning. These are outlined to clarify the types of use that some research and literature focuses on. Table 1 summarises the features of each of the categories.

Table 1: How digital technologies are used in teaching and learning.

\begin{tabular}{|c|c|c|c|}
\hline Use: & Technologies & Purpose & Learning \\
\hline $\begin{array}{l}\text { i. Subject specific } \\
\text { programme or tool }\end{array}$ & $\begin{array}{l}\text { Logo } \\
\text { Simulations }\end{array}$ & $\begin{array}{l}\text { Developing } \\
\text { conceptual } \\
\text { understanding, } \\
\text { problem solving, } \\
\text { developing computer } \\
\text { skills } \\
\text { Mastery activities - } \\
\text { memorise } \\
\text { information or } \\
\text { practise key } \\
\text { processes }\end{array}$ & $\begin{array}{l}\text { Subject based } \\
\text { Constructivist } \\
\text { Cognitive } \\
\text { Differentiated }\end{array}$ \\
\hline ii. Presentation & $\begin{array}{l}\text { Word processing, } \\
\text { PowerPoint, } \\
\text { interactive } \\
\text { whiteboard, data } \\
\text { projector, teacher } \\
\text { laptop }\end{array}$ & $\begin{array}{l}\text { Transmission of } \\
\text { information, ideas } \\
\text { and concepts }\end{array}$ & $\begin{array}{l}\text { Transmission } \\
\text { Passive learning } \\
\text { Engaging students } \\
\text { using multimedia }\end{array}$ \\
\hline $\begin{array}{l}\text { iii. Accessing } \\
\text { information and } \\
\text { students presenting } \\
\text { 'projects' }\end{array}$ & $\begin{array}{l}\text { Internet, Web 1.0, } \\
\text { web pages, Word } \\
\text { processing, } \\
\text { PowerPoint. }\end{array}$ & $\begin{array}{l}\text { Inquiry } \\
\text { Web quests, FOFO } \\
\text { constructivism }\end{array}$ & $\begin{array}{l}\text { Inquiry learning } \\
\text { constructivism }\end{array}$ \\
\hline iv. Connections & $\begin{array}{l}\text { Mash ups, Web 2.0, } \\
\text { video conferencing, } \\
\text { e-learning, m- } \\
\text { learning (through } \\
\text { forums discussions } \\
\text { and interactions) }\end{array}$ & $\begin{array}{l}\text { Create knowledge by } \\
\text { making connections } \\
\text { between } \\
\text { information, ideas or } \\
\text { people }\end{array}$ & $\begin{array}{l}\text { Global knowledge } \\
\text { development } \\
\text { Diversity, } \\
\text { personalisation }\end{array}$ \\
\hline
\end{tabular}


The first use is one of using particular programmes and technologies for specific purposes within subjects. This aligns with what Brown (2004) called the problem solving wave, the instructional wave and mind tool wave. Examples include the use of Logo in mathematics or technology, and simulation activities in the social sciences.

The second use is the developing use of technologies to present information, ideas and concepts. This includes teachers developing paper-based resources using word processing software in the 1980s and including PowerPoint presentations and internet-based information and multimedia presentations through a data show or interactive whiteboard since 2000.

In a study of 39 schools in England it was found the main use of digital technologies in the English schools was word processing, presentations and accessing information from the internet (Ofsted, 2005). This aligns with the uses found in the harnessing technology survey (Kitchen et al., 2007).

In a study of New Zealand teachers' use of laptops, it was found that at the end of 2005 $60 \%$ used their laptops with data projectors and the most prevalent use of the laptop and peripherals was to present visual material as part of the instruction to the class (Cowie et al., 2008). Teachers who used their laptops during lessons to present multimedia materials reported that this engaged students creatively and critically in their learning. Having the teacher presenting multimedia materials to the class can be a transmission approach to teaching. Students are likely to find the range of visual media more engaging than listening to a teacher standing by a board and talking or writing notes to be copied.

The third use resulted from increasing availability and reliability of information through the internet which coincided with a growing trend towards the use of inquiry-based learning, particularly in the social sciences and sciences in secondary school. This is evidenced in the wording of curriculum documents of the 1990s (Ministry of Education, 1993). Digital technologies have been used by students to access information, then present completed projects. It appears that a focus on project-based learning has been categorised as constructivist learning in the research, for example refer to the work of Hernández-Ramos (2005).

Experienced teachers who are introducing digital technology alongside their existing teaching practice have been found to be impressed when students use presentation 
software or other ways of using digital technologies which require minimal cognitive engagement by students (Clifford et al., 2005). Where a teacher previously asked students to create a poster that pulls together information gathered from books, they may now ask the student to print off a presentation using online sources. Instead of copying drawings and paragraphs they would cut and paste and use fonts, word art and other software to make the output look impressive. If the teacher has focussed on the content and presentation of the finished product and not the learning or the process, they are likely to be impressed. This finding illustrates the teacher's pedagogical beliefs not changing though their teaching practice has altered to include students using digital technologies.

The fourth use of digital technologies in schools is to make connections across geographical spaces, between information sources, media and ideas. There are fewer examples of teachers doing this in the literature which is not surprising as the open source tools for this to occur have only recently become widely available and known about. To use digital technologies in this way does require students to be using digital technologies creatively and collaboratively.

Becta (2007) carried out a study of about 1200 British teachers in 2007 and found that one third reported sometimes or often using IT to help students to be creative and $16 \%$ sometimes or often used ICT to help learners to work with others. The harnessing technology survey (Kitchen et al., 2007) found few teachers using digital technologies to support student creativity or collaboration.

A challenge identified in the harnessing technology review (Becta, 2007) was developing the use of technology from enhancing and enriching learning to also extending and empowering it, and developing a broader repertoire of practitioner skills. This sentiment appears to be in the blame and train approach, unless the broader range of practitioner skills was referring to pedagogical knowledge and practice.

There is research around underpinning pedagogy and the way computers are used in schools, but it tends to be limited to examining searching for information on the web, or students learning to use software. The way that digital technologies are used in schools has been found to be causing a disconnection between formal and informal learning where the learner in school is placed in a passive role and informal learning has the learner in an active role (Becta, 2007). This has meant that students do not 
always want to engage with digital technologies in school the way that teachers may envisage learning with digital technologies happening.

Furthermore, the uses of digital technologies can vary between subject domains. Differences in digital technology use between subjects in secondary schools were identified in the harnessing technologies survey (Kitchen et al., 2007). The researchers reported that geography teachers were more likely to use internet-based resources, music and English teachers were less likely to use presentation technologies, and music, science and mathematics teachers were more likely to use subject specific software. Ofsted (2005) found variation in the way that digital technologies were used, noting that good application of ICT was seen in design and technology, languages and art.

Another means of investigating how teachers use digital technologies in teaching is by examining the approach utilised. Cox et al. (2004) carried out a literature review and case studies in England in 2003 and identified three categories of uses of digital technologies by teachers:

\footnotetext{
Integrated approach: planning the use of ICT within the subject to enhance particular concepts and skills and improve pupils' attainment.

Enhancement approach: planning the use of an ICT resource which will enhance the existing topic through some aspect of the lessons and tasks.

Complementary approach: using an ICT resource to empower the pupils' learning, for example by enabling them to improve their class work by taking notes on the computer, or by sending homework by email to the teacher from home, or by word processing their homework. (p.33)
}

These approaches reflect ways that teachers build digital technologies into their existing practice. The first two approaches appear to be similar in that they both enhance the existing teaching practice. The third approach is using digital technologies as part of the management and organisation of the teaching and learning process. This suggests that either the reviewers did not identify an approach to the use that is based on the affordances of digital technologies (such as being able to connect with the global environment or create knowledge or works of art in ways not possible without digital technologies) or that these were not recognised as being present in the literature reviewed. 


\section{Impact digital technology has on teaching}

Changes to pedagogical practice have been reported as teachers use digital technologies in their classroom practices. The introduction of digital technologies into schools was expected or was hoped to cause a catalytic change in teacher pedagogical practices (Karsenti et al., 2002). The most significant widespread change in pedagogical practices that is evidenced in research is the movement from whole class teaching to a more student-centred, personalised pedagogy (Becker, 1999; Hennessy, Deaney, \& Ruthven, 2003; Kozma, 2003; Moseley et al., 1999; Ofsted, 2005; Pedretti, Mayer-Smith, \& Woodrow, 1998; Somekh et al., 2007; Starkey \& McCarthy, 2008). Many of these studies involved teachers enthusiastic about using digital technologies rather than a representative sample of teachers.

Research has found that experienced teachers who use digital technologies tend to personalise learning for their students, making the learning meaningful to the lives and learning needs, which could mean that teachers who would like to personalise learning use digital technologies in their practice. Becker (1999) recognised that teachers in the USA who believe in project-based teaching and other constructivistcompatible practices have found computer technologies to have an emancipating effect, enabling teachers to personalise learning to cater for the diversity of learners found in a classroom.

Using digital technologies to cater for the learning needs of diverse students was found in a study of 39 schools in England where the best examples of using ICT for teaching extended high attaining students and provided support for low attaining students (Ofsted, 2005). Kozma (2003) examined findings from case studies of innovative pedagogical practices using technology from 28 countries and found that teachers were changing from being the prime source of information for students to information being accessed through digital technologies and the teacher focussing on being the learning instructor. In a study of the use of digital technologies (computers, data projectors and scientific calculators) in English and senior secondary mathematics classrooms, it was found that digital technology facilitated collaborative inquiry. This occurred during small group interactions and whole class discussions where students used the computer, calculator or screen projection to share and test their mathematical understanding (Goos et al., 2003). The ICT test bed researchers reported that students had greater control over their learning and there was increased personalised learning with opportunities for the students to follow their current interests or needs (Somekh et 
al., 2007). The research did not investigate the extent to which these changes are as a result of the ICT or was the result of the complex mix of increased support, action research and professional learning that was put into the schools, which would have been examined if utilising a complexity theory framed research. The presentation software was reported as improving the teachers' ability to hold whole class attention, and increase interaction between the teacher and the student which does not suggest a change in pedagogical approach or a radical move towards personalising learning. While it appears that the use of digital technologies in schools has not produced a catalytic change in the way that teachers teach, it has enabled teachers to personalise learning, to cater for diversity and foster collaborative inquiry learning, reflecting the complexity of influences and considerations that occur when a change is introduced to a complex system.

\section{Impact digital technology use has on learning}

Digital technologies have been found to have a motivating effect on learners, and when combined with effective teaching some studies have reported that students can achieve better in traditional assessment measures. Student learning has been reported to be effected when teachers begin to personalise learning as they use digital technologies. A longitudinal study of Technology-Enhanced Secondary Science Instruction (TESSI) in Canada (Pedretti et al., 1998) found that the majority of students responded well to the student-centred learning environment enjoying the self-paced and peer learning. Students who worked at a faster or slower pace than their peers were the exceptions - preferring to work individual and go directly to the teacher for support. Personalising learning could also include teens building their own learning or information space which would mean students taking control of their own learning (Loertscher, 2007).

Not all studies show a positive effect. A study of at-risk students in an English school found no improvement in their achievement following the integration of digital technologies in their classrooms (Muir-Herzig, 2004). In another study where presentation software, internet access, support and professional learning were put into clusters of schools in poor neighbourhoods in England, there was a resulting increase in achievement at the primary level and minimal change at the secondary level (Somekh et al., 2007). However, an extensive review of the literature found that there had been a positive effect with specific uses of ICT on attainment in almost all national curricular subjects in England (Cox et al., 2004). 
A review carried out in New Zealand by the Education Review Office (ERO, 2005a) looked at e-learning in secondary schools. The researchers looked at 48 schools during 2004 and concluded that while teaching programmes that incorporated elearning generally increased student motivation and enjoyment of learning, the extent to which e-learning was embedded in teaching practice and supported students' learning goals was limited. The way that the evaluators measured effectiveness was by focusing on critical thinking and information literacy but the report did not explain how this was measured.

Digital technologies can have a short or long-term motivating effect on learners. There can be a novelty factor which increases motivation when digital technologies are first introduced to learners. This motivation will be temporary when learning is focused on the technological aspects rather than the learning aspects of a digital technology. Where the purpose of digital technology use is underpinned with effective pedagogy in mind, the longer-term decline in motivation is negated (Moss et al., 2002).

In a study into the motivational effect of ICT on pupils, Passey et al. (2004) used a sample of 17 schools across England to measure the motivational effects of ICT on pupils. They found that students and teachers involved in the study felt largely that access to ICT and resources had reached a level where ICT could be applied to the curriculum and the curriculum purpose could be supported by ICT. All except one secondary school teacher interviewed thought that ICT positively enhanced the range of teaching approaches that could be used. The approaches described involved using presentation software and downloading information from the internet. It did not include collaborative knowledge production beyond the classroom intranet environment. It appears that the students were motivated as a result of the auditory, visual and kinaesthetic stimulation that was a result of working with Web 1.0 and presentation software and hardware, and motivated by the improvements to the quality of their work in terms of writing, appearance and presentation. Being able to develop drafts and get formative feedback and knowing the end point or aim of the learning was a factor which students reported improved the quality of work and motivation. Sharing the aims of learning, giving focussed individual formative feedback to learners and having fast-paced lessons with high expectations of the students have been found to be effective teaching practices (Alton-Lee, 2003) and were found to be motivational in the research by Passey et al. (2004). The schools in 
this study were selected because the students were motivated in their learning while using ICT. The analysis shows that the students were motivated due to the effective teaching practices of the teachers as they used ICT in the learning programmes. These results align with the findings of Cox et al. (2004) who noted in their review of literature that ICT makes a difference to learning when it is accompanied by effective teaching practice.

Roschelle, Pea, Hoadley, Gordin and Means (2000) examined in more specific terms how computer technology can be used to motivate learners. Their research found that active engagement, participation in groups, frequent interaction, gaining feedback and connections to real-world contexts enhanced how children learn while using computerbased applications. These align closely with the features of effective teaching practice identified in an evidence-based synthesis of research carried out in New Zealand (Alton-Lee, 2003). A common feature of exemplary teachers is the belief that building relationships with students is rewarding (Williams, 2003). Classroom observations and interviews of teachers and students has found that positive learning relationships between a teacher and his or her students contributes to effective student engagement in learning (Bishop \& Glynn, 1999). Relationships are an important aspect of complexity theory and connectivism learning theory. The connections is where knowledge is created, so it is logical that in a connectivist focussed approach to teaching the learning relationships between the learners and their teacher(s) are established to encourage a learning environment where creating knowledge can occur.

In a doctoral study which analysed the impact of an e-classroom environment on the social, cognitive and affective elements of student work practices it was found that the positive impacts of digital technology use was the result of sound teaching practice and due to the novelty factor as students saw the use of computers as play rather than real work (Falloon, 2004). In this study the students had a stronger preference for using computers at the start of the year rather than later in the year as the novelty factor wore off.

School education policy makers in New Zealand view new technologies as a vehicle to transform education (Ministry of Education, 2006). At the core of the strategy document is the belief that the appropriate use of technology will move education from a transmission, behaviourist model towards a constructivist, student-centred one that can meet the demands of a contemporary workplace and society, which 
emphasises self-directedness, lifelong learning, communication and collaboration skills (Becta, 2007).

\section{The problem with measuring effectiveness}

There is a growing body of literature that examines how effective the use of digital technologies is in schools, although it appears that the interpretation of effective use varies. The effectiveness of digital technology use has been measured based on the frequency of use, the type of use, and the impact on student achievement.

Hernández-Ramos (2005) focussed on the frequency of use while reporting on the effectiveness of digital technology use by teachers. He found that the teachers in Silicon Valley used technology at a similar rate to other teachers in the USA. The research objective was to report on the level of technology use by the teachers, but this research reported only the percentage of teachers who designed technologybased project learning. Without further analysis of the types of learning activities, it is not possible to identify whether any (or all) of the teachers were using the digital technology effectively for student learning.

The effect that digital technology has on education can depend on how the technology is used. Some authors have researched how digital technologies are used as a basis of effectiveness, though where this has occurred, the definition of effectiveness is not clear. Ofsted (2005) reported observing good application of ICT in design and technology, languages and art. Most frequently, the good application covered such topics as presentational work including web page construction, webrelated research, revision, and accessing information from the internet. This list does not include a focus on collaboration or knowledge building.

Examining learning using digital technologies has been approached in different ways; most studies report on student behaviours such as observed engagement rather than learning achievements. In a study of effectiveness of digital technology use in Tennessee (Lowther et al., 2008), programme effectiveness was measured by direct classroom observations, surveys, student performance assessments, focus groups, and student achievement analysis. Observers used a rubric of meaningfulness of computer activities and examined how computers were being used, noting cooperative learning, project-based learning, higher level questions, experiential hands-on activities, independent inquiry, student discussion or when students were producers. By counting 
the times that these activities were present, the researchers were able to summarise that there was less transmission teaching observed as a result of the extra support, though it did not include the learning within the activities that was taking place.

Cox et al. (2004) in a synthesis of literature, focussed on application, stating that effective learning with ICT occurs when a teacher challenges students to think. This appears to be a narrow teacher centric belief as students can think and construct meaning through other situations. Measuring the way that digital technologies are being used in the teaching and learning process could be a valid way of examining effectiveness, if the link between the use and the learning is explicit. Research to date rarely makes this link explicit; therefore the evaluation appears to be based on the researcher's beliefs about learning which are too often not expressed or vague.

Heppell (1999) argued that the ways in which we assess learning using digital technologies is problematic as the measures are constructed through a transmission teaching pedagogy. Measuring student learning based on traditional achievement measures is unlikely to take account of the way that students learn in a connected world or apply the use of digital technologies to construct knowledge so is therefore an invalid measure (Loveless, 2002). For example, when Larry Cuban (2001) examined the use of computers in Silicon Valley, he reported an unexpected outcome: "In the schools we studied, we found no clear and substantial evidence of students increasing their academic achievement as a result of using information technologies" (p. 133).

While the researcher had expected to find teachers to use digital technologies innovatively, the student learning or achievement was measured using traditional measurements. Not only should the content of assessment reflect the digital age, but modes of assessment should also reflect what is important for the world beyond school (Sutherland et al., 2004).

Computer use has been reported to have a negative effect on school achievement. A negative relationship was found in a US study (Wenglinski, 1998) which compared the frequency of computer use with school achievement, though certain uses of technology were found to have positive effects leading the author to conclude that how digital technology is used is more important than the frequency. It could be that if different measurements were taken, the effect of computer use may have been different. 
The link between digital technologies and student performance is complex. The research by Lowther et al. (2008) included gathering student achievement data in two levels of standardised tests. Analysis showed that the students taking part in the programme which had digital technologies and support performed as well or better than the control students in most, but not all, of the tests. While this suggests that the introduction of digital technologies and associated support did not make a significant difference to student achievement, as Haskell (2001) points out, it does depend on whether what was being measured as effectiveness was compatible with the aims of integrating digital technologies into the teaching and learning process. The students observed spent more time learning through student-centred studies and cooperative learning activities, which may have benefits in other areas not measured directly in the tests.

The predominance of using presentation software and the internet to access information reflects a focus on learning as an internalisation process (the ways that knowledge and skills can be taken into the mind through the senses) or an externalisation process (the ways that the knowledge within the mind can be relayed to others), or transmission teaching rather than focussing on internal cognitive processes (evaluating, comparing, analysis). Students in the study by Passey et al. (2004) were motivated (engaged) when they were successful in the internalisation or externalisation process. Where attainment is measured within this context ICT is reported to have a positive effect on learning. The results are likely to be different if measured in an alternative framework which measures internal cognitive processes. Passey et al (2004) noted that:

Motivational impacts and outcomes of learning in terms of attainment, if related, might be expected to manifest themselves in a similar way. If attainment is linked to internal cognition, then current practice with ICT will have less impact upon attainment than it does upon other parts of the learning process. (p.5)

In the complex context of schooling it is difficult for researchers to unpick the teaching from teaching tools.

Cox et al. (2004), in their review of the literature, found that as with most teaching, lessons that are poorly planned or executed lead to unfocussed students and limited learning. It appears that it is the teacher rather than the technology that influences the effectiveness of digital technology use in schools. It tends to be teachers who demonstrate exemplary practice within the context of their schools; it is unlikely that 
there is exemplary practice across an entire secondary school due to the diverse nature of schools and the complexity of the management and organisational structures needed to support such diversity effectively (Auld et al., 2008).

The reported effectiveness can also be dependent on research participants' mental models of the way learning should occur. There is currently a lack of models which offer a way of measuring effective use of digital technologies in a connectivist learning environment. Research findings about effectiveness are framed in the researcher's perspective about teaching, learning and the nature of schooling.

\section{Measuring effective use of digital technologies in the digital age}

Cox et al. (2004) identified effective pedagogical practices from a literature review of ICT and pedagogy. The list included the need for teachers to:

- understand the relationship between a range of ICT resources and the concepts, processes and skills in their subject;

- use their subject expertise to select appropriate ICT resources which will help them meet the specific learning objectives; this includes subject-specific software as well as more generic resources;

- be aware of the potential of ICT resources both in terms of their contribution to pupils' presentation skills, and their role in challenging pupils' thinking and extending their learning in a subject;

- develop confidence in using a range of ICT resources, via frequent practice and use beyond one or two familiar applications;

- appreciate that some uses of ICT will change the ways in which knowledge is represented, and the way the subject is presented to and engages pupils;

- know how to prepare and plan lessons where ICT is used in ways which will challenge pupils' understanding and promote greater thinking and reflection;

- recognise which kinds of class organisation will be most effective for particular learning tasks with ICT, for example, when pupils should work on their own, how working in pairs and groups should be organised, and when to use ICT for whole-class teaching. (Cox et al., 2004, p. 4)

This list is underpinned by an outcomes-based pedagogical model where teachers are developing an understanding of ICT, rather than a model where teachers have an understanding of digital technologies and are developing their pedagogical knowledge. This is because the list is developed from existing research that was dominated by experienced teachers learning about ICT while teaching within the constraints of an outcome-based curriculum. In a connectivism learning environment using Web 2.0 applications and teaching a flexible curriculum, the emerging pedagogy would include interaction beyond the classroom, appreciation and 
encouragement for students to construct knowledge rather than solely gaining an understanding of the facts that already exist.

Teachers are being studied by researchers as they strive to use digital technologies in educationally meaningful ways. Therefore a way of evaluating such learning activities is needed. Evaluating learning using digital technologies has been attempted in a number of ways. Cassady (2002) summarises ways of evaluating learning in the cognitive domain that are measured by improved student achievement over a project. This type of evaluation differs from one which seeks to evaluate the potential and actual depth of learning in the design of an activity. An effective evaluation tool would recognise the range of ways technologies can be used for learning and the importance of critical thinking, creativity (knowledge creation) and making connections in an information rich Web 2.0 world.

The effectiveness of learning in a connectivist learning environment would include ideas about knowledge in the digital age, including critical thinking, connections, collaboration, and creating knowledge. Any measure of effective use of digital technologies in digital age schooling should be underpinned by a view of knowledge that is relevant to the digital era. Ideas about 'knowledge' appear to be changing from something that is found in the heads of individuals or in books to something that is not fixed, is debatable, accessible through a range of mediums and created through networks, connections and collaboration (Bereiter, 2002; Gilbert, 2005; Siemens, 2006). It would be appropriate to include these ideas in a model to examine learning through digital technologies.

The use of critical thinking has been identified as particularly important in the digital age. Relatively quick access to a wide range of information means that the user needs the ability to critically evaluate the validity and relative value of information accessed. A change in the approach to learning has been caused by the extensive access to a range of information. In the past the library, a book or an expert (e.g., a teacher) were consulted, and the value or validity was less likely to be questioned (Rowlands et al., 2008). This is one way in which critical thinking is an important aspect of learning when using digital technologies and this should be underpinned by the belief that knowledge is debatable.

Jonassen, Peck, and Wilson (2000) wrote about the use of computers as a learning tool, stressing that digital technologies promote meaningful learning only when 
learners are engaged in knowledge construction, conversation, articulation, collaboration, authentication and reflection. To engage in this meaningful learning the learners would have to have connections to other learners or people with whom they can converse, collaborate and gain authentication. These people could be within the schooling community or, using Web 2.0 technologies ideas, they could be beyond the school environment.

A review carried out in England, titled 'harnessing technology' (Becta, 2007), identified some issues and challenges in the use of digital technologies in education. This included using technologies to support learners working together and learners accessing a more personalised curriculum. A model to evaluate effectiveness of digital technologies should encourage and consider the collaborative nature of knowledge creation and the personalisation of the learning process.

A model to evaluate learning activities in the digital age would include critical thinking (critique), connections, collaboration and the creation of knowledge. Understanding how the creation of knowledge can be included in a model to evaluate learning may be gained through exploring the definition of creativity and applying this to knowledge. Creativity has been described in various ways. Wikipedia (Wikipedia, 2007) notes that 'more than 60 different definitions of creativity can be found in the psychological literature.' Plato described creativity when he compared two types of artist; true artists as those who bring into birth some new reality as opposed to artists who deal only with appearances and not with reality itself. (Plato, 360 BCE, as cited in Anderson, 1959, p. 57). He was making a distinction between artists who were skilled at manipulating tools and artists who were able to show something new as a result of manipulating the tools. This distinction is important. Taking this definition, being able to reproduce an existing reality or knowledge should not be considered as demonstrating creativity in schools.

A second definition of creativity comes from an educational setting. The National Advisory Committee on Creative and Cultural Education in England (1999) gives a schooling-based definition of creativity as: "Imaginative activity fashioned so as to produce outcomes that are both original and of value" (p. 29). This aligns with Plato's definition.

Stephen Downes (2007), a leading voice in e-learning research and regular blogger on the use of digital technologies in schools, defined creativity as 'the manipulation 
of one's experiences using the tools at one's disposal.' In this definition, Downes implies that original ideas are the result of experiences. This definition, like the previous one, requires a product, but differs in that it specifies that tools are an important aspect of creativity.

Not all definitions of creativity include having a tangible product. In a Ted Talk presentation titled 'Do schools kill creativity?', Sir Ken Robinson (2006) defines creativity as 'having original ideas that have value.' A model of creativity has been developed (Starkey, 2008) which combines the ideas of Plato, NACCCE, Downes and Robinson and considers the context of the digital age.

The notion of connections and collaboration become explicit in a model of creativity in the digital age. Knowledge is rarely developed in isolation, and between the students' ideas and the creative product, there would usually be input from other people. The phenomenon of the long tail (Anderson, 2006) means that through the World Wide Web, learners and knowledge creators are able to connect with others in the world with similar interests who are able to critique and give feedback, something that was not so easy prior to Web 2.0. A creativity model for the digital age as illustrated in Figure 1 could also represent knowledge creation in the digital age.

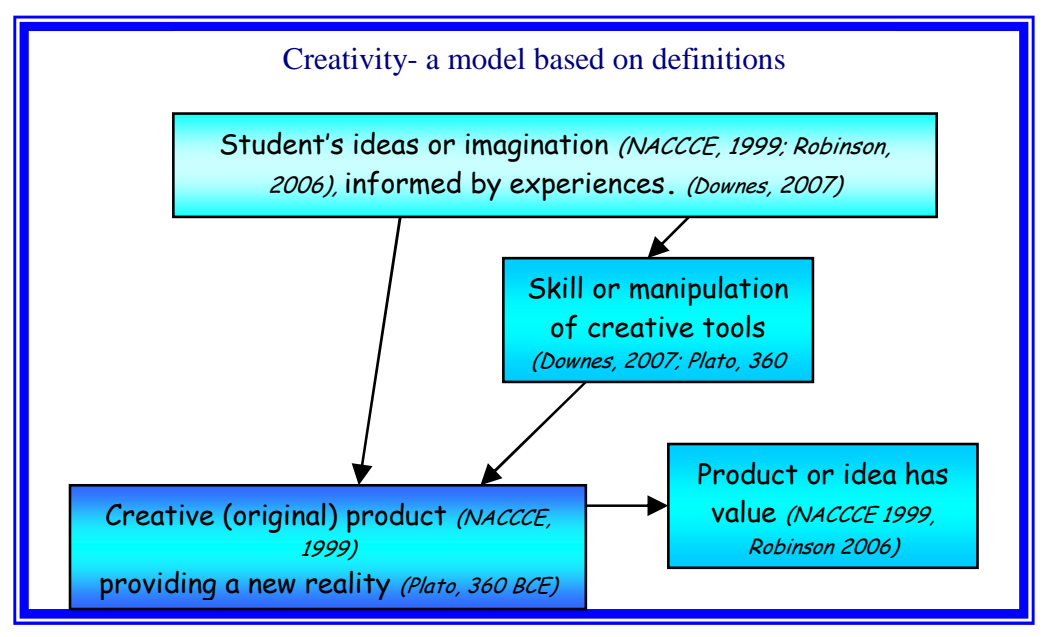

Figure 1: Model of creativity based on definitions (Starkey, 2008)

Ideas about connectivity in the digital age are applied to the model of creativity in Figure 2. 


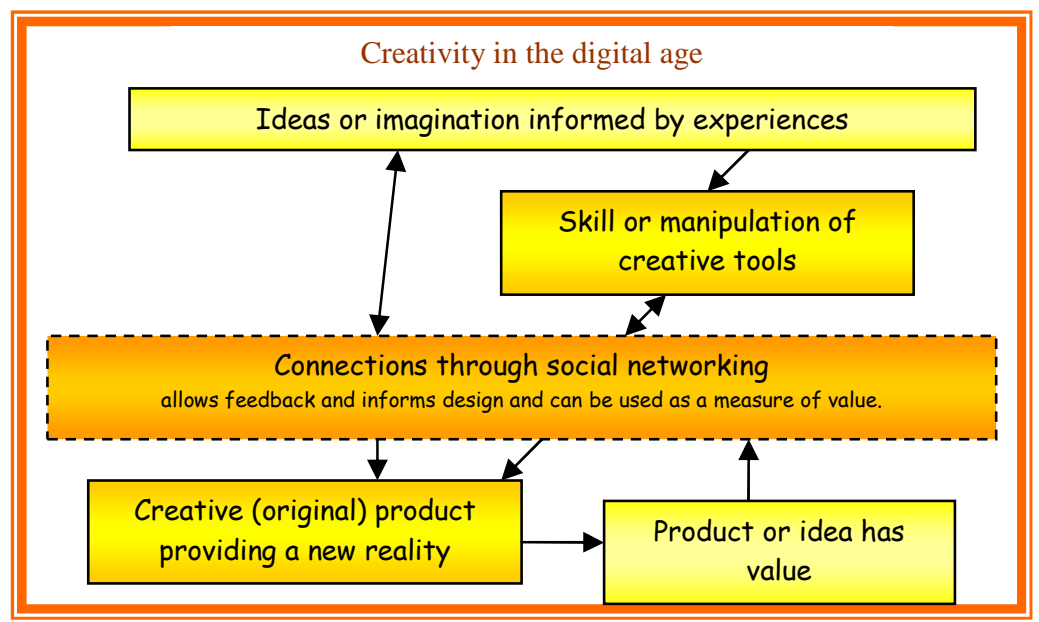

Figure 2: Creativity in the digital age

A knowledge creation model (Figure 3) was developed by applying the ideas about creativity in the digital age to connectivism theory. Knowledge is developed or created by connecting different sets of existing ideas. Individuals, groups or technology can make those connections. Value is difficult to ascertain as it may be recognised as important new knowledge retrospectively in the future after further knowledge is developed, or perhaps what is valued as created knowledge today is not recognised as such in the future. Figure 3 illustrates how knowledge creation could appear in the digital age if based upon ideas of creativity.

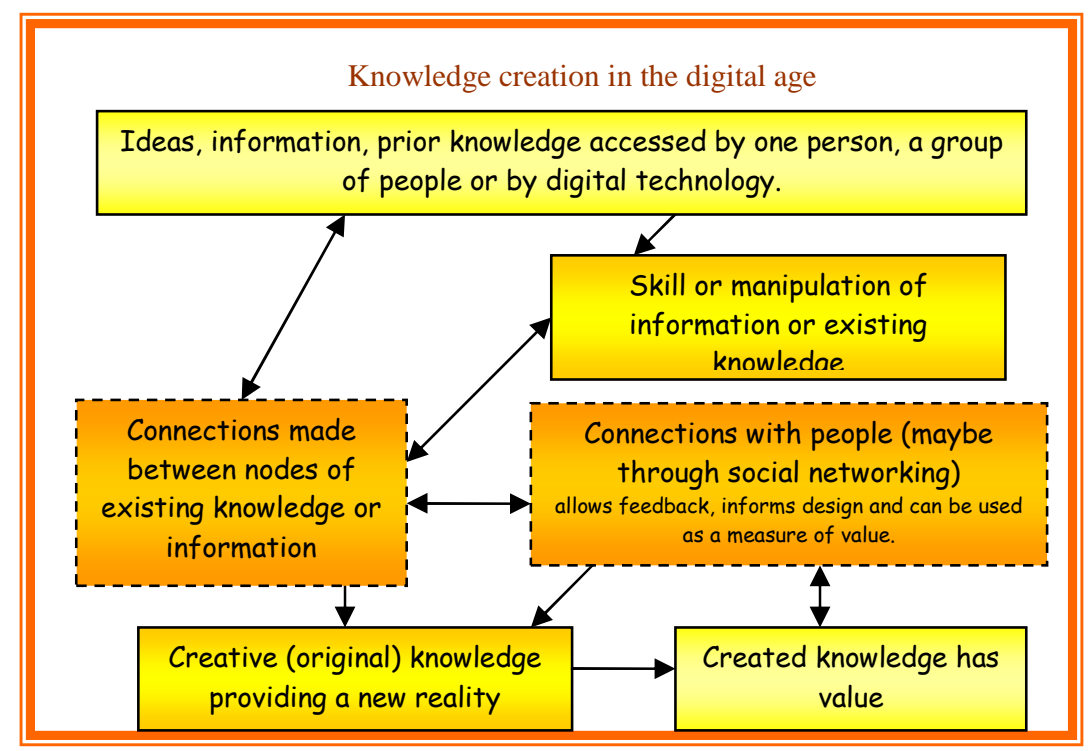

Figure 3: Knowledge creation model

The focus of research has moved from whether there are digital technologies in schools (measuring ratios), to whether they are being used (e.g., Cuban, 2001) including the barriers to teachers using them, to how they are being used and measuring the effectiveness of use. There is currently a lack of clarity in how 
effectiveness is measured and how developing digital age notions of creating knowledge, connectivism and critical thinking can be included in evaluating effectiveness.

\section{The digital saviours}

Sandholtz, Ringstaff and Dwyer (1997) believe that digital technologies drive change in teaching methods and may facilitate the transition from traditional methods to a more eclectic set of learning activities which include knowledge creation situations. Young teachers entering the profession have been expected to be a catalyst for change because of their expertise in digital technology use. This expectation has been expressed by teachers and by researchers (Cowie et al., 2008; Karsenti et al., 2002).

In a New Zealand study of teacher use of laptops, it was found that teachers reported looking to recently qualified teachers for insights into ICT appropriate pedagogies (Cowie et al., 2008). Teachers were looking to recent graduates for information and ideas about how they might exploit the affordances of the laptop and ICT in teaching and learning. Karsenti et al. (2002) suggest that it is crucial that future teachers be able to serve as catalysts for desired change in education if experienced teachers continue to say they make little use of ICT and feel qualified in only a limited range of applications.

The idea that beginning teachers will lead an educational revolution, even to be able to make major changes in schools, is likely to be unrealistic due to the complex contexts that beginning teachers find themselves facing. Clifford et al. (2005) found that student teachers who were confident in the use of digital technologies in their personal use were not necessarily confident in decision making in planning and implementation of digital technologies in their teaching practice. This reinforces the idea that effective digital technology integration is not solely a technical issue but also a pedagogical issue, or what Williams (2003) called a technopedagogical issue. It also indicates that beginning teachers cannot be assumed to sweep into schools as the digital saviours.

Becker (1999) found that younger teachers (under 30 years old) were more likely to think that the use of the internet was essential in their classroom. In the same study, he found that teachers with fewer than 4 years experience were slightly less likely than other teachers to use the internet in their teaching, though they were more comfortable with the internet in terms of their own use, which reflects the complexities that beginning teachers face in their first years of teaching. Clifford et 
al. (2005) also noted that the emerging teachers should not be viewed as 'digital saviours'. They identified a lack of research examining how student teachers, who use digital technologies routinely in their lives, will learn to use appropriately the technology to foster meaningful, deep learning.

The motivation of student teachers to integrate digital technologies into their teaching was the subject of research by Karsenti et al. (2002) Five factors were identified in a Canadian study of the motivation of student teachers to integrate ICT into their teaching. These included:

- The integration of ICT in their placement classrooms;

- The student teacher's level of computer literacy;

- The pedagogical integration in the teacher education programme;

- The future teacher's expectations of success in integrating ICT; and

- The value placed on ICT by future teachers.

Therefore the experiences of the students, the context of the schools in which they teach and their teacher education programme appear to influence whether or not student teachers use digital technologies in their teaching programmes.

\section{Teacher education programmes}

The teacher education programme has an impact on a beginning teacher's attitude to the integration of digital technologies into their teaching practice. Sime and Priestley (2005) found that the student teachers in their study were actively developing their attitudes and ideas about efficient uses of ICT in schools, a perspective that had been under-emphasised by previous research in this field.

A large scale research project carried out in Alberta, Canada, examined emerging practices in teacher preparation identified by university deans as being particularly effective in preparing and supporting pre-service teachers to use technology for teaching and learning within the existing local ICT teaching framework (Clifford et al., 2005). Student teachers were interviewed, and some observed while on practicum. Student teachers in 2005 were found to have experienced little access to digital technology in their own schooling yet were keen to use digital technologies as they tried out new ways of teaching, different to how they had been taught (Clifford et al., 2005). This research had examined student teachers who were taking part in 
effective innovative teacher education papers; therefore it could be assumed that they were more likely to be interested in implementing digital technologies in their teaching practice.

Lai (2005) noted that teacher education programmes across the world have not proved to be successful in preparing teachers with the knowledge, attitudes and confidence to use technologies in class. He speculated that most teacher education programmes were focused on the technological skills rather than the use of ICT for learning. Sandholtz and Reilly (2004) recommended that teacher education programmes focus on integrating technology into the school curriculum rather than on technical skills.

Teacher education programmes focus on preparing student teachers for the classrooms of the future. Many of the student teachers in a study by Sime and Priestley (2005) found themselves between two cultures: the culture of the schools where digital technologies were perceived as a separate subject, and the culture of the teacher education programme where the focus was cross curriculum integration. It was difficult or not appropriate for student teachers to challenge routines and different practices on teaching practicum.

In a New Zealand study of primary school student teachers, Shaw (2004) examined their attitudes towards ICT and ideas about ICT integration. She concluded that students were positive about ICT use, though do not often see effective use on practicum placement. Shaw recommended that placing students in carefully selected classes may help to overcome this problem. This aligns with the finding by Karsenti et al. (2002) about the importance of the teaching experience in developing future teacher practices, though the current model of teacher placement and availability of expertise in New Zealand is unlikely to make placement with expertise possible for all student teachers. None of the research articles identify the underpinning pedagogies for the digital era which should be included in teacher education programmes.

Sime and Priestley (2005) noted that student teachers often expressed their lack of confidence in their ICT skills and this implicitly affects their attitudes towards the use of ICT in their teaching. They recommended that the development of ICT pedagogies be underpinned by a reasonable level of generic IT skills. This conclusion may be limited to the pedagogical model under which the teachers were 
working. It appears that the authors reached this conclusion as the classes were working under a model where the teacher had to feel in control of learning activities rather than the children, therefore had to know more about how to use the technologies than the children. The underpinning pedagogical beliefs of the researchers appear to align more with a transmission model of thinking than a student-centred connectivist or constructivist approach. It may be the lack of confidence rather than IT skills that affects teacher attitudes.

Focussing professional learning of technical computer skills is not necessary to integrate digital technologies into teaching (Sandholtz \& Reilly, 2004). This conclusion was drawn after the authors worked with a school district to advance the use of computers in their classrooms by focusing on the curriculum, rather than the technology. In this study the teacher development programme generated a collegial network for support and ideas, which seems to be a key feature in successful schoolwide ICT implementation studies (Ham et al., 2002).

The same type of finding has occurred in teacher education programmes. Campbell and Yates (2005) examined the experiences of students working online in a teacher education programme. They found that: "barriers imposed by the technology evaporate when we focus on our goals of quality teaching and learning that model the way we expect our teacher education students will work in their own classrooms and schools" (p.49).

\section{The reality of the first year of teaching}

Applying complexity theory to a research topic includes consideration of the complexities faced by the participants. The reality for teachers during their first year of teaching has been the subject of recent studies. Moir (2008) described the phases that beginning teachers face including survival, disillusionment, reflection and anticipation. Almost all beginning teachers interviewed in 2003 as part of a study from 20 secondary schools across New Zealand said they faced many challenges. These included: an overwhelming amount of paperwork, managing classroom behaviour, feeling obliged to take on extra curricular activities such as sports coaching, and a lack of easily accessible resources and prepared lessons. The support the teachers received for classroom management and from the head of department was reported as being pivotal (Dewar, Kennedy, Staig, \& Cox, 2003). 
The teachers in an ERO (2005b) study reported similar concerns in their reflections at the end of their first year, with additional stress reported when the resources they lacked included not having enough desks and chairs. In this study, which combined surveys and evaluation visits to 79 primary and 32 secondary schools in 2005, the education review officers deemed that for beginning teachers, for teaching and support to be effective, the following factors were identified as likely to be present:

- a team of beginning teachers at one school

- strong school support for the beginning teacher

- a teacher mentor playing a positive role in the beginning teacher's professional development.

The key challenges that beginning teachers in their first two years identified included: learning school policies, procedures and systems, time for planning, accessing professional development opportunities, getting to grips with the curriculum, establishing a rapport with students and meeting the expectations of colleagues and management (ERO, 2005b).

Teachers may answer interview questions differently when asked by a reviewing body such as ERO than when asked by independent researchers. The theme of enculturation was identified as an important challenge identified in independent studies (Feiman-Nemser, 2003; Moir, 2008). Teaching can be an isolating experience, especially during the enculturation phase of the first year in a new school. The importance of the context that a beginning teacher finds themselves in their first year of teaching is an important aspect as the context underpins the beginning teacher's enculturation. In a review of literature on beginning teachers, Feiman-Nemser (2003) found that the enculturation process, which includes learning the ropes of how things are done within the particular context, is a key part of beginning teaching, and the mentoring received and relationships a beginning teacher builds are going to influence how they approach their teaching and whether they integrate digital technologies into their teaching practice.

Hargreaves (1995) emphasised that relationships with colleagues are critical in the development and socialisation of teachers. Gratch (2001) built on this idea in a study of 38 students and first year teachers $(n=10)$, finding that the school culture impacted on the self-concept of the teacher and the choices the teachers made about teaching practice. Therefore whether a beginning teacher chooses to integrate digital 
technologies into his or her teaching practice is partly dependent on the school (or department) context in which they teach.

The Galileo network has published the most significant research to date that examines emerging teachers in the digital age (Clifford et al., 2005). One of the aims of this research project was to identify innovative pedagogical practices that prepare and support pre-service teachers. In one of the case studies, the researchers recognised the power of "working side by side with trusted colleagues when you are learning new things" (Clifford et al., 2005, p. 78). They noted that traditional modelling systems are no longer appropriate in teacher education, and asked how can emerging teachers be mentored that allows them to be innovative? The answer could be found in literature by Bereiter (2002), and Hargreaves and Fullan (2000).

Teacher education has traditionally used 'expert' mentors in their programmes, where students (novices) learn about the theory of teaching, then see it in practice in the classroom. This model has resulted in the 'craft' of teaching changing very slowly over generations of teachers (Bereiter, 2002). The mentoring model used with beginning teachers and student teachers needs to be shared inquiries into practice rather than a hierarchical model where positional power can limit opportunities for innovation (Hargreaves \& Fullan, 2000). The mentors are more effective if they recognise that they bring to the relationship much experience in teaching and learning and the emerging teacher may bring a new way of examining how digital technologies can be used. These relationships are important in the development of emerging knowledge within a school.

\section{Transfering learning of digital technologies.}

Beginning teachers bring with them experiences from their schooling, undergraduate degree, postgraduate diploma and from informal learning. The knowledge they have may be transferred to their teaching practice. How beginning teachers transfer their knowledge of digital technologies to their teaching practice early in their teaching careers is the focus of this research. Transfer of training or learning is a field of educational research that is complex and debated. As the beginning teachers have not been 'trained' specifically in the use of particular digital technologies for teaching practice, the examination of transfer of learning appears to be more appropriate than transfer of training. 
One taxonomy that could be useful to apply to the beginning teachers' application of prior knowledge of digital technologies to the teaching context, developed by Haskell (2001), is the type of transfer that occurs. Haskell's approach draws on research findings from education psychology, training and neurology (Leberman et al., 2006).

According to Haskell (2001), transfer is classified based on the type of knowledge involved: “...declarative, procedural, strategic, conditional, and theoretical knowledge...." (p.31). Researchers in the field of cognition and instruction typically mention the first four types; Haskell added the fifth one. As a beginning teacher transfers their knowledge of digital technologies to their teaching practice, all of these types of knowledge are likely to connect and transfer to some extent as the teacher undertakes pedagogical reasoning and action to develop learning activities for students.

Shulman (1987) recognised a teacher's base knowledge as including pedagogical content knowledge, conceptual knowledge, pedagogical knowledge, contextual knowledge, and knowledge of educational purposes and values, this base knowledge remains relevant today. A cognitive approach to transfer of learning was developed by Bransford and Schwartz (1999). This approach recognised that when a learner is in a new context or situation they bring with them their beliefs and experiences which includes four types of knowledge: conceptual knowledge, procedural knowledge, strategic knowledge and tacit knowledge. The cognitive approach is more generic than the teacher centred base knowledge (Shulman, 1987). The barriers and enabling conditions or factors that occur during the transfer process are an important aspect in studies of transfer of learning. Barriers and enabling factors (forces) are a key aspect in studies of the transfer of learning (Haskell, 2001) and the earlier force field analysis (Lewin, 1943). A key barrier in transferring learning is the lack of suitable support, and strong support has found to be an enabling factor (Haskell).

\section{Summary of findings from the literature}

This chapter examined research and literature in areas relevant to beginning teachers using digital technologies in the classroom through a complexity theory perspective. The review examined research which focussed on the wider context (the digital age), including the learners (students and beginning teachers), the learning process 
(relevant learning theories and how learning could be measure) and the schooling context. The research reflects the time in which it was conducted and the beliefs of the researchers at the time. In an emerging field such as the use of digital technologies in schools the evolving understanding through research and debate provides an important historical context. The following summary links the findings from the literature with the research questions which informed this thesis.

Instant access to the internet via digital technologies means that information and communication can be connected at the click of a button or tap of a screen. This has led to a new way of examining knowledge, how it is created, revised and connected (Bereiter, 2002; Bereiter \& Scardamalia, 1998; Gilbert, 2005; Siemens, 2006). Education is based on understanding and creating knowledge so a new perspective has implications for teaching and learning in the digital age. Through complexity theory, the notion of connectivism as a learning theory is developing and being debated through the Web 2.0 networks of educationalists. Within the framework of connectivism knowledge is created through connections of nodes of information within networks. This occurs at various scales from within a brain to across the globe. Relationships are a key aspect of complexity theory and of connectivism and the complex nature of schools and learning means that it cannot be reduced to a linear cause and effect model (Davis \& Sumara, 2006; Siemens, 2006). Examining the beginning teachers' connections within and beyond the schooling context could give insight into their pedagogical reasoning and action (Shulman, 1987) as they seek to use digital technologies in the schooling context.

Many young people are learning through a range of digital technologies in everyday life. They create, connect, play and communicate in a way that is different to the way they learn at school (Lenhart et al., 2007; Loertscher, 2007; Vincent, 2004) or are expected to teach as they enter the teaching profession. Not all young people are digital enthusiasts; there is diversity within the group, and not all have access to make the connections or reach the information. Diversity is a key factor within complexity thinking. It is through diversity that redundancy and knowledge can emerge (Davis and Sumara, 2006). The diversity amongst the digitally able beginning teachers can be identified through case study which aims to gain an in depth understanding rather than generalising a population (Stake, 2006). 
The majority of the research about teaching and learning in digital age secondary schools is focussed on the teachers' voice or young people talking about their use of digital technologies beyond school; there are few examples of what students say about their learning or experiences in school. A case study approach based around a beginning teacher gives the opportunity to listen to students during their learning.

A complexity theory conceptual framework acknowledges the importance of the historical context which in this study included the examination of what was being researched. The research focus has changed over time from examining ratios of computers to pupils, to examining whether teachers are using digital technologies and if not, why not, to examining the impact the use of digital technologies is having in schools. Research that examined the use of digital technologies in schools reported on experienced teachers who are new to using digital technologies in their teaching and learning, rather than the digitally able entering the profession.

While a pedagogical revolution has been heralded by some educationalists (Cowie et al., 2008; Karsenti et al., 2002), the reality is that most teachers add digital technologies to their existing teaching practice and beliefs (Tearle, 2003). A significant change in teaching practice due to the use of digital technologies is the enabling of personalisation of learning to meet the needs of diverse learners (Cox et al., 2004; Pedretti et al., 1998). Whether teachers use digital technologies or not cannot be reduced to direct causes and effects and though researchers working from a predict and control paradigm have tried to narrow down influencing factors, the literature shows a complex range of connected influences within the contexts that teachers operate which impact on pedagogical decisions, a finding which aligns with complexity thinking. A teacher's pedagogical reasoning and action can be examined through a case study approach.

Teachers have reported using digital technologies for three primary functions in their teaching. The most commonly reported use is the use of presentation software, which appears to be to enhance a transmission approach to teaching. The second use is of subject specific technologies or programmes for specific pedagogical content knowledge. Using the internet for student inquiry projects is the third use, which has been recognised by some researchers as encouraging constructivist learning (Becker, 1999; Lowther et al., 2008). A further approach using Web 2.0 software was rarely 
reported in the literature. Few examples of collaborative knowledge construction through digital technologies or creativity were reported in research literature.

The literature that examines the effectiveness of digital technologies is problematic. The interpretation of effective use is dependent on the perspective of the evaluator. Research measurement includes; the number of times digital technologies are used, the type of use, or the impact on student achievement. The first two measures are not measuring effectiveness and the third typically measures student achievement through existing standardised tests not designed for learning in the digital age (Heppell, 1999). Where student achievement attributed to the use of digital technologies is measured, the findings reported can be misleading as the complexity of teaching, learning and schools means that causal links are difficult or impossible to accurately establish (Twining et al., 2006). There is a need for a measurement tool to examine and guide effective use of digital technologies for learning in the digital age (Cassady, 2002). In a complex connectivist learning environment this would include creating knowledge, making connections, collaborating and critiquing.

Beginning teachers have been viewed as digital saviours, though in reality it appears from the literature that while they might be familiar with the use of digital technologies and would like to use them in their teaching practice, they do not always do this. Literature on transfer of learning tends to examine the transfer of specific learning rather than applying learning from a range of contexts including the informal learning of beginning teachers. An appropriate framework will focus on examining the base knowledge and influences that enable or constrain the use of that knowledge in the complex schooling setting acknowledging that a complex system is multileveled, ambiguously bound and can not be examined as isolated parts (Waldrop, 1992)

A literature review underpinned by complexity theory acknowledges that as new knowledge develops about how digital technologies influences the teaching and learning process in schools, new questions are asked and previous literature is reviewed through a new lens. This review aimed to situate the study in a historical context and to build on the emerging knowledge of teaching and learning in the digital age. Gaps or research directions identified in the literature that this thesis hopes to develop include: a way of measuring effective application of digital technologies in the digital age, the way that the digitally able beginning secondary 
teachers transfer their base knowledge to the classroom, and the voice of the students learning in schools in the digital age. This research examines the question: How do digitally able beginning teachers use digital technologies for teaching and learning? 


\section{Chapter 3. Methodology and research design}

This thesis examines the experiences of beginning teachers as they enter the world of teaching. The methodological approach taken in this research was interpretative multiple case studies based on complexity theory conceptual framework. The research focussed on six digitally confident beginning teachers' experiences of using digital technologies during their first year of secondary teaching and data were collected through interviews, observation and student think alouds. A peer reviewed digital age learning matrix was developed as a tool to consider learning activities within a digital era. From the data, case based assertions were drawn then compared in a cross analysis of the case studies. A generic inductive qualitative analysis (Hood, 2007) was used to identify findings beyond the research questions. The methodological approach taken is discussed in this chapter, followed by details of the research design.

Cohen, Manion, \& Morrison (2000) define methods as a range of approaches used in educational research to gather data which are to be used as a basis for inference and interpretation for explanation and prediction. Complexity theory would suggest that prediction can be problematic when transferring findings from one context to another or to a broader context (making generalisations). Table 2 (adapted from Fritze, 2003) describes the research framework:

Table 2: Methodological approach

\begin{tabular}{|l|l|}
\hline Conceptual framework & Complexity theory \\
\hline Paradigm & Qualitative \\
\hline Model for research & Interpretive case study \\
\hline $\begin{array}{l}\text { Methods or tools for data } \\
\text { collection }\end{array}$ & $\begin{array}{l}\text { Interviews, think alouds and application of a } \\
\text { digital age learning matrix }\end{array}$ \\
\hline Data analysis: & $\begin{array}{l}\text { Individual case analysis applying logic } \\
\text { models and cross case synthesis which } \\
\text { includes comparative analysis and aspects of } \\
\text { generic inductive qualitative analysis }\end{array}$ \\
\hline $\begin{array}{l}\text { Organisational } \\
\text { structures or networks of } \\
\text { the participants: }\end{array}$ & $\begin{array}{l}\text { Beginning teachers (and to a lesser extent } \\
\text { their students) } \\
\text { Schools and teacher/individual support } \\
\text { networks. }\end{array}$ \\
\hline
\end{tabular}




\section{Conceptual Framework}

Complexity theory was the basis for the conceptual framework chosen to examine the rapidly developing field of research into the use of digital technologies in teaching and learning. Four key constructs underpinning complexity theory informed the methodological approach:

1. A complex system is not static; it constantly faces change through its structures, participants, parts, processes and knowledge (Morrison, 2002).

This research acknowledges that schools and ideas about education are not static. The thesis focuses on teachers new to teaching and to the schools in which they teach. The processes and structures that influence their teaching practice were examined, narrowly looking at those that impinge on or enhance the use of digital technologies. This included the interactions between the beginning teacher and their self-identified support networks to examine the type of knowledge that was emerging,

2. New knowledge will emerge through connections and in consideration of the history, culture and experiences of the organisation and participants (Buchanan, 2000).

A case study approach was chosen to situate the participants within the complex system in which they were teaching. The beginning teacher's experiences prior to their teaching was examined, thus an interpretive approach allowed consideration of factors that may influence the emergence of knowledge.

3. While the system or organisation remains in tact, the structure, knowledge or systemic processes may change. The type and nature of the resulting change or emerging knowledge is not predictable (Prigogin, 1997)

A generic inductive qualitative analysis of the data took into account the unpredictability of the findings, while a structured qualitative approach allowed for the examination of the structure and processes within a complex system. The use of a logic model (as a graphic organiser) and digital age learning matrix guided the structure for data gathering. Variables of interest focused the research on influences identified by the literature and previous research while the use of semi-structured interviews and think alouds gave the flexibility to examine the unpredictable. 
4. A complex system is multileveled, ambiguously bound and can not be examined as isolated parts (Waldrop, 1992)

The data was analysed at three levels; the individual case studies, a comparison across the case studies and a generic inductive qualitative analysis to consider the data in the wider schooling context.

This complexity theory conceptual framework is in direct contrast to a scientific framework. The main area in which they diverge is in the perceived role of the individual. Unlike the behaviourists, who believe in the deterministic nature of our behaviour, this framework is underpinned by the belief that we individually and collectively construct reality (Stake, 2006). Analysis focused on the context in which learning takes place and on the human being and all our complexities rather than simplistic mathematical models of behaviours. A complexity theory approach to research should be open and flexible including consideration of a range of factors such as relationships, culture, motivation and past experiences (Buchanan, 2000, Morrison, 2002). The interpretivist nature of this research means that such approaches are concerned with human observation and qualitative methods, recognising that the investigator is bound up in the situation, rather than being a detached, objective observer, reflecting the belief that knowledge is constructed by the individual and is socially negotiated (Guba \& Lincoln, 1989).

The aim of this research was to examine how beginning teachers use digital technologies. It is not just the superficial facts but the rich information within the reasons why or why not the types of learning that occur and the connections, collaborations and knowledge created as a result that are of interest. These aspects are subject to people's perceptions - the perception of the teacher, students and researcher. Therefore this research is qualitative where the findings are constructed by the researcher and the participants checked and approved these.

\section{Multiple case study}

A multiple case study (Stake, 2006) was the logical methodology as it allowed the research to focus on the complex forces and relationships that impact on the beginning teacher within the context of the school and environment in which they teach. Case study is a methodological approach that involves systematically gathering enough information about a particular person or group and situation to 
permit the researcher to effectively understand how the subject operates or functions (Berg, 2004). The aim of this research is to explore beginning teachers' use of digital technologies in their first year as a teacher by concentrating on individual teachers within the context of a complex schooling system.

The detail that can be included in case studies allows the reporting of complex dynamic and unfolding interactions or events, human relationships and other factors in unique situations. This aligns with underpinning ideas from complexity theory. The depth of the personalised and contextual detail gathered from the case studies allowed analysis of the complexities of relationships, context, skills experiences and beliefs of each of the case study participants. Proponents of complexity theory argue that the whole cannot be analysed by examining the parts in isolation (Morrison, 2002); therefore case study is a logical method to explore complexity theory. Case studies can penetrate situations in ways that are not always accessible through numerical analysis (Cohen et al., 2000). The research methodology is interpretive case study grounded in complexity theory in which the researcher places all data, decisions and methodological approaches through a filtering lens that is shaped through personal experiences and beliefs.

\section{Research design}

This research was conducted in an interpretivist - qualitative paradigm underpinned by complexity theory conceptual framework. The aims of the research and the questions that have emerged, pointed to case study as being the most appropriate methodology. The use of propositions, triangulation and generalising as suggested by Yin (2003) was replaced by variables of interest and assertions to align the case study approach underpinned by complexity theory.

Multiple case study was chosen to explore the research questions across six cases, to ascertain patterns, replication, or contradictions of findings. Yin (2003) noted that using multiple case studies increases the generalisability of the findings, adding validity to the research, which appears to take a positivist perspective. The detail of beginning teachers' experiences within the complexities of the school context is the focus of this research, hence the purpose of using case studies is as Stake (1995) puts it: “the real business of case study is particularisation, not generalisation' (p.8). 
In this study a sample of the current generation of beginning teachers' use of digital technologies was the area of interest. The context was the New Zealand secondary school in 2007/2008. The variation between the case studies included different secondary schools (decile, cultural, size, geographical location), curriculum areas being taught and experiences beliefs and attitudes brought to teaching. The timeframe involved examining the teachers across their first year of teaching.

A theoretical framework to identify important influences was developed from the synthesis of the literature. A logic model (or graphic organiser) (Figure 4) guided the data gathering and analysis of the individual case studies. Embedded in the logic model were four research questions. Each research question included variables of interest to ensure that aspects which could be relevant to the study were not overlooked.

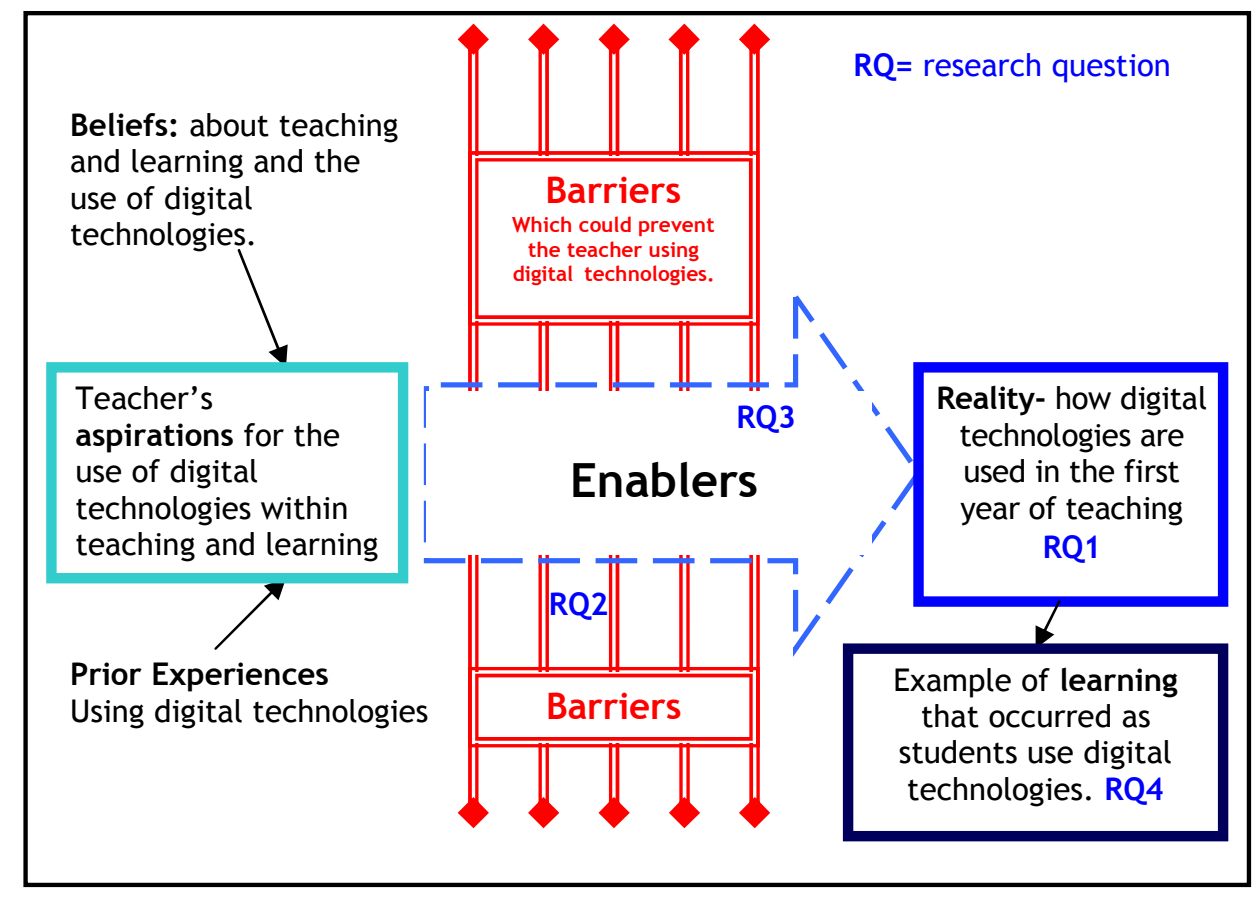

Figure 4: Logic model to guide research

Constructivist, complexity and connectivist theories underpin the logic model in Figure 4. This research builds on the constructivist notion that learners (in this case the students and teachers) actively construct knowledge drawing on what they already know, have experienced and believe (Bruner, 1966). Complexity theory emphasises the importance of the context or organisation in which the learners are situated (Morrison, 2002). The teachers are in schools which are influenced by those present (each person's culture, experiences, knowledge and beliefs), the processes, school culture, hierarchical structures, and historical events all of which have shaped 
a schools' culture. Connectivism emphasises that learning or knowledge creation occurs between nodes of knowledge which includes social groups, digital technologies and individuals (Seimens, 2004). Therefore connectivism points to where learning occurs, constructivism gives a model for how learning occurs for the individual teacher, and complexity theory helps explain the importance of the context and relationships within the context.

\section{Research questions}

One main research question arose following a survey of the literature and three related questions gave further form and scope to the research. Within each of the questions there were variables of interest identified from the literature and modified during initial data collection. Yin (2003) advocated using propositions that emerge out of the literature noting that "each proposition directs attention to something that should be examined within the scope of study" (p.20). This helped to focus and detail the scope of the research questions. Propositions are like hypotheses which are found to be true or false, with conditions or cause/effect attached. The concept of using propositions through an interpretive case study appeared incongruous as they had the potential to limit flexibility, ignore complexities and restrict emerging findings. The use of propositions was therefore limited to the initial design phase where key findings and assumptions arising from an initial review of literature were made explicit to focus the research. The research methodology used aimed to construct meaning from data and observations while taking into account the complex relationships within the context in a holistic way. In this research method "propositions" were broadened at the design phase to become "variables of interest." Variables of interest were designed to take account of the existing literature and to focus the research into aspects that might be useful to explore, but not limiting the findings to these.

The research design (Figure 5) was kept flexible to allow for changes during the research process. This allowed for alterations in the research questions as a result of findings and emerging literature. Parlett and Hamilton (cited in Stake, 1995) noted the need for progressive focussing during the research process. The initial draft of the research included five questions with support and mentoring being a major component. This was refined after the first round of interviews to include just four questions, integrating the support and mentoring into the variables of interest of 


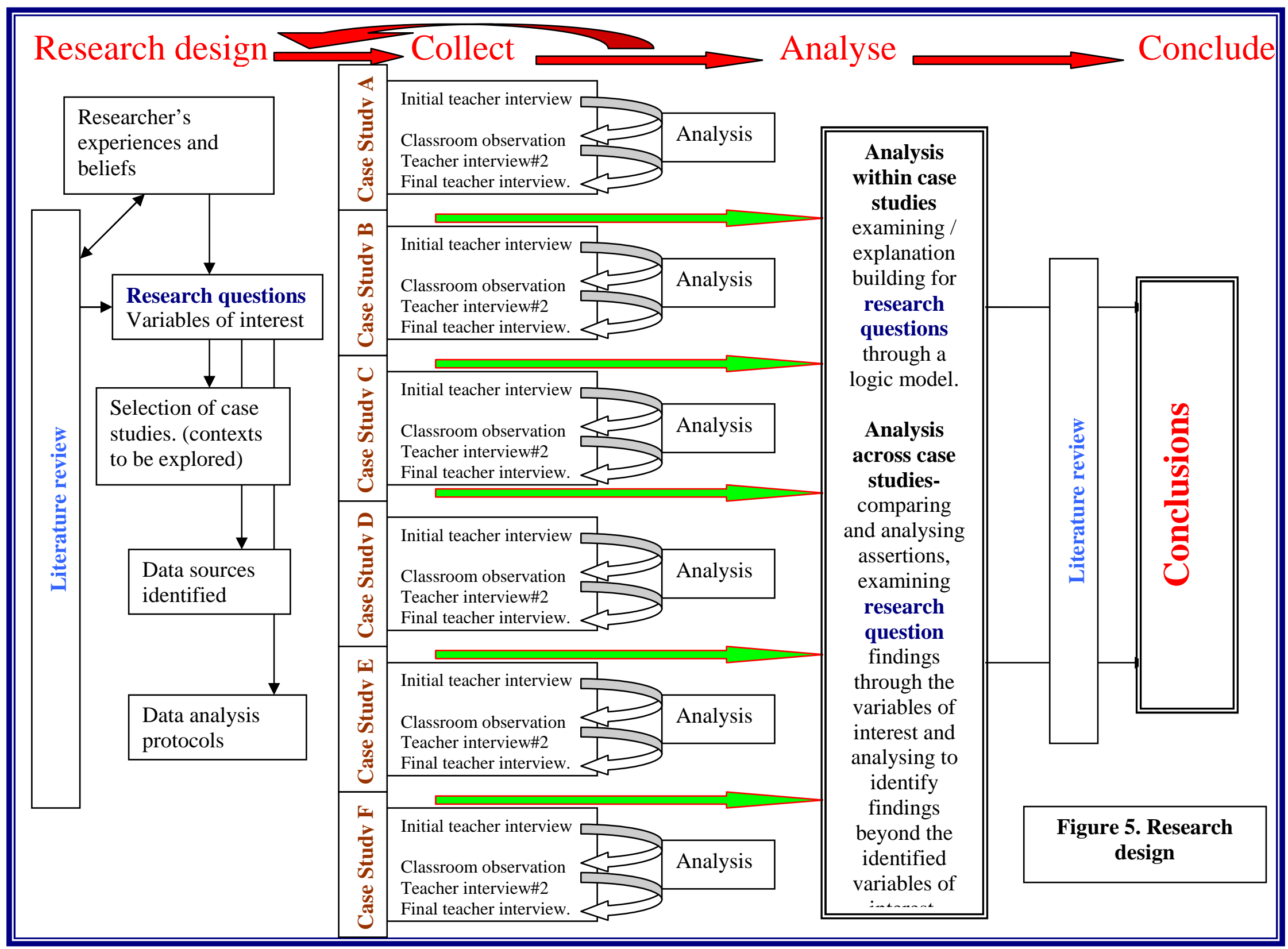


another research question (refer appendix 8). Stake, (1995) noted that: "the most difficult task of the researcher is to design good questions, research questions that will direct the looking and thinking enough and not too much" (p.15). I believe the refined questions were able to do this.

\section{Main research question}

Given the right conditions, the current generation of secondary teachers could apply their experiences and knowledge of digital technologies to their own professional learning and teaching practice in a way that is relevant in the digital era. To explore the extent to which this was occurring, a main research question and three subquestions were used to guide the research. The fundamental research question was: How do digitally able beginning teachers use digital technologies for teaching and learning?

For each of the questions the variables of interest and an accompanying explanation are outlined. Each generation of beginning teachers has had longer exposure to the use of digital technologies than the previous generation. The use of social networking software (Web 2.0) allows connections and collaboration in learning which has increasingly become available since 2005 . Increasing numbers of student teachers are joining the teaching profession having experienced a range of digital technologies in their everyday life and in their undergraduate degree and previous work experience. These teachers are comfortable with the use of some of the technologies, yet have minimal experience in seeing them integrated into a teaching and learning programme to foster meaningful, deep learning. (Clifford et al., 2005). This study examines a small sample of beginning teachers who are confident users of digital technologies to ascertain how they attempt to integrate digital technologies (such as Web 2.0) into their teaching programme and professional learning within a complex organisation (a school).

Variables of interest for the main research question include the purpose (accessing information, recording, processing information, gaming, communicating), type of learning activity and the type of technology being used.

For the purposes of this research the following operational definitions were adopted:

Beginning teachers - teachers in their first year of secondary school teaching. 
Current generation - young adults who integrate digital technologies regularly in their everyday life.

Digital technologies - this includes a wide range of products including computers, laptops, PDAs, cell phones, interactive whiteboards, MP3 players, digital cameras, data projectors and associated software and applications available through these.

Use for teaching - this could be the teacher or his/her students using the technologies for the purpose of the students learning in class or beyond the classroom. In this thesis teaching is the deliberate act of helping students to develop knowledge and/or skills.

Use for learning - this includes both the teacher and the students learning. In this thesis learning is the process whereby someone gets to know something or how to do something they did not know or could not do before the learning took place. Digital technologies may be used by the teacher to learn about pedagogy, assessment, subject content etc. They could access information, interactive activities or people to help with learning.

\section{Sub-questions}

Three sub-questions also helped to guide the research. Following a similar format to the main research question, each is outlined, explained and the variables of interest that were included in the research are listed.

Whether beginning teachers choose and are able to transfer their knowledge of digital technologies use to their teaching or professional learning depends on a range of factors. These factors will be different to those previously identified by research because of the nature of technology (for example Web 2.0) and the current generation of beginning teachers. Thus the first sub-question was: What factors impede or encourage the use of digital technologies by beginning teachers?

The connections and interactions within a complex system or organisation such as a school are important in the development of an individual's and organisational knowledge (Morrison, 2002). Factors that impede or enable the use of digital technologies in teaching for experienced teachers have been identified in previous research (Becker, 2000; Lai, 2005; Passey et al., 2004; Sime \& Priestley, 2005) and can be broadly categorised under four categories: Access, experience, beliefs and support. These 
categories became variables of interest within this sub-question. By 2007/8 some of the factors identified in previous studies, such as unreliable internet access, were no longer relevant and the factors were likely to be different for beginning teachers. The implications of identifying the relevant factors may help to understand how to prepare and support beginning teachers who aim to use digital technologies in their teaching.

How the current generation of teachers use digital technologies is also of interest. One of the recent developments was the improved interactivity and connectivity available through Web 2.0 applications. Beginning teachers could use social software (Web 2.0) to connect and collaborate in their teaching and professional learning. A second sub-question focused the research on the connectivity functionality of digital technologies: How do beginning teachers connect and collaborate in their teaching and professional learning?

To be successful as a teaching professional, the connections with colleagues and peers are important. Becker and Riel (2000) noted a positive correlation between the informal connections a teacher has with colleagues and their use of ICT in their teaching and learning. Social software (Web 2.0) allows global networking and collaboration from almost anywhere, at anytime. There are growing online networks of teachers and there are networks being used by classes. The current generation of beginning teachers are likely to be familiar with this technology and may apply it to their professional learning and/or use it in their teaching practice. Variables of interest that emerged from the literature included: How digital technologies are used to connect and collaborate, who is included in the networks, types of collaborations, and the nature of professional learning.

As well as whether and how the beginning teachers use digital technologies, the learning associated with their use was a focus in this research. This builds on the current debate about the impact of digital technologies on learning and knowledge (For example; Bereiter, 2002, Gilbert, 2005). Different levels and types of learning occur depending on the application and type of digital technology used. Learning can be measured according to connections, creativity, conceptual understanding, critique and reflection. A third sub-question in this research was: What is the potential learning and the actual learning that occurs in a beginning teacher's classroom as students use digital technologies? 
The aim of teaching is learning. While the types of technologies being used or not used by teachers are of interest, the learning resulting from the use of technology gives the research depth. Current models of professional development would suggest that the learning that students experience is an important measure to evaluate the use of digital technologies in the process of learning (Guskey, 2000; Kirkpatrick, 1994). While exploring how beginning teachers currently use digital technologies in their teaching, it is important to focus on the quality of the learning that the students experience while using digital technologies. Reeves (1995) discusses the relevance to social responsibility when researching the use of digital technologies in education. He points out that while research often focuses on understanding more clearly the use of research, it does not always link to how the research will help improve education. Schools and education are about learning; therefore by examining the quality of learning by the students, the usefulness of the research findings have the potential to directly impact on learning in the classroom, thereby strengthening the social responsibility of the research. The variables of interest for this sub-question include: engagement levels, creativity, conceptual understanding, critical thinking, reflection, and connections.

The research questions do not exist in isolation. They are connected and through the connections a greater understanding of teaching and learning in the digital age will be constructed (Figure 6).

\section{Selection of participants}

Purposive sampling was used to select the case studies. Cohen et al. (2000) defined purposive sampling as sampling for a specific purpose and picking a group who fit a profile. In this case graduates from the same cohort, who were young, confident and familiar with the use of digital technologies and keen to use digital technologies with students were chosen. Five cases were monitored from July 2007 to June 2008 and each was a beginning teacher who graduated from the same university with a post graduate teaching diploma at the end of June 2007 and began teaching in a New Zealand secondary school in July 2007. A sixth joined in February 2008 when one of the original participants headed to England to teach. Both remained in the study. All the students in the cohort graduating in July 2007 were invited in May 2007 to indicate their interest in participating in this study through an information sheet and consent form. 


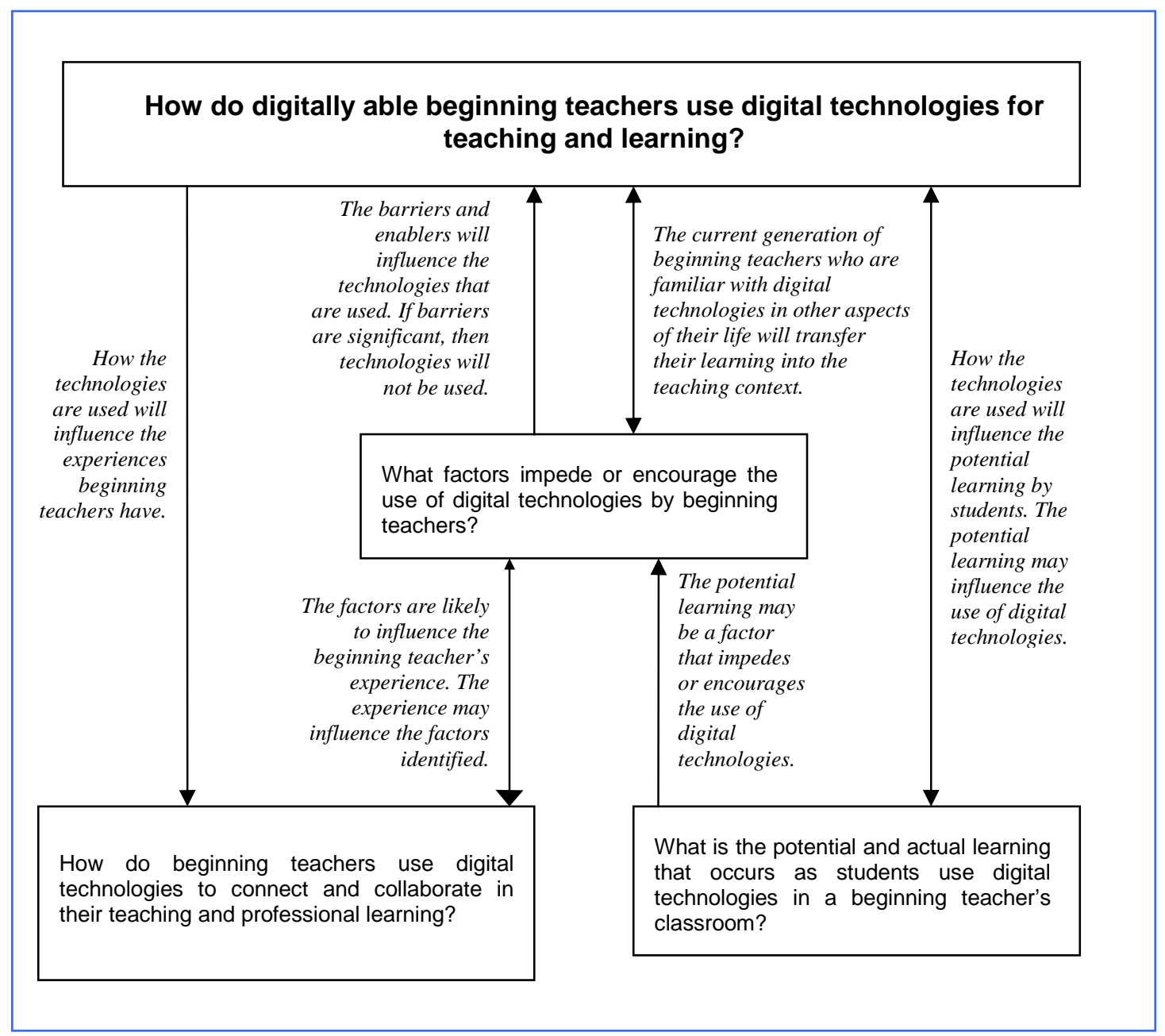

Figure 6: The relationship between the research questions

The aim was to select four to six case studies from the volunteers. One cohort was approached from one university. This was to limit any wide variability in the preservice teacher education programmes, and to keep all the case studies in the same timeframe. The graduating student teachers were invited to volunteer to take part in the research if they were enthusiastic about introducing digital technologies into their teaching practice during the first year of teaching. This approach was taken after careful consideration about how to best capture the reality for a beginning teacher in their first year of teaching. If the participant was indifferent about integrating digital technologies into their teaching then the research would be less likely to show innovative practice as it would be easier for the teacher to teach as they were taught or as those around them are teaching. Using case studies rather than cohort surveying allowed examination of the complexity of the contexts in which beginning teachers find themselves which are difficult or impossible to capture through larger scale qualitative research. 
Eight student teachers volunteered to become participants. Five were selected to become the case studies; all were new to teaching, expressed an interest in using digital technology in their teaching and had secured work across a range of types of schools. Of the three who volunteered and were not selected, one did not secure a teaching job in the following six months, one was an experienced teacher already who held an overseas qualification that had not been recognised, and the third was an older student, not fitting the 'current generation' criteria. The schools employing these teachers from July were asked to agree to be involved in the research, and permission was gained from the schools' principals, the students that were involved and their caregivers.

The researcher knew each of the participants, having been their lecturer for one or more papers in the pre-service teacher education programme. Having an established relationship with the participants had ethical and research/interpretive validity implications. This was taken into consideration in the design, data collection and analysis.

\section{Data collection}

Yin (2003) advocates the use of multiple data sources for construct validity. For each of the research questions in this study, there were at least three types of data sources. Data were compared within and across case studies to maximise validity. The relationship between the data sources, research questions and variables of interest are outlined in Table 3.

Data sources included: physical artefacts (lesson plans and student work), transcribed interviews of teachers and classroom observations/ student think alouds as students use digital technologies in their learning.

Case study teachers were interviewed during their first term of teaching to gain an understanding about their beliefs and experiences (appendix 5). During the following three terms, one or two face-to-face meetings with each of the case study teachers was held, apart from case study $\mathrm{C}$ who went to England after which further communication was by email. During these recorded open-ended interviews, the use of digital technologies was discussed. The notes and transcripts from these meetings were kept as part of the research documentation. Any negative results were closely analysed, as recommended by Bereiter (2002). Each case study was invited to have 
Table 3: Data sources, research questions and variables of interest.

\begin{tabular}{|c|c|c|c|c|c|c|}
\hline Possible data source & \multirow[b]{3}{*}{ Variables of interest: } & \multirow[b]{3}{*}{ Literature } & \multirow{3}{*}{$\begin{array}{l}\text { Physical } \\
\text { artefacts- } \\
\text { exemplars }\end{array}$} & \multirow{3}{*}{$\begin{array}{l}\text { Interviews at } \\
\text { start of the year } \\
\text { with beginning } \\
\text { teachers }\end{array}$} & \multirow{3}{*}{$\begin{array}{c}\text { Classroom } \\
\text { Observations/ } \\
\text { student think } \\
\text { alouds }\end{array}$} & \multirow{3}{*}{$\begin{array}{l}\text { Interviews at } \\
\text { end of the year } \\
\text { with beginning } \\
\text { teachers }\end{array}$} \\
\hline Probable data source & & & & & & \\
\hline Research questions & & & & & & \\
\hline $\begin{array}{l}\text { How do beginning teachers use } \\
\text { digital technologies for teaching and } \\
\text { learning? }\end{array}$ & $\begin{array}{l}\text { purpose (accessing } \\
\text { information, recording, } \\
\text { processing information, } \\
\text { gaming, communicating), } \\
\text { type of learning activity } \\
\text { and type of technology. }\end{array}$ & & & & & \\
\hline $\begin{array}{l}\text { What factors impede or encourage the } \\
\text { use of digital technologies by } \\
\text { beginning teachers? }\end{array}$ & $\begin{array}{l}\text { access, experience, } \\
\text { beliefs and support. }\end{array}$ & & & & & \\
\hline $\begin{array}{l}\text { How do beginning teachers use } \\
\text { digital technologies to connect and } \\
\text { collaborate in their teaching and } \\
\text { professional learning? }\end{array}$ & $\begin{array}{l}\text { Who is involved in the } \\
\text { networks, types of } \\
\text { collaborations, nature of } \\
\text { professional learning? }\end{array}$ & & & & & \\
\hline $\begin{array}{l}\text { What is the potential and actual } \\
\text { learning that occurs as students use } \\
\text { digital technologies in a beginning } \\
\text { teacher's classroom? }\end{array}$ & $\begin{array}{l}\text { Engagement, creativity, } \\
\text { conceptual understanding, } \\
\text { critical thinking, } \\
\text { reflection, connections. }\end{array}$ & & & & & \\
\hline
\end{tabular}


an observation of a lesson in which digital technologies were being used. This occurred in three of the case studies where the researcher visited the school and observed the learning (where it was appropriate) and had a recorded discussion with students about their learning in the form of a think aloud (appendix 6b). During the final term of the study, in 2008, the teachers were again interviewed (appendix 7) using semi-structured questioning.

\section{Interviews}

Open-ended semi-structured interviews were used for gathering data from the case study teachers about their experiences (appendices 5-7). Interview questions were developed to align with the research questions, previous findings/interviews and variables of interest. The guiding interview questions are included in the appendices.

Open-ended interviews were chosen to align with complexity theory ideology. Yin (2003) recommends using open-ended interviews as this allows discussion to flow and show the complexities that exist which are unique to a context or may give rise to patterns across the contexts.

Kvale (1996) outlines qualifications for an interviewer. These were taken into consideration when preparing for interviews and form the basis of the first column of Table 4.

The first interviews were carried out after the teachers had been teaching in their first teaching position for 7-10 weeks. The purpose of this interview was to explore their beliefs, experiences and aspirations for the use of digital technologies in their teaching and learning. The interview questions and format that was used is included in appendix 5. The questions were designed as a starting point for the case studies, to explore the previous experiences of the participants. While this was mainly a qualitative approach, respondents were asked to indicate in the tick box spreadsheet which applications they had experience with and on continuums, the level of confidence they felt. This was designed to be used with pattern matching later if appropriate. 
Table 4: Planning for interviews using Kvale's guidelines.

\begin{tabular}{|c|c|}
\hline $\begin{array}{l}\text { Kvale (1996) } \\
\text { Interviews should be: }\end{array}$ & How this was carried out: \\
\hline $\begin{array}{l}\text { Structured and clear } \\
\text { (making clear the } \\
\text { purpose of the } \\
\text { interview and keeping } \\
\text { to the point) }\end{array}$ & $\begin{array}{l}\text { The purpose of the research and the interviews was outlined } \\
\text { in the initial information and gone through verbally prior to } \\
\text { each interview. } \\
\text { The interviews were semi-structured with key guiding } \\
\text { questions prepared and peer reviewed in advance. } \\
\text { The participants were emailed copies of the interview } \\
\text { questions prior to each interview. } \\
\text { A written copy of the questions was given to the participants } \\
\text { at each face-to-face interview to help guide them. } \\
\text { Prompts were developed prior to interviews in case they } \\
\text { were needed to help participants. (See appendix } 6 \mathrm{~b} \text { for an } \\
\text { example of this). The interviewer would check that all the } \\
\text { ideas from prompts had been explored before moving on to } \\
\text { another question. }\end{array}$ \\
\hline $\begin{array}{l}\text { Gentle, open and } \\
\text { sensitive (enabling } \\
\text { subjects to say what } \\
\text { they want to say in its } \\
\text { entirety and in their } \\
\text { own time and way) }\end{array}$ & $\begin{array}{l}\text { The time and the venue for interviews were chosen by the } \\
\text { interviewees. } \\
\text { The interviews were semi-structured. There was no specific } \\
\text { time limit, just a guide for how long they would take. The } \\
\text { questions were asked, then the interviewees were given as } \\
\text { much time as they needed to answer each question. }\end{array}$ \\
\hline $\begin{array}{l}\text { Remembering } \\
\text { (recalling earlier } \\
\text { statements or } \\
\text { experiences and } \\
\text { relating to them during } \\
\text { the interview) }\end{array}$ & $\begin{array}{l}\text { The interviewer read through the information from each case } \\
\text { prior to each interview. } \\
\text { The interviewer would refer back to ideas or statements } \\
\text { made in prior interviews or earlier in the same interview } \\
\text { during an interview. }\end{array}$ \\
\hline $\begin{array}{l}\text { Interpreting and } \\
\text { questioning (clarifying, } \\
\text { confirming and } \\
\text { disconfirming the } \\
\text { interviewee's } \\
\text { statements with the } \\
\text { participant) }\end{array}$ & $\begin{array}{l}\text { Additional questions were asked in the semi-structured } \\
\text { interviews to seek further information on points of interest to } \\
\text { the research, or clarification of a statement made. } \\
\text { Each interview was audio recorded. This allowed the } \\
\text { interviewer to concentrate on actively listening to the } \\
\text { participant's answers during the interview. Digital recording } \\
\text { was chosen for ease of data management and transcription. } \\
\text { The transcription of each interview was typed up and } \\
\text { emailed to each participant within } 48 \text { hours of the interview } \\
\text { with the purpose of the interviewee to confirm (or correct) } \\
\text { that what had been recorded was what they had meant. } \\
\text { Sometimes there were clarifications sought that arose from } \\
\text { the transcription process, like a phrase unable to be } \\
\text { transcribed. }\end{array}$ \\
\hline
\end{tabular}

\section{Refining the research questions}

After the first round of interviews the research design was refocused to refine the research. The literature review had informed the initial research questions, variables of interest and the first round of interview questions with the teachers. These 
interviews were analysed using generic inductive qualitative analysis methodology and the findings resulted in the research questions and variables of interest being refined. Appendix 8 outlines the initial research questions, the reasons they were changed and the resulting questions. The research questions were refined from an initial seven to four. Nisbet and Watt (1984) recommend reviewing and refining questions during the research process. This revision process aligns with the underpinning complexity theory conceptual framework which recognises that changes to the processes can occur, but the overall system or structure (of the thesis) remains in tact.

The second semi-structured interview was held towards the end of the year, at a time that the teacher was using digital technologies with his or her students. The focus of this interview was to examine the intended and actual use of digital technologies. This interview coincided with a classroom observation of the use of digital technologies in three schools, with the students being interviewed through a think aloud process of data gathering.

\section{Think alouds}

Samples of students were interviewed about their use of digital technologies in three case study schools to give greater depth of understanding about the teaching and learning in the case studies. The interviews were conducted as think alouds (Ericsson, 2006), involving the students talking through what they were doing and learning as they used digital technologies. Think alouds was a way to examine cognitive thought during a learning activity which minimised discrepancies and inconsistencies that can occur when interviews are carried out after the event or through introspection. Ericsson reviewed evidence and concluded that think alouds have not been found to change the underlying structure of the thought processes and thus avoids the problem of reactivity. This method of interviewing was used to identify information that passed through the students' attention while they used digital technologies for a learning activity. Students were interviewed either individually or in groups depending on which was most appropriate for the learning activity they were engaged in. The student think alouds were during the last quarter of the first year of teaching, this timing was chosen as according to Moir (2008), and the beginning teachers should be feeling more comfortable and positive about teaching than earlier in their first year. Limiting the observations to this one quarter did limit participation in this aspect of the study. Three case studies were unable to 
be included in the think alouds as one was based in England, the other two were not using digital technologies at the time.

The third semi-structured interview with the beginning teacher was carried out at the end of the year. The purpose was to reflect on the use of digital technologies over the year, the perceived barriers, enablers, student learning, professional learning and support. A copy of the interview questions is included in appendix 7.

\section{Data analysis}

In preparation for data analysis a systematic filing system was used as suggested by Berg (2004). Data were analysed by individual case study and across case studies as outlined in Figure 7.

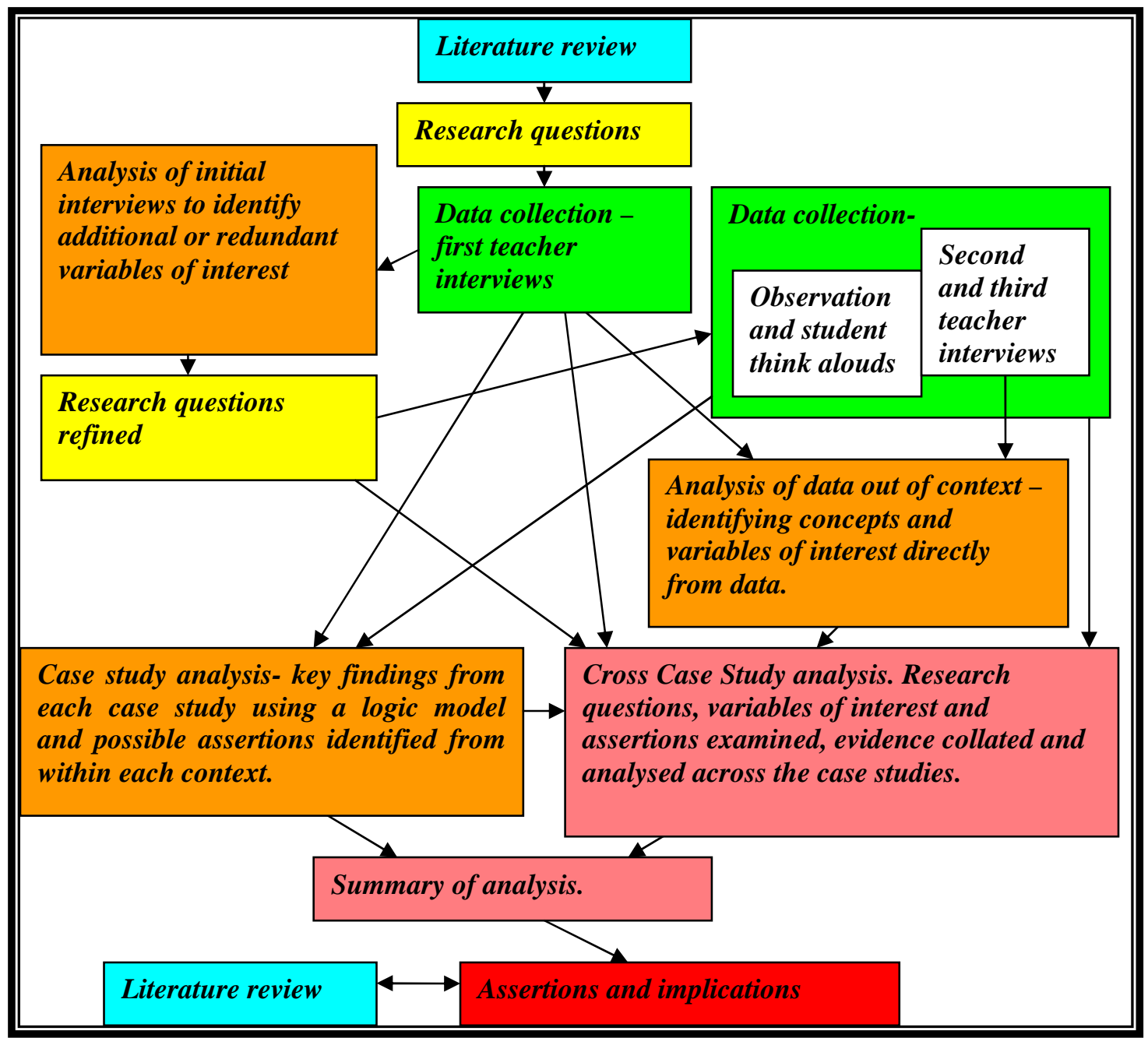

Figure 7: Overview of analysis 


\section{Individual case study analysis}

All data were examined within the context of the individual case study. Results from the data sources were compared to strengthen validity and utilise a time-series individual-level logic model as recommended by Yin (2003) for each of the case studies. The logic model (Figure 8) provided a consistent format for analysis across the case studies. The data were examined for evidence for each stage of the model and described in Chapter 4, with relevant quotes and evidence to portray a comprehensive description of events and patterns of activity in individual case studies, in effect creating an audit trail of the analysis.

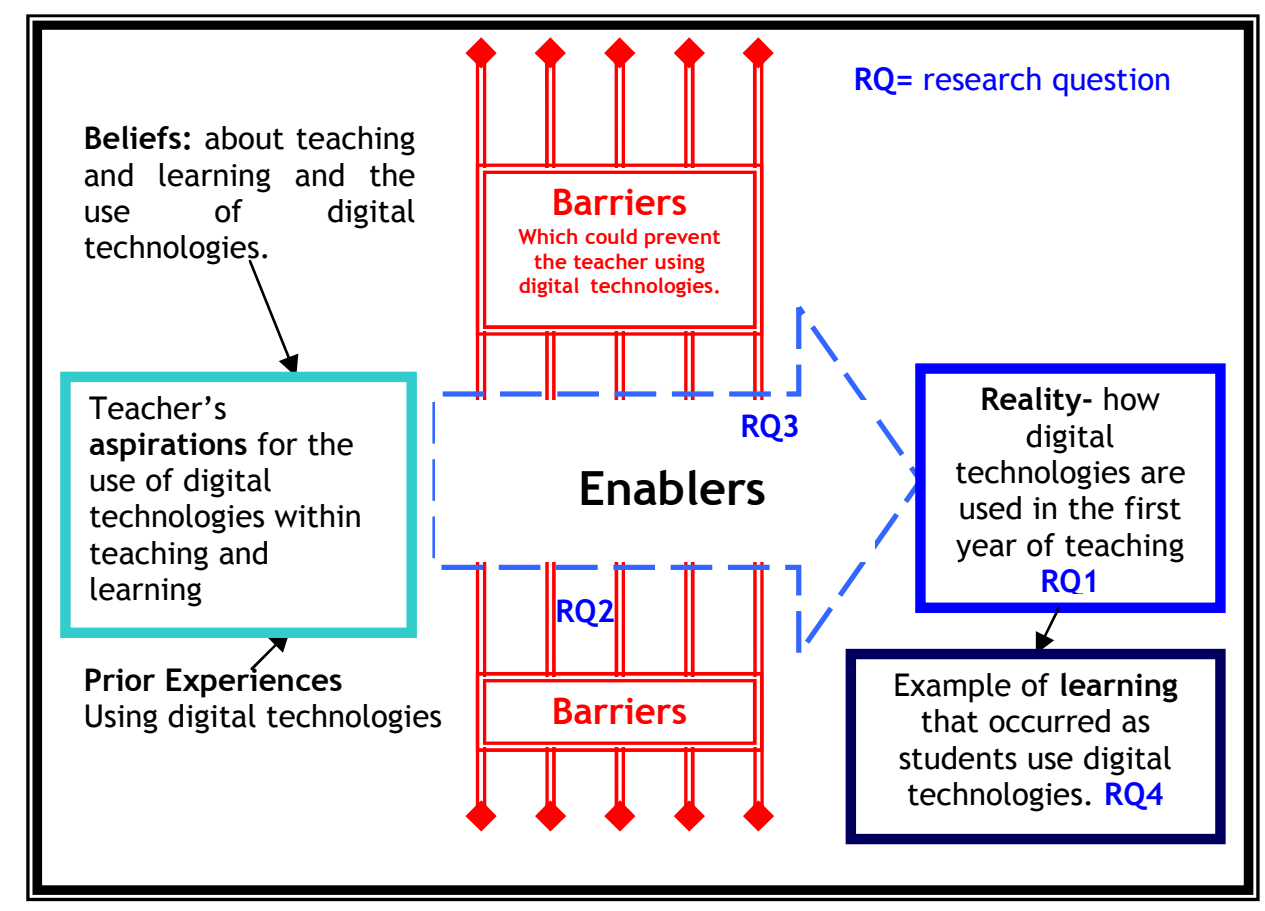

Figure 8: Generic logic model of digital technology use within a single case study

The logic model (Figure 8) was designed to summarise the key beliefs and experiences identified that may have influenced the teacher's aspirations for using digital technologies. To turn the aspirations into reality the teacher faced various barriers and also things that enabled them to use digital technologies. The reality of uses in the first year of teaching may or may not look like the aspirations. The reality of use impacts on the learning that the students accomplished as they used digital technologies in the case study. Using a logic model was to provide a framework for understanding of the individual case studies and inform the cross case analysis.

A second tool was needed as a guide to how digital technologies are being used within the context of learning and creating knowledge in the digital age. Emerging 
ideas of knowledge creation, connectivism and critical thinking in the digital age form the basis for higher level learning in the digital age learning matrix.

Existing taxonomies, while useful and relevant, did not suit the needs of the tool. The SOLO taxonomy (Biggs \& Collis, 1982) includes a useful progression, but it fundamentally focuses on the knowledge being within the learner, not including the learning or knowledge creation that can occur between learners in a connected world as described by Siemens (2006). It implies that students are learning what is already known and fails to acknowledge the importance of connections with others in the process of learning. Bloom's (1956) taxonomy puts knowledge at the lowest level of cognitive processing which is now thought to be inappropriate. However, the modified Bloom's taxonomy developed by Anderson and Krathwohl (2000) could be useful alongside the matrix even though it is based on cognitive processes and is too linear and restrictive for the holistic approach needed. Table 5 compares the digital age learning matrix with the modified Bloom's and SOLO taxonomies.

Bloom's modified taxonomy has 'create' at the highest level in the cognitive domain, SOLO has extended abstract - noting the link between the learning and other contexts. In a digital world, "creativity" especially in terms of "creating knowledge" could be considered as the penultimate learning experience for developing conceptual or procedural understanding. The ultimate level is sharing and ascertaining that the created knowledge has value. This can be done through connections in a Web 2.0 learning environment.

Six different levels of learning using digital technologies are identified in the research tool which incorporates critique, collaboration, connections and creating knowledge, the key aspects of learning in the digital age. The basic level is when students do something within one context. This includes looking on the internet for some information, posting pictures to a wiki, take a quiz to rote learn facts or post a comment on a blog. The second level of learning is when students are being asked to make connections within the context of intended learning. It may include a compare and share activity, how to do something in different contexts or connecting to a person to share ideas. The third level of learning requires students to demonstrate conceptual understanding of 'big ideas' (conceptual knowledge). The fourth level involves critique and evaluation, exploring the limitations and potential of information, sources or a process (procedural knowledge). The fifth level is where 
students create new knowledge. At this level students develop an original product that provides a new reality, using ideas or processes that they have critiqued and evaluated. The final level of learning brings together the idea of connectedness, critique and creativity. It occurs when students share the new knowledge through authentic contexts and gain feedback to measure value.

Table 5: Comparison of levels of learning on the digital age learning matrix with the modified Bloom's and Solo taxonomies.

\begin{tabular}{|c|c|c|}
\hline Digital age learning matrix. & $\begin{array}{l}\text { Modified Blooms taxonomy } \\
\text { - cognitive process domain. }\end{array}$ & $\begin{array}{c}\text { Structure of } \\
\text { Observed } \\
\text { Learning } \\
\text { Outcomes taxonomy } \\
\end{array}$ \\
\hline $\begin{array}{l}\text { Doing } \\
\text { Isolated information. Focus } \\
\text { on completing a measurable } \\
\text { task. }\end{array}$ & $\begin{array}{l}\text { 1. Remember } \\
\text { recognising } \\
\text { recalling }\end{array}$ & $\begin{array}{l}\text { Prestructural: students are } \\
\text { simply acquiring bits of } \\
\text { unconnected information, } \\
\text { which have no organisation } \\
\text { and make no sense. }\end{array}$ \\
\hline $\begin{array}{l}\text { Thinking about connections } \\
\text { Connecting thinking. } \\
\text { Simple connections made } \\
\text { within the context of intended } \\
\text { learning. Compare and share. }\end{array}$ & $\begin{array}{l}\text { 2. Understand } \\
\text { interpreting, } \\
\text { exemplifying, } \\
\text { classifying, } \\
\text { summarising, inferring, } \\
\text { comparing, } \\
\text { explaining } \\
\text { 3. Apply } \\
\text { executing, } \\
\text { implementing }\end{array}$ & $\begin{array}{l}\text { Unistructural: simple and } \\
\text { obvious connections are } \\
\text { made, but their significance is } \\
\text { not grasped. } \\
\text { Multistructural: a number of } \\
\text { connections may be made, } \\
\text { but the meta-connections } \\
\text { between them are missed, as } \\
\text { is their significance for the } \\
\text { whole. }\end{array}$ \\
\hline $\begin{array}{l}\text { Thinking about concepts } \\
\text { Develop conceptual } \\
\text { understanding of 'big ideas' }\end{array}$ & $\begin{array}{l}\text { 4. Analyse, } \\
\text { differentiating, } \\
\text { organising, } \\
\text { attributing (?) }\end{array}$ & $\begin{array}{l}\text { Relational level: the student } \\
\text { is now able to appreciate the } \\
\text { significance of the parts in } \\
\text { relation to the whole. }\end{array}$ \\
\hline $\begin{array}{l}\text { Critiquing and evaluating. } \\
\text { Evaluating and critiquing to } \\
\text { explore the limitations and } \\
\text { potential of information, } \\
\text { sources or a process. }\end{array}$ & $\begin{array}{l}\text { 5. Evaluate } \\
\text { checking, } \\
\text { critiquing }\end{array}$ & \\
\hline $\begin{array}{l}\text { Creating knowledge. } \\
\text { Creativity-Applying ideas, } \\
\text { processes and/or experiences } \\
\text { to develop a new reality. }\end{array}$ & $\begin{array}{l}\text { 6. Create } \\
\text { generating, } \\
\text { planning, } \\
\text { producing }\end{array}$ & $\begin{array}{l}\text { Extended abstract: the } \\
\text { student is making connections } \\
\text { not only within the given } \\
\text { subject area, but also beyond } \\
\text { it, able to generalise and } \\
\text { transfer the principles and } \\
\text { ideas underlying the specific } \\
\text { instance. }\end{array}$ \\
\hline $\begin{array}{l}\text { Sharing knowledge. } \\
\text { Sharing the new knowledge } \\
\text { through authentic contexts } \\
\text { and gaining feedback to } \\
\text { measure value. }\end{array}$ & & \\
\hline
\end{tabular}


The levels are not necessarily sequential, and not all learning activities in secondary schooling should be aiming for the highest levels. The purpose of the matrix was as a research tool, one that a teacher and the researcher can sit down together and discuss the aims and outcomes of a learning activity that uses digital technologies. Ideally teachers will design activities that often include the second, third and fourth level. The fifth and sixth level will occur less often and only after a thorough understanding of concept(s) or process(es) is gained, depending on the aims of the teaching and learning needs of the students.

The digital age learning matrix (Table 6) combines the levels of learning with categories of digital technology use. Teachers using the matrix highlight the boxes that reflect where they believe the level of learning and digital technology use intersect for the learning activities they design. It was used as the basis for discussion during interviews as teachers explain what they are planning or how they have used digital technologies with their students and as a way of summarising and analysing selected learning activities within case studies.

The digital age learning matrix was developed to be used as a research tool when examining the types of learning activities that incorporate the use of digital technologies in the classroom. It was trialled successfully by applying it to learning activities that were developed by preservice teachers who gave feedback on the application. It was presented in a blind refereed paper at the Australian Computers in Education Conference to gain peer feedback and critique (Starkey, 2008) and has successfully been used with practising teachers developing use of digital technologies in their teaching practice.

Each of the case studies generated one or more context-based assertion which is further examined in the cross-analysis section of the thesis. 
Table 6: Digital Age Learning Matrix

\begin{tabular}{|c|c|c|c|c|c|c|}
\hline $\begin{array}{l}\text { Level of } \\
\text { learning: }\end{array}$ & Doing & $\begin{array}{l}\text { Thinking about } \\
\text { connections }\end{array}$ & $\begin{array}{c}\text { Thinking about } \\
\text { concepts }\end{array}$ & $\begin{array}{l}\text { Critiquing and } \\
\text { evaluating }\end{array}$ & $\begin{array}{c}\text { Creating } \\
\text { knowledge }\end{array}$ & $\begin{array}{c}\text { Sharing } \\
\text { knowledge }\end{array}$ \\
\hline $\begin{array}{l}\text { Explanation of level } \\
\text { of learning: } \\
\text { Digital technology } \\
\text { use: }\end{array}$ & $\begin{array}{l}\text { Isolated information. } \\
\text { Focus on completing } \\
\text { a measurable task. }\end{array}$ & $\begin{array}{l}\text { Connecting thinking. } \\
\text { Simple connections } \\
\text { made within a } \\
\text { context. Compare } \\
\text { and share. }\end{array}$ & $\begin{array}{l}\text { Develop conceptual } \\
\text { understanding of 'big } \\
\text { ideas'. }\end{array}$ & $\begin{array}{l}\text { Evaluating and } \\
\text { critiquing to explore } \\
\text { the limitations and } \\
\text { potential of } \\
\text { information, sources } \\
\text { or process. }\end{array}$ & $\begin{array}{l}\text { Creativity - Applying } \\
\text { ideas, processes } \\
\text { and/or experiences to } \\
\text { develop a new reality. }\end{array}$ & $\begin{array}{l}\text { Sharing the new } \\
\text { knowledge through } \\
\text { authentic contexts } \\
\text { and gaining feedback } \\
\text { to measure value. }\end{array}$ \\
\hline Presenting & $\begin{array}{l}\text { Present information } \\
\text { using: } \\
\text { Sound } \\
\text { Pictures } \\
\text { Words } \\
\text { Video }\end{array}$ & $\begin{array}{l}\text { Presented information has } \\
\text { clear connections across } \\
\text { formats or ideas. }\end{array}$ & $\begin{array}{l}\text { Presentation (or } \\
\text { explanation of } \\
\text { presentation) has explicit } \\
\text { conceptual underpinning. }\end{array}$ & $\begin{array}{l}\text { The presentation, } \\
\text { methods and results are } \\
\text { critiqued and evaluated. }\end{array}$ & $\begin{array}{l}\text { Critiqued and developed } \\
\text { ideas or new knowledge } \\
\text { is presented. }\end{array}$ & \multirow{4}{*}{$\begin{array}{l}\text { The value of the product } \\
\text { is determined by the } \\
\text { quality and quantity of } \\
\text { feedback from beyond the } \\
\text { classroom environment. } \\
\text { Learning occurs when the } \\
\text { feedback is considered } \\
\text { and analysed. }\end{array}$} \\
\hline $\begin{array}{l}\text { Processing } \\
\text { information }\end{array}$ & $\begin{array}{l}\text { Information is processed } \\
\text { or data/images are } \\
\text { manipulated in isolation. }\end{array}$ & $\begin{array}{l}\text { Connections are made } \\
\text { between or within } \\
\text { processed } \\
\text { information/data or } \\
\text { images and relevant } \\
\text { concepts. }\end{array}$ & $\begin{array}{l}\text { Processed data or } \\
\text { information has clear } \\
\text { conceptual underpinning. }\end{array}$ & $\begin{array}{l}\text { Process and product are } \\
\text { critiqued and evaluated. }\end{array}$ & $\begin{array}{l}\text { Ideas and new knowledge } \\
\text { are developed. }\end{array}$ & \\
\hline $\begin{array}{l}\text { Gaming and } \\
\text { interactive } \\
\text { programmes }\end{array}$ & $\begin{array}{l}\text { Play a game } \\
\text { Take a quiz } \\
\text { Enter a virtual world }\end{array}$ & $\begin{array}{l}\text { Links made between the } \\
\text { game/ quiz/ virtual world } \\
\text { and other knowledge. }\end{array}$ & $\begin{array}{l}\text { The relevant concepts } \\
\text { within the game, quiz or } \\
\text { virtual world are } \\
\text { identified and explained. }\end{array}$ & $\begin{array}{l}\text { The game, quiz or virtual } \\
\text { world is critiqued and } \\
\text { evaluated within a } \\
\text { conceptual context. }\end{array}$ & $\begin{array}{l}\text { Original ideas are used to } \\
\text { create a knowledge } \\
\text { product in any medium. }\end{array}$ & \\
\hline Communicating & $\begin{array}{l}\text { Send a communication } \\
\text { Receive a communication } \\
\text { Read a communication }\end{array}$ & $\begin{array}{l}\text { Ideas compared and } \\
\text { shared with other learners } \\
\text { through a two way } \\
\text { conversation (written or } \\
\text { verbal) }\end{array}$ & $\begin{array}{l}\text { Communication explicitly } \\
\text { develops conceptual } \\
\text { understanding. }\end{array}$ & $\begin{array}{l}\text { Critique other people's } \\
\text { work or ideas. }\end{array}$ & $\begin{array}{l}\text { Through interaction and } \\
\text { communication new } \\
\text { knowledge is constructed. }\end{array}$ & \\
\hline
\end{tabular}




\section{Cross case study analysis}

Three approaches were undertaken to examine the data within context and out of context across the six case studies. Firstly, an analysis of the assertions from each case study evaluated their limitations and transferability to other contexts. Secondly, an analysis of the interview, think alouds and observation data was made to reexamine the data out of the context of the case studies to identify themes directly from the data that may have been otherwise overlooked. The third approach involved analysing the data against each of the research questions and variables of interest including examining the raw data in detail (sentence by sentence), the data within the case studies (within context) and across the case studies. Conclusions (and limitations of the conclusions) were drawn as a result of the analysis and synthesis.

The interview transcripts were analysed using general inductive qualitative analysis procedures following Miles and Huberman's (1994) methodological approach. This approach provided a representation of participant experiences from the data to broaden the findings beyond the contexts and identifying concepts or variables of interest that may not be evident by examining the data within individual contexts or from the literature review.

The analysis progressed through stages, beginning with the creation of analysis instruments from the first round of interviews. This included coding the data by dividing the text into small units (sentences or paragraphs) and assigning one or more code to each unit. The codes were based on concepts or main ideas from participant interviews, as recommended by Cresswell and Clark (2007). It was found that the majority of the concepts in the data were aligned to the research questions' variables of interest as identified by the literature, though additional variables of interest were identified through this process and these were integrated into subsequent data gathering and analysis processes. This initial analysis helped inform the next step of data gathering and organised the data for final analysis.

The interview data were detailed in spreadsheets, with the left margin used for source and the right margin used for concept or ideas followed by themes (renamed variables of interest for consistency), following the process outlined by Miles and Huberman (1994). An example is included in appendix 10. 
Examination of the research questions involved selecting one research question at a time and building up a commentary of the findings across the case studies in terms of each of the variables of interest. The variables of interest were identified initially through the literature, modified after the first interviews through the initial data analysis and developed further following the second data analysis.

To compare the findings from each case study a variety of tables was developed based on examples of worksheets by Stake (2006). An example is included in appendix 9. Refinements to the instruments and data collection continued in parallel with analysis of the data. Devising and refining the data collection and analysis framework was not an automatic or mechanical process, but involved both logical and intuitive thinking, making judgements about meaning, about the relevance and importance of issues and about implicit connections between ideas. It was also related to ensuring that the original research questions were being fully addressed (Ritchie \& Spencer, 2002).

In a study of a small group of teachers using ICT, Brown (2004) found that teachers will each have a different opinion, perception and belief on the way the same experience has affected teaching and learning. Thus, the research design needed to recognise and analyse the diversity carefully.

Cross-case study analysis can include more than one data analysis orientation (Stake, 2006). There were three data analysis orientations used in this research, not independent but different. The first was the assertions that emerged from the individual case studies and were contextual. The second orientation was from across the case studies through directly examining findings to the research questions guided by the variables of interest. The third orientation was through a generic inductive qualitative analysis to capture any findings or themes not evident in the first two orientations. All three orientations were treated as forces for understanding, drawn together in the cross-case analysis and discussion to consolidate and extend understanding of the research topic.

\section{Reporting findings}

The findings are reported in a logical sequence following the three orientations of analysis. The individual case studies are reported first with each case study following a similar format. This was followed by the cross-case analysis which included a 
comparison of the assertions from the individual case studies, examined the research questions and presents findings emerging from the generic inductive qualitative analysis. The discussion examines findings in relation to existing literature and the implications of the findings. Reporting the findings in this way meets what Lincoln and Guba (2002) term the four classes of criteria for judging the quality of case study reports. These include: resonance criteria (which is the overlap between the report and the basic belief system of the paradigm followed), rhetorical criteria (the report should have unity, clarity and craftsmanship), empowerment criteria (it should evoke and facilitate action on the part of readers, at the least this should be consciousness raising), and applicability criteria (the reader should be able to draw inferences that may apply to his or her own context).

\section{Ethical considerations}

The research was given ethical approval by the Faculty of Education Human Ethics Sub-Committee of Victoria University. There were a number of key ethical considerations. These included maintaining the confidentiality of the identity of the teachers, students and schools, accurately representing the experiences and perspectives of the research participants and empowering participants so that they trusted and felt comfortable with the research process.

Identities were kept confidential to the researcher in this study. Individual case studies were randomly assigned letters A-F. Teachers were given a name that began with the same letter as the case study (for simplicity). Approval for the names was sought from the participants. Confidentiality was necessary to protect the teacher participants from any employment or personal repercussions as a result of being candid in the research. The school's identity likewise was kept confidential as the publishing of details about an aspect of a school has the potential to be taken out of context and impact in the competitive quasi market system of secondary schooling that currently exists. Keeping the school's identity confidential also prevents the reader from applying presumptions or knowledge of a school while reflecting on the findings. To keep identities confidential, all records and transcriptions had names of participants and schools changed at the data collection stage. Confidentiality was discussed with participants at initial interviews and was included in information sheets and consent forms. All raw data were destroyed a year after the conclusion of the research. 
The teachers participating in the research had each been students of the researcher when at university. Therefore a professional relationship existed in which the researcher had been guiding the participants in their professional practice as a teacher. This meant that the researcher had previously been in an authoritative position compared to the teachers. Also the teachers knew the type of professional behaviours and praxis that were supported by the researcher. In an attempt to balance this, the research design included: open information about the purpose and design of the research through information sheets, interviews were scheduled at a time and location to suit the teacher, at the start of interviews a discussion about the purpose of the research including there is no such thing as wrong answers and the research is focussing on the reality of the beginning teacher's experiences and carefully following the questions and prompts during interviews, encouraging the teachers to explore and explain their experiences and reality without judgement. All interview transcriptions and a draft of the final case study report were sent to the relevant teacher to check that their reality was accurately represented in the research.

Reflexivity is where interviewees give the interviewer what they believe the interviewer wants to hear (Yin, 2003). This had the potential to be particularly problematic in this case study as the interviewees were aware of my perspectives on effective teaching practices and the use of digital technologies. To minimise this, I articulated at the start of each interview that this was about the interviewees' reality, and as the teacher was answering questions, prompts and encouragement were given for all aspects, positive and negative, that were linked to the research questions and variables of interest.

The call for participants to take part in the research occurred while the researcher was still the lecturer for some of the sample group. To ensure that the research could not impact on the teaching and assessment of students, the indication of interest to participate in the research was collected by the researcher's supervisor. The researcher was unaware of the identity of volunteers until grades had been finalised for the courses.

Consent was asked for and given by the principals of the schools where each teacher was employed. This was undertaken through initial contact by phone, followed by posting out an information sheet with consent form and return envelope attached. 
Information sheets were given to students and to their parents. Consent forms were signed by students before taking part in the think alouds; if the students were year 10 or below a parent or guardian was also required to give consent before the student was interviewed. When a student chose not to take part or did not have a parental consent form (where they were year 10 or below), any statement they made was not included in the data.

\section{Validity and reliability}

Validity and reliability of research findings are important if research is to add to the body of knowledge in society. The concepts of validity and reliability are multifaceted; there are many different types of validity and different types of reliability (Cohen et al., 2000). Validity in qualitative research relates to authenticity of the reporting of findings, where the researcher aims to have the findings as 'trustworthy' as possible. How validity and reliability are defined and measured in qualitative research has been the subject of considerable discussion and debate. A researcher's perspective on validity appears to be intrinsically linked to the philosophical paradigm in which they are operating.

Research underpinned by a complexity theory conceptual framework should consider that multiple meanings of the world are constructed by individuals through ongoing interaction with others. Guba and Lincoln (1989) have proposed standards that can be used to establish and improve the 'trustworthiness' of a naturalistic inquiry that parallel the traditional criteria, using the terms of 'credibility', 'transferability', dependability' and 'confirmability' (p. 236). These criteria acknowledge the irreducible complexity of the case study context, the perspectives and meanings drawn from the inquiry by individuals, which must be reflected in the research design and methods. The criteria were applied to this research at the design phase to strengthen the trustworthiness of the resulting findings as shown in Table 7.

\section{Construct validity}

To maximise construct validity the research questions and parameters were clearly defined. The development of a research tool to measure learning using digital technologies was correlated with other measures from the literature to tease out the constructed meaning of creativity and knowledge construction in the digital age. To maximise the validity of this research tool it was trialled with teachers and double 
blind refereed as a paper presented at an international conference where attendees were encouraged to give feedback. An aspect of the research included evaluating the effectiveness of this tool. This evaluation included examining construct validity by acknowledging conflicting interpretations of the construct.

Table 7: Quality of research design

\begin{tabular}{|l|l|}
\hline $\begin{array}{l}\text { Naturalistic/constructivist inquiry: } \\
\text { demonstrating 'trustworthiness' } \\
\text { (after Guba \& Lincoln, 1989, pp. } \\
233-43)\end{array}$ & $\begin{array}{l}\text { Interpretive case study design for } \\
\text { constructivist philosophy in complex } \\
\text { contexts. }\end{array}$ \\
\hline $\begin{array}{l}\text { Confirmability } \\
\text { Data and processes for judgements made } \\
\text { can be tracked. }\end{array}$ & $\begin{array}{l}\text { Multiple sources of evidence } \\
\text { Establish chain of evidence } \\
\text { Explanation building } \\
\text { Address rival explanations } \\
\text { Logic models and digital age learning matrix } \\
\text { used } \\
\text { Reflexivity potential acknowledged and } \\
\text { aimed to be minimised. }\end{array}$ \\
\hline $\begin{array}{l}\text { Credibility } \\
\text { Compatibility between the constructed } \\
\text { realities of the respondents and the } \\
\text { reconstructions attributed to them in the } \\
\text { inquiry. }\end{array}$ & $\begin{array}{l}\text { Research participants review draft case } \\
\text { study report and interview transcripts. } \\
\text { Sensitivity to participants, cultures and } \\
\text { circumstances during the research process } \\
\text { (cultural validity) }\end{array}$ \\
\hline $\begin{array}{l}\text { Transferability } \\
\text { Others are able to decide on the } \\
\text { application of findings in other contexts, } \\
\text { based on judgment of overlap of contexts } \\
\text { between individual cases. }\end{array}$ & $\begin{array}{l}\text { Full description of context and } \\
\text { complexities within the context is given } \\
\text { without compromising confidentiality. }\end{array}$ \\
\hline $\begin{array}{l}\text { Dependability (reliability) } \\
\text { Changes in methodology can be tracked } \\
\text { and attributed to particular sources, or } \\
\text { better insights. }\end{array}$ & $\begin{array}{l}\text { Use of case study protocols and case study } \\
\text { database. } \\
\text { Changes in methodology carefully } \\
\text { documented. }\end{array}$ \\
\hline
\end{tabular}

The research questions and variables of interest emerged out of the literature review to develop construct validity. Multiple sources of evidence were used in data collection, across a one-year time period. The planning of interviews, evidence and observations were all cross matched with the research questions and variables of interest. A chain of evidence was developed during the data collection and analysis phases of research as advocated by Yin (2003). This chain of evidence should be evident in this thesis.

What was being recorded and reported was checked to ensure an accurate representation of the ideas and experiences of the research participants. The case 
study participants reviewed their interview transcriptions and draft case study report, correcting any aspects that were not valid representations.

\section{Limitations of this study design}

The case studies are unlikely to be representative of all beginning teachers, as student teachers from one particular programme from one institution were invited to take part and young teachers who were enthusiastic about integrating technology into their teaching practice in their first year was the cohort studied. Not all beginning teachers were enthusiastic about using digital technologies in their teaching practice. Thus there was some homogeneity in the sample. The sample also included diversity in that the teachers were teaching a range of subjects and each in a different context.

The topic studied is one that is undergoing rapid change with new technologies and applications becoming available on a daily basis. Therefore the findings may have a limited shelf life before a critical revisionist approach to the findings will be required.

All the teachers who volunteered to take part in the study were students with whom I had already established a professional relationship. In this relationship I was their mentor and assessor of their progress as a teacher which created both a power imbalance and also meant that the teachers knew my beliefs about effective teaching practice. This could have influenced what the teachers reported and chose not to report.

The teachers by being part of this study were regularly being asked about their use of digital technologies in their teaching practice by the researcher. This could have raised their awareness and was likely to have impacted on the frequency of use during the year.

\section{The researcher's perspectives}

In the process of constructing reality I believe it is important to acknowledge my background and perspectives. All research passes through the lens of the researcher and it is through this lens that the research questions develop, literature is acknowledged or ignored, and findings interpreted. While attempts are made to ensure the conclusions are valid, the nature of the research is always influenced by the researcher. 
The lens through which I view the world has been shaped by experiences including: conversations, academic study, reading and observations. My approach to research has been influenced by undergraduate study in the sciences with a major in geology. During this time I learnt to examine the land on a macro and micro level and apply existing and emerging theories to explain how it may have got to be how it is today. This involved understanding the complex relationships of aspects such as mineralogy, time, heat, pressure, evolution and geological processes. This background influenced the methodology and analysis by drawing on existing and emerging theories.

I have taught in a range of secondary schools in urban and rural New Zealand. The students taught me that they were more likely to engage when I let them know I expected them to be successful, built a teaching and learning relationship with them, and considered their individual interests and learning needs when designing teaching activities and giving feedback. While classroom teaching I completed a Masters in Education to gain greater insight into teaching and learning processes.

I have held leadership positions in three secondary schools which has involved focusing on improving school-wide teaching and learning practices through professional learning, school structures, and policies. This included mentoring of, and responsibility for, beginning teachers in their first two years of teaching which provided an insight into the realities of a range of beginning teachers. It was during this time that I was able to explore first hand the complexities of secondary schooling from a leadership perspective.

I became interested in the growing accessibility of digital technologies and the potential they had to engage adolescent students in learning. With this focus, I assumed a leadership role at a distance education school that included a significant proportion of excluded and alienated students and during this time I was able to establish an online collaborative classroom environment for 13-15 year-olds. A coconstructed integrated curriculum, collaborative inquiry learning, individualised goal setting, and reflections underpinned this.

In 2005 I joined the tertiary sector as a university lecturer working with preservice teachers. I have explored the use of Web 2.0 through research, reading and various professional networks which discuss and share ideas about the use of digital 
technologies in teaching and learning. I work closely with preservice teachers as they explore how they might use digital technologies for teaching and learning.

It is through reading, observation, conversations and experiences that I have come to value teaching and learning programmes in secondary schools which aim to engage students in the learning process through:

- acknowledging and considering youth culture

- having high expectations and a learning relationship with each student

- encouraging critical thinking, creativity, conceptual understanding and collaboration

- personalising learning including feedback of progress for students.

I believe that the use of digital technologies can help students to engage in learning through subject specific application, Web 2.0 applications, personalised learning environments and networking.

There is a parallel between the development of complexity theory and my own learning experiences. Both began oriented towards the sciences and moving towards education and the social sciences. This could be why I have chosen to use a complexity theory conceptual framework- it seems a logical choice for the area of study and aligns with my beliefs. 


\section{Chapter 4. Case Study Descriptions}

We also have an old slide projector; we tell the kids it is part of history. (Erina)

The following six case studies were developed by combining the information from interviews of beginning teachers, student think alouds, observations and documentation such as lesson plans. The interviews recorded beginning teachers' interpretations of their reality as they attempted to use digital technologies during their first year of teaching.

Each of the case descriptions follows a similar format, with variation depending on the depth and breadth of information gathered in each particular case. They start with a description of the teacher's experiences and beliefs and the context in which they taught during their first year teaching. These are important when examining the factors that may have enabled or limited their use of digital technologies. It also helps to understand the perspective of the teacher and their aspirations, expectations and disposition.

The second part of the case study description focuses on the main research question: How do digitally able beginning teachers use digital technologies for teaching and learning? It is an outline of the teacher's aspirations for using digital technologies as expressed in their first interview and the different ways that they did use digital technologies as reported and observed throughout the year.

In each case study the learning activities were examined to gather detailed data for the sub-question: What is the potential learning or the actual learning that occurs in a beginning teacher's classroom as students use digital technologies? The learning that occurred (or potential learning) as students used digital technologies was compared against the digital age learning matrix. In case studies $\mathrm{B}, \mathrm{E}$ and $\mathrm{F}$ a specific example is described incorporating the observations, student interviews or think alouds, teacher interviews and documentation gathered. Not all case studies included student think alouds. Case studies A and D did not include student interviews as the students did not take part in a learning activity using digital technologies at the end of the teacher's first year of teaching. Case study $\mathrm{C}$ was based in England which made observation beyond the budget and time available for this research. 
The barriers and enablers faced by the teachers as they used digital technologies are described through the above two sections and reiterated and discussed further in the next section to focus on sub-question: What factors impede or encourage the use of digital technologies by beginning teachers? A specific example of digital technology use is explored in case studies B, E and F which include the results from the student think alouds and observations.

The support networks as described by the teachers are shown in a diagrammatic form (Figure 9) to explore the sub-question: How do beginning teachers connect and collaborate in their teaching and professional learning? The diagrams distinguish between the support received at the school (red rectangles), support from other teachers or educators (yellow ovals) and friends or other support people outside education (blue clouds). The stronger the level of perceived support the bolder the outline. Above each of the connector lines is how the support was given and below the lines is the nature of the support.

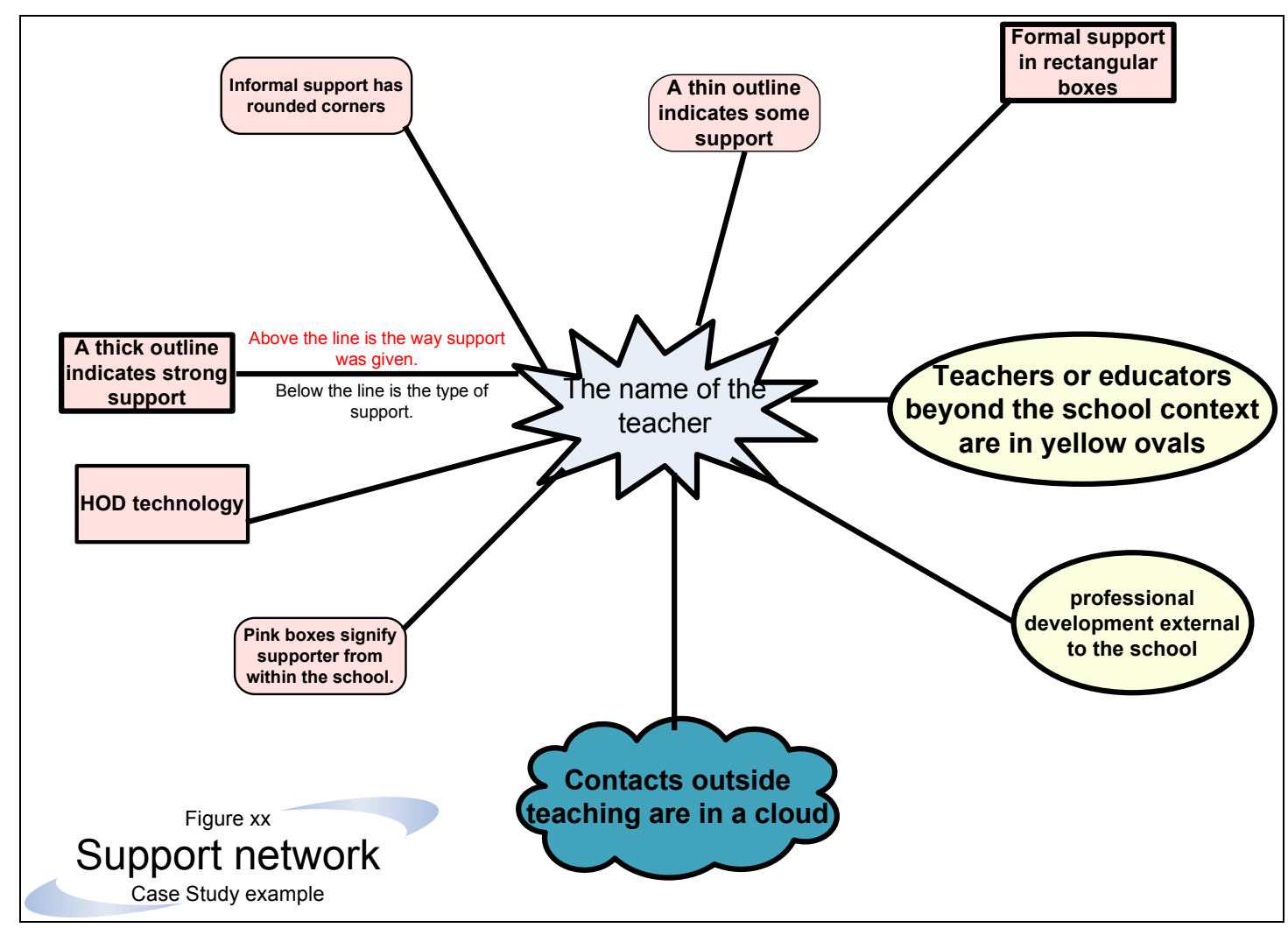

Figure 9: Support network example

A summary of the use of digital technologies for the case study is then shown within a logic model (Figure 9). The model is designed to summarise the key beliefs and experiences identified that may have influenced the teacher's aspirations for using 
digital technologies. To turn the aspirations into reality the teacher faced various barriers and also things that enabled them to use digital technologies. The reality of uses in the first year of teaching may or may not look like the aspirations. The reality of use impacts on the learning that the students accomplished as they used digital technologies in the case study.

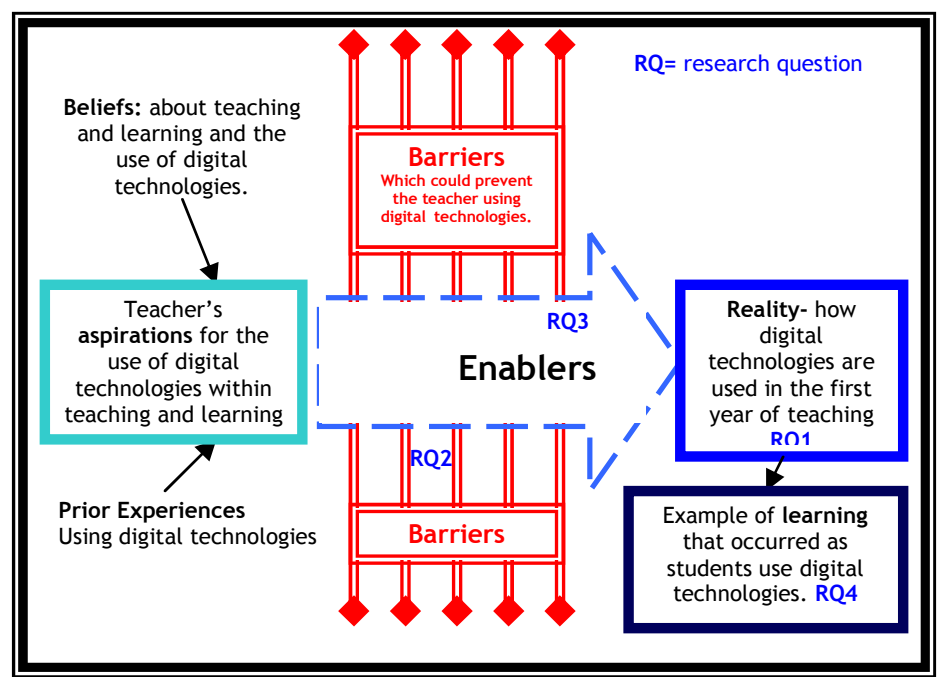

A generic logic model of digital technology use in teaching was used to organise data collection and case study analysis (Figure 10). The summary model is followed by a description, explanation and evidence of the key assertions emerging from the case study.

\section{Figure 10: A generic logic model of digital technology use in teaching}

\section{Case study A}

Isn't it nice when things just work?

(Ana, 2008)

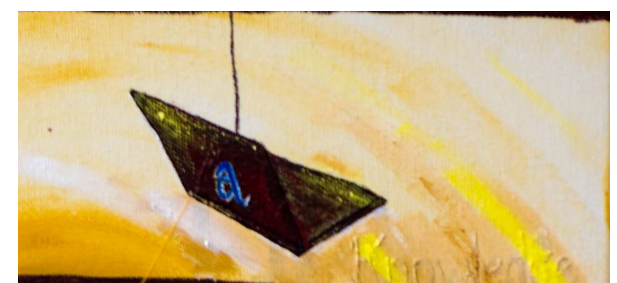

\section{The teacher}

Ana was turning 26 when she began teaching. She had completed two degrees: a Bachelor of Human Nutrition and a Bachelor of Fashion Design before studying teaching through the Graduate Diploma of Secondary Teaching. These qualifications gave her a strong content basis as a teacher of textiles and home economics. In the degree programme she had used presentation software such as PowerPoint (though this was not expected), and she was experienced in social networking sites such as Facebook for her own use.

Ana felt confident in her ability to integrate digital technologies into her teaching practice providing she had adequate access to the necessary hardware and software, 
which at the start she felt she did not have. She had been innovative in her use of digital technologies prior to teaching. She recalled being an early adopter of PowerPoint as an undergraduate: "I used PowerPoint to do a presentation at university. I was the only one who did and the lecturers hated it. They were angry at me like it was a big deal."

Supporting the students in their learning was important to Ana. At the start of her teaching year she went to the public library to get books for students to use in class for research and ideas. She felt there were insufficient resources available in school through the library and department, and the information on the internet was inaccessible.

Ana admitted that organising paperwork was not a strength in her first year of teaching, and she found that digital technologies did not help this: "I am just as bad at filing digitally as I am with paper.”

In summary, Ana had strong content knowledge and a willingness to use digital technologies. She believed in supporting students in their learning and using the internet as a source of information. She had limited experience of using digital technologies or seeing them being used for teaching and learning in her subject areas.

\section{The context}

Ana was appointed to a permanent position teaching textiles with some home economics to students in years 9 to 13 . Initially she had a full teaching load teaching 5 classes, two of which were combined year levels. A relief teacher would teach her classes one day out of six to release her for planning and professional development as part of her beginning teacher 0.2 time allowance. Ana had to set the work for the relief teacher to use. The school she was teaching in was a suburban decile 5 school with about 900 students and 70 teachers. She was the only textiles teacher in the school.

The school had about ten provisionally registered teachers (PRTs) who were supported through fortnightly meetings with a senior management team member, offered help with classroom management by the specialist classroom teacher and given ongoing support from a designated person. Ana's designated mentor was the head of department (HOD) of technology, a position which had a change in personnel during her first year teaching. 
The department Ana was teaching in experienced a high teacher turnover during her first year of teaching with one position having had four different teachers appointed to it. The changes in teaching staff meant that by the end of her first year of teaching Ana was supporting a new teacher to the department and had been in the department longer than a number of her colleagues. This instability of teaching staff was likely to impact on the goal setting and professional learning plan within the department and hence the professional pedagogical support Ana was receiving.

Ana was given a TELA laptop (laptops for teachers scheme) when she started teaching which cost her $\$ 6$ a week. Her room had internet access and during the year she had a data projector fixed to the ceiling in her room with a remote control. The teaching space also had a digital voice projection system with surround sound which she could use to amplify sound from the laptop. There were four computer rooms with classes timetabled in them. One of these was next door to Ana's classroom; she was able to send students through to use a couple of the computers on an ad hoc basis. One of the specialist computing teachers was willing to accommodate extra students, another was less flexible. There was a digital camera available for use by the five teachers in the technology department; She was hoping to get a personal digital camera for her birthday that she could use in her classroom.

\section{Digital technology use}

Ana used digital technologies during her first year of teaching to access information, entertain students, record student achievement and for the moderation of student work.

At the start of teaching Ana said that she would like to incorporate a range of digital technologies into her teaching and professional learning. She was interested in including presentation software like Word, Excel and PowerPoint, Web 2.0 tools like social networks, wikis or blogs and learning mastery games and using some sort of communication technology like text messaging, but did not want to give students her phone number. She would also have liked to carry out and analyse online surveys, but thought that internet access would make this difficult.

During her first year of teaching Ana did use a range of digital technologies on different occasions. She was using the internet and DVDs as a source of ideas, pictures and information for research: 
I let them (the year 11 students) do internet research on the laptop... They are all doing different projects at the moment. They are looking at an innovative textiles product that has had an impact on society, so they are all doing different things. One is doing shoes, one is doing synthetic fibres, nylon stockings - that sort of thing.

In this example internet research involved finding relevant coloured pictures and downloading and printing these off on the coloured printer. This method was used as she did not have access to the colour photocopier; students who wanted colour pictures in their research presentations would print them on the inkjet printer.

The year 13 textiles students were examining Moulin Rouge theatrical costumes. This involved:

a combination of watching the DVD - the Nicole Kidman one and also looking at the actual show, you know the actual Moulin Rouge show. So it is a combination of those, it is a kind of gimmick. The internet was used to actually research the place, the Moulin Rouge. To see how many acts, how many scenes to see how many costume changes there are. You don't really get that from the DVD, as the DVD is so different. The screen is different to the stage show. It is easier for them to see, they look at the DVD for the inspiration for the costumes, then the internet for the technical things like the change in scenes and the costume changes. (Ana, 2007)

A year 9 class had used internet shopping (without the final purchase phase) to decide on ingredients for hamburgers they were designing that were to cost under $\$ 2$ each.

Ana examined topics for textiles with her class through the data projector:

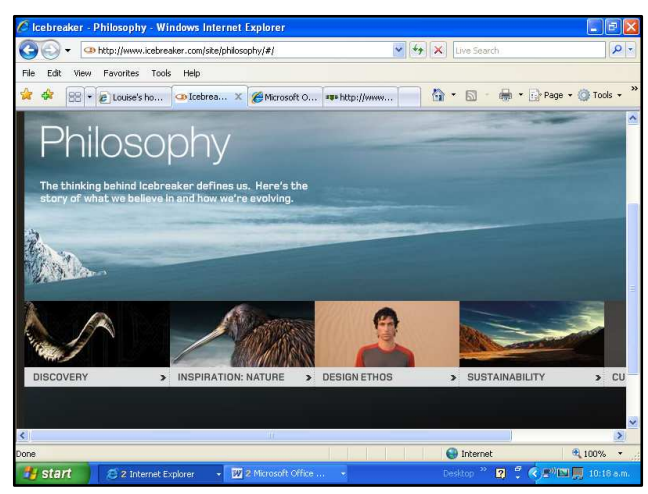

I found a great source of video - Icebreaker. How fabric goes from sheep to product. The site includes all the key things we look at like sustainability, human rights. I would like to get them to talk to our students but that can be difficult so this is the next best thing showing a video.

Ana used the data projector within her classroom for entertainment purposes too.

We have a study period each week, it is a bit of a disaster really I show them videos to calm them down. Form time is good time to use data projector. I download boggle.

Boggle was a game that students can play collaboratively which can help foster an effective learning environment (Alton-Lee, 2003). Fostering relationships was also 
through the use of digital technologies to work with parents to keep students attending school: "I can email them or text them when the students forget permission slips or are absent from class" (Ana, 2007).

Ana used the department digital camera to record student progress for moderation, record achievements and to give students printed images of their work:

I have little name tags for my kids when they are cooking. Everything they cook I take a photo of it so they can stick it in their books sort of like a recipe book. I also show this on the data projector. For some reason they like seeing their stuff up on the screen. I don't know what is so exciting about it, but they love it.

She took photographs of students' work such as garments so that she does not have to send away the actual garment for moderation.

At the end of her first year teaching the teacher was developing a Facebook page for her students. She had put in images of student work from a visit to an Art Gallery where the students had made garments from paper, and from a wearable arts exhibition the department had recently held. She was planning to use this as a place for reflection and information:

In the future I will add wearable arts photos, add in homework, notes, links to websites. For example we are doing knitting at the moment and one of the students just came in and showed us a good website. Another student found a good website for ball dresses. She wrote it on the board. A link in facebook would be more useful.

Although Ana liked using PowerPoint for its ability to include multimedia, she did not use it in her teaching due to the personalised nature of learning textiles. She did not teach the whole class as students worked on their individualised projects. At the end of a year teaching she felt that she had been "slack" in her use of digital technologies.

\section{Learning}

The digital age learning matrix was applied to the learning activities that Ana had described and collated in Table 8. With classes that she taught Ana was using digital technologies to help students make connections in their thinking and she reported two examples where digital technologies were used to help students to think about key concepts. 
Table 8: Digital age learning matrix applied to learning activities in case study A.

\begin{tabular}{|c|c|c|c|c|}
\hline Level of learning: & Doing & $\begin{array}{c}\text { Thinking about } \\
\text { connections }\end{array}$ & $\begin{array}{l}\text { Thinking about } \\
\text { concepts }\end{array}$ & $\begin{array}{l}\text { Critiquing and } \\
\text { evaluating }\end{array}$ \\
\hline $\begin{array}{l}\text { Explanation of level } \\
\text { of learning: } \\
\text { Digital technology } \\
\text { use: }\end{array}$ & $\begin{array}{l}\text { Isolated } \\
\text { information. Focus } \\
\text { on completing a } \\
\text { measurable task. }\end{array}$ & $\begin{array}{l}\text { Connecting } \\
\text { thinking. } \\
\text { Simple connections } \\
\text { made within a } \\
\text { context. Compare } \\
\text { and share. }\end{array}$ & $\begin{array}{l}\text { Develop conceptual } \\
\text { understanding of } \\
\text { 'big ideas' }\end{array}$ & $\begin{array}{l}\text { Evaluating and } \\
\text { critiquing to explore } \\
\text { the limitations and } \\
\text { potential of } \\
\text { information, } \\
\text { sources or process. }\end{array}$ \\
\hline $\begin{array}{l}\text { Accessing } \\
\text { information } \\
\text { Learning } \\
\text { activity: }\end{array}$ & $\begin{array}{l}\text { Accessing: } \\
\text { Pictures } \\
\text { Graphs } \\
\text { Movies/Video } \\
\text { Data } \\
\text { Information } \\
\end{array}$ & $\begin{array}{l}\text { Information from more } \\
\text { than one source is } \\
\text { connected or compared } \\
\text { in analysis. }\end{array}$ & $\begin{array}{l}\text { Information explicitly } \\
\text { develops conceptual } \\
\text { understanding. }\end{array}$ & $\begin{array}{l}\text { Information and sources } \\
\text { are critiqued and } \\
\text { evaluated. }\end{array}$ \\
\hline $\begin{array}{l}\text { Innovative textile } \\
\text { product. }\end{array}$ & $\begin{array}{l}\text { Downloading pictures } \\
\text { from the internet to } \\
\text { illustrate a study }\end{array}$ & $\begin{array}{l}\text { Connections between the } \\
\text { images and the study are } \\
\text { made. }\end{array}$ & & \\
\hline $\begin{array}{l}\text { Manufacturing } \\
\text { and } \\
\text { sustainability }\end{array}$ & $\begin{array}{l}\text { Accessing information } \\
\text { and video clips from a } \\
\text { particular site. }\end{array}$ & $\begin{array}{l}\text { Sustainability, human } \\
\text { rights and fabric } \\
\text { manufacturing links are } \\
\text { made. }\end{array}$ & $\begin{array}{l}\text { Aim is to develop } \\
\text { conceptual } \\
\text { understanding of the } \\
\text { ideas of sustainability } \\
\text { and human rights. }\end{array}$ & \\
\hline $\begin{array}{l}\text { Theatrical } \\
\text { costumes }\end{array}$ & $\begin{array}{l}\text { Watching a DVD, web } \\
\text { sites about the Moulin } \\
\text { Rouge - the place and } \\
\text { the musical. }\end{array}$ & $\begin{array}{l}\text { Comparing the DVD } \\
\text { and the internet } \\
\text { information, connections } \\
\text { between scenes and } \\
\text { costumes }\end{array}$ & $\begin{array}{l}\text { Students were being } \\
\text { asked to gain an } \\
\text { understanding of } \\
\text { theatrical costumes. }\end{array}$ & \\
\hline $\begin{array}{l}\text { Price of } \\
\text { ingredients }\end{array}$ & $\begin{array}{l}\text { Find out the price of } \\
\text { ingredients to purchase } \\
\text { to make hamburgers for } \\
\text { under } \$ 2\end{array}$ & $\begin{array}{l}\text { Link between } \\
\text { ingredients and final } \\
\text { product. }\end{array}$ & & \\
\hline $\begin{array}{l}\text { Gaming or } \\
\text { interactive } \\
\text { programmes }\end{array}$ & $\begin{array}{l}\text { Play a game } \\
\text { Take a quiz } \\
\text { Engage in an interactive } \\
\text { programme } \\
\text { Enter a virtual world }\end{array}$ & $\begin{array}{l}\text { Links made between the } \\
\text { game/ quiz/ virtual } \\
\text { world and other } \\
\text { knowledge. }\end{array}$ & $\begin{array}{l}\text { The relevant concepts } \\
\text { within the game, quiz or } \\
\text { virtual world are } \\
\text { identified and explained. }\end{array}$ & $\begin{array}{l}\text { The game, quiz or } \\
\text { virtual world is } \\
\text { critiqued and evaluated } \\
\text { within a conceptual } \\
\text { context. }\end{array}$ \\
\hline Playing games & $\begin{array}{l}\text { Entertaining and } \\
\text { facilitate relationship } \\
\text { building in form class } \\
\text { or study group*. }\end{array}$ & & & \\
\hline
\end{tabular}

* Form classes and study groups are not classes that are 'taught', the teacher who timetabled these has a pastoral or supervisory role.

In Ana's first year teaching, digital technologies were used to access information and for games. She was aiming to develop her use of digital technologies in future years; the Facebook activity was in the process of being developed and students were being asked to communicate and share ideas with each other.

\section{Barriers and enablers}

The perceived barriers to the use of digital technologies decreased over the first year of teaching for Ana. At the start of the year she was frustrated with the number of barriers she perceived to be preventing her from accessing and using digital technologies: "I would like a data projector - is that too much to ask for in 2007?" It was not only a data projector, she had also found that she could not access a colour printer, computer rooms, websites and a digital camera. 
Ana had a leased laptop but was unable to use a data projector due to the difficulties in accessing one, and when she did access one she did not have a power point close-by, extension cord or curtains to enable the students to view the projection. She did not have access to the colour printer so would use the inkjet printer in her room instead.

They [the students] like to download the pictures so that they can have coloured pictures. That is another thing, they don't have access to a photocopier so they have to download a whole lot of stuff rather than getting them out of books and photocopying it. So I will go and do some photocopying for them but it is black and white as I don't have a code for the colour photocopier.

She also found getting access to the computer rooms and some software such as surveys, to be frustrating. During the year these issues were overcome. She obtained a data projector for her room, found a way to have students researching on her laptop or going to a computer room in a small group and gained access to a colour printer (this required knowing the access codes).

Ana had wanted to use surveys with her students, but did not have access to the software and she had found a number of websites blocked by the school's protection software. The software that limited student access to internet sites at school created constraints as she set up a Facebook site for her students:

I couldn't do it at school as the site is blocked so I had to take it home. I used my school email which meant I had to go back to school to pick up the information. I have since found that I can access school email from home. I can't check Facebook at school and I can't show them at school.

To get round the blocks on sites she was sometimes able to use proxies; the students were often able to help her access blocked sites.

Sharing the digital camera with other people in the department has been less than ideal. She would like to have a digital camera on hand to take photos of students' work as they develop products and ideas. To overcome this she was hoping to get a camera herself and use it at school.

There were some clips on YouTube that Ana would have liked to share with her students. YouTube was a blocked site and while she has managed to get access to it through the proxy, she had not managed to get the videos to run. She was actively investigating alternatives like downloading the videos at home, then showing them at 
school. This type of trial and error approach was seen in all the case studies - where the teachers were unable to accomplish something one way they would seek alternatives.

At the end of the first year of teaching Ana felt that she did not face so many barriers: "I have just about everything I need. I have the data show, the laptop and the speakers." She felt that she had enough time to accomplish all she wanted to: "I am teaching 0.9 now; it seems like I have a lot of time." When she began teaching she was given 0.8 time by being given one day off a week, but she still had to set the work and assess it on her day off, so being given 0.9 without having to set and mark work seemed like more time, and in reality it may have been. She compared her first year of teaching and trying to use digital technologies with a Honda Accord television advertisement ${ }^{1}$ where the voice over at the end says "isn't it nice when things just work?"

\section{Support network}

Ana reported that she was receiving support from the formal structures within her school, from colleagues and support from a network of textile teachers. This is illustrated in Figure 11. Within the school she taught she had about three meetings a term with the designated PRT coordinator and the other ten PRTs, where they set goals and discussed teaching. Furthermore, the head of the technology department met with her and another PRT in the department about three times a term. These meetings included aspects on dealing with difficult students and getting registered.

Ana spoke informally, and was supported by a number of staff, including other technology teachers, another PRT who she shared preparation time with, and her HOD technology. She found that students were a source of support when she was teaching - they would share useful websites and sometimes help with technical problems like how to get past blocked internet pages. An important source of pedagogical support was through the local textile teachers' group. A different school hosted the group once a term and through the group, resources and ideas are shared. For example, Ana had emailed the group for any local photos they may have for a specific design project, and she has also used resources that other schools have that she doesn't have access to:

\footnotetext{
${ }^{1}$ An advertisement for the Honda Accord which took 606 takes to make. It can be seen on the Honda UK website at: http://video.honda.co.uk/hondatv/honda_cog.htm
} 
A year 11 wanted to do an intricate design, we don't have the technology, another teacher does so she has offered to make the screens for me. I feel bad as I don't have anything to offer in return. My classroom is fairly bare.

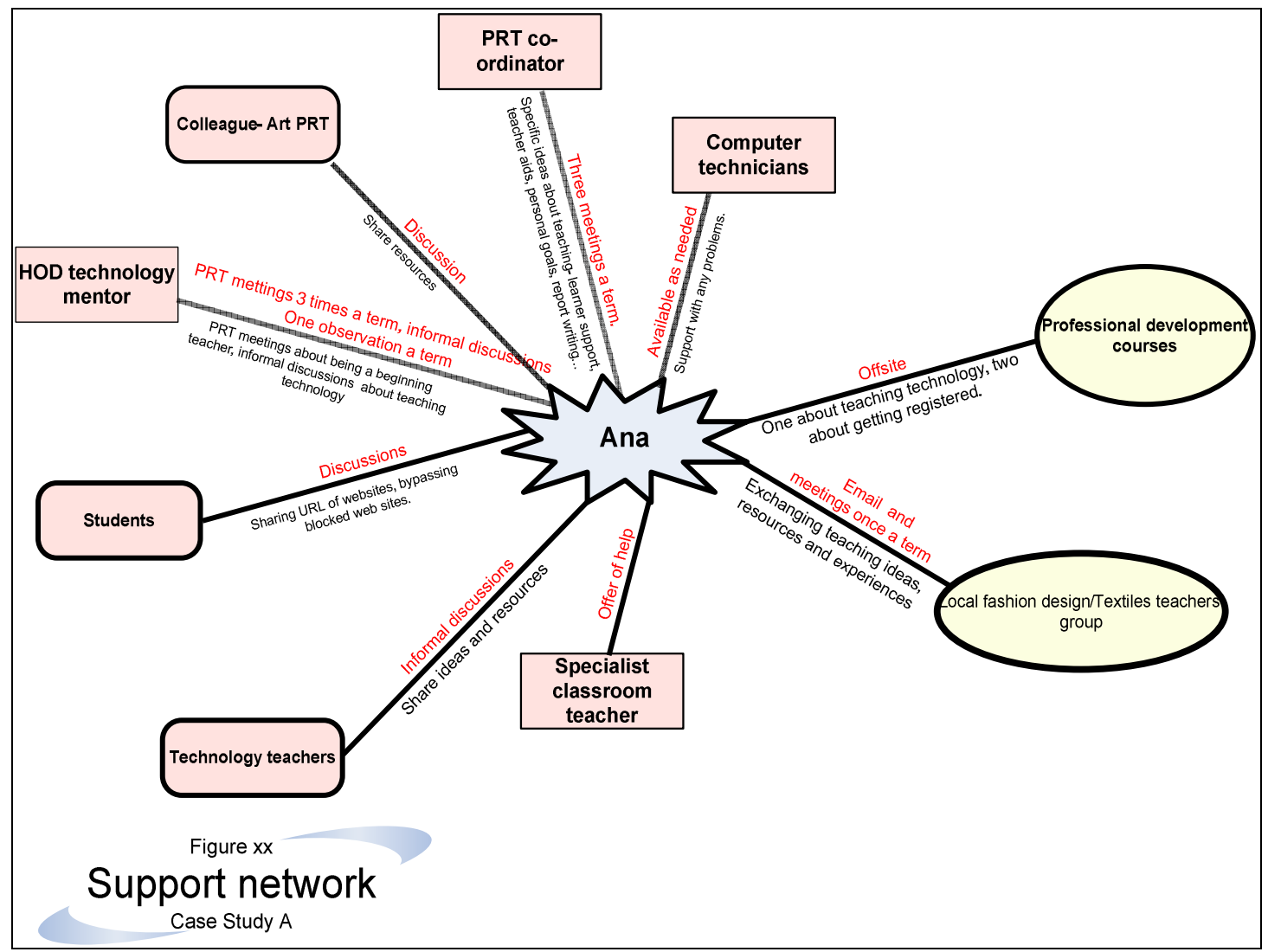

Figure 11: Case study A support network

A range of formal supports were in place in the school she was teaching in, though the focus did not appear to be pedagogical or using digital technologies for learning. Access to pedagogical support was through the local teacher network and informal discussion with her HOD included teaching technology.

\section{Summary}

Ana had strong academic background knowledge but limited experience of digital technology use in her specialist area. She was keen to use digital technologies and was not reluctant to be the first to use them. However, she lacked the pedagogical and technical support and access in the school she was teaching in to enable her to be successful. The department had a high staff turnover and she was the only textiles teacher. She was initially unable to access the hardware or have students accessing the technology she wanted them to use. Figure 12 summarises this case study in a logic model. 
At the beginning of the year Ana found digital technology use in the school to be a source of frustration. By the end of her first year she was looking to introduce Web 2.0 technologies into her teaching programme.

Ana used digital technologies to help students gain access to resources (colour pictures) and information through the internet and using DVDs. She recorded student achievement digitally and was in the process of putting resources on a social network site for students to access. She used digital technologies to entertain students while supervising study periods and form time. The students using the digital technologies were sometimes doing this without linking the use to learning (such as when using the technologies for entertainment purposes) or they were making connections to concepts or other learning. She had hoped to use digital technologies more in her teaching.

Ana's belief in the importance of integrating new technologies into teaching and learning to enhance students' access to information appear to have been a key motivator in her use of digital technologies. Ana had wanted to use Web 2.0 technologies with her students. She found that she was unable to use a range of technologies for student learning at the start of her teaching career due to not having access to the hardware. Later in the year she found access to internet sites to be a more significant barrier as she had gained the desired data show for her classroom.

Ana had limited experience in the use of digital technologies within her area of expertise or for teaching and learning. She tried to transfer the learning she did have (such as using PowerPoint, word documents and social networks) but found that she was unable to get her students the access she needed to digital technologies so this was difficult for her to achieve.

One aspect of this context was that Ana perceived that she did not have the power and/or ability to ask for the resources that she needed, or to gain the access through the net filtering software. It appeared that she had no sense of being able to influence school policies or processes. Thus she found it difficult to overcome access barriers she faced which resulted in her subverting formal processes by using proxies as recommended by students or other staff members to access blocked sites or her supplying technologies herself. 
Beliefs:

- Digital technologies are an important part of society
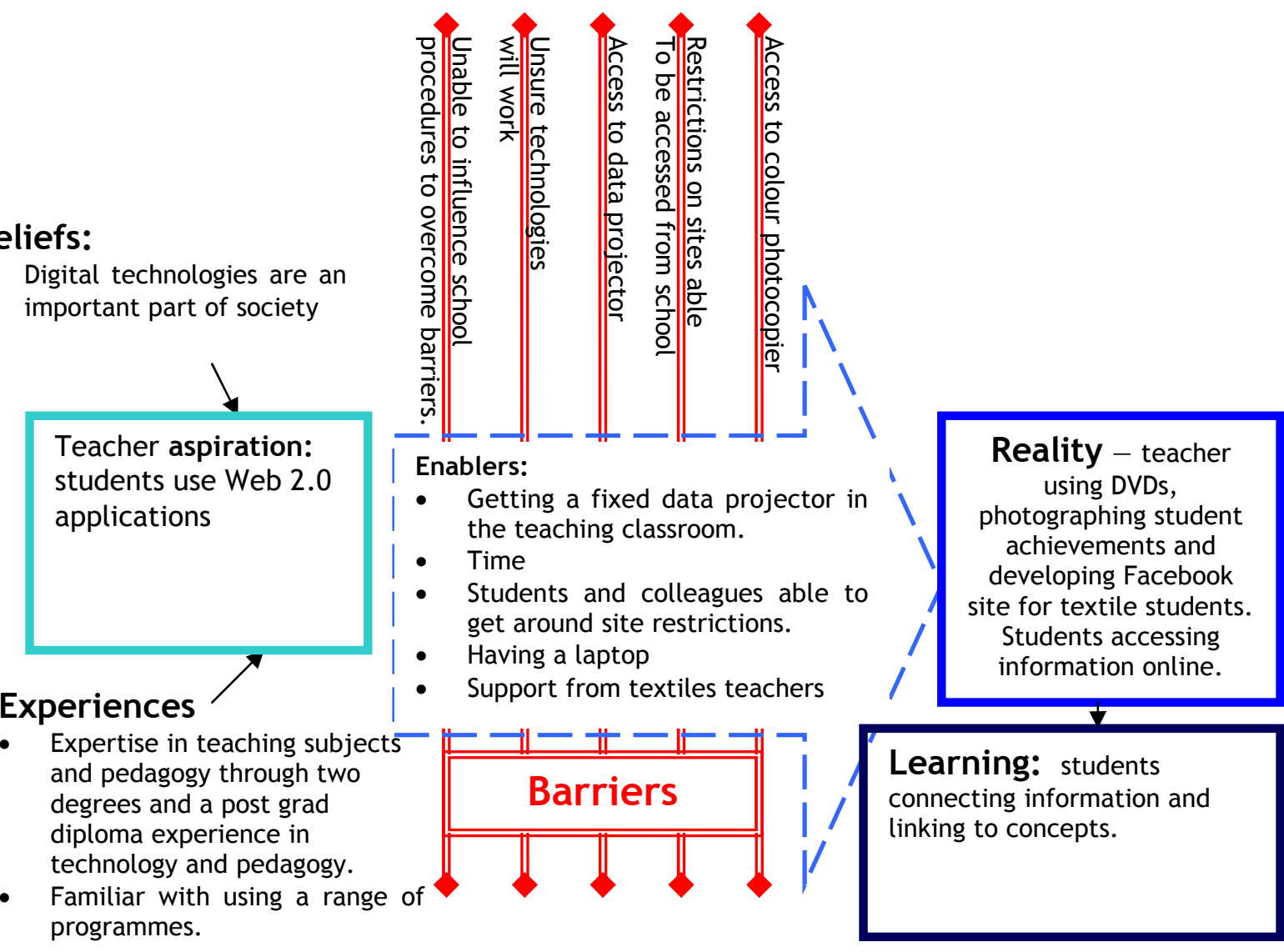

Figure 12: Logic model, case study A

She was teaching in a department which had a high teacher turnover and where she was the only textiles teacher. Her HOD (and primary mentor) changed during her first year of teaching. The situation in the department meant that developing pedagogical approaches using digital technologies was evidently not a high priority. Ana received collegial support and formal support, though this appeared to be at a practical and morale level rather than a structured pedagogical development programme. The support which appeared to impact the greatest on her use of digital technologies for teaching and learning came from a network of regional textile teachers who met each term and shared teaching ideas and resources.

After a year of teaching Ana appeared to have successfully settled into teaching and was ready to try new technologies. She had established her credibility with her classes noting that: "I don't have behaviour problems in my classes, I am lucky." This luck could be linked to a focus on engaging students in learning. This included co-curricular activities like a wearable arts show and taking students to a local art gallery and local clothing manufacturer. Students were about to embark on an investigation to create new uniform designs which they could present to the school's 
board of trustees. This was likely to involve the use of digital technologies: "Videoconferencing would be useful. To take year 10s to a place where uniforms are made is seeming difficult, so a virtual field trip would be good." Ana was planning to continue to try to find ways to engage the students through personalising learning to make it authentic for the students:

I am not sure if Facebook is the right place. I tried blogs but they are all over the place and so much advertising. Bebo may have been better as that is what the students use themselves more.

While Ana had not used digital technologies to engage students in creating knowledge in her first year of teaching, it appeared likely that this would happen in the future as her confidence and knowledge of school cultural systems increased.

\section{Assertions from case study A:}

A1. Confident and innovative beginning teachers may limit their use of digital technologies for creating knowledge if they believe they do not have the power to gain the necessary access or pedagogical support.

A2. Beginning teachers who are the only teacher of a subject in a school can benefit from belonging to an active local or regional subject association.

A3. The experiences of using digital technologies will fundamentally affect the choices a teacher makes about using digital technologies. Beginning teachers who are familiar with presentation software and accessing information will transfer this use of digital technologies to their teaching practice.

\section{Case study B}

The current priority in teaching is to focus on having very structured lessons to settle the classes and create an effective learning environment, and that this is limiting the use of digital technologies. Some of the classes are not settled because they have had three different teachers this year so far. (Barry, 2007)

\section{The teacher}

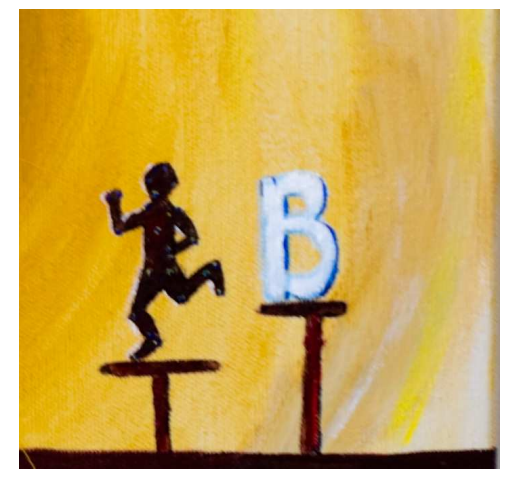

Barry holds a bachelors degree in physical education and had work experience in this discipline. He chose to begin teaching at the age of 24 , after completing a one-year Graduate Diploma in Teaching (Secondary). He had experienced using digital technologies in the workplace, as part of his bachelor's degree, teaching diploma and 
in his personal life. This included using a client database (class for windows) within the context of gyms and fitness centres, video-conferencing, and a biomechanical package to analyse body movement using attachment sensors. He had experienced podcasting, the use of wikis, and web pages within the context of teaching and learning while a student teacher and was familiar with the use of data presentation software such as word processing and spreadsheets, and mobile technology such as cell phones. He appreciated the potential of using the technologies he was familiar with in an educational setting.

Barry began his teaching career purposely choosing a school with a diverse student group in a lower socio-economic suburb of a New Zealand city. He was focussed on attaining the very best level of teaching possible. He believed that developing and refining his teaching skills in the first few years of his teaching career in a school in which he was likely to experience challenging behaviour would be a good grounding for a career in teaching.

Barry believed that the future of digital technologies in learning was essential, inevitable and necessary to prepare students for life-long learning:

If they wanted to research something, find something out, you could spend a lot of time teaching them how to find things rather then looking through text books The reality is when they leave school they are not going to have access to the texts books, they are not going to have access to that information. Whereas if they learnt to find that information on the internet they will be able to use it when they go out whether it be through journals or through Wikipedia or through Google.

He was also aware of his professional persona. He did not have a Facebook or Myspace account:

I've decided, you know that up to $40 \%$ of job dismissals in the States are from information from pages like Facebook and Bebo. Plus I've always thought six degrees of separation...I would just rather not have one. I am pretty paranoid.

At the start of his teaching career, he was interested in using digital technologies such as PowerPoint, learning games and websites as part of his teaching repertoire.

\section{The context}

Barry was teaching in a suburban college, a school with over 600 year 9-13 students, approximately 50 teachers, and a socio-economic decile rating of 3. Initially he was employed for six months on a fixed term contract to teach mathematics and science to year 9-11 students. After six months he was offered a permanent position as a 
mathematics teacher, he successfully negotiated to include teaching physical education, but was given another fixed term employment contract.

I am not sure what happened there and the HoDs aren't too sure. But they gave me a laptop. I think I am the only one who realises that I am not permanent. There is plenty of work there so I am not worried. I think even the principal thinks that I am permanent.

Barry was one of 15 PRTs in the school, approximately eight of whom were first year teachers. The PRTs met with the person with the allocated responsibility for beginning teachers every second week for an hour. At these meetings they looked at a topical issue, a professional reading or something related to events in the school such as report writing. He had a mentor or associate teacher whom he met formally every week during a timetabled slot. His mentor was the head of the mathematics department. He also had informal chats on a daily basis with his mentor.

The school offered practical support to beginning teachers:

PRTs can do things that other teachers can't like you can refer stuff straight to the deans a little bit easier there are deans detention that PRTs can use, it makes it a lot easier. People who aren't PRTs should have gone through a whole chain of events first. They should have a lot more classroom management strategies. The deans are quite good and supporting. This is a very good supportive school for new teachers.

The school had three computer suites, with 20-25 computers in each, enough for one per student. Computer classes operated in the suites, which limited access, though he was able to book a room a week in advance through the online booking system. Data projectors were fixed in the computer rooms, or could be booked lesson by lesson for use in other rooms. Video cameras were available through departments; the physical education department had a video camera and to access this Barry just needed to ask.

The laptops in this school were offered to permanently employed teaching staff under the TELA. Barry was offered a laptop after teaching for six months which cost him $\$ 7$ a week for the lease. For the first six months Barry only had access to the internet through the computers in the staff workroom which limited his ability to use data projectors in classrooms as a teaching tool. There was a wireless network in areas of the school; rooms without wireless access had an access cable available into which laptops were plugged. 


\section{Digital technology use}

At the start of his first teaching year Barry indicated he would like to use digital technologies as part of a routine in his classes. This was his initial focus as a teacher partly due to timetabling and perceived student needs. He was teaching in different classrooms each lesson which meant moving around the school carrying resources, sometime getting to a classroom after the students had arrived, limiting his classroom preparation time. For some classes he was the fourth teacher that year, so developing a rapport, routines and having very structured lessons to focus the students on learning were his priority. Barry noted how digital technologies could help him to establish time efficient routines with his classes:

Ideally I would like to have a projector and be able to have my starter and things preplanned so I don't have to come in and write it on the board, I can come in and just bang it up on the screen it is ready to go. It would give me more time because it is pre prepared I would move onto the next thing, the example, put that onto the board and you can work through it more efficiently, without having to spend that time writing.

For mathematics, he wanted to have access to the internet for students to try out mathematics problems or mathematics-based learning games. The opportunity arose during a national mathematics week.

I booked most of my mathematics classes into the computer rooms for a couple of lessons during mathematics week. There was a mathematics week website that they had all these different games that they could do, numeracy games and you got points for them. The kids log in, they collect the points and at the end of the week if you played the games, you could do it at home as well, you are eligible to bid for prizes. You bid your points for different prizes - calculators, all different sorts of prizes.

Support within the mathematics department provided access to digital format lesson plans and math programmes:

I use the mathematics intranet site quite extensively... There are activity worksheets, games, worksheets for games, other explanations how to play the games. Everything is there and it is in one place. It is accessible from anywhere. If I am at home I can get hold of all the mathematics stuff at school and I don't have to carry stuff home. So that is the biggest thing I do for planning.

Barry was teaching prepared units of work to his science class which did not have digital technologies integrated into the lessons. When asked about how he would like to use digital technologies in physical education he was able to identify a range of uses including video-analysis to improve students' skills, learning games and 
presentations such as PowerPoint to illustrate ideas or show resources. The calculator function on students' cell phones was being used in a mathematics class:

I decided that a lot of students don't have calculators at school, or don't have them. They all have cell phones, and I thought - people don't have a calculator on them very often if they are out and about but to be able to use that cell phone calculator function is quite important as it is there. So I have been letting them use the calculators on their cell phones in class, but not for tests.

This was initiated by the students. It was apparent that mobile phones were a ubiquitous item for New Zealand teenagers and using the calculator function in class was likely to encourage the transfer of learning to contexts outside the classroom. Making learning authentic was a priority.

Barry taught mathematics and physical education to a class of year 10 boys who were identified as underachieving academically and were targeted to have their engagement in learning and achievement levels raised. The class had male teachers; the majority held head of department positions. For this class, he used digital technologies to tailor learning to the interests of his students to engage them in learning while integrating mathematics and physical education.

For statistics we got the data projector out and they watched some rugby league. There are 26 in the class, so each student was given a player/position and they had to tally up the number of tackles per player, use excel to graph the results - which player, team, position did the most tackles. This was useful, took a couple of weeks. It worked really well for that class... The league hooked them in and they were able to watch it in class time, they liked the competitive aspect and taking on the persona of a player.

This example demonstrates the use of video and spreadsheets to personalise learning by applying a context appropriate to the students' interests.

\section{Learning}

The digital age learning matrix was applied to the learning activities that Barry had described and was collated in Table 9. Barry used digital technologies to help students make connections in their thinking and he reported two examples where digital technologies were used to help students to think about concepts; both of these activities included physical education, an area in which Barry was more comfortable teaching. 
Table 9: Digital age learning matrix applied to case study B

\begin{tabular}{|c|c|c|c|c|}
\hline Level of learning: & Doing & $\begin{array}{l}\text { Thinking about } \\
\text { connections }\end{array}$ & $\begin{array}{l}\text { Thinking about } \\
\text { concepts }\end{array}$ & $\begin{array}{l}\text { Critiquing and } \\
\text { evaluating. }\end{array}$ \\
\hline $\begin{array}{l}\text { Explanation of level } \\
\text { of learning: } \\
\text { Digital technology } \\
\text { use: } \\
\text { Learning activity: }\end{array}$ & $\begin{array}{l}\text { Isolated information. } \\
\text { Focus on completing } \\
\text { a measurable task. }\end{array}$ & $\begin{array}{l}\text { Connecting thinking. } \\
\text { Simple connections } \\
\text { made within a } \\
\text { context. Compare } \\
\text { and share. }\end{array}$ & $\begin{array}{l}\text { Develop conceptual } \\
\text { understanding of 'big } \\
\text { ideas' }\end{array}$ & $\begin{array}{l}\text { Evaluating and } \\
\text { critiquing to explore } \\
\text { the limitations and } \\
\text { potential of } \\
\text { information, sources } \\
\text { or process. }\end{array}$ \\
\hline $\begin{array}{l}\text { Gaming or } \\
\text { interactive } \\
\text { programmes }\end{array}$ & $\begin{array}{l}\text { Play a game } \\
\text { Take a quiz } \\
\text { Engage in an interactive } \\
\text { programme } \\
\text { Enter a virtual world }\end{array}$ & $\begin{array}{l}\text { Links made between the } \\
\text { game/ quiz/ virtual world } \\
\text { and other knowledge. }\end{array}$ & $\begin{array}{l}\text { The relevant concepts } \\
\text { within the game, quiz or } \\
\text { virtual world are } \\
\text { identified and explained. }\end{array}$ & $\begin{array}{l}\text { The game, quiz or virtual } \\
\text { world is critiqued and } \\
\text { evaluated within a } \\
\text { conceptual context. }\end{array}$ \\
\hline Maths website. & $\begin{array}{l}\text { Taking part in the } \\
\text { mathematics week } \\
\text { interactive website }\end{array}$ & $\begin{array}{l}\text { Applying mathematical } \\
\text { knowledge to website } \\
\text { activities. }\end{array}$ & & \\
\hline $\begin{array}{l}\text { Processing } \\
\text { information }\end{array}$ & $\begin{array}{l}\text { Information is processed } \\
\text { or data/images are } \\
\text { manipulated in isolation. }\end{array}$ & $\begin{array}{l}\text { Connections are made } \\
\text { between or within } \\
\text { processed information/ } \\
\text { data or images and } \\
\text { relevant concepts. }\end{array}$ & $\begin{array}{l}\text { Processed data or } \\
\text { information has clear } \\
\text { conceptual underpinning. }\end{array}$ & $\begin{array}{l}\text { Process and product are } \\
\text { critiqued and evaluated. }\end{array}$ \\
\hline $\begin{array}{l}\text { Using cell } \\
\text { phones as } \\
\text { calculators }\end{array}$ & $\begin{array}{l}\text { Calculator function on } \\
\text { the cell phone is used for } \\
\text { mathematical equations. } \\
\text { (processing information) }\end{array}$ & & & \\
\hline $\begin{array}{l}\text { Accessing } \\
\text { information }\end{array}$ & $\begin{array}{l}\text { Accessing: } \\
\text { Pictures } \\
\text { Graphs } \\
\text { Movies/video } \\
\text { Data } \\
\text { Information } \\
\end{array}$ & $\begin{array}{l}\text { Information from more } \\
\text { than one source is } \\
\text { connected or compared in } \\
\text { analysis. }\end{array}$ & $\begin{array}{l}\text { Information explicitly } \\
\text { develops conceptual } \\
\text { understanding. }\end{array}$ & $\begin{array}{l}\text { Information and sources } \\
\text { are critiqued and } \\
\text { evaluated. }\end{array}$ \\
\hline $\begin{array}{l}\text { Processing } \\
\text { information }\end{array}$ & $\begin{array}{l}\text { Information is processed } \\
\text { or data/images are } \\
\text { manipulated in isolation. }\end{array}$ & $\begin{array}{l}\text { Connections are made } \\
\text { between or within } \\
\text { processed } \\
\text { information/data or } \\
\text { images and relevant } \\
\text { concepts. }\end{array}$ & $\begin{array}{l}\text { Processed data or } \\
\text { information has clear } \\
\text { conceptual underpinning. }\end{array}$ & $\begin{array}{l}\text { Process and product are } \\
\text { critiqued and evaluated. }\end{array}$ \\
\hline $\begin{array}{l}\text { Rugby league } \\
\text { mathematics }\end{array}$ & $\begin{array}{l}\text { Students watch rugby } \\
\text { game on digital player } \\
\text { and record statistics } \\
\text { (processing and } \\
\text { accessing information) }\end{array}$ & $\begin{array}{l}\text { Statistics are graphed and } \\
\text { compared using Excel. } \\
\text { (processing information) }\end{array}$ & $\begin{array}{l}\text { Concept of ratios and } \\
\text { performance percentages } \\
\text { is examined. } \\
\text { (processing information) }\end{array}$ & \\
\hline $\begin{array}{l}\text { Accessing } \\
\text { information }\end{array}$ & $\begin{array}{l}\text { Accessing: } \\
\text { Pictures } \\
\text { Graphs } \\
\text { Movies/video } \\
\text { Data } \\
\text { Information } \\
\end{array}$ & $\begin{array}{l}\text { Information from more } \\
\text { than one source is } \\
\text { connected or compared in } \\
\text { analysis. }\end{array}$ & $\begin{array}{l}\text { Information explicitly } \\
\text { develops conceptual } \\
\text { understanding. }\end{array}$ & $\begin{array}{l}\text { Information and sources } \\
\text { are critiqued and } \\
\text { evaluated. }\end{array}$ \\
\hline $\begin{array}{l}\text { Gaming or } \\
\text { interactive } \\
\text { programmes }\end{array}$ & \begin{tabular}{|l|} 
Play a game \\
Take a quiz \\
Engage in an interactive \\
programme \\
Enter a virtual world \\
\end{tabular} & $\begin{array}{l}\text { Links made between the } \\
\text { game/ quiz/ virtual world } \\
\text { and other knowledge. }\end{array}$ & $\begin{array}{l}\text { The relevant concepts } \\
\text { within the game, quiz or } \\
\text { virtual world are } \\
\text { identified and explained. }\end{array}$ & $\begin{array}{l}\text { The game, quiz or virtual } \\
\text { world is critiqued and } \\
\text { evaluated within a } \\
\text { conceptual context. }\end{array}$ \\
\hline $\begin{array}{l}\text { Anatomy and } \\
\text { Physiology (see } \\
\text { below). }\end{array}$ & $\begin{array}{l}\text { Accessing information } \\
\text { and using interactive } \\
\text { programmes. }\end{array}$ & $\begin{array}{l}\text { Connections made } \\
\text { between in class learning } \\
\text { about bones and } \\
\text { interactive activities. }\end{array}$ & $\begin{array}{l}\text { Concepts about muscle } \\
\text { movement and bone } \\
\text { structure were developed. }\end{array}$ & \\
\hline
\end{tabular}

\section{Barriers and enablers}

Barry had indicated that he would like to use presentation software during lessons to show images and information quickly, minimising the time he spent writing on the whiteboard. This was particularly applicable when he was moving between classrooms to teach. He found he was not able to do this easily because he did not 
have access to a laptop for the first six months and data projectors needed to be booked, then set up in a classroom each lesson.

A second barrier to the use of digital technologies was a pedagogical consideration. Barry started teaching half-way through the academic year. For some of his classes he was the fourth teacher they had been allocated during the year. This was likely to have disrupted the continuity in the teacher/student relationship which is an important aspect of establishing an effective learning environment (Alton-Lee, 2003). Accordingly, to establish an effective learning environment routines were established as well as clear boundaries, consequences and predictability in lessons. He felt that until an effective learning environment was established the students should not be taken too far out of their comfort zone by using unfamiliar learning technologies or learning spaces. As a result Barry felt he did not use digital technologies as much as other teachers at school:

I probably use (online mathematics games) the least (of the mathematics teachers) with my classes, because my junior classes need the structure and routine first. My focus had been basic classroom structure. Once they have that I can do a bit more.

Being a beginning teacher and teaching outside of his specialist area also limited Barry's innovative capacity. He had not experienced the use of digital technologies in mathematics and sciences as he had for physical education. It is understandable that he was less likely to have the subject and subject pedagogical knowledge to confidently integrate digital technologies into learning as an authentic learning practice than he would in physical education:

... because I am teaching my more supporting subjects. If I was teaching senior physical education which I am more comfortable in, I would have been more innovative whereas I spend more time trying to grasp hold of and not reinvent the wheel and I get as much stuff off other people as I can to support my teaching.

He was more likely to integrate digital technologies into a physical education lesson than a mathematics lesson as he was more aware of the range of relevant applications.

Barry acknowledged that he was more likely to use a programme he had experienced:

I did have a go at wetpaint (a wiki), probably because it was less familiar and because I had to send an email then send a list of people, it seemed a bit confusing. I thought it would be cool to use at some stage as they (the students) could contribute their own ideas, but maybe a more senior class. I just wanted them to have a home base to start with. I knew Protopage so that was easy. 
The need to be able to use paper and pen was perceived as a barrier to the use of digital technologies when teaching mathematics: "I think that is one of the problems, they might be able to do it interactively but they can't do it back on paper and that's where most of the tests are, so they still have to be able to do it on paper." With greater subject pedagogical knowledge and experience, this may become less of a barrier as flexibility in assessment tasks is explored.

Factors which enabled Barry to use digital technologies included access to computer rooms, having a laptop to prepare and develop learning activities and the support he received both within the school and beyond the school.

\title{
Specific example - anatomy and physiology
}

One of the lessons was observed where the students were using digital technologies. Barry chose to use interactive websites with his NCEA level 1 physical education class as he wanted them to understand how muscles function during physical activity as part of the learning towards achievement standard 90068 'Demonstrate knowledge of body structure and function related to performance of physical activity'. From his own learning (his bachelor's degree in physical education), he knew that having bones and muscles to work with in a lab was an effective way to learn, but this was not feasible in the school due to ethical and management reasons. Using three dimensional interactive images was the closest alternative he was aware of. A friend from his support network had told him about a website:

\begin{abstract}
The goal for today's lesson is to let the students get into the website, I want them to have a look at the anatomy stuff, we have covered a lot of anatomy and this gives them a chance to bring it into a 3 dimensional perspective and see how it looks. I want them to also test themselves. I have also added in some aspects for their own interests as a lot of them have a lot of interest in careers in this area. For example if they can't see the context of why we are doing this, they can go into the careers sites and see where it leads to at university and the New Zealand Institute of Sport.
\end{abstract}

Barry set up a protopage with links for the students to access (Figure 13). The students were told the learning intention and how to go about using the site. They were encouraged to look at the careers information that had been included. The activity design limited the links and information to keep the students focussed and engaged:

I found that using the protopage kept them on track. If I said that you can go to these five websites, then it is hard to manage whether they are going to those sites, doing the right thing, but it is quite easy to tell if they are doing the right thing as they are either on the starting page or one of the links. There were not too many links, so it was manageable for the students. 


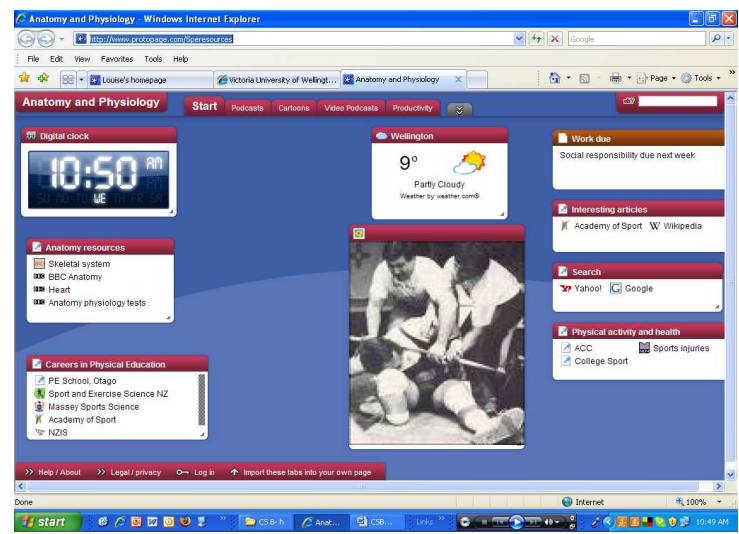

Figure 13: Case study B protopage with links to keep students focussed.

The teacher's specific learning intention was for the students to be able to identify and name the major muscle groups in the body. From the student interviews, observations and teacher reflection it is clear that the students focussed on learning about more than the muscles.

The students spent time examining the BBC anatomy site. The researcher asked the students what and how they were learning using think aloud methodology. The majority of the students were focussed on muscles, bones, organs or nervous system, learning about the function and location of these through the information and activities on the linked sites. When asked what they had learnt, student responses varied, for example:

We get to learn about body anatomy, bones, types of joints in the body and what they are used for.

(I have learnt) where your muscles are, and where the voice box is. It is pretty interesting. You understand it more.

I have learnt where the muscles go... I am [now] trying to learn about muscles.

I found out that not everything goes to the brain, like the knee joint is connected to the base of the spine, that is where the nerves go so that was really interesting.

While the teacher had stated a learning intention, the actual learning outcomes were broader and within the context of the wider unit of learning.

Three students spent time examining a link titled 'brain sex' that included a series of perception type activities, each of which tends to have gender differentiated outcomes. As one of the students works on an activity that involves matching lines (Figure 14), she said: "What do I do? Oh my gosh - is this an activity for the boys?" 
She completed the activity, and a score was automatically generated, achieving 8/20. The boy next to her had achieved 14/20, and clearly she was used to achieving higher scores than him: "Oh my gosh you outperformed me!" From taking part in this activity she identified that there can be gender differences in the ability to do different tasks.

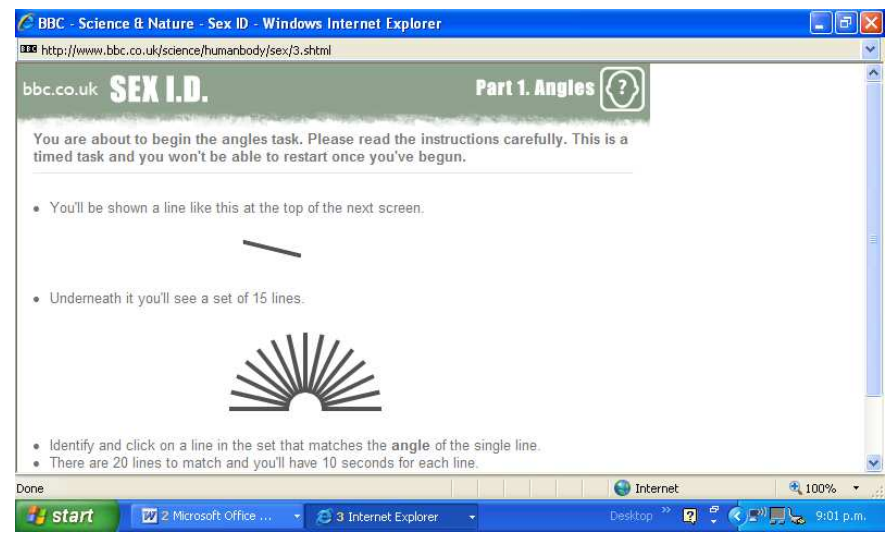

Figure 14: Brain sex activity

While the brain sex activity was not directly helping students to understand about body structure and function, it did serve the purpose of engaging the students in thinking about their bodies and gave them confidence in using the internet site. These students did go on to look at muscles after this (and following a prompt from their teacher).

Sometimes the games and quizzes were not perceived as learning: "I am looking at the body, I am not learning much, I am just playing the games...[do the games help?] a bit, shows me where things are, muscles, the names of the bones, stuff like that."

Students built on the knowledge they had, which was evidence of the teacher scaffolding the students to construct their understanding of the concepts. For example, a student chose to look at activities involving the skeleton initially: "I know about the skeleton, don't know much about the muscles." This student felt more comfortable examining content he was familiar with before moving on to look at the muscle activities; the muscle activities followed a similar format so beginning with the familiar skeleton activities scaffolded his learning.

In this lesson the students made connections between the learning and the use of the content knowledge beyond school, making links to sports they play and possible careers where this information would be useful (Table 9). The learners used the resources to develop their conceptual understanding of the body and how it functions. 
The teacher's reflection of the lesson acknowledged a broader understanding.

Part of the goal was to give them the other context to learn it in. I know that some of the students will have learnt it all really thoroughly in the classroom. I was hoping that by giving them a different context that showed them lots of information in a different way it would help them learn. Gaming - they were making the links between the game and what they were learning. They should be identifying and explaining the stuff next lesson.

The way the students approached learning varied. The researcher observed students using the web sites as a stimulus then confirming ideas with peer discussion, taking part in a quiz and going back to information when stuck, using the interactive software in a trial and error way; and others were reading the information then doing a quiz afterwards.

Some students read the information first and then tried to complete the interactive activities. Other students went straight to the activities, then used the information when they were stuck:

I went to this website that shows all the bones in the body. There is a site at the bottom where you get to choose male or female and you have to put the bones back in the correct place and figure out where they all go. They give you a clue. I am stuck on this one.

She then dragged and dropped the bone in the wrong place then reads out loud: "the bone is made up of four fused vertebrae." (Figure 15). She clicked on the hint, read it then dragged and dropped the coccyx into the correct position giving a sigh of satisfaction.

This was the most common approach to the interactive activities - a trial and error method using the drag and drop followed by reading the accompanying information and/or asking the person next to them, for example, a student called out to his friends: "where is the voice box fellas?" 


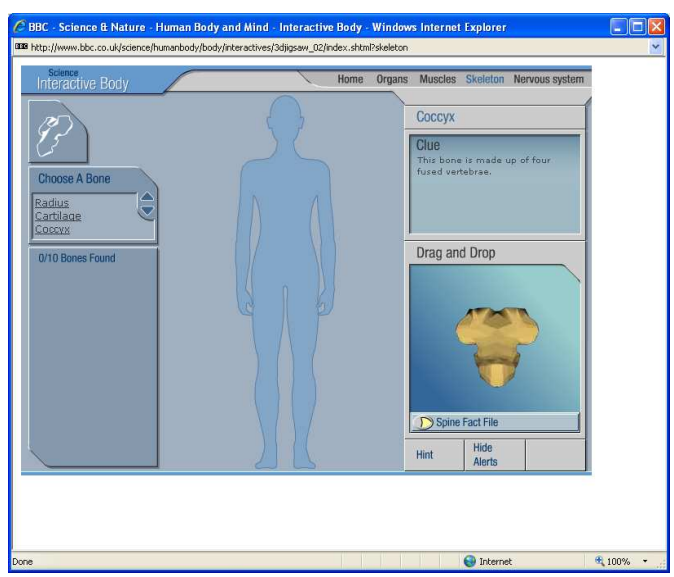

Figure 15: Using the help menu

Students also spent time examining information, for example, one student was looking at the picture of a foot (Figure 16), saying: "It is upside down - how come it goes like that? Is that the heel? What is a phalanges?" He then read the information and was able to answer his own questions.

Students demonstrated some control over the focus and order of their learning: "I have been doing a bit of muscles, and trying to learn about the skeleton. ...I have also looked at the tests. They are pretty good. You get to revise all the muscles and stuff before you do it."

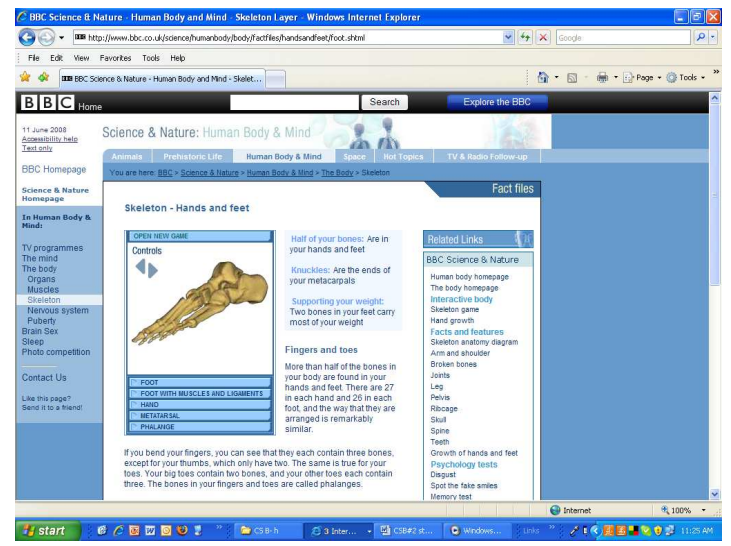

Figure 16: What is a phalanges?

After the lesson the teacher reflected on the effectiveness of focussing students on learning about muscles during the lesson:

I watched all of them have a go at the muscle game. I watched at least half of them do the test on that. Which was good to see. They did look at the skeleton and I didn't mind them doing that as we have done this, we have looked at the bones, as this goes with the muscles. I have no problems going with the bones as we have done it. 
Most of the students were engaged in learning throughout this lesson. This engagement was evaluated through feedback from the teacher, the students and observations. While some of this engagement may have been due to the novelty of being in the computer room for a physical education lesson for the first time during the year, the feedback from the students and observations suggests that the lesson was engaging as the students could learn at their own pace, follow their interests, get instant feedback on their learning, and the interactive three dimensional resources kept them focussed.

When I do this I know straight away if I am wrong and I learn the right answer.

...it is easier to learn because it is like one on one time, not waiting for the teacher to go round all the other students.

It is easier to learn. I need to read what is written to learn more.

Better [way to learn than usual way] because it is easy to find what we want to learn.

It is a good way to learn because you get to read about it and do the activities, learn about the stuff as you go, at your own pace. When I do the worksheets sometimes I don't understand them as I don't have all the information but here I can go and look at all the information. You can look at it then try and do the tests.

... you don't have to read a text book, it is interactive, you are not just writing everything down, you learn by putting things in places, instead of drawing it you have a 3D model that shows where it all goes.

The students believed that the content of the lesson was important. The teacher had included links to career sites and encouraged the students to think about how learning about anatomy and physiology might help them in their careers. From the interviews it was clear that the students had looked at the careers (Barry reported that the girls all went straight to the careers information whereas the boys went straight to the lesson activities). The content was also seen as immediately useful with one student saying (unprompted) that he would apply what he had learnt to the stretches he did while playing rugby league.

Most of the students planned to access the site again after the lesson. Commonly this was to revise prior to a summative assessment or in the future for reference. One student when asked if she would go back to this site again responded enthusiastically: "probably this afternoon to show my Mum. 'Mum, look at what we did!"” which indicated the engaging and possibly the novelty of this learning activity.

In reflecting on the engagement of the students in this activity, Barry said:

The students did as hoped. I was worried that the students would get bored, the activities wouldn't sustain them and they would get off task. But really only two 
of the students got off task, they are the least mature in the class, I expected that, they focussed on the brain sex aspect, which is useful information, but not anatomy which they needed to focus on, they did go back to the anatomy. They were interested in it, which was one of the aims - have them interested in finding out more.

All the students were positive about the value of using these activities for learning about anatomy and physiology.

\section{Discussion - anatomy and physiology}

The belief that underpinned the decision to use digital technologies for this learning activity was that students will learn this content best through a three dimensional environment. A logic model illustrates the way that transfer of learning occurred in this situation (Figure 17).

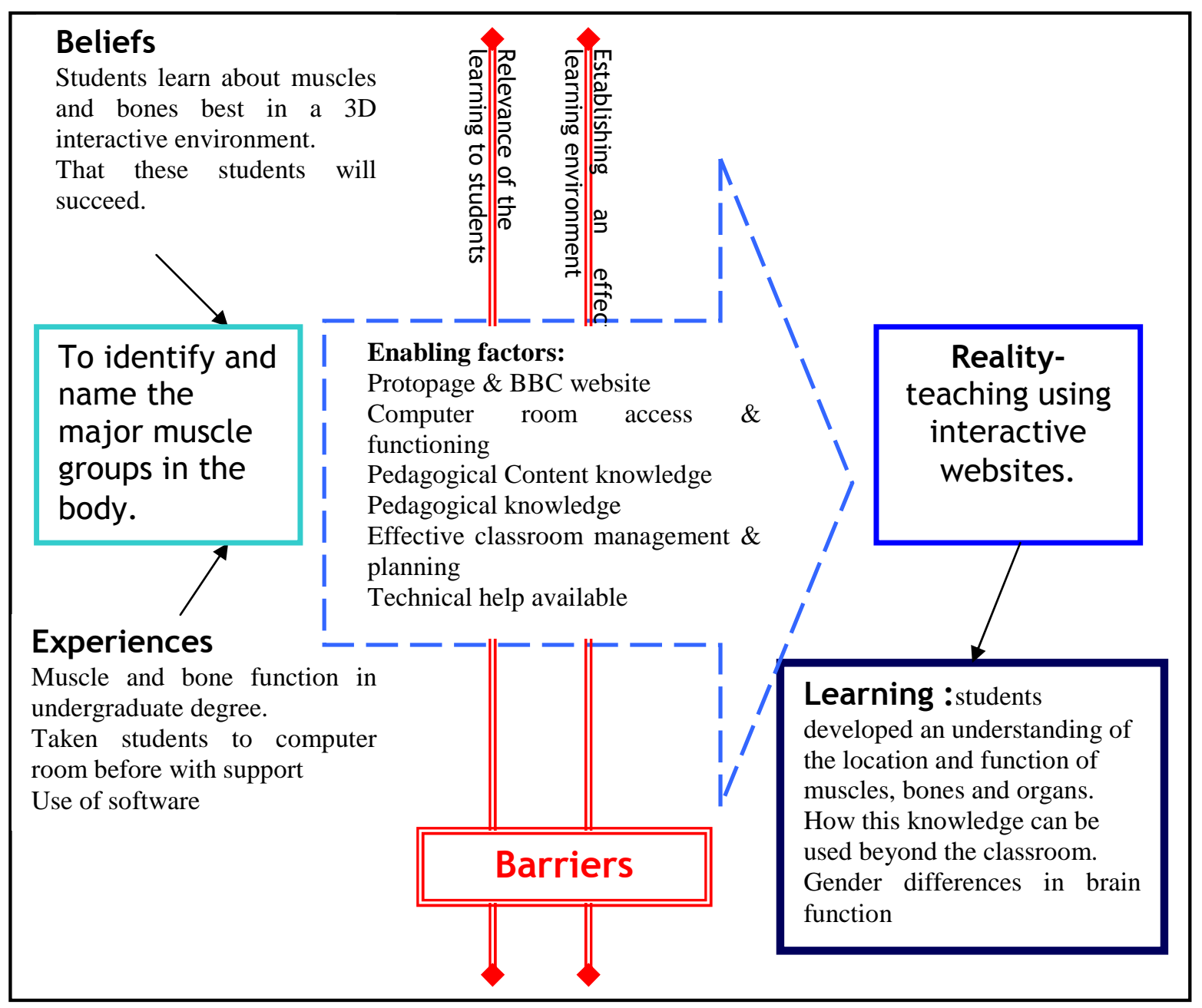

Figure 17: Case study B anatomy and physiology logic model

Experiences that enabled Barry to use digital technologies in this lesson included experience with the software, university study that included examining bone and 
muscle function, having successfully taken a class to the computer room before, and a conversation with a friend who showed him the site.

I had used Protopage in the digital technologies course [at university] and I went and checked out my old one from then, that had some useful stuff, so I shared some information across from that.

Factors which evidently enabled the successful use of digital technologies included access to hardware and software, relevant knowledge and an effective relationship with the class. For this learning activity the students each had access to a computer with broadband internet where the download speed of the computers seemed to be sufficient that the students stayed on task.

Using one webpage (http://www.protopage.com/5peresources) that contained links to the anatomy and physiology sites and tertiary/career possibilities enabled the student to keep focussed on task (Figure 12). This was a deliberate teaching decision made by Barry.

I found that using the Protopage kept them on track. If I said that you can go to these 5 websites, then it is hard to manage whether they are going to those sites, doing the right thing, but it is quite easy to tell if they are doing the right thing as they are either on the starting page or one of the links. There were not too many links, so it was manageable for the students.

Barry had established an effective learning environment based on careful planning and having high expectations of the students' ability to learn. He was aware of how to keep the students focussed on the learning. He understood the diversity within the classroom, the dynamics, behaviours and how to focus the students on learning. He planned the lesson with this in mind, was vigilant throughout the lesson, he gave time to each student in the class as they accessed the major muscle group activities and he set up the lesson to minimise predicted off-task behaviour. During the lesson he was aware of what each student was doing:

The only one who wasn't on it was Adam who was making his own stencil things. He had a tab open on word. I kept an eye on what he was doing, he was just writing out the alphabet as he was making a poster next period... He had the tab hidden under the internet one and would bring it up when he thought I wasn't looking. Besides that it was quite easy to manage as it was all in one.

An important factor in the success of this lesson included the direct and indirect support. For direct support technical assistance was available during the lesson: 
The internet technician talked to me at the start and said that there had been some downloading time issues with some of the accounts and to let him know if this was an issue. I know the network does get a bit slow sometimes. And it can be a bit slow to upload Protopage.

Barry also had indirect support through his support network and this included both encouragement through mentors and suggestions and links to the resources he used. For example, the interactive site was shown to him by a friend. The importance of the support network is discussed further below.

The learning intention seemed to focus on just one aspect of what the students actually learnt. The students learnt a lot more than the muscles, but the time spent examining muscles suggest that the learning was likely to be superficial, though this was the first lesson looking at the muscles and the in-depth understanding would be more likely to develop in the following lessons. There were clearly concepts being examined during the learning and the students linked the learning to authentic contexts. At this stage of learning developing new knowledge was not evident and would be more likely to be seen later in the learning sequence. The chosen teaching strategies kept the students focussed on learning.

\section{Support network}

Barry had an extensive support network within the school where he was teaching, and was actively keeping in contact with friends and fellow graduates who also gave him support through exchanging ideas and experiences. Figure 18 shows the support network that Barry reported.

A key support in the use of digital technologies in Barry's teaching and learning was his mentor and the HOD mathematics. They officially met once a week as part of the PRT programme, they also had informal chats:

HOD mathematics is my 'go to' guy. He is really onto it with anything digital. He said the other day are we doing enough in our PRT meetings? They generally end up with him showing me a new mathematics website or how to put a quiz on the ipod - like who wants to be a millionaire for the ipod. It is kind of like we get sidetracked and he shows me these cool things. He said I should probably be spending more time talking about classroom management with you, but I said no, no for me there are two things - you are giving me all sorts of ideas and resources to use and the other thing is it gives me time away, it relaxes me and it is quite nice to be able to talk to someone about it. He is brilliant, any sort of computer based stuff I can just hit him up and he is a wiz. So he is the number one guy.

The support from the physical education department was collegial with Barry as one of the digital innovators. This included working with the HOD to develop a physical 
education page for the intranet and wiki pages for students to access for the different programmes.

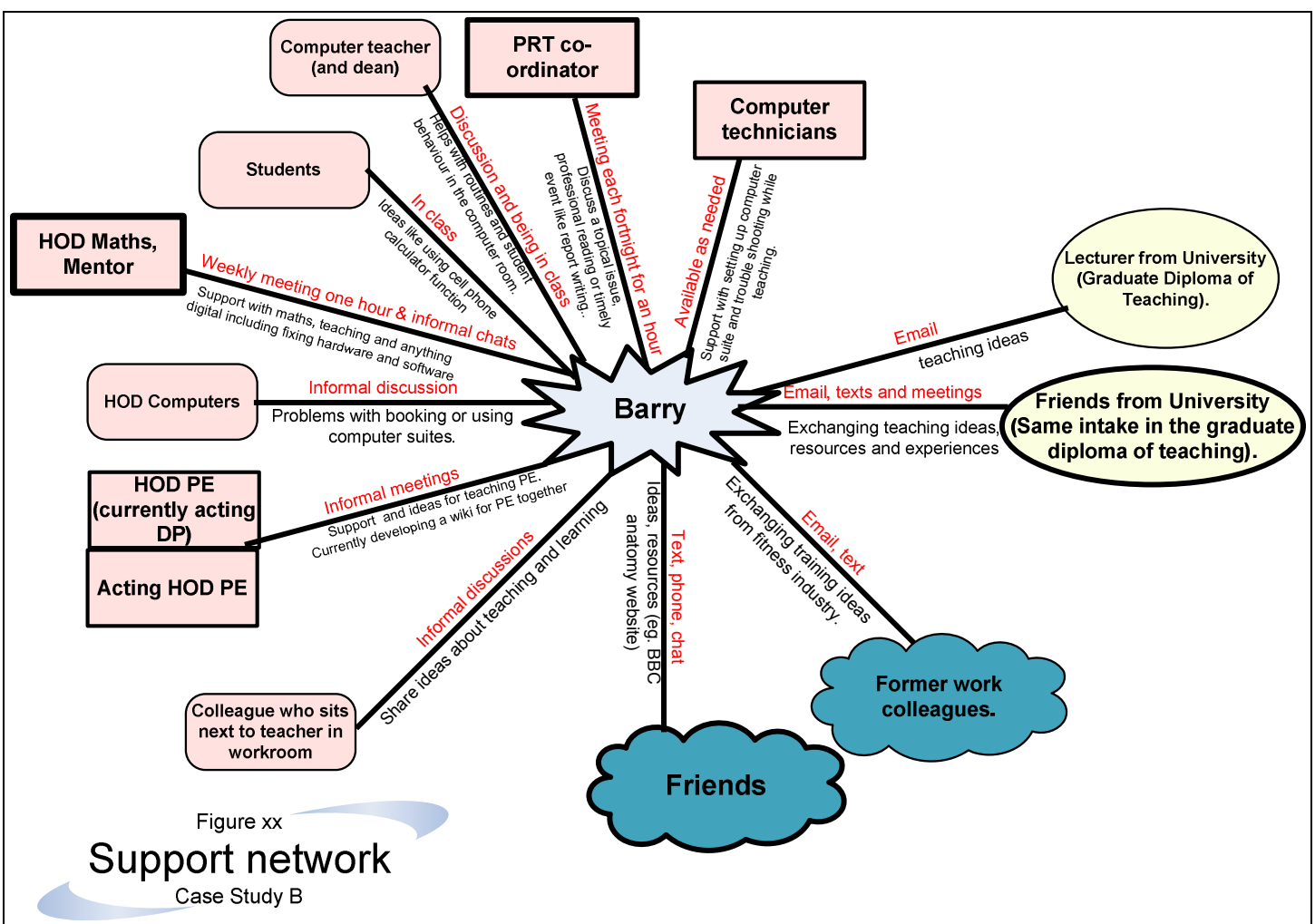

Figure 18: Support network case study B

The HOD computing and the computing technicians were supportive in the practical booking and use of the computer suites. This support involved accessing expertise rather than collaborating. His colleagues were also a source of support like the teacher who sat next to him in the staff room and shared ideas about teaching and resources.

Barry also drew support from beyond the school. He was in contact with peers who had graduated at the same time, teachers with whom he now shared ideas and resources. He also recognised that he was supported by friends not involved in teaching such as friends from university and former work colleagues who sent him interesting links and possible online resources.

An important enabler in using digital technologies in his teaching was the support that he accessed. During New Zealand mathematics week in his first six months of 
teaching Barry took a mathematics class to the computer room to use the interactive mathematics activities.

One of the computer teachers (who is also a dean) has been quite supportive of me when I have gone in there with my class. A tough class, she has stayed and helped, supported me, made sure the students are aware of the rules and routines around the classroom. That has made it much easier for me. Not having to just go in there, remember it all and try to enforce it when I haven't actually seen it. So having someone who knows it and supports makes it a lot better.

\section{Summary}

Barry was able to draw on his previous experiences, support and pedagogical content knowledge to use digital technologies in physical education to enhance students' understanding of concepts. He was hesitant in the use of digital technologies in his secondary teaching subjects, finding more barriers due to the lack of pedagogical content knowledge. A summary of the transfer of learning is illustrated in Figure 19.

Barry had wanted to use digital technology in his teaching practice, but during his first year of teaching his use was limited to interactive websites to help students of physical education understand how bones and muscles work during physical activity and for mathematics students to develop their numeracy skills. The students in his mathematics class used their cell phones as calculators. Accessing information, gaming and processing data were types of uses reported. The learning focussed on gaining conceptual understanding and using technologies for processing data.

Underpinning Barry's use of digital technologies was his beliefs and experiences. Barry was confident in the use of digital technologies in physical education due to his experiences of using these in his undergraduate degree. He did not have this experience in mathematics and science, subjects which he was also teaching. He was focussed on establishing an effective learning environment for his students. This meant that his priority was on establishing routines and focussing students on learning. Once he had established this he was more likely to use digital technologies. 


\section{Beliefs:}

- $\quad$ Being able to establish effective learning environments in a low decile school is a good grounding for a teaching career.

- Digital technologies are an important part of the world today and in the future.

Teacher aspiration: to integrate digital technologies for classroom routines and help understand concepts.

\section{Experiences}

- Study of Physical Education at University

- Working in gym management.

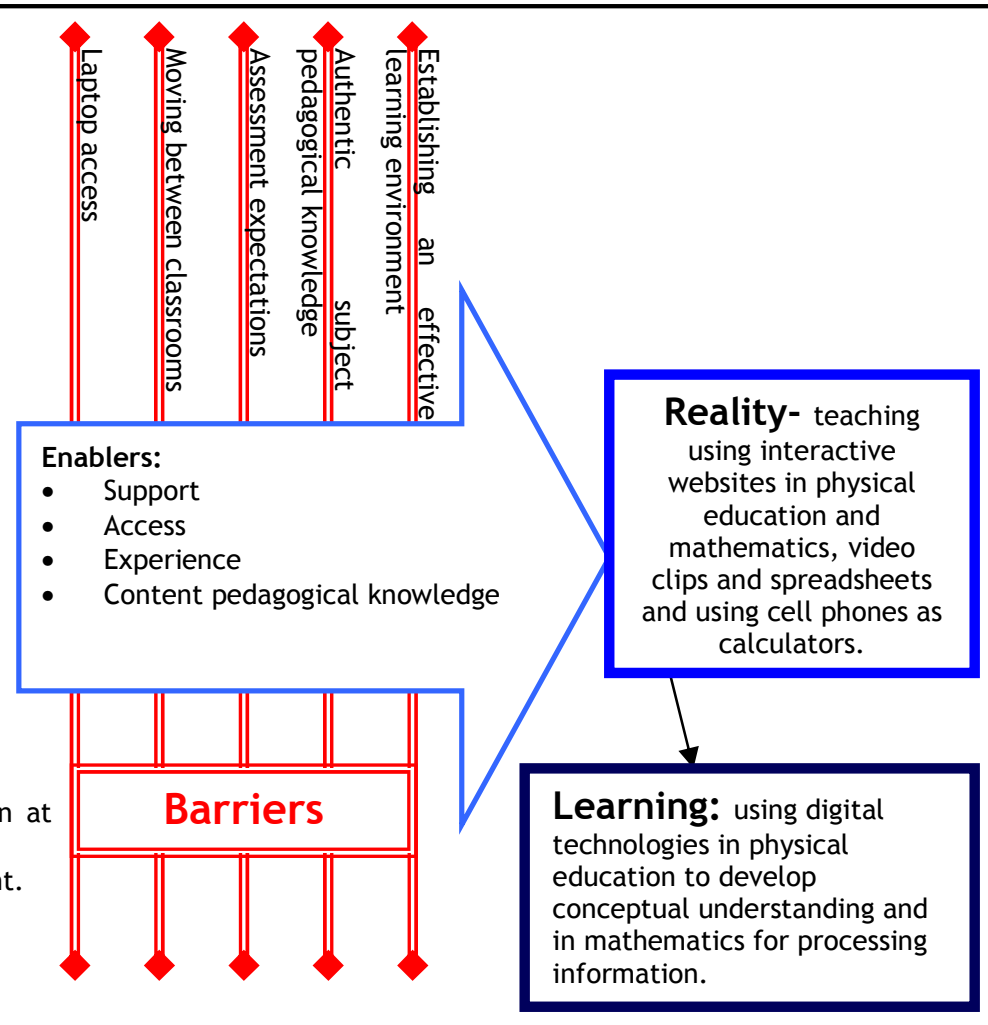

Figure 19: Case Study B logic model

He was teaching in a school where he was strongly supported as a PRT and as a member of the science, mathematics and physical education departments. This support was essential in his integration of digital technologies into his teaching and learning and included both practical classroom management support and pedagogical focussed professional development. Other factors included the access he did or did not have to a laptop and data projectors and his belief that students of mathematics had to use paper and pens for assessment purposes.

The students in Barry's class used a trial and error, ask a friend approach to learning when using digital technologies. The design of this activity - with the students knowing what they needed to learn or understand, having a place that they could self check their understanding and having sources of information and activities linked and easily found - made this way of learning appropriate. 


\section{Assertions from case study B:}

B1. Beginning teachers are more likely to integrate digital technologies for creating knowledge when teaching their specialist subject area.

B2. Using digital technologies allows for personalisation of learning. This includes linking activities to context, a range of media, allowing students to learn at their own pace and explore a greater range of information, and receive instant formative feedback.

B3. Using digital technologies can help students understand concepts.

\section{Case study C}

I think the thing with digital technologies is that it is quite scary not knowing. (Cath 2007)

\section{The teacher}

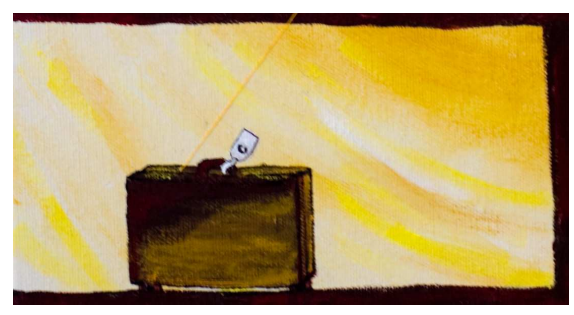

Cath was 23 when she began teaching. She had completed a bachelor's degree in physical education before studying teaching through a Graduate Diploma of Secondary Teaching. In the degree programme Cath had used presentation software such as PowerPoint and Word and had made digital videos. She was familiar with using the internet and social networking sites such as Facebook.

When Cath was a student teacher she had observed year 10 students taking part in an integrated curriculum challenge where they made ice-cream and then used movie maker to create advertisements for their ice-cream. She had also had students she was teaching using the internet to research environmental issues.

At the start of her first year of teaching, Cath did not feel particularly confident in her ability to integrate digital technologies into her teaching practice unless she had professional development and support.

For my age I am kind of OK but I still feel very left behind talking to the kids who are at school now. I am like 'Ahhh I don't know how to use that and don't want to seem stupid'. I don't want to ask someone and have them go - 'What? You don't know, you are still young and you have just left teachers college!'

She was more confident and determined to use digital technologies at the end of her first year of teaching: 
I still believe that digital technologies are a very useful way of aiding teaching and learning in the classroom for both me and the students. It can be a very effective tool to learning as it can be interactive and allows students to see similar information in a different way.

Cath was keen to offer a variety of learning activities to her students to help to engage them in learning:

My beliefs are that all students have something to offer in the classroom and offering a variety of different ways of teaching e.g. demonstrations, student driven teaching, technologies or visual, plus hands on I think are very important to teaching and learning. I get sick of the sound of my own voice so I am sure that the students do also.

She believed that students could succeed in school in some way:

There are different ways that anyone can be knowledgeable. It makes me think of a kid we have in year 12 who was made to leave school because he wasn't applying himself in subjects except outdoor ed. and technology. He was quite successful in those two subjects, but that wasn't good enough as he wasn't succeeding in like mathematics and English. I thought that was sad. He could have got more credits with me and in construction. It seems that there was the stigma that you can't be successful unless you can write good essays and count. Why aren't we celebrating that this kid can make what he does in construction? He didn't even have a job to go to so someone had written him off somewhere in the past. I thought it was really sad.

\section{The context}

Cath taught in two contrasting schools in her first year of teaching. Her first school was in rural New Zealand, a decile 6 school of about 300 students and 30 teachers. She was the only specialist physical education teacher in the school teaching students up to their final year. This job ended after six months as the teacher returned to the position. Cath then taught in an urban school of 1500 students, teaching diverse students in a low socio-economic area in England. She taught practical-based junior physical education and mathematics. She had access to a data projector, interactive whiteboard and computer rooms. There was no support for Cath as a beginning teacher.

Cath owned her own laptop which she used at home to access lesson plans and a range of resources she had from her degree course and postgraduate teaching qualification. She used the laptop when examining different games and strategies to use within the classroom 


\section{Digital technology use}

At the start of teaching Cath said that she would like to incorporate a range of digital technologies into her teaching and professional learning. She was interested in students making movies, using PowerPoint, learning mastery games, Web 2.0 tools like wikis and podcasts, games, interactive whiteboards and videoconferencing.

During her first year of teaching Cath did use a range of digital technologies. One use was with a year 13 physical education class, where the students had to analyse their performance during volleyball and compare it to national criteria. A student suggested recording the shot using a digital video camera:

They needed to be able to have some way of seeing themselves. When we looked at it I found it hard to break down the skill by just visually looking at it at that speed. I was like, there must be some way we can break this down. One of the kids who is a bit of a guru said 'let's have a look at it'. We were able to break it down into parts and print it off, step by step like you see the ball coming down, the kids getting ready for the shot and then performing the shot and the afterwards. It was very effective.

This innovation was effective as Cath was willing to listen to students' ideas and let them have some input into how they learn.

She used digital cameras to record students during the gymnastics and the dance units. The recordings were stored on a shared drive for students to look at their own performance and a record of achievement. She also used PowerPoint to present information. She thought that the students focused more when she used PowerPoint with "pretty colours and pictures." She was using PowerPoint with the year 12 and 13 physical education classes at the first school she taught in.

At the second school she had taken her mathematics class to a computer room where: "The students used it to create shapes-and colour them in. We did it to look at fractions (the computer did it for them but they had to do the presentation and write up of the shapes)." She reported that the students learnt about the fractions of different shapes and how to work that particular computer programme. The students engaged in this learning activity and showed pride in their achievements.

I believe it is important that students have access to digital technologies. You should have seen their faces after they had made the shapes on the computer they were so excited and proud of themselves and they finally understood fractions. They took their work home to show home and they carried it around to show some of their other teachers. I eventually got it off them to put up around the classroom. It was pretty special!!' 
She had used a data projector to show mathematics students about the difference between units of measurement: $\mathrm{mm}, \mathrm{cm}, \mathrm{m}$ and $\mathrm{km}$ and how different objects are measured. Cath said that the students learnt about unit measurements and how different objects are measured in different units.

\section{Learning}

The digital age learning matrix was applied to the learning activities that Cath had described and collated in Table 10. Cath used digital technologies to help students make connections in their thinking, helped students to think about key concepts and to critique and evaluate their performance in volleyball.

\section{Barriers and enablers}

Cath appeared to face a number of barriers due to the contexts and situation she found herself in. Her first teaching position was for sixth months only in a rural school. She was the only teacher of senior physical education, and the regional support network of physical education teachers either did not exist or if it did, it did not extend to her. While this school gave Cath general support as a beginning teacher, she did not feel that the pedagogical support was available.

The second school had even greater barriers. She was on a fixed contract and appeared not to qualify for beginning teacher (or other) formal school-based support. Cath found that she did not have access to digital technologies such as computers, data projectors, video cameras that she would have liked to use in her teaching practice, or know how to gain access:

...there was no access in any of my physical education lessons - if I had the technology I would have shown the students videos or snapshots on how to perform different skills e.g., the shot put throw was something they were unfamiliar with and did not grasp the concept of it well, even after demonstration. A video would have made a lot of difference - not for a long time but maybe as a starter to the lesson. I had printed out pictures but these were not effective. I had $\mathrm{NO}$ access to digital technologies during any of my lessons-not even a camera to record students' gymnastics performances which I have done in the past and even though students say how much they hate watching themselves I know that they secretly enjoy it, and it's good for them as well. 
Table 10: Digital age learning matrix applied to case study C

\begin{tabular}{|c|c|c|c|c|c|}
\hline Level of learning: & Doing & $\begin{array}{l}\text { Thinking about } \\
\text { connections }\end{array}$ & $\begin{array}{l}\text { Thinking about } \\
\text { concepts }\end{array}$ & $\begin{array}{l}\text { Critiquing and } \\
\text { evaluating }\end{array}$ & $\begin{array}{l}\text { Creating } \\
\text { knowledge }\end{array}$ \\
\hline $\begin{array}{l}\text { Explanation of level } \\
\text { of learning: } \\
\text { Digital technology } \\
\text { use: } \\
\text { Learning activity: }\end{array}$ & $\begin{array}{l}\text { Isolated information. } \\
\text { Focus on completing } \\
\text { a measurable task. }\end{array}$ & $\begin{array}{l}\text { Connecting thinking. } \\
\text { Simple connections } \\
\text { made within a } \\
\text { context. Compare } \\
\text { and share. }\end{array}$ & $\begin{array}{l}\text { Develop conceptual } \\
\text { understanding of 'big } \\
\text { ideas' }\end{array}$ & $\begin{array}{l}\text { Evaluating and } \\
\text { critiquing to explore } \\
\text { the limitations and } \\
\text { potential of } \\
\text { information, sources } \\
\text { or process. }\end{array}$ & $\begin{array}{l}\text { Creativity - Applying } \\
\text { ideas, processes } \\
\text { and/or experiences to } \\
\text { develop a new reality. }\end{array}$ \\
\hline $\begin{array}{l}\text { Processing } \\
\text { information }\end{array}$ & $\begin{array}{l}\text { Information is processed } \\
\text { or data/images are } \\
\text { manipulated in isolation. }\end{array}$ & $\begin{array}{l}\text { Connections are made } \\
\text { between or within } \\
\text { processed } \\
\text { information/data or } \\
\text { images and relevant } \\
\text { concepts. }\end{array}$ & $\begin{array}{l}\text { Processed data or } \\
\text { information has clear } \\
\text { conceptual underpinning. }\end{array}$ & $\begin{array}{l}\text { Process and product are } \\
\text { critiqued and evaluated. }\end{array}$ & \multirow[t]{2}{*}{$\begin{array}{l}\text { Ideas and new knowledge } \\
\text { are developed. }\end{array}$} \\
\hline Volleyball video & $\begin{array}{l}\text { Students videoed } \\
\text { themselves as they } \\
\text { practised volleyball. }\end{array}$ & $\begin{array}{l}\text { Connection made } \\
\text { between volleyball shot } \\
\text { and theory }\end{array}$ & $\begin{array}{l}\text { Concepts to do with } \\
\text { movement and sports } \\
\text { developed. }\end{array}$ & $\begin{array}{l}\text { Performance was } \\
\text { critiqued through the } \\
\text { video. }\end{array}$ & \\
\hline $\begin{array}{l}\text { Rotational } \\
\text { symmetry (see } \\
\text { specific example } \\
\text { below) }\end{array}$ & $\begin{array}{l}\text { Students watched the } \\
\text { shapes rotate and } \\
\text { predicted the number of } \\
\text { rotations. (processing } \\
\text { information) }\end{array}$ & $\begin{array}{l}\text { Reasons for the different } \\
\text { answers were discussed. }\end{array}$ & $\begin{array}{l}\text { Students were able to } \\
\text { apply and explain this } \\
\text { rotational activity to } \\
\text { other rotational } \\
\text { examples. }\end{array}$ & $\begin{array}{l}\text { The game, quiz or virtual } \\
\text { world is critiqued and } \\
\text { evaluated within a } \\
\text { conceptual context. }\end{array}$ & $\begin{array}{l}\text { Original ideas are used to } \\
\text { create a knowledge } \\
\text { product in any medium. }\end{array}$ \\
\hline
\end{tabular}


Cath had developed and used digital resources for teaching physical education in the first school and while on teaching experience but in the second school the limited access prevented her from doing this:

I would have loved to use my power point (sic) presentation on anatomy as often it was raining and I found myself teaching indoors with whiteboard access and my lousy drawings on the board. If I could have got my laptop and a projector I could have shown the students anatomy in 3D to aid them in their learning. I would try and incorporate anatomical names to them in our gym class lessons so that they would access the names before reaching year 9 .

It appeared that policies in the school limited access and not just the policies about computer room access: "The school had interactive whiteboards, but only the senior math teachers got to use them...go figure!" The enabling factor that Cath identified was that she was able to use computer rooms occasionally with her mathematics classes: "A computer room that was finally free for one period after the seniors left during my year 8 mathematics class."

\section{Specific example - rotational symmetry}

Cath used the data projector and a mathematics programme to look at rotational symmetry with a low achieving year 7 class of 30 students she was teaching in England. She intended that the students would learn to work out the rotational symmetry (or order of symmetry) of basic shapes. She chose to use digital technologies for this aspect because:

It allowed the students to see a 3D image rotated. They were able to count the number of times it rotated. It gave them a visual image to work with as some of them found it difficult to grasp the concept of rotation.

The students looked at the shape and made an estimation of the number of rotations. One of the students then used the keyboard to rotate the image as the class counted the rotations. This was followed by a class discussion and watching the rotation a second time.

\section{Support network}

Cath reported the lowest level of support out of all the case studies; a summary is represented in Figure 20. She had support from friends from university and colleagues she had worked with: "I keep in touch with some of the crew from college and will text them with questions about my teaching, so I do use it for my own learning." 
At the first school she taught at there were formal support networks for beginning teachers which she was able to access, though no-one had in-depth pedagogical content knowledge to help her with her senior physical education classes, and she was unaware of a regional support network. Therefore teaching in a small rural school limited her options for support in her specialist area

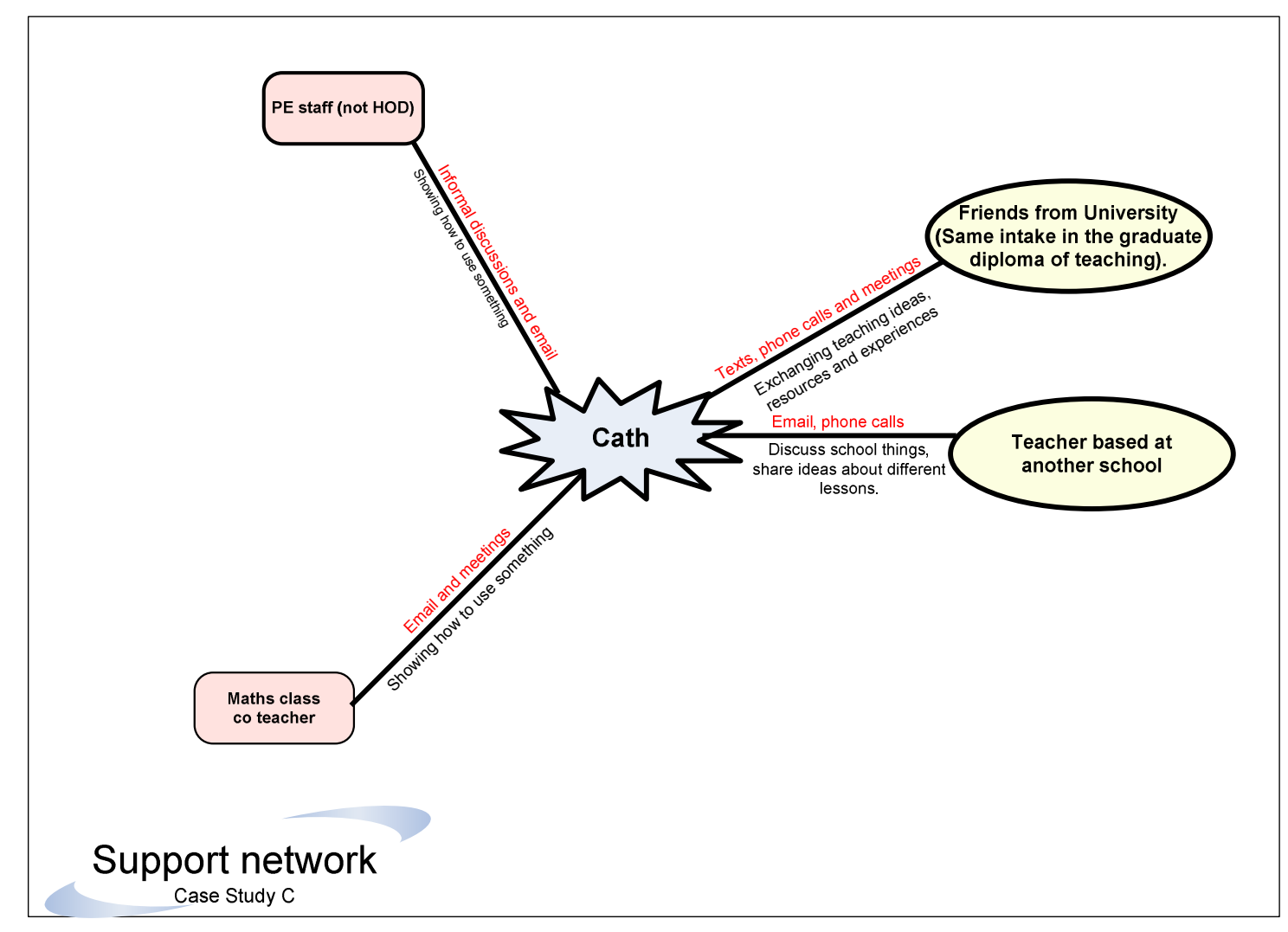

Figure 20: Case study C support network

In the second school she was teaching in, which was a large urban school, she also lacked support. It appears that as she had a six months contract, the curriculum leaders did not put time aside to support her: "[I received] no help in either department from HOD or other staff (particularly in the math department, I hadn't even met properly the staff in that department)."

Despite the difficulties in using digital technologies, Cath appeared even more committed to their use at the end of her first year teaching than at the start. This is likely to be due to the year's experience of teaching boosting her pedagogical content knowledge and her confidence in her use of digital technologies with students:

Unfortunately for me I have not had the support in using digital technologies often and in my second school that was mainly due to the lack of support and access to it. Although this will no doubt change as the school had been granted Sports 
College and ICT status...so a lot of money will be pumped into both areas so it would have been interesting for me to be a part of that while it had been up and running. My experience would have been very different I believe.

\section{Summary}

Cath's experience of attempting to transfer her knowledge of digital technologies to the teaching situation is illustrated in a logic model, Figure 21.

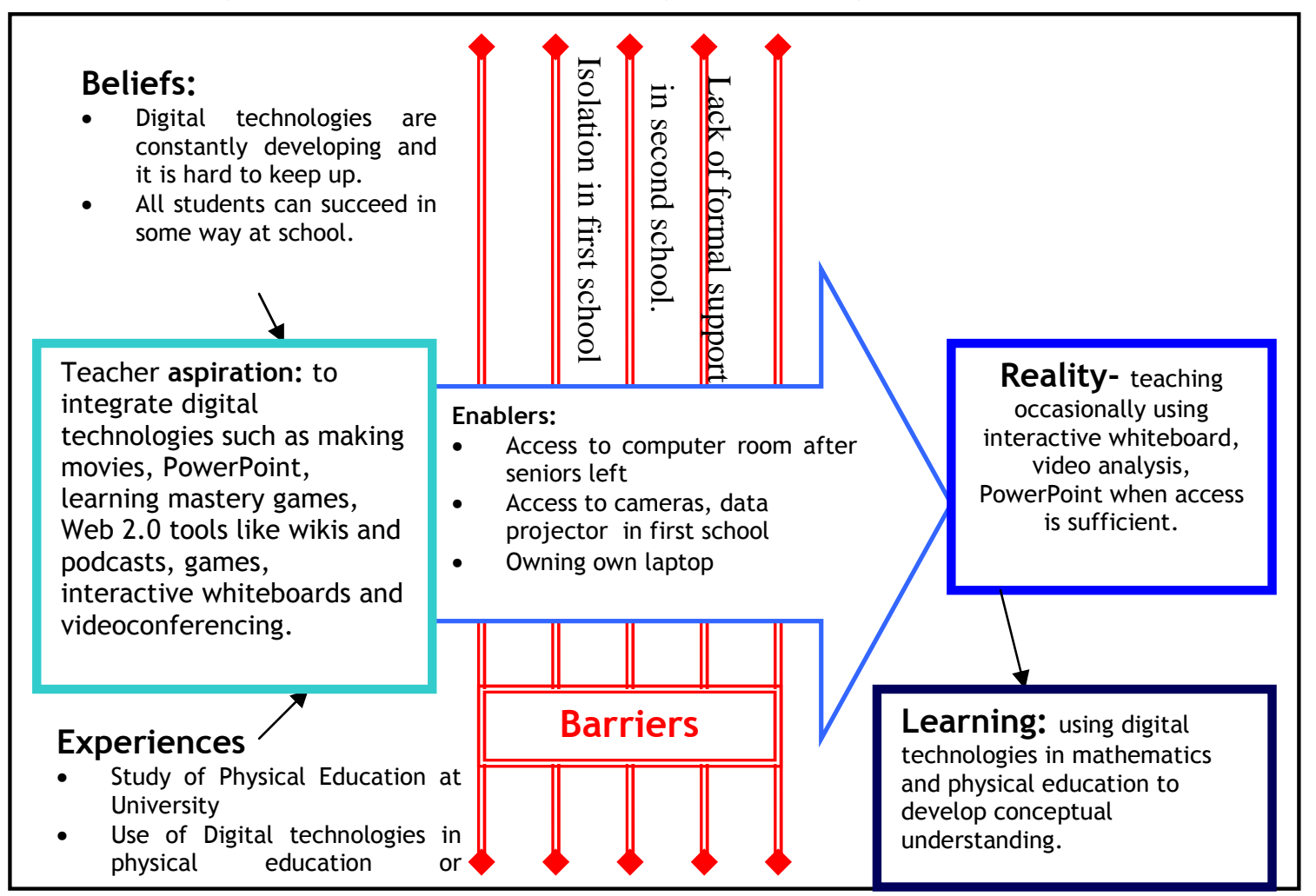

\section{Figure 21: Case study C logic model}

Cath started her first year teaching in a rural school, which offered support but lacked colleagues with pedagogical content knowledge in her specialist field of physical education. She initially lacked confidence in using digital technologies with the students as she felt that they knew so much more than she did; however, she did use digital technologies as she believed they would help the students to learn, and to understand the concepts she was teaching. She incorporated student suggestions into her teaching which reflected her belief in power sharing. Cath then went to England where she was teaching mathematics in a large urban school with little support or access to digital technologies which limited the ways she was able to integrate digital technologies into student learning activities.

At the end of her first year of teaching Cath appeared to be more confident and less concerned about the students knowing more about digital technologies than her. She 
was determined to integrate digital technologies in her teaching practice in the future despite the lack of support she had received.

\section{Assertion from case study C}

C1. Beginning teachers familiar with digital technology use in their everyday life may not feel confident in their abilities to use digital technologies in a teaching situation.

It is unlikely to be a simple cause-effect link between abilities to use digital technologies and the integration into the teaching practice. There are many decisions a teacher has to make about how they engage students into learning or creating knowledge. When beginning teaching in a new school or for the first time there is an enculturation period when a teacher is getting to know how a school operates and getting to know the students (and the students are getting to know the teacher). To many beginning teachers this is a time when they need to appear in control, to be the expert; hence it can be a legitimate concern that the students may know more than the teacher when it comes to digital technologies. This, along with access, pedagogical content knowledge and support could all impact on the decision whether to use digital technologies or not.

C2: Lack of access and support limits the ability for a teacher to use digital technologies, but has little effect on their belief in their value for learning.

After a year of teaching and facing difficulties in accessing support and digital technologies Cath was still enthusiastic about the value of digital technologies in the learning process:

I would like to use it more in different situations, although not as a constant as I think that it might take away the effectiveness of it if I used it too often. But in the above examples I would definitely like to use it in different ways. Right now I am just starting to apply for jobs in physical education so I hope that I do get the opportunity/access/support to use digital technologies.

C3: The beginning teacher becomes more confident in integrating digital technologies into their teaching practice during their first year of teaching. This is likely to be due to a number of reasons including increased confidence in their role as a teacher and greater pedagogical content knowledge. 


\section{Case study D}

My teaching philosophy hasn't changed. It is sometimes hard to stay true to it. I don't mind going the extra mile. I am passionate - I don't want any of my students to fail. Even though some are brats and deserve to fail I can't just walk away. (Dayna)

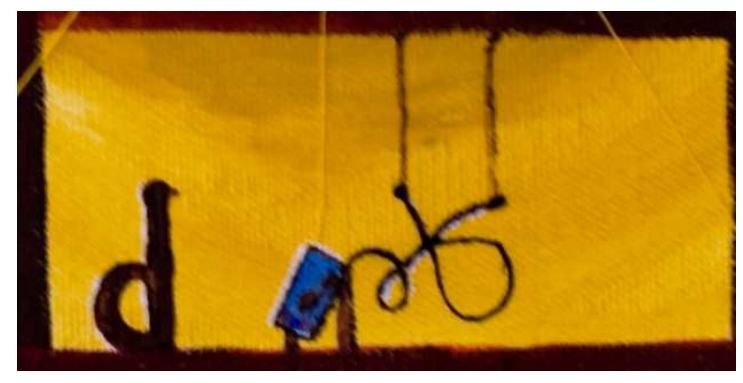

\section{The teacher}

Dayna began teaching when she was 25, having completed a bachelor's degree in design and a Graduate Diploma in Teaching. Dayna gained experience in the use of digital technologies through her formal studies, her interest in art and through communicating with friends. She gained an understanding of how digital technologies can be used in art and design through studies at design school where she experienced machinery for three dimensional modelling, a range of computer aided drawing (CAD) programmes and presentations using PowerPoint with embedded animations. She specialised in the teaching of art and technology in the Graduate Diploma of Teaching.

Dayna has an expectation that all students will develop their knowledge in her classes. She is passionate about teaching and art. She was confident in her use of digital technologies within teaching as long as she understood the technology she was using but also believed she could learn. This was evident in examples she gave of developing her skill with Studio Edit and the learner management system:

Based on what I know I am very confident. But less confident if I don't know it, but knowing that if I need to know it and the resources were there then I have the know how to figure out how to do it and that I have the support of the school to go and learn how to do it. Support can be a very important aspect of confidence.

Dayna was supporting students beyond the timetabled class time:

All the resources I make for the students, I give them a physical copy and I have it up on the network for them to access. I also started to send them home by email to parents which I don't like as it puts a lot more ownership on me to be like teaching the parents and then the parents teach the kids from home, for some of the slower kids it has been really good but David told me not to as it becomes an expectation so I don't mind doing it at this point but I don't know if I want to keep doing it as they get higher up in the levels. 


\section{The context}

Dayna was teaching in a decile 10 urban co-educational secondary school with approximately 1200 students and 90 teachers. For the first 6 months Dayna was employed on a fixed term contract teaching years 9, 10 and 11 art, year 12 design and a year 12 photography class (which was one timetabled period a week and individual help as needed through the week). Her contract was then renewed for a year, and she taught both art and fashion design. This meant that during the second half of her first year teaching she was teaching across two departments and in two classrooms. Dayna found it beneficial to be teaching in two departments:

Teaching in a different subject, where there is different resourcing and different priorities has been really good. It is uber organised. The HOD is very well organised, he is totally pro technology and he gets things done. It is well resourced. It is good to be under two umbrellas.

The school had a formal system for supporting PRTs which included three first year teachers and two second year teachers. A coordinator met with the PRTs twice a term and a designated PRT support teacher was allocated an hour a week to supports PRTs. This could involve observing lessons and giving advice and was negotiated between the PRT and the teacher. Dayna did not access the PRT support teacher.

The school has four computer suites, the art room has five computers attached and there is in area in art that is set up with a data projector and screen that is used to show movies and presentations. There was no data projector in the fashion design room; however, the adjacent classroom had one that was shared across the department. The school has click view and the textiles department had a digital camera and a digital silk screen printer which was a new \$3000 machine. Digital colour photocopiers are available for the students and teachers to use. Dayna did not have a laptop for the first six months she was teaching. She received a school laptop after six months.

\section{Digital technology use}

Dayna integrated technologies into her teaching practice for administration purposes, teaching, learning and communicating. Using digital technologies for administrative purposes was in a developmental stage at the school. The school was in the process of introducing a new student management system and exploring a learner management system. Dayna was an 'early adopter' of both systems. At one interview 
she had just began to use the new student management system (SMS) and was finding it useful in providing support to students and their families.

It was really cool as when I went to call parents last night I found I could type in the student, bring up all their information - all their report comments so that I could see if there was consistency across the subjects and over time before I spoke to parents.

At the time of the final interview the school was in the process of introducing a learning management system (LMS). Folders had been set up for art and Dayna had uploaded resources for fashion design. She recognised that using a LMS should be different to using paper-based resources and was in the process of exploring how.

Dayna used digital technology to archive student work for moderation and exemplar purposes in both art and fashion design following departmental systems and processes. This reduced the physical space needed for storage, allowed fashion students to wear their creations rather than store them, and saved visual arts students money in processing and printing. A digital camera sits on the teacher's desk in fashion design so that students can record their progress at any stage of the process.

Dayna expected students to use the internet for research and integrated research into art and fashion design learning programmes. Two examples of using the internet for research follow:

- A task given to her year 12 art class included using the internet to find examples of designers who developed poster designs for marketing or branding. The students identified five images they could explore, then narrowed this to three before closely analysing the designs. Dayna then asked the students about the designers responsible, which meant going back to the original task and finding another piece of work by that designer. This information was linked to their own poster designs.

- Year 9 textile students were booked into the computer room for a week to carry out research. This was the first time they were researching online in this class so Dayna gave them clear guidance and close supervision. Dayna made up an A5 handout which included specific questions that they had to answer, and websites that were possible starting points before googling the answers. They had to find so many images for each of their questions so Google images were used quite a bit. It was set up from a workshop. As students 
found different things, they would share their findings with the class by putting useful websites on the board. The students had to research Matisse using pre-identified websites. They found environmental reasons for why they should make a sustainable product and researched the use of appliqué. They later applied the concepts they had learnt as they made a Matisse style bag.

Digital technologies were integrated into Dayna's teaching programme within the separate disciplines of art and fashion design. Photoshop was the programme most commonly used in Dayna's art classes. Students used Photoshop to develop digital images for their portfolios and to manipulate painted and drawn images. For example, the year 12 art design students were taking photos of manually rendered images, uploading the images into Photoshop, digitally manipulating them such as adding typography, changing colour, shape and/or size or combining images, printing them off then further manually manipulating them, eventually producing a business card. The year 9 art students drew a self portrait which they overlaid with a self selected image of a superhero.

Specific to art, she used images from the internet to develop resources in Word for herself and for her students such as building a library about different artists. Dayna has her resources in digital format and makes these available to her students; she also prints off physical copies for her students to access. She used digital images of student art works as exemplars for the students to see what they have done so far in the year and for inspiration with future students.

In fashion design Dayna used a newly purchased (and much admired) digital silk screen printer for fabric printing in years 11, 12 and 13. This involved developing a design and using the silk screen printer to print it onto fabric. A second unique use of technologies in fashion design was to access sewing patterns. These were initially found by students on pattern websites which they then purchase locally. Sometimes students order these online, but this can cause a delay in starting as delivery time can be unpredictable.

Dayna used PowerPoint, showing images to her students through a data show across teaching subjects and levels. She recorded student achievement and tracked her budget using Excel. 
Digital technologies played a part in the classroom atmosphere. Dayna found that the students were bringing ipods to class and each one was listening to their own music. Dayna felt that listening to music while creating art work was good practice, but it was antisocial with each student listening to their own music, so she set up a system where the students take turns in sharing their music with the class.

We now have 20 minute slots when we have to listen to 3 people's music through a lesson. Now they just do it themselves, I don't have to orchestrate that part. I would rather the junior classes were noisy and talking.

Dayna used cell phone technologies to communicate with her students. She sent text messages to her senior students if they were away and needed to bring something to the next lesson. She had tried emailing students but found that they did not check their emails. She used her personal phone for text messages; she was on a payment plan with unlimited texts so there were no personal costs. She did not encounter students behaving inappropriately and expressed confidence in her ability to deal with any problems should they arise.

\section{Learning}

The digital age learning matrix was applied to the learning activities that Dayna had described and collated in Table 11. Dayna used digital technologies to help students make connections in their thinking, which helped students to think about key concepts. In her teaching programme she had students creating knowledge (applying concepts to create a new reality); this involved using digital technologies in the business card learning activity.

Dayna used technology to help her in her teaching and learning. Where she meets a new technology she is confident enough to explore how it works and also acknowledges that tutorials or support can be helpful:

We have also had a student management system introduced (a programme that runs all the reports on the students' data). Because it was new and I thought everyone knew how to use it so I went and figured it out myself. We had our first tutorial on it yesterday morning and I found that none of the other staff had been taught how to use it... I had kind of figured out how to find out the information by myself but I was going through a long channel so yesterday was really good for those kinds of things. 
Table 11: Digital age learning matrix applied to case study D.

\begin{tabular}{|c|c|c|c|c|c|}
\hline Level of learning: & Doing & $\begin{array}{l}\text { Thinking about } \\
\text { connections }\end{array}$ & $\begin{array}{l}\text { Thinking about } \\
\text { concepts }\end{array}$ & $\begin{array}{l}\text { Critiquing and } \\
\text { evaluating }\end{array}$ & Creating knowledge \\
\hline $\begin{array}{l}\text { Explanation of level of } \\
\text { learning: } \\
\text { Digital technology } \\
\text { use: } \\
\text { Learning activity: }\end{array}$ & $\begin{array}{l}\text { Isolated information. Focus } \\
\text { on completing a measurable } \\
\text { task. }\end{array}$ & $\begin{array}{l}\text { Connecting thinking. } \\
\text { Simple connections made } \\
\text { within a context. Compare } \\
\text { and share. }\end{array}$ & $\begin{array}{l}\text { Develop conceptual } \\
\text { understanding of 'big ideas' }\end{array}$ & $\begin{array}{l}\text { Evaluating and critiquing } \\
\text { to explore the limitations } \\
\text { and potential of } \\
\text { information, sources or } \\
\text { process. }\end{array}$ & $\begin{array}{l}\text { Creativity-Applying ideas, } \\
\text { processes and/or } \\
\text { experiences to develop a } \\
\text { new reality. }\end{array}$ \\
\hline $\begin{array}{l}\text { Accessing } \\
\text { information }\end{array}$ & $\begin{array}{l}\text { Accessing: } \\
\text { Pictures } \\
\text { Graphs } \\
\text { Movies/video } \\
\text { Data } \\
\text { Information } \\
\end{array}$ & $\begin{array}{l}\text { Information from more than one } \\
\text { source is connected or compared } \\
\text { in analysis. }\end{array}$ & $\begin{array}{l}\text { Information explicitly develops } \\
\text { conceptual understanding. }\end{array}$ & $\begin{array}{l}\text { Information and sources are } \\
\text { critiqued and evaluated. }\end{array}$ & $\begin{array}{l}\text { New conceptual understanding is } \\
\text { developed. Building on or } \\
\text { linking accessed information. }\end{array}$ \\
\hline Presenting & $\begin{array}{l}\text { Present information using: } \\
\text { Sound } \\
\text { Pictures } \\
\text { Words } \\
\text { Video }\end{array}$ & $\begin{array}{l}\text { Presented information has clear } \\
\text { connections across formats or } \\
\text { ideas. }\end{array}$ & $\begin{array}{l}\text { Presentation (or explanation of } \\
\text { presentation) has explicit } \\
\text { conceptual underpinning. }\end{array}$ & $\begin{array}{l}\text { The presentation, methods and } \\
\text { results are critiqued and } \\
\text { evaluated. }\end{array}$ & $\begin{array}{l}\text { Critiqued and developed ideas or } \\
\text { new knowledge is presented. }\end{array}$ \\
\hline $\begin{array}{l}\text { Processing } \\
\text { information }\end{array}$ & $\begin{array}{l}\text { Information is processed or } \\
\text { data/images are manipulated in } \\
\text { isolation. }\end{array}$ & $\begin{array}{l}\text { Connections are made between } \\
\text { or within processed } \\
\text { information/data or images and } \\
\text { relevant concepts. }\end{array}$ & $\begin{array}{l}\text { Processed data or information } \\
\text { has clear conceptual } \\
\text { underpinning. }\end{array}$ & $\begin{array}{l}\text { Process and product are critiqued } \\
\text { and evaluated. }\end{array}$ & $\begin{array}{l}\text { Ideas and new knowledge are } \\
\text { developed. }\end{array}$ \\
\hline $\begin{array}{l}\text { Developing } \\
\text { business cards }\end{array}$ & $\begin{array}{l}\text { Students found images and } \\
\text { information about poster designs } \\
\text { and relevant artists. The } \\
\text { manipulated digital images of } \\
\text { their drawn and painted art } \\
\text { pieces in Photoshop. }\end{array}$ & $\begin{array}{l}\text { A range of websites are accessed } \\
\text { and as a class the findings are } \\
\text { discussed. Findings from the } \\
\text { internet are applied to } \\
\text { developing art work. }\end{array}$ & $\begin{array}{l}\text { Concepts developed in the art } \\
\text { works include; effective design } \\
\text { and artistic techniques. }\end{array}$ & $\begin{array}{l}\text { In narrowing choice down to } \\
\text { three, evaluations were made. } \\
\text { Self, peer and teacher evaluation } \\
\text { during the process of developing } \\
\text { the business cards. }\end{array}$ & $\begin{array}{l}\text { Final product - the business } \\
\text { cards represent a new } \\
\text { interpretation based on } \\
\text { researched artists. }\end{array}$ \\
\hline
\end{tabular}




\begin{tabular}{|c|c|c|c|c|c|}
\hline Level of learning: & Doing & $\begin{array}{l}\text { Thinking about } \\
\text { connections }\end{array}$ & $\begin{array}{c}\text { Thinking about } \\
\text { concepts }\end{array}$ & $\begin{array}{c}\text { Critiquing and } \\
\text { evaluating }\end{array}$ & Creating knowledge \\
\hline $\begin{array}{l}\text { Accessing } \\
\text { information }\end{array}$ & $\begin{array}{l}\text { Accessing: } \\
\text { Pictures } \\
\text { Graphs } \\
\text { Movies/video } \\
\text { Data } \\
\text { Information }\end{array}$ & $\begin{array}{l}\text { Information from more than one } \\
\text { source is connected or compared } \\
\text { in analysis. }\end{array}$ & $\begin{array}{l}\text { Information explicitly develops } \\
\text { conceptual understanding. }\end{array}$ & $\begin{array}{l}\text { Information and sources are } \\
\text { critiqued and evaluated. }\end{array}$ & $\begin{array}{l}\text { New conceptual understanding is } \\
\text { developed. Building on or } \\
\text { linking accessed information. }\end{array}$ \\
\hline $\begin{array}{l}\text { Accessing } \\
\text { information }\end{array}$ & $\begin{array}{l}\text { Accessing: } \\
\text { Pictures } \\
\text { Graphs } \\
\text { Movies/video } \\
\text { Data } \\
\text { Information }\end{array}$ & $\begin{array}{l}\text { Information from more than one } \\
\text { source is connected or compared } \\
\text { in analysis. }\end{array}$ & $\begin{array}{l}\text { Information explicitly develops } \\
\text { conceptual understanding. }\end{array}$ & $\begin{array}{l}\text { Information and sources are } \\
\text { critiqued and evaluated. }\end{array}$ & $\begin{array}{l}\text { New conceptual understanding is } \\
\text { developed. Building on or } \\
\text { linking accessed information. }\end{array}$ \\
\hline $\begin{array}{l}\text { Online } \\
\text { Patterns }\end{array}$ & $\begin{array}{l}\text { Students found patterns online } \\
\text { that they could purchase locally. }\end{array}$ & & & & \\
\hline
\end{tabular}


Dayna found that she needed to teach students how to use various programmes and functions:

The year 9s didn't know how to save stuff to somewhere they can access it in the future. They were saving to my documents which meant they could only access it from the exact same computer next time, so I had to teach them to save it onto their own folder in the student drive. When they opened it in the textiles they were like wow!

She was developing her own knowledge of programmes that may be useful in teaching art, such as edit studio:

I am working on to further my own skills. I can cut movies together and overlay in flash and stuff. I just kind of understand that if we get the resources then I can teach it.

Dayna used student administration programmes. For the first six months she worked out how to use these without being given a laptop; she saved the files she needed to the intranet and borrowed a laptop, used the art room computer (though it did not have Photoshop or the design programmes loaded) or a student computer.

Dayna has aimed to have students creating knowledge through the use of digital technologies. This was evident in a number of the activities that her students engaged in including the making of Matisse bags, developing business cards, and superhero portraits. The potential learning in Dayna's class rates highly on the learning matrix.

\section{Barriers and enablers}

Dayna was able to use digital technologies in a variety of ways due to the accessibility, her knowledge of how to use digital technologies, how to apply digital technology to enhance learning in fashion design and art and the support she received in school and through friends. She faced barriers when trying to access the use of digital technologies and sometimes frustration at not being able to implement what she perceived as logical sound practice using digital technologies.

Dayna had a clear understanding of how current digital technologies could and should be used in art and design. She had experienced using a range of digital technologies at design school during her recent undergraduate degree. Her experience of using digital technologies at design school had influenced her ideas about using digital technologies for teaching and what she expects from her student, 
as she is aware of the types of things they will be expected to do in a tertiary design setting. This knowledge was an enabling factor in her use of digital technologies.

Dayna was confident in her abilities to learn to use a new unfamiliar digital technology. On at least three occasions during her first year of teaching she taught herself a new application that she perceived as useful in a teaching and learning situation. She also learnt about software applications through friends and through formal and informal learning at the school.

Access to hardware and software enabled her to use digital technologies for administration and teaching purposes. However, there were limitations. For the first six months Dayna was not allocated a laptop which made accessing administration programmes and using a data show for PowerPoint presentations difficult, though with perseverance Dayna found a way to gain access:

Researcher: Do you have a laptop?

Dayna: No. it is the bane of my existence. I use the HOD's that is set up in here, or I use the computer in the art room there, but it doesn't have Photoshop or the design programmes, but it has the basics. Or else I am fighting with the students to get on the computers, depending what day of the week it is. I can save my work to my file on the intranet, it is all linked up.

Teaching in two departments during the second half of the year meant that Dayna had two different classrooms she used. One classroom had the internet connection and cabling all set up on the teacher's desk, which made it easy to set up her laptop in class. The other classroom had three power points in the room which did not work, making it impossible to use her laptop as it did not have a battery. However, there was access to a data projector close to this classroom:

There is one in the room by the art room. If I want to present anything it goes up in here, it is a matter of moving them from the classroom. They get excited and ask where the popcorn is as it is like a movie theatre.

Dayna found that she needed to consider each class's unique combination of individual students and the resulting learning environment when deciding how and whether to use digital technologies. Some classes she could set up with their learning activities then leave the class, returning later to find the students still focussed on learning. Other classes she would return to find mayhem. She found it depended on the individuals in the class and the combinations of students. This was a limiting or enabling factor in how she used digital technologies. Some art classes could have 
learning activities which included individuals or groups using the pod of five computers near to the art room with minimal supervision. Other classes could only use computers if all the students were taken to the computer suite or the task was set as a homework task with the assumption that all students could and would access the internet beyond class time (which was found by Dayna to be a realistic expectation at this school). Dayna would have liked at least three computers in the classroom to allow supervised internet access within such a class.

To have all students carry out research simultaneously requires the use of one of the school's four computer suites. These are in demand, requiring a booking weeks in advance. Dayna sacrificed the flexibility of beginning research when the students were ready to ensure she did have access at approximately the right time.

There were obstacles that Dayna was not able to overcome. One such obstacle was the rules of assessments for qualifications.

NZQA doesn't accept (digital submissions) for their final submission yet. Some kids do animations that must be turned into 2D images onto a board. It takes them ages then they have to flatten them for their final assessment. It is crazy.

The factors that Dayna identified as impeding or encouraging the use of digital technologies included access, her experiences, the support she had and the learning environment. An important enabling factor appeared to be her beliefs about teaching, learning and confidence in the use of digital technologies.

\section{Support network}

At the start of her teaching career Dayna saw her friends as an important source of support and inspiration - both those whom she met on a regular basis and those with whom she was in contact through digital technologies:

I have lots of friends who are travelling all over the world and looking at amazing stuff at the moment. They are on things like Bebo. And I have just joined Facebook which I am still learning how to use you know so that I can see what my friends are doing. I got sent a whole lot of pictures of artwork, photographs of amazing architecture from Greece. I have some coming in from all over the world as far as resources are concerned, just ideas.

Friends as a source of direct support diminished over the year as they moved away, keeping in touch via digital technologies: 
I keep in contact but it is not the same as having a cup of coffee, having your drawing books out and sharing 'what's this?

Dayna appeared to be well supported within the school she was teaching in. This support was through formal support structures set up by the school and through informal networks as illustrated in Figure 22.

The formal support networks included PRT support, (see context), which includes meetings twice a term and the hierarchical department structure meant that the heads of the art and the fashion design department had an official support role. However, this support operated in different ways. Dayna had a scheduled meeting time with the HOD technology:

I officially meet with Diana every Tuesday afternoon for an hour to touch base. I wanted it to be formal as it is a new subject that I am teaching so I wanted to make sure that I check what I have coming up the next week and what I did the last week to stay on top of it and any concerns.

This is in contrast to the support structure in art, where the HOD is considered her main mentor and support:

I don't officially meet with HOD art, but we have lunch together most days and we talk out issues. It is more fluid. We will often be like, well, what do you think of this student's work and have you seen this technology. Sometimes we have a 'no work today let's just eat cookies and drink coffee'. We work right through lunchtime. (Dayna)

The use of digital technology is not the key focus of this support, but it is encouraged through the support networks.

She had experienced support from the school's senior management team when a parent wrote to question her subject knowledge in fashion design. This was dealt with in such a way that her confidence in teaching the subject was boosted.

The support network includes unofficial support, such as a professional friendship with another teacher who graduated a year before Dayna:

I have developed a good relationship with Deidre who has come from the same background, but working in a different dept, so she has come up and observed some of my lessons and I have watched some of hers. She has helped me deal with some behavioural issues. The resources in her room are different to what are in my room so we kind of poach stuff.

She also experiences support from other teachers within the departments she teaches. 


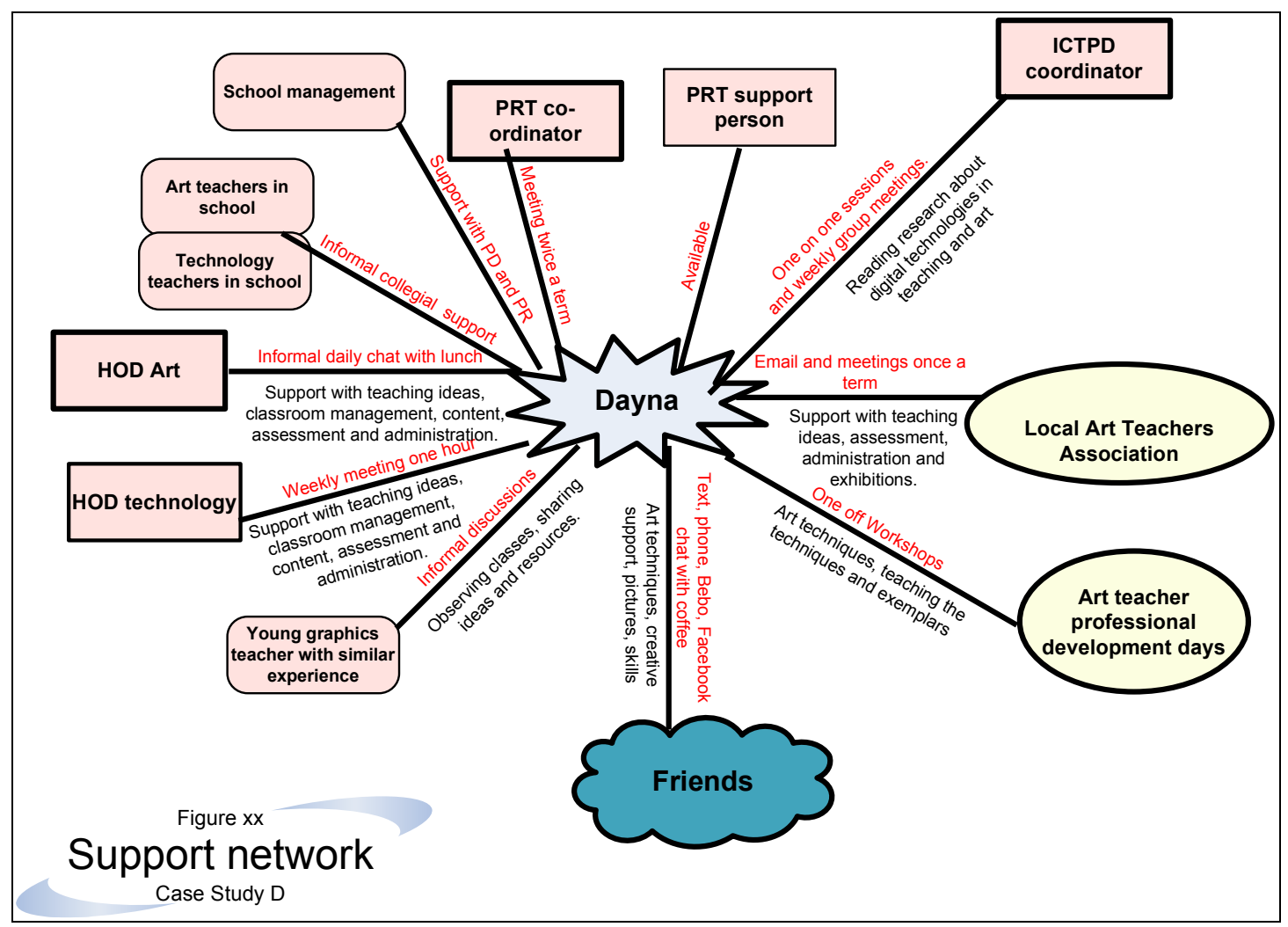

Figure 22: Support network, case study D

Dayna was in the digital technologies development group that was exploring how it could be used in the future. It was run by the person responsible for staff ICT professional development in the school:

Every Tuesday morning we have alternating one hour tutorial on digital technologies followed by reflection on how we have been putting it into place, we do readings and different things. My biggest thing is it must be different to how we do it with paper.... The group started with a whole computer room of us, but out of frustration there is about 10 of us now. When it is new and you are the guinea pig people get a bit frustrated.

As part of the group Dayna has been exploring how digital technologies are or can be used to teach visual arts.

I have learnt lots of stuff and do lots of research on how digital technologies are being used in other art rooms. There is this guy who uses a big drawing block connected to an imac, A3 size and they are like painting straight on to the computer. The guy who has this only has one so it is like one form of media and you can use Photoshop separately, but this is like a whole different type of media.

Dayna has also accessed support beyond the school through attending professional development days for art teachers and the local art teachers' association meetings which are held twice a term: 
[the local art teachers'] meetings have been amazing, a group of teachers you can talk to, they meet twice a term and we are in email contact. The teachers are putting together an exhibition at the end of the year. ...At the meetings we sometimes have conversations about using digital technologies. Last month's meeting we had suggestions about storage of materials - how to back up etc.

By attending workshops Dayna is keeping up to date with content pedagogical knowledge which includes developments in the use of digital technologies in art and design:

Last Friday I went to my first art teacher's workshop - the had a drawing workshop. It included drawing techniques. They gave us a drawing journal set up with student examples, the approach she takes and we went through new methods - she used solar printing. I wish our school could afford to try that. We came out with a workbook with examples to bring back to our students. We persuaded the department to buy some new resources.

Dayna has found that to use digital technologies effectively she sometimes has to ask various people within the school to provide support in the form of hardware, software or support to fix things. She has had mixed results.

It is all about how you put things forward - like data projectors now we have one and it is going to be permanently attached. I am really lucky with my HODs. Art HOD is not very technologically advanced. I am teaching her how to do stuff on a daily basis. She is open to suggestions especially if I can suggest how it is going to make her life easier and the students work better. If I can justify those things she is like umm yes, maybe.

She has been less successful in getting the fuse replaced in her classroom so that the power points work, or the battery fixed or replaced in her laptop, she has been waiting for six months for these. She did, however, successfully ask for a laptop in December when her contract was renewed, pointing out that she was going to Auckland over the school holidays and needed a laptop to plan for the following year.

Dayna identifies herself as innovative and has been willing to initiate changes using digital technologies. She has taken on a default leadership role in the implementation of digital technologies in the art department. This is occurring as she develops ways to use digital technologies through the support given to her by her colleagues, her own prior experiences and through being part of the ICT professional development group. The developments include department administration:

I have redesigned all our layouts and everything like for our folio boards, how we put those together and getting students to take the digital photographs then we manipulate them on the computer then we fling them over to me via email then I 
am laying them all out in Photoshop and things. I don't mind reinventing the wheel a little bit and getting the students doing it rather than the teacher doing it. I did all my colleagues' layouts on the computer as well. That was awesome. I have got all the students in training so that I don't have to do it next year.

The leadership role is also through developing and sharing digital based resources:

If I have an idea about how I can do it with the bare minimum of resources, then I already have the support. My HOD and associate is like "yeah, yeah, try it. Yours is great, I will do it like you too." It has been really cool, like I did a big board up of Kelsy Taratoa's images and stuff that I found on the net and printed them off. I see her trucking into her classroom with my board under her arm to show her kids. You know...that's cool.

\section{Summary}

Dayna brought beliefs and experiences to her teaching that she applied as she attempted to use digital technologies in her teaching practice. Figure 23 summarises her experience during her first year of teaching.

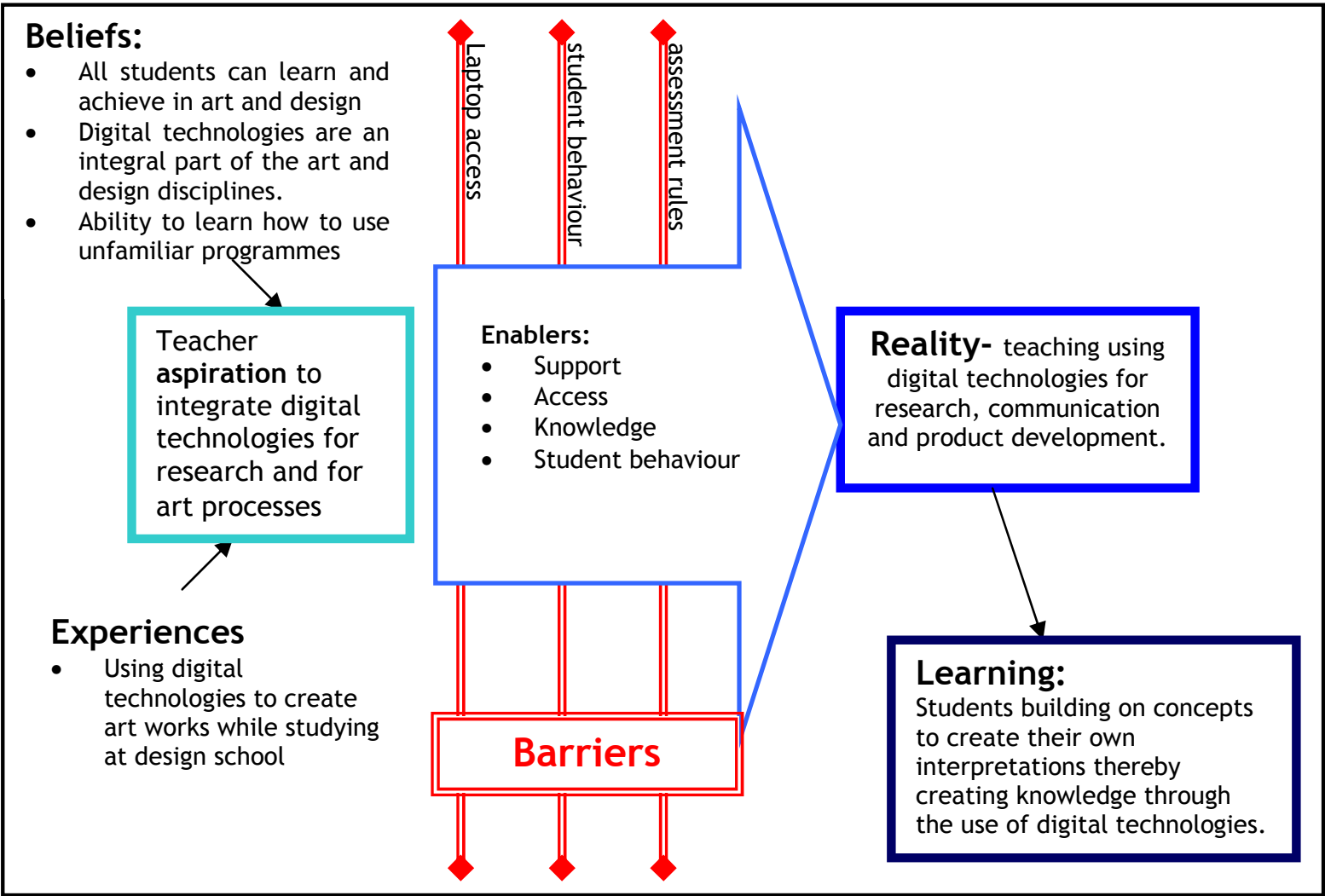

Figure 23: Case study D logic model

Dayna is using a range of digital technologies in the classes she teaches, drawing on her experiences from design school and her confidence in learning unfamiliar programmes and hardware. She has a strong network which she draws on for support 
in her teaching and has found ways to overcome most of the barriers she has faced as she has tried to use digital technologies. Her students are being taught how to create knowledge by building on concepts through the use of digital technologies.

\section{Assertions from case study D:}

D1. Beginning teachers can contribute to school or department development when given a role in implementing the use of digital technologies in the departments in which they teach. This includes the use of digital technologies for administrative purposes such as student management systems and student work storage and for teaching and learning purposes.

D2. Few barriers, strong support, strong pedagogical content knowledge and experience of using digital technologies in a subject discipline contribute to the successful use of digital technologies in knowledge creation.

D3. Classroom learning environment is an important factor in the successful implementation of the use of digital technologies.

Case study E

You have to learn and incorporate digital technologies in teaching for today's society; you have to be up with it. It enhances your teaching for sure instead of standing up the front and teaching or having the students watching a video. (Erina, 2008)

\section{The teacher}

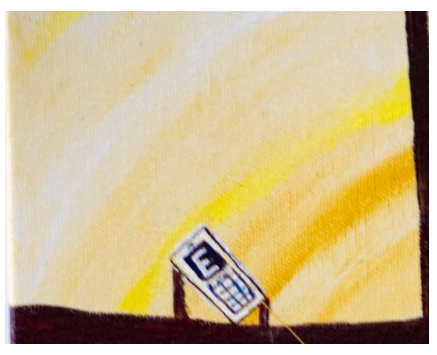

Erina began teaching at age 23 , confident in her ability to use a range of digital technologies or learn how to use unfamiliar technologies. She had learnt how to use programmes such as Word and Excel while at school. After school she gained a Bachelor of Physical Education, learning how to use a range of digital technologies within the context of physical education such as heart rate monitors, PowerPoint, and filming. She began teaching after completing the one-year diploma in secondary teaching. The diploma included a paper that looked at how teachers might use digital technologies:

Taking the technologies paper at uni - I never knew what a blog or a wiki was, how to create websites. I never knew all that stuff that the kids are into now. I was stuck on using Word and Excel and Clipart. I haven't used these in teaching yet, it has given me the understanding of what they are talking about, it is there if I want to use it. 
In Erina's first year of teaching she held two different positions, each of them on short-term contracts. The first teaching position was for one term (10 weeks) to fill in for a geography teacher who took sabbatical leave. The second position was for a year, teaching physical education in a school where she had previously had teaching experience. The job was not advertised; she had phoned to see if there were any vacancies and the teacher who was her former associate teacher organised a job for her.

Erina believed that:

You have to learn and incorporate digital technologies in teaching for today's society, you have to be up with it. It enhances your teaching for sure instead of standing up the front and teaching or having the students watching a video.

Where Erina was confident in the curriculum, she took a student-centred approach to teaching:

I like to see what they know. If they know stuff, I like them sharing what they know. That is pretty much how all of my classes operate - based around what they know already then adding to it. These kids are quite bright - they know what they are going on about. I obviously do a lot of my own talking.

Where she was less confident she took a more teacher-centred approach:

History is a bit different as I have never taught it before and never studied it. I like to kind of teach myself then teach them.

\section{The contexts}

The two schools Erina taught in provide contrasting contexts. The first school was based in a town an hour away from the nearest city. The school was a co-educational school with about 50 teachers and 600 students. The school had a socio-economic decile rating of 4. She was employed to teach geography and social studies while the regular class teacher took a sabbatical. The classroom she was allocated was the biggest in the school and had a computer, data projector, DVD, video, and a link to the library with 10 computers. The school also had three computer classrooms, one available for booking and two timetabled for specialist classes. There was limited formal PRT support organised in the school - there were two PRT meetings in 6 months, one of which was combined with another school. There were three PRTs in the school and the other two were completing their second year of teaching. The HOD of social sciences observed one of her lessons. She was the only geography teacher in the school. 
The second school Erina taught in was twice the size, a city-based girls' school with about 85 teachers and 1200 students. The school had a socio-economic decile rating of 10. In this school she was teaching physical education and health, and a year 10 history option. While physical education and health were Erina's areas of expertise, history was a new subject for her. There was a team of physical education teachers who shared an office. The teaching units were prepared and available for Erina to use and adapt. PRT professional support and development appeared to be well organised. There were three first year PRTs in the school. Each week they would meet with the PRT coordinator and focus on different topics:

We have parent teacher interviews this week, so last week it was on parent teacher interviews. We had a session with the guidance counsellor, and one with the NCEA liaison teacher, one with the specialist classroom teacher - they just vary each week. It is pretty good, well organised. We have these folders and the coordinator makes sure we are getting observed.

The school had four computer labs containing 30, 23, 19 and 17 computers, an art pod with 11 computers and another pod of 5 computers available for booking. There was technical help from the computer people; one was a teacher and the other one was part time. The teacher was available to help at anytime. A group of students with programme expertise were available to teach and help teachers and students during one lunchtime a week. The department had digital cameras and every classroom had a data projector. The teacher was given a laptop when she started teaching there at no cost to her. There were interactive whiteboards in the school and the physical education department had video cameras that Erina could access.

\section{Digital technology use}

At the first school Erina used the technology that was available in the class to show students videos, DVDs and PowerPoints. She had the students carry out research projects using information from the internet. Her year 13 Geography class used the computers to complete a major research project on tourism development over four weeks, including gathering digital photographs. While the data collection involved digital technologies, the final presentation was paper based.

The use of digital technologies at this school was enabled by the easy access to the technology in her classroom and the computers in the library adjoining the classroom. Without this easy access it is unlikely that Erina would have used digital technologies on a daily basis as she did. 
At the second school the units of work for physical education and health were prepared and available for Erina to use. She used digital technologies as suggested in these prepared units, adapting them to suit her own students' unique learning needs. She said that in the future she was likely to adapt them further. The year 10 health class researched a sports injury. They spent two lessons researching an injury that occurs in a sport of their choice, using internet sources to find the cause, treatment and prevention, and presenting the information to the class in a PowerPoint.

Students send in assignments via email into an assignment box:

I have just done PowerPoint presentations with my physical education class - they presented them in class and also sent them to me rather than printing them off and handing them in.

Presentation software appeared to form the basis of her lesson planning:

I use Word all the time in my teaching. All my lesson plans are done in Word. I use PowerPoint in history heaps. I don't write on the whiteboard, all my notes are in PowerPoint... My history room has a projector all set up so it is easy for me to bang it on and the kids either write notes or fill in the gaps, depending on how many notes it is.

The year 10 history class carried out a research unit on the Romans. Students worked in small groups examining topics like education, the Colosseum and religion. It involved the students going on the internet to access information, writing short study notes in a Word document and emailing this to the rest of the class.

Erina integrated a range of technologies into her history class including PowerPoint, DVDs, internet research and web quests, though it is not all digital technology: "We also have an old slide projector; we tell the kids it is part of history."

Erina made use of the girls' attachment to their cell phones by getting them to use them for organisational tasks like reminders for homework, to go to the computer room the following lesson or sending a message to the sports teams she coaches about where and when to meet.

Erina believed that the use of digital technologies aligned with her aim to have students actively engaged in learning:

I would rather they do web quests. The advantage of a web quest is that it is more student based learning, they have to find it themselves rather than just sitting there. They don't have $100 \%$ concentration when watching a video, especially an old history documentary. 
The digital age learning matrix was applied to the learning activities that Erina had described and was collated in Table 12. Erina used digital technologies to help students make connections in their thinking about key concepts.

\section{Barriers and enablers}

At the first school Erina taught in she used digital technologies largely because she could - they were accessible and she had the necessary skills and experience. The hardware and software were set up and available in her classroom or nearby and she had been using a range of software since studying computing at high school. Her familiarity with presentation software (like Word and PowerPoint) made it easy for her to use it to organise her teaching and guide students through lessons.

The second school she taught in was quite a different experience. Erina was teaching physical education, health and history. The classes she taught outside of the gym were located in different rooms around the school which meant that time was a constraint - getting to the right classroom then setting up a digital application could be a daunting task, especially as the school operated 50 or 45 minute periods, though all classes did have data shows so it was possible. The students at the second school were familiar with a range of programmes which meant that Erina did not have to incorporate basic technical skills in her teaching programme, allowing for greater focus on the learning of her subject.

The way that the department organised their teaching programmes was to have all the units of work prepared and available for the teachers. This meant that lessons using digital technologies were not developed by Erina, and any physical education teacher in the school would be carrying out a similar activity. This contrasted with the history department where Erina was encouraged to develop her own way to teach topics. 
Table 12: Digital age learning matrix applied to case study E

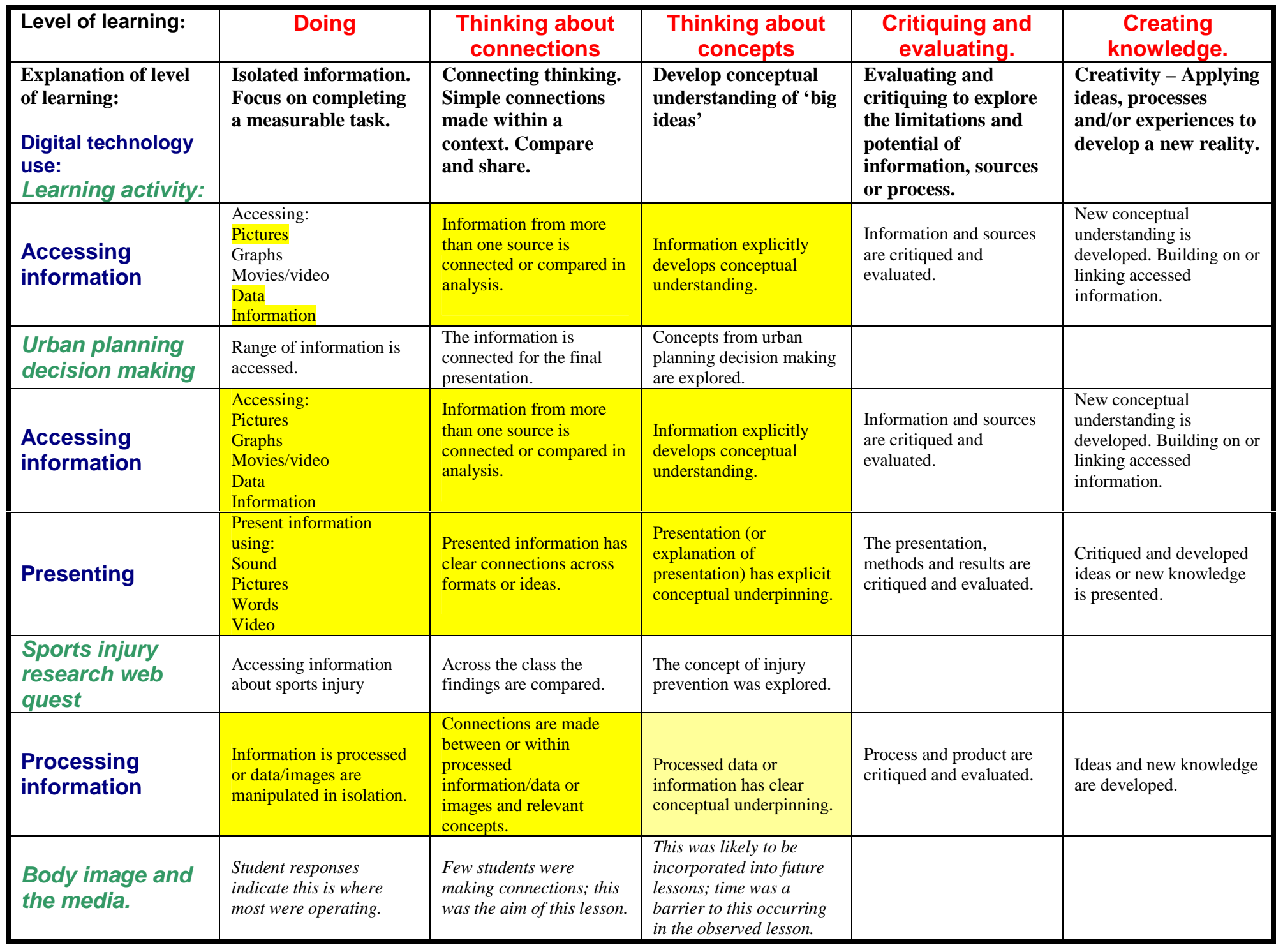




\section{Specific example - body image}

Erina was teaching her year 10 health class about body image. This class met once a week and had missed a number of classes due to holidays and teacher only days so timetabling was a constraint.

The unit was prepared by the physical education department and Erina had adapted it to take account of the unique needs of her class. The class consisted of 30 students in three notable groups that Erina labelled -'high achievers, academic physical education haters, and the non academics'. She had been trying to get the students to mix more, to get to know girls who were not part of their group as she believed this would create a better learning environment in physical education. The learning activities were carefully examined before beginning to consider the needs of a student in the class who was battling anorexia.

In previous lessons the students had considered their own body image, the importance of self esteem and how body images are represented in media. The teacher had taken each student's photo using a digital camera and had sent the photo to the student's school email address. She found that this did not work for a number of students.

The students were paired with one of each pair having received a photo. Erina carefully selected the pairs to help broaden the class's knowledge of each other. The pairs quickly got onto the task, though the pairings for this brief lesson did not always enhance the learning experience: “Another barrier was that the class didn't know each other that well so some pairs didn't engage as well as they could have."

The lesson that was observed involved the students using Photoshop to adjust their images as they would like them to be changed if they were to appear on the cover of a magazine. This could include changing hair colour, removing any blemishes, altering body shape etc. The learning intention of the lesson was that: "the students learn how their self esteem can be enhanced through the perception of themselves through images."

To prepare for this lesson Erina had to book a computer room, organise the images to be sent to students and learn how to use Photoshop herself. Gaining access to a computer room could be problematic. She needed to book the computer room five weeks in advance. Erina had felt that this activity may have been better the following 
lesson as some aspects in previous lessons had to be rushed, but the room was booked and not available later so the lesson and learning had to be adapted to fit the booking constraints. To personally learn how to use Photoshop, Erina looked at the programme in the morning of the lesson in the physical education teachers' work area and her colleagues helped to familiarise her with the programme. The students were familiar with Photoshop having been introduced to it in the year 9 ICT skills programme.

The time available for this learning activity was shortened that day to 45 minutes, instead of the usual 50 minutes due to timetabling. The lesson began with routines and briefing in a classroom, then the class moved into a computer room. They had about 30 minutes on the computers working on this activity; they could have easily spent twice as long.

Erina overcame a number of barriers in using digital technologies this lesson - these are summarised in Table 13.

\section{The learning}

The researcher spoke to students who had brought in permission slips from home to participate in the research and who themselves agreed to take part. The way that the students approached the learning varied, most used one or more of the following methods.

Table 13: Barriers and solutions during one teaching example

\begin{tabular}{|l|l|}
\hline Barrier & How it was overcome \\
\hline Unknown programme & $\begin{array}{l}\text { Familiarised herself with the programme } \\
\text { in the morning using collegial expertise. }\end{array}$ \\
\hline Access to computer room. & Booked a room weeks in advance \\
\hline Unable to email photos & $\begin{array}{l}\text { Students worked in pairs where one of } \\
\text { the pair had successfully received a } \\
\text { photo }\end{array}$ \\
\hline $\begin{array}{l}\text { Establishing an effective learning } \\
\text { environment }\end{array}$ & $\begin{array}{l}\text { Carefully selecting the pairs that will } \\
\text { work together to broaden student } \\
\text { familiarity with their peers }\end{array}$ \\
\hline Timetabling & $\begin{array}{l}\text { Building clear reminders and links to } \\
\text { previous lessons into lessons. }\end{array}$ \\
\hline
\end{tabular}


One approach was trial and error. A student using this method talked through what she was doing as she was adjusting her image. She clicked on the redeye symbol and got rid of the red eyes:

Researcher: Have you done this before?

Student: No, I just saw the picture of the eye.

The student then clicked through other options for the eye.

Student: Umm, green, I would like green eyes.

A variation on trial and error was: trial, error then ask a neighbour. An example of this was observed when a student was using the liquefy function to change her hair to a bouffant style, then tries to add streaks into the hair, unable to find out how to do this she asks the next group: "How do you do the hair thing?" they show her and she tries it out successfully.

Another approach involved reading instructions which were handed out:

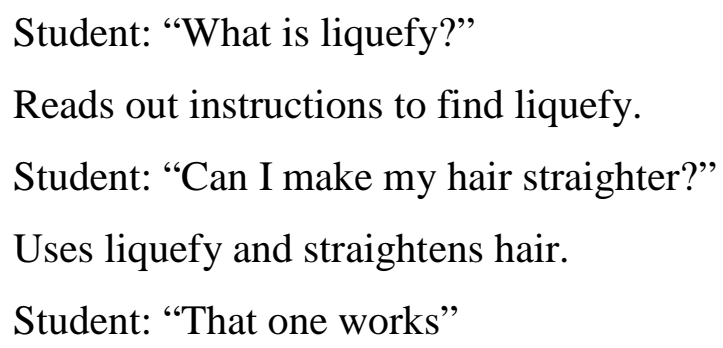

The activity itself was designed so that students used digital technologies to develop their understanding of the concept of media manipulation of images. The majority of students should have been able to connect thinking, making connections between the photos they were processing and the concept of media manipulation of images. During the lesson the students were asked what they were learning, a question that most found difficult to answer, with some students responding in terms of the skills in Photoshop they had learnt inferring the learning was isolated in that the students were finding it difficult to link what they were doing to the concepts. One student did manage to articulate in terms of conceptual understanding:

I have learnt how to use the spot thing, and how people use Photoshop to manipulate images and that it is bad to aspire to be like someone in a magazine because they have been Photoshopped, so it is impossible to look like that unless you do the same. 
The learning activity was focussed on the students altering an image - this was a “doing" type activity with the purpose of developing understanding about concepts in consequent lessons (refer Table 12).

When reflecting on the lesson, Erina thought the lesson could have been better. She noted that:

The learning in the lesson had the potential for students to create new knowledge, most were making links to concepts, some weren't. ... I think they enjoyed it, they were all on task and doing it so that showed that they were interested which is good. There were some interesting pictures that came out of it. I anticipated that they would develop pictures that looked like their ideal body image. There were some that came out totally crazy, but it was interesting to see how they wanted to see their body, some did take the Mickey and add things like big ears but a lot of them were doing what they wanted, like straight hair and no spots, changing eye colours, getting rid of frizz in their hair. That is the whole self image thing we are doing. They probably didn't learn what I intended them to learn. But I think that they did learn that the media changes images that they show, the media portrays people as ideal images, but everyone is not perfect.

The learning intention may have been realised the following lesson as they reviewed the lesson and looked at the concepts. Erina felt that the greatest barrier to achieving the links to concepts during the lesson was time:

I hate the time here, we only have 50 min lessons and on a Tuesday they are only 45 mins and moving into a computer lab is a pain and moving between classrooms doesn't help. I only see them once a week and these kids don't remember what they were doing yesterday let alone the week before.

This learning activity had the potential for students to critique and evaluate. In the observed lesson the students appeared to focus on the task at hand with few being able to talk about what they were learning beyond the Photoshop applications being used. This may have been different with more time or if the students were asked after the following lesson. The constraints caused by teaching the class once a week, having to book a room so far in advance and having 45 minutes to complete everything made it difficult for Erina to give the students time to really think about links across lessons and the concepts underpinning the activity. The success of this activity was because the students were familiar with the programme being used, the teacher was confident in her ability to use Photoshop (due to her familiarity with a range of programmes and a quick lesson that morning), the activity being part of a unit that had been taught many times and the lack of any technical hitches. The difficulty experienced in emailing photos to students turned out to be an opportunity to further nurture the learning environment as the students had to work in carefully selected pairs. 


\section{Summary of body image learning activity}

This lesson is an example of the complex forces that a beginning teacher faces as she or he attempts to use digital technologies with their classes. The process is illustrated in Figure 21.

\section{Support network}

Support as a beginning teacher and to use digital technologies was notably different at the two schools that Erina taught in. The first school had a comparatively smaller and older staff with limited support given to her as a PRT. She was teaching a subject that was not her specialist area and she was the only geography teacher in the school. The support she received while teaching at this school is outlined in Figure 24.

Erina accessed pedagogical content support from the teacher she was replacing:

the guy who I took over from was really helpful, he was willing to help me so I would email him a bit. When I had to mark two year 13 achievement standards I would check with him. He was so appreciative of me coming in two days before the end of the term.

\section{Beliefs:}

- Digital technologies are an important part of society

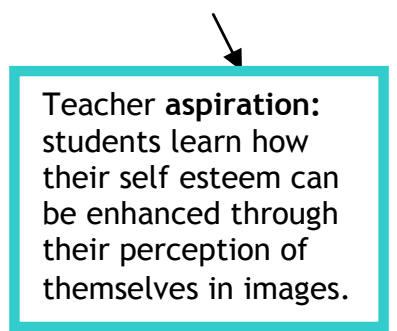

\section{Experiences}

- Quick introduction to Photoshop.

- Familiar with using a range of programes.

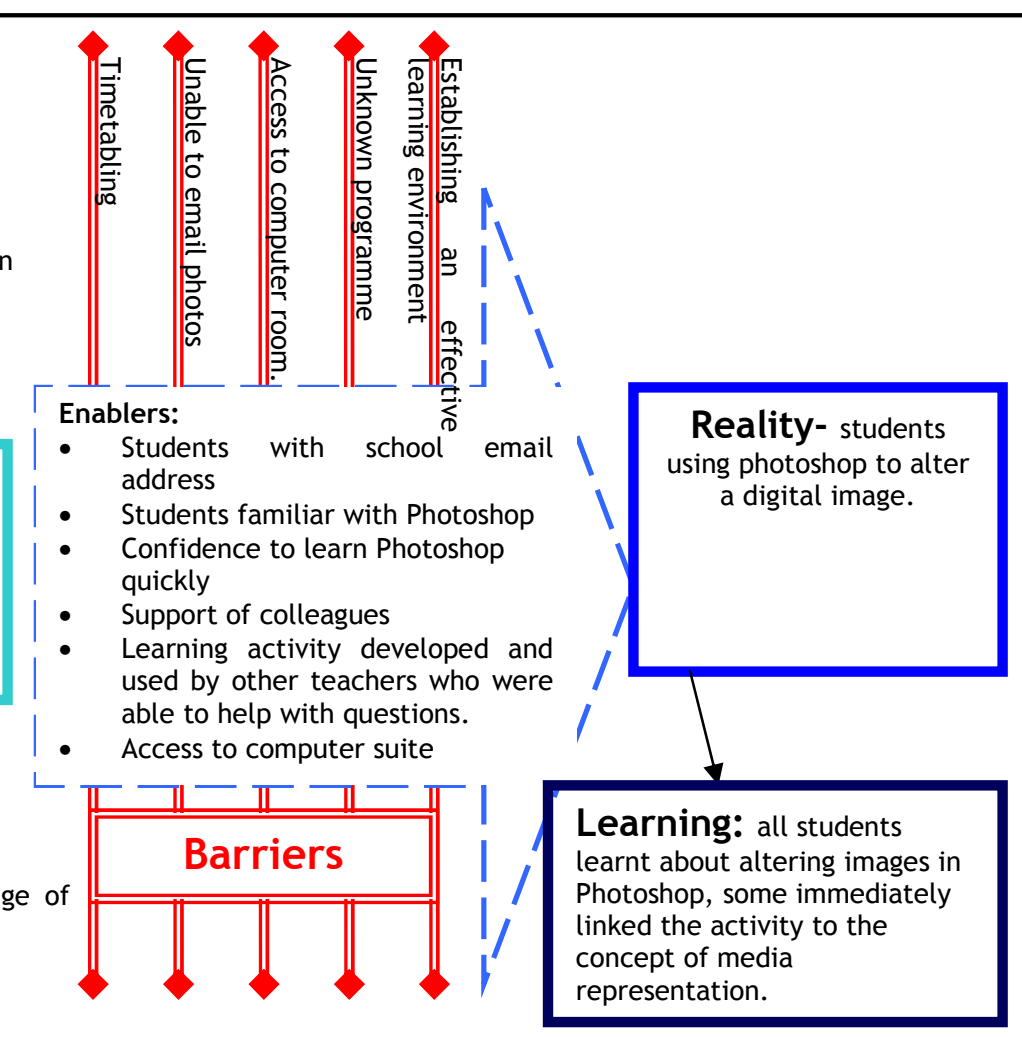

Figure 24: Body image learning activity logic model 
For further support Erina contacted a lecturer of geography teaching at the university where she had completed her diploma in secondary teaching: "I did get in touch with Evan at University and he was a great help with achievement standards."

Erina felt isolated in the staff room as she felt she was young:

The next youngest was 28 and she was leaving at the end of the year. I found I could have a conversation easier with the year $13 \mathrm{~s}$ (which I found a bit weird) but while I was there, a student teacher was there for 5 weeks and also a guy from Canada who was out for 14 weeks on placement, so I was lucky.

She found the young teacher mentioned above a source of support:

The person I did go to for support was another young teacher, she had nothing to do with geography. She was approachable. I found it hard being a young teacher and it isn't an everyday occurrence that they have a young teacher.

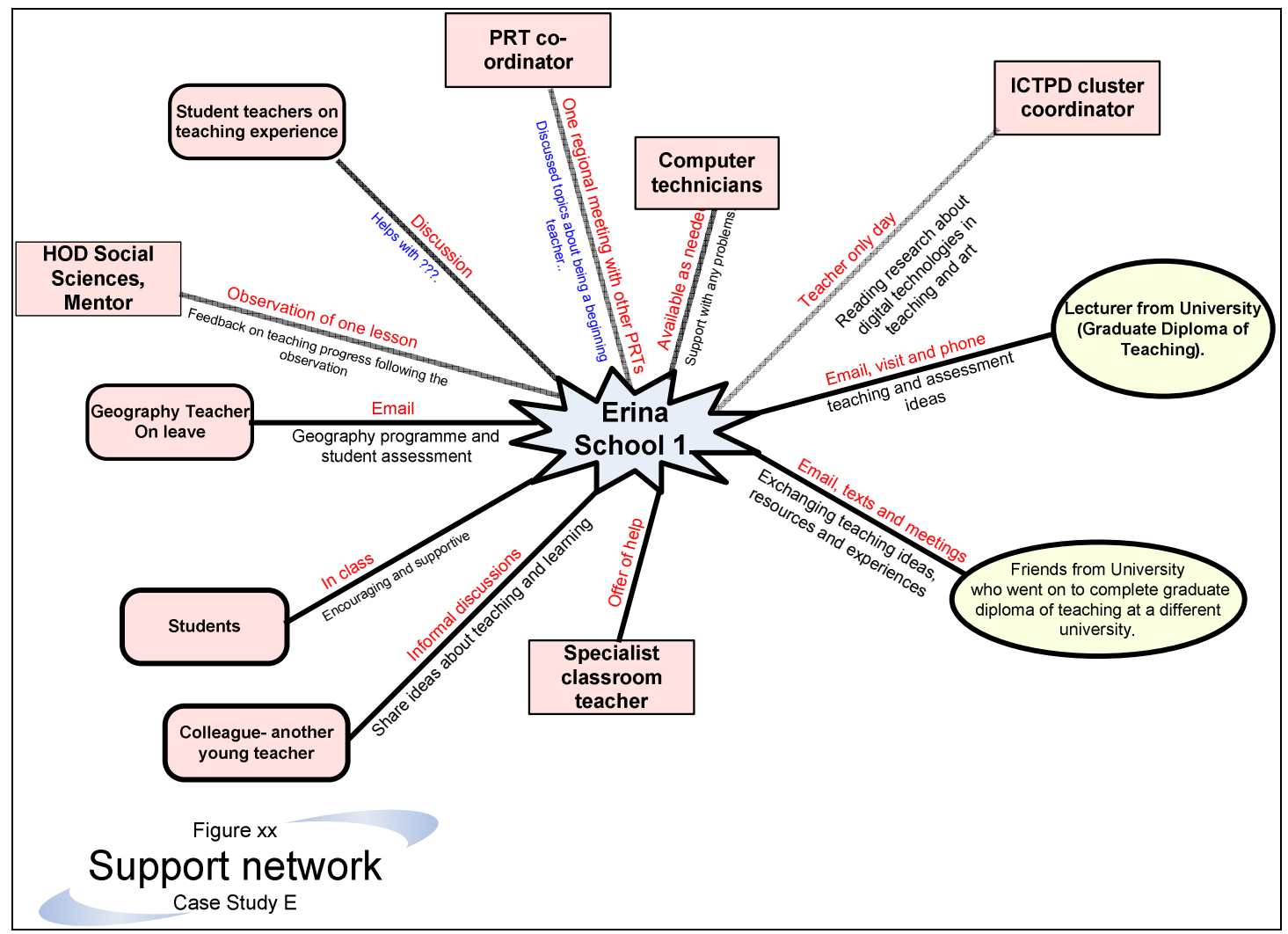

Figure 25: Support network case study E, first school

An important source of support was the students:

Most of the support came from the kids. They knew I had never taught geography. They were cool about it. They were awesome. If they asked me something and I didn't know the answer I would like say its ok I can find out tonight. I tended to get along better with the kids than the teachers. The year $12 \mathrm{~s}$ and $13 \mathrm{~s}$ were really appreciative as they thought they weren't going to have a teacher for the term. (Erina) 
Erina did not find the opportunity to collaborate with other teachers and share digital resources:

Everything I made there I just kept to myself because it was easier to do that. I don't think anyone else would understand or use anything I put up.

The support she received as a beginning teacher included a regional meeting with other PRTs, and the HOD Social Sciences observing one lesson. She reported that she did not sit down with her HOD to discuss teaching and the HOD did not show interest in using digital technologies.

Erina was more innovative in her use of digital technologies at the first school, this was probably as a result of the circumstances:

I was more innovative in teaching geography as I was making an effort to make it interesting for the kids. I was learning it as I was teaching as I was making a lot more resources out there than here, maybe because they weren't already there.

For specialist help with digital technologies, Erina had access to an IT support person in the school and there was a regional cluster group IT specialist who ran a professional development session for teachers at one of the regional schools and was available to help with one on one sessions.

I went to a teacher only day at (another) College. I sat next to a teacher who must have been about 40 . She had no idea about computers so the day would have been awesome for her; she made a PowerPoint.

At the second school circumstances were quite different. Her support network for the second school is mapped in Figure 26. The PRT supervisor was one of the school's assistant principals. She supported Erina in a formal way through weekly PRT meetings and observing her teaching to give her individual feedback. Another of the assistant principals coordinated hockey and Erina was coaching a hockey team so she felt that she could ask for support at any time. 


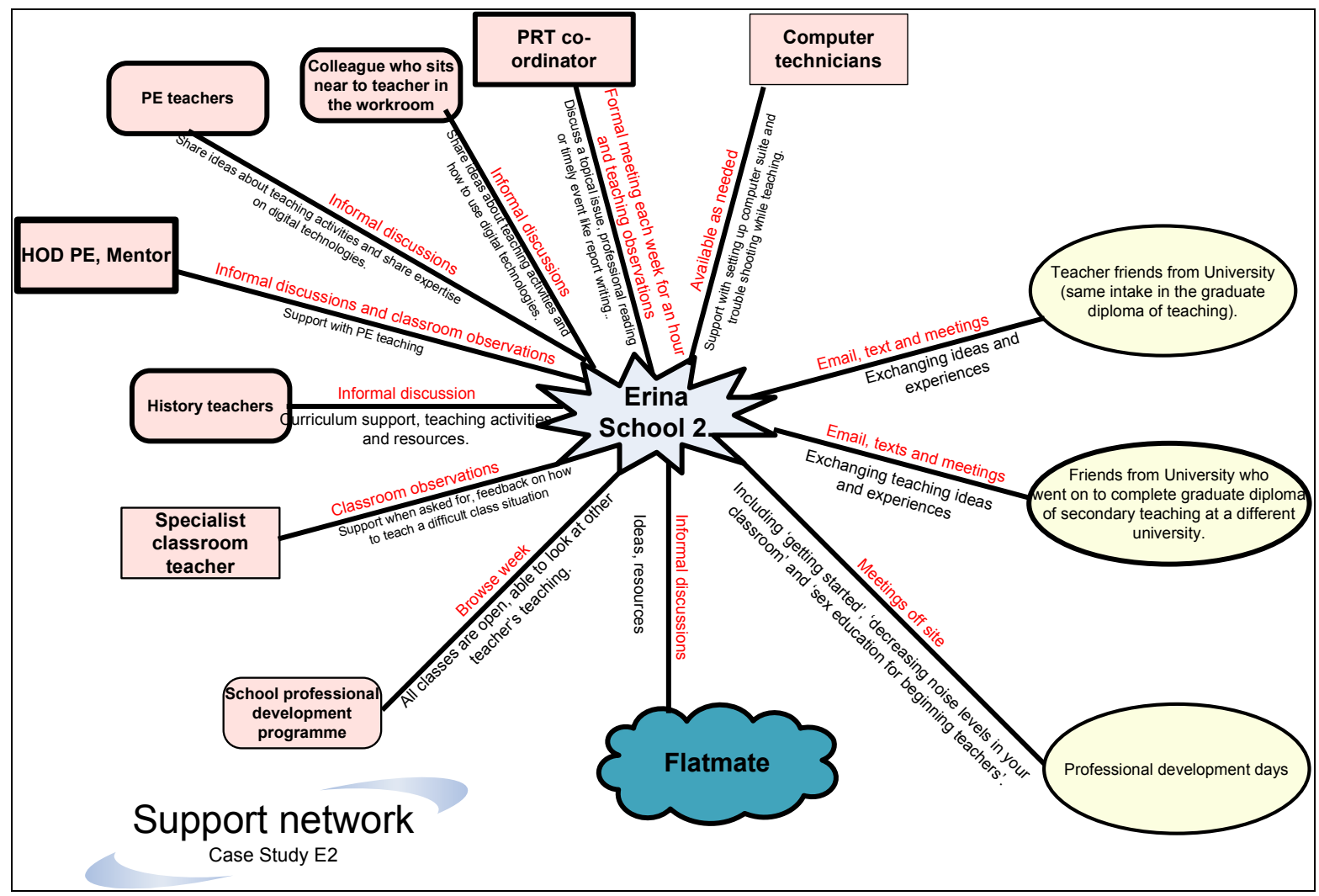

Figure 26: Support network case study E second school

The school had general professional development available for teachers which Erina found useful:

We have a browse week which is an open door policy, where you can go round a look into anybody else's classroom, including going to see how your class is taught by another teacher.

The HOD of physical education was Erina's designated mentor and sat next to her in the physical education teachers' workroom:

We don't have formal meetings, pretty much everyday she will say how are your lessons going? It is all good so there is no point in sitting down and saying is this $\mathrm{OK}$, is this $\mathrm{OK}$ ?

The HOD carried out formal classroom observations of Erina's teaching.

Erina accessed support from a range of staff members at this school. The specialist classroom teacher made himself available as support for beginning teachers, and in this case she did engage his help:

I had the specialist classroom teacher come into one of my physical education lessons just because I had quite an academic class and not a lot of them were into physical education so I was finding it quite hard to motivate them, but they are OK now. 
The person in charge of junior history worked closely with Erina as she was unfamiliar with the programme. The other history teachers also offer support: "They are always saying how is the history going?" Colleagues from the physical education department were mutually supportive, sharing their digital expertise: "Emma is really onto it with KAMAR. Everyone just helps each other. Everyone else had used Photoshop before so they helped me with that."

Being part of a large department resulted in ongoing pedagogical content support. For example, the school was introducing interactive whiteboards, rather than everyone going to the same training - a couple of the physical education teachers went then taught the rest of the department. This meant that Erina and the other young teachers in the department were not seen as the digital experts.

The department was a key support for Erina; she said that she felt it enhanced her teaching:

The support enhances my teaching. When I go to do something and it isn't how I would like to do it I change it, I make resources and put it on the shared drive so that anyone can use it.

One of the physical education teachers worked closely with Erina:

Emma is new this year and so we talk about it all the time - we tend to be teaching about the same lesson and we might be saying this doesn't work so this is what I did or will do next time. (Erina)

Erina had taken part in three professional development days including 'getting started', 'decreasing noise level in your classroom' and 'sex education for beginning teachers'. No digital technologies were included in these. She also attended a teacher only day at a sister school which involved examining key competencies and implementing a new curriculum.

Erina was able to bounce ideas off some of her friends who were teaching in other schools. She was in contact with two friends that she made at university while studying towards a bachelor in physical education. Her friends live in different locations, so contact is made through email and text messages or during holidays. These two friends did their teaching preparation at a different university and had different resources and ideas. Her flatmate was a sportsperson working at getting children active, and shared ideas and games. 


\section{Summary}

Teaching at two contrasting schools gave Erina different experiences in the use of digital technologies. The experiences Erina had over the year are summarised in Figure 27. At the first school Erina was teaching outside her area of expertise and given limited support as a beginning teacher, but offers of help were there if she chose to access them. She did use digital technologies regularly because they were available in her classroom and she had the experience, encouragement and knowledge of how to use them:

I think that coming from Tcoll [teachers' college] helped me to use digital technologies where it was very much encouraged.

Her main sources of support were through her students, a young teacher, the geography teacher she was replacing, and a lecturer at university.

The second school Erina taught at gave strong support for beginning teachers and department support. Erina was teaching mainly within her area of expertise, physical education and health, moving between classrooms which had digital technologies available within them. She was teaching department prepared units of work which had digital technologies integrated into learning activities which enabled her to use digital technologies, but also limited her need to be innovative. She was teaching history where she used web quests, research, PowerPoint and Word, building on her experience from the first school. She felt that the school timetabling structures limited her ability to engage the students in learning due to lack of time. Erina appeared to be one of a team, learning about using digital technologies collaboratively through sharing their various expertise. 
Beliefs:

- $\quad$ Students should be actively involved in learning.

- Digital technologies are an important part of the world today and in the future.

- $\quad$ Giving students choice and input into their learning helps to actively engage them in learning.

Teacher aspiration: to integrate digital technologies to actively involve students in their learning.

\section{Experiences}

- Study of physical education at university

- Use of digital technologies in teaching diploma course.

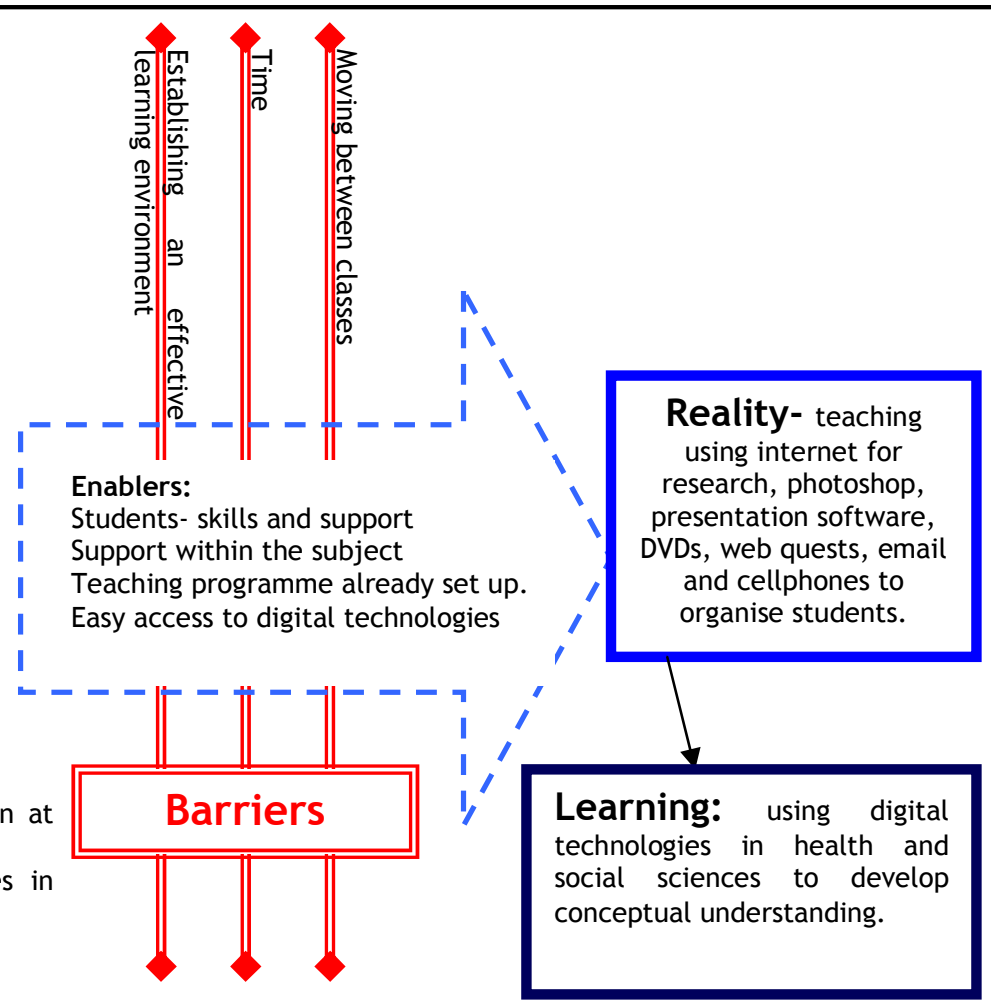

Figure 27: Case study E summary logic model

\section{Assertions from case study E:}

E1. Easy access to technology, experience of digital technology use, knowledge and teaching a subject for the first time encourages the development of digital resources and learning activities.

E2. Structures operating within a school can constrain the learning achieved while using digital technologies.

E3. Whole school programmes can increase the use of digital technologies and quality of learning experienced by students of beginning teachers. 


\section{Case study F}

I have a bit of weight and I am going to push for it. I have been quite vocal. I get on quite well with the person in charge. He has even said to me 'Fiona, I forget that you are a beginning teacher and that is why you don't always come to mind for stuff'.

\section{The teacher}

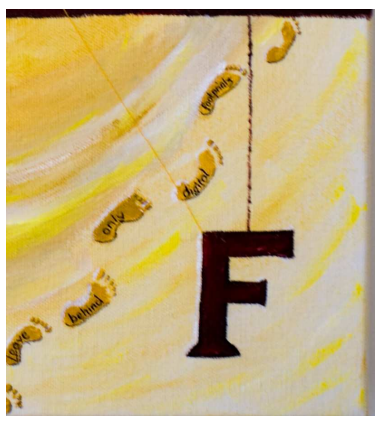

Teaching is Fiona's third career. Initially she trained and worked as a graphic designer, then as a chef. While at design school in the 1990s Fiona learnt to use programmes such as illustrator, freehand, Photoshop, basic 3D animation, Fontographer which is a type face generating programme and basic web design. These skills were used and further developed as she worked as a graphic designer, initially full time then freelance as she retrained and worked as a chef. Before going teaching Fiona spent a year at university completing the Graduate Diploma in Secondary Teaching. As a student teacher she had used a wiki. Fiona was 35 when she started teaching and as a result of these experiences she was confident using design software and familiar technologies within her teaching programmes.

For the first six months Fiona was teaching year 10 home economics, years 11, 12 and 13 food technology, and a year 12 career development class, subjects which were not her majors at university.

\section{Beliefs and experiences}

Fiona believed that students should have input into their learning. This was evident in her approach to coordinating students involved in enviroschools. Students planned to develop a movie to take to the following year's enviroschools national hui, as she was firm in her belief that students had to 'own and manage' the project; she would give technical support only.

In a lesson the researcher observed, Fiona asked students for input into the content of the wiki that she was developing for them and gave them a choice of context to use.

Fiona was aware of the role digital technologies play in the graphic design discipline through her bachelor's degree and experience as a graphic designer. She was clear about the importance of using digital technologies for teaching and learning; she believed digital technologies should be used as 'a tool to discover and learn.' 
Fiona believed that students would prefer to work in their comfort zone, taking an easy option where possible. She aimed to take students slightly out of their comfort zone to extend their thinking and engage them in learning. She identified digital technology as a way to achieve this aim:

Instead of always making a poster I would like them to collectively work on something that they can construct. I think they are just bored.

At the start of her teaching Fiona indicated that she was confident using what she termed 'low end stuff' for teaching and learning like PowerPoint, Moviemaker, Photoshop and Freehand. She saw herself as less confident in 'high end stuff' like wikis, blogs and podcasts. She acknowledged that it would not take her long to build confidence as she learnt how to use applications. Once she knew how to use an application she was confident in applying it to teaching and learning. By the end of her first year teaching she was using a wiki with her students.

Fiona was not afraid to ask for access to technologies that could help her teach - she was assertive and felt that she had the power and right to ask for what she needed:

I currently don't have a data projector in the room I will be teaching in. But I have a bit of weight and I am going to push for it. I have been quite vocal. ... I really pushed for the food and nutrition dept to get them [data projectors] and they got them.

Fiona was prepared to put in extra time to help students to learn. This was recognised during an interview of three students:

Student 1: I learnt how to trace that then how to make it like a blue outline then I could draw on top of it which I would never have known without [the teacher]. She is really good because she will offer you one on one like in breaks and stuff.

Student 2: Yeah definitely - she's real dedicated.

Student 3: Yeah, real dedicated.

\section{The context}

The school Fiona taught in was located in an urban area. It was a coeducational school of over 1000 year 9-15 students and more than 100 teachers. It had a socioeconomic decile rating of 5 out of 10. Fiona was appointed to a permanent teaching position at short notice following her completion of a teaching qualification. For the first six months she was teaching home economics which she considers her 
secondary subject, her stronger discipline knowledge being in art and design. She had solid background experience to draw on for teaching home economics including industry experience as a chef and studying pedagogy of teaching home economics in the Graduate Diploma of Teaching. Before the first year of teaching was complete, Fiona had changed departments to be teaching mainly arts and graphic design areas.

The school had about 15 PRTs. To support these beginning teachers the associate principal would meet with the group each fortnight for an hour. Her HOD technology was appointed her mentor. The school was in the process of putting data projectors in every room. For the first six months Fiona had a computer in the front of her main teaching room where she accessed her electronic rolls, the internet and click view (which gave her access to the school's DVD resources) and showed them through the data projector which she had requested and received. She did not have speakers installed which made watching DVDs problematic. There were five computers at the back of the classroom which students could access. The school had four computer rooms plus a set of 28 computers and a data projector in the library along with a pod of 14. There were digital cameras in most of the rooms that Fiona used. The art room she taught in had a computer and data projector set up at the front of the classroom. Attached to the art room was a pod of 16 computers seen from the classroom through a room length window. Fiona used her own personal laptop for teaching and preparation.

\section{Digital technology use}

At the start of her first year of teaching Fiona indicated she would like to use digital technologies in her teaching. At the time she was teaching home economics and leading the enviroschools group. She identified that videoconferencing would be a useful way for her enviroschool students to connect with students with similar interests from other schools and she wanted to have her senior home economics students creating their own websites. Neither of these uses came to fruition. Videoconferencing for enviroschools did not eventuate within the first year due to other priorities and time constraints and by the end of the year she was no longer teaching home economics. However, she was using digital technologies in many other ways with her students.

Students in home economics and food technology used digital technologies for research, web quests and developed PowerPoint that they presented to the class. 
Fiona developed PowerPoints and used interactive websites with her students. One example of this involved examining the nutritional value of fast foods:

I have found an interactive website that has all the fast food places. They have the entire menus, and when you roll over the what to purchase it has the nutritional value, the percentage of your daily calorie intake, the cholesterol and sodium levels. You can click the boxes and tally it up. You can add up breakfast lunch and dinner. It was quite amazing. It sort of freaked the kids out so it was quite good.

This type of activity involved booking the students into a computer room and taking the class there so that each student had access to a computer. She would use any spare time in the computer room to introduce students to interactive games such as how to stack food correctly in a fridge. She sometimes had a few students working on the computers in the back of the room. For example, one lesson she had the ESOL students in her class learning how to build a hangi. ${ }^{2}$

Fiona found that the students would sometimes ask questions that she did not know the answer to. When this happened she would use digital technology (google) to access information:

I guess it is what I was taught at teachers college, if you don't know something, look it up in front of them don't be afraid to not have all the answers. I have a computer in front of me so if I need to google something I just do it. If I need to find something I can say, hey, I will get back to you in five seconds, then I will just announce it in front of the whole class.

Another type of technology that Fiona used was a microphone she wore in the food room:

In the food rooms we have headsets as they are really big rooms and really loud. When the kids are doing practicals I would end up shouting and losing my voice. So I put the thing in a pocket so that I can walk around the room and talk. It has big speakers. You sometimes pick up another teachers frequency, that can be amusing, perhaps a barrier, like when the batteries run out. The students love it. If they are doing group work and have to report back you give them the microphone and they think it is awesome. I don't need it in the art rooms. I would use it to read the notices to my form class

The way that she used digital technologies in teaching changed as she began to teach more design classes. The HOD art was very interested in the use of digital technologies for teaching and learning which contrasted with the HOD technology, who preferred a more traditional approach to teaching.

\footnotetext{
${ }^{2}$ http://www.tki.org.nz/r/wick_ed/hangi/index.php
} 
The HOD art was developing a wiki for the students to access; Fiona was going to work on this development. The HOD had initially allowed the students input into the wiki development:

The wiki was set so that the students could blog but the year 13 students abused the system, like the language and what they wrote, so students are now readers only, not able to write. Sad, but they are students. So it is limited but at least they can access it from home.

Fiona used information from the internet as a source for her professional learning: “... because I am having to learn so much. More for information. Just surfing the net for information. At the moment it is the balance of trying stuff out, trial and error." Digital technologies were being used for teaching, student learning and teacher learning.

\section{Learning}

The digital age learning matrix was applied to two of the learning activities that Fiona had described and this was collated in Table 14. Fiona had used digital technologies to help students make connections in their thinking, access information and ideas, help students to think about key concepts and to create knowledge (applying concepts to create a new reality).

\section{Barriers and enablers}

Fiona had relatively good access to the internet, computers and data projectors, but there were limitations which created barriers to their use; for most barriers she was able to find a solution.

There were data projectors in each of the classes she taught with a networked computer attached. She found that one of the computers did not have enough RAM to run DVDs so she had to use her own laptop to show students and this was not attached to a data projector. When Fiona was teaching home economics, she needed to book the computer room or another classroom when she wanted the students to access a DVD or interactive website as there were not enough computers in her room and the data projector did not have a sound system. 
Table 14: Digital age learning matrix applied to case study F

\begin{tabular}{|c|c|c|c|c|c|}
\hline Level of learning: & Doing & $\begin{array}{l}\text { Thinking about } \\
\text { connections }\end{array}$ & $\begin{array}{l}\text { Thinking about } \\
\text { concepts }\end{array}$ & $\begin{array}{l}\text { Critiquing and } \\
\text { evaluating }\end{array}$ & $\begin{array}{c}\text { Creating } \\
\text { knowledge }\end{array}$ \\
\hline $\begin{array}{l}\text { Explanation of level } \\
\text { of learning: } \\
\text { Digital technology } \\
\text { use: } \\
\text { Learning activity: }\end{array}$ & $\begin{array}{l}\text { Isolated information. } \\
\text { Focus on completing } \\
\text { a measurable task. }\end{array}$ & $\begin{array}{l}\text { Connecting thinking. } \\
\text { Simple connections } \\
\text { made within a } \\
\text { context. Compare } \\
\text { and share. }\end{array}$ & $\begin{array}{l}\text { Develop conceptual } \\
\text { understanding of 'big } \\
\text { ideas' }\end{array}$ & $\begin{array}{l}\text { Evaluating and } \\
\text { critiquing to explore } \\
\text { the limitations and } \\
\text { potential of } \\
\text { information, sources } \\
\text { or process. }\end{array}$ & $\begin{array}{l}\text { Creativity - Applying } \\
\text { ideas, processes } \\
\text { and/or experiences to } \\
\text { develop a new reality. }\end{array}$ \\
\hline $\begin{array}{l}\text { Accessing } \\
\text { information }\end{array}$ & $\begin{array}{l}\text { Accessing: } \\
\text { Pictures } \\
\text { Graphs } \\
\text { Movies/video } \\
\text { Data } \\
\text { Information } \\
\end{array}$ & $\begin{array}{l}\text { Information from more } \\
\text { than one source is } \\
\text { connected or compared in } \\
\text { analysis. }\end{array}$ & $\begin{array}{l}\text { Information explicitly } \\
\text { develops conceptual } \\
\text { understanding. }\end{array}$ & $\begin{array}{l}\text { Information and sources } \\
\text { are critiqued and } \\
\text { evaluated. }\end{array}$ & $\begin{array}{l}\text { New conceptual } \\
\text { understanding is } \\
\text { developed. Building on or } \\
\text { linking accessed } \\
\text { information. }\end{array}$ \\
\hline $\begin{array}{l}\text { Processing } \\
\text { information }\end{array}$ & $\begin{array}{l}\text { Information is processed } \\
\text { or data/images are } \\
\text { manipulated in isolation. }\end{array}$ & $\begin{array}{l}\text { Connections are made } \\
\text { between or within } \\
\text { processed } \\
\text { information/data or } \\
\text { images and relevant } \\
\text { concepts. }\end{array}$ & $\begin{array}{l}\text { Processed data or } \\
\text { information has clear } \\
\text { conceptual underpinning. }\end{array}$ & $\begin{array}{l}\text { Process and product are } \\
\text { critiqued and evaluated. }\end{array}$ & $\begin{array}{l}\text { Ideas and new knowledge } \\
\text { are developed. }\end{array}$ \\
\hline $\begin{array}{l}\text { Gaming or } \\
\text { interactive } \\
\text { programmes }\end{array}$ & $\begin{array}{l}\text { Play a game } \\
\text { Take a quiz } \\
\text { Engage in an interactive } \\
\text { programme } \\
\text { Enter a virtual world } \\
\end{array}$ & $\begin{array}{l}\text { Links made between the } \\
\text { game/ quiz/ virtual world } \\
\text { and other knowledge. }\end{array}$ & $\begin{array}{l}\text { The relevant concepts } \\
\text { within the game, quiz or } \\
\text { virtual world are } \\
\text { identified and explained. }\end{array}$ & $\begin{array}{l}\text { The game, quiz or virtual } \\
\text { world is critiqued and } \\
\text { evaluated within a } \\
\text { conceptual context. }\end{array}$ & $\begin{array}{l}\text { Original ideas are used to } \\
\text { create a knowledge } \\
\text { product in any medium. }\end{array}$ \\
\hline $\begin{array}{l}\text { Fast food } \\
\text { nutritional value. }\end{array}$ & $\begin{array}{l}\text { Accessing interactive } \\
\text { website. }\end{array}$ & $\begin{array}{l}\text { Links made between their } \\
\text { own eating habits and the } \\
\text { information in the game. }\end{array}$ & $\begin{array}{l}\text { Concept of healthy food is } \\
\text { examined. }\end{array}$ & & \\
\hline
\end{tabular}


Students in her art design class had computer access through a pod of 18 computers attached to the room. For other classes it required booking a room of computers. There was a shared drive for students which was new at the school and Fiona had only just started to explore it. She had put hyperlinks into a document in the drive to make it easy for students to get to identified websites.

Fiona noted that some students came from homes with very little money. She considered this to be a barrier to their use of digital technologies for learning as some did not have internet access at home which limited their opportunities to access the internet for homework activities. She observed that when students did not have access at home they tended to want to play games when they got online at school. The consequence for playing games during class was loss of their computer licence. A loss of licence was a barrier to learning with digital technologies as students without a licence were not able to log onto a computer. Students could also lose their computer licence through not paying school fees or through a system of demerit points. If they misbehave, wear incorrect shoes or untidy uniform they were given demerit points. Too many demerit points and they lose their computer licence. The students from lower socio-economic households were found to be more likely to lose their computer licence and therefore not be able to access computers at school than those from wealthier households.

Another barrier was the school's use of WebMarshal which limited access to internet sites. Fiona found it frustrating, as sometimes sites she had wanted to use with her students had been blocked. Students were not able to access google and Fiona has experienced WebMarshal shutting down a site part way through a lesson. Fiona was able to ring the technicians who unfroze it immediately. Time was a further barrier to using digital technologies for teaching. Finding time to develop the department wiki and organise online resources was problematic.

Fiona reported a range of enabling factors when it came to using digital technologies. The level of technical support was the strongest of all the case studies. In the art design area a doctoral student was available to support students as they used programmes like illustrator. He would spend time with students as they carried out activities in the class and trouble shoot with any computer problems. His role was like a teacher aide/technician. Fiona noted how useful this was: 
Some of the questions that students ask take time to work through so having two people in the room is fantastic.

Interactive activities purpose built for the subjects being taught enabled learning as did access to programmes to develop designs such as illustrator and having Adobe CS3 installed across the school. Industry experience and use of digital technologies at university gave Fiona the confidence and ability to authentically integrate digital technologies into her teaching programme. Furthermore, she felt that if she asked for support through the school she would receive it:

I could put it forward that I need to go on a course, I might do that. If we don't get time to work on the Wiki in the holidays I will push to get some release time for us to work on this.

For the first six months Fiona was teaching a subject which was a secondary subject for her, as she had not studied home economics at university. She was teaching in a department that did not have a head of department available to support her. She felt that this limited her ability to use digital technologies innovatively: "But I am trying to be as creative as I possibly can. But not having a whole lot of support from the faculty."

Student behaviour was sometimes seen as a barrier to the use of digital technologies. The wiki was restricted to teacher input due to the inappropriate use by year 13 students, and some technically minded students had caused restrictions on student access:

We don't allow the students to touch our computers as they have been steeling the ram and things like that, wiping things off, so because we have more access than the other computers, they can't do it on their computers. So I would like to get another computer in here for students to use.

\section{Specific example - using symbols to communicate clearly}

A class of 21 year 12 students was observed and invited to participate in an interview as they developed symbols in an art design class. During the previous lesson students used words from a brainstorm list and came up with symbols pertaining to those words. Using a PowerPoint as a guide, the teacher led a class discussion including: what a symbol was, what symbols can mean and the permeations that you can get from one symbol (e.g., what happens if you rotate it slightly, put a line over it etc.). They then worked through a webquest that the teacher had developed, examining symbols. This was reviewed at the start of the observed lesson and developed further with the students developing their own symbols. This art design class used digital 
technologies regularly to generate imagery - the students were familiar with the programmes and processes. It was intended that during the observed lesson the students would develop their knowledge of how to use symbols to communicate clearly. The logic model for this lesson is illustrated in Figure 28.

The lesson included some of the students using Illustrator to develop their images:

We have used illustrator, like we have manipulated images, we put our types and logo in then manipulate it. It is really fun. We scanned in our hand drawn type then we had to go over it with the pen and outline it. It was quite tricky, took a while to perfect how to do it because it took so much time.

The lesson included a DVD of an artistic short film played through the data projector. For most of the lesson this was background, but on at least one occasion the students all stopped to watch a segment.

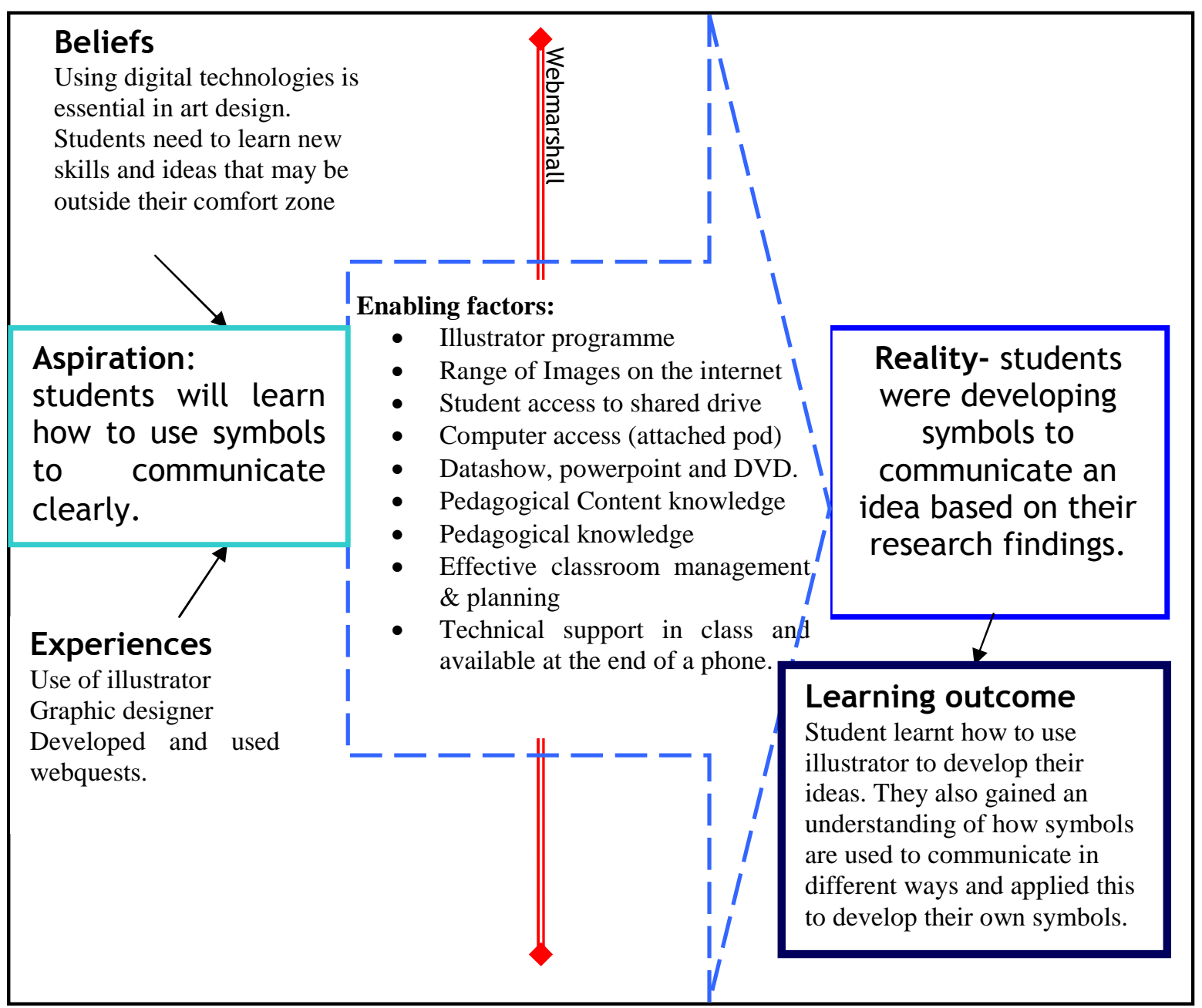

Figure 28: Logic model using symbols to communicate 
Students used a suite of computers to develop their images using Illustrator. They accessed the shared drive for information and storage, and a technician was on hand to help:

A guy who is doing his doctorate helps out the art and design teachers a few days a week. So if we are doing something like using Photoshop or Illustrator he is there as well. Some of the questions that students ask take time to work through so having two people in the room is fantastic. His skills are similar to mine, but he is probably more fresh on the programmes than I am.

By combining these aspects he was able to create his own version of a new reality.

The knowledge and experiences identified to make this teaching activity successful were identified by the teacher as including:

- Knowledge of relevant available websites. She had been collecting web addresses and checked that the links still worked before using them with students. This knowledge was based on experience: "I found at teachers' college that I need to check that the links still work before I use them with students."

- Having a clear idea of what it was that she wanted the students to achieve. This included: "sifting through the work that I asked them to look at so that they can generate ideas using those tools."

- Technical knowledge, including knowing her way around the internet, Illustrator programme and PowerPoint, and

- Pedagogical knowledge including how to get students to look at symbols and sift through them without being obvious about what they mean, guiding them to think and build on their knowledge of using symbols.

There was clear evidence from the lesson outline and interview with the students that they were applying conceptual understanding to develop their knowledge. Through a web quest students had learnt about different images, what different images mean and what the colours represent. They then explored their choice of theme. One student had downloaded images of movie superheroes, sports teams and masculine sporting brands, compared and critiqued these to identify common features, then developed his own logo: 
I used different fonts and styles to present it all, for the superheroes I used bold letters to emphasise it like they do in the movies and stuff, different bold colours to illustrate strength.

\section{The learning}

During the observed lesson evidence was found that students were creating knowledge. Through using the webquest, the questions guided the students to consider concepts. For example, they were thinking about the concept of ambiguity and examining other ways to look at signs (critiquing). Using this information they created unambiguous signs that used symbols to communicate a message, thus creating knowledge. This is illustrated in Table 14, where the digital age learning matrix is applied to this activity.

Students used Illustrator to manipulate images. The students started with a limited outline; the image was processed in isolation. The students then applied the concepts they have been developing as they add in effects like 3D or fire pattern. They had to evaluate and critique their own work - one student reported that she had to decide whether to leave her design scribble like, or make it perfect and justify why she would leave it or change it. A lot of previous drawing had been done without analysing. The teacher reported that this activity was the first time they were examining drawing as "design" rather than art. They developed ideas and new knowledge as they had not used this process or concept before. Students worked together to share and develop their ideas: "We share the work with each other - ideas and stuff. We are always giving each other ideas. It is cool. We do learn from each other."

The belief that underpinned the decision to use digital technologies for this learning activity was that students should be using authentic processes, similar to those used in the design industry.

\section{Support network}

Fiona was in a large secondary school and much of the support she received was from within the school. A summary of Fiona's support network is illustrated in Figure 29. 


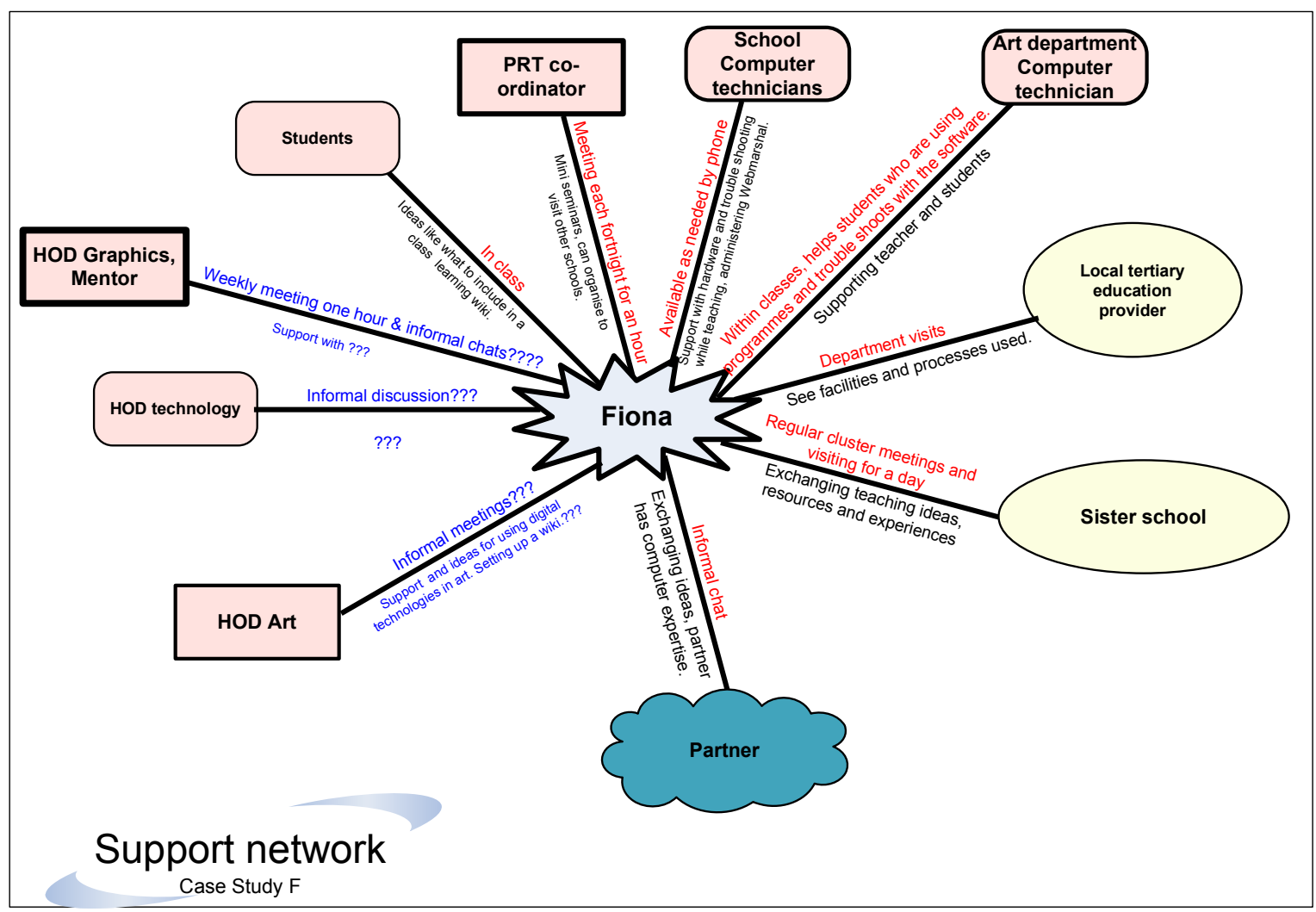

Figure 29: Support network case study F

The school appeared to have very good technical support. Fiona reported that technicians based in the library were constantly monitoring the computers and were able to be contacted by phone. While she felt that it was a bit like big brother watching, the instant feedback and help made the use of digital technologies easier.

The school had a formal structure to support its 15 PRTs. The PRT coordinator was the associate principal, and he held fortnightly meetings which included mini seminars. The associate principal was described by Fiona as being 'techy', and encouraged her to use digital technologies in teaching. He offered to support Fiona if she wanted to go to another school to look at their programmes.

Fiona initially felt that she lacked support in home economics. She began teaching half-way through the year and found at the start that there was limited support for her as a beginning teacher: 
I think they are too busy at the moment. My (food tech) HOD is very old school so is completely (digitally) illiterate but my supervisor who is the technology HOD is actually my supervisor because my food tech HOD is not actually a qualified teacher so he is probably the more qualified but he teaches hard materials. So I kind of have to bounce around to find who can help. I just came into school at a time of year that it is all just a little bit crazy. Noone wants to know me just yet.

Fiona's support for using digital technologies was often organised by herself as she was assertive in her approach to accessing technologies she needed: "I get on quite well with the person in charge. He has even said to me: 'Fiona, I forget that you are a beginning teacher. And that is why you don't always come to mind for stuff.", Therefore the level of support may have been lower than a less capable and assertive beginning teacher: "I am always touching base with my supervisor. I might change supervisor to one of the art department people as I am changing departments.”

Fiona was involved in school-based professional learning. Teaching staff met each Monday to focus on professional learning. The school had a sister school and operated programmes where the staff are funded to visit the sister school for a day. Fiona took this opportunity to spend a day gathering teaching resources. Through the sister school liaison a cluster group formed that met regularly to discuss art teaching and learning.

The art department had links to the local tertiary provider. When the art department teachers were thinking about introducing digital photographic screen printing, they visited to see and discuss facilities and processes.

\section{Summary}

Fiona started teaching experienced in the use of digital technologies in art design which made her confident in her ability to infuse digital technologies into her teaching programme. She began the year teaching in her secondary specialist area, with access to computers and a data projector in her teaching space. She used this with the students where she found the opportunity - such as showing PowerPoints and for student research. Later in the year Fiona changed departments and began teaching in her specialist area - art design. Here she applied her industry experience, and with strong technical support was able to have students focussing on developing their understanding of concepts, critiquing and evaluating and using their research and skills in using technology to create knowledge products. Fiona was assertive which enabled her to access the hardware she needed to overcome some barriers she 
faced as she tried to use digital technologies in school. Fiona's experiences are summarised in Figure 30.

Beliefs:

- Digital technologies are an integral part of the discipline of design.

- Students learn when they are taken out of their comfort zone.

Teacher aspiration: Integrate digital technologies in teaching to challenge and extend student learning.

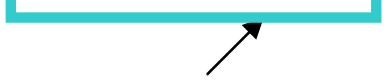

\section{Experiences}

- $\quad$ Study of graphic design at University

- $\quad$ Graphic design industry experience.

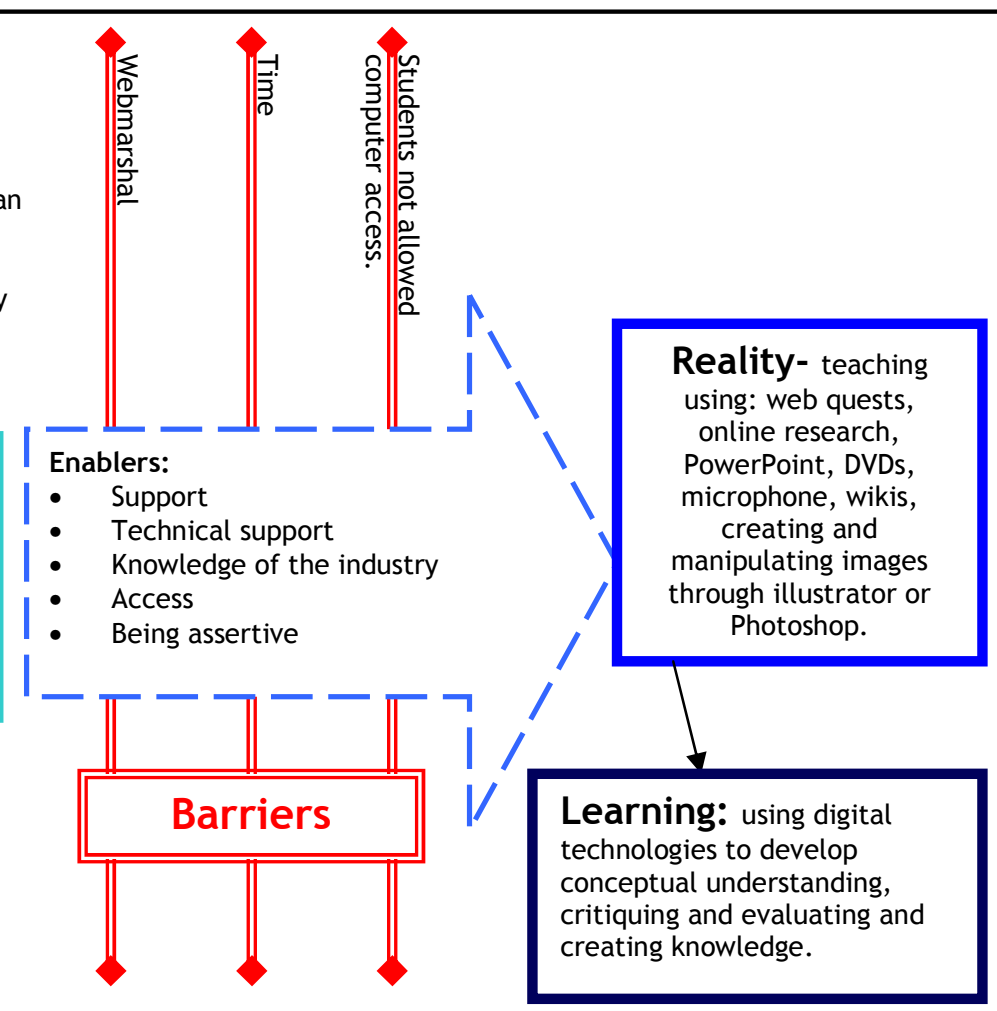

Figure 30: Summary logic model, Case study F

\section{Assertions from case study F:}

F1. Teachers are more likely to integrate digital technologies for creating knowledge when they have experience and knowledge of the use of digital technologies within the discipline, are determined and assertive.

F2. Using digital technologies allows for personalisation of learning. This includes giving students choice, linking activities to a meaningful context, explore a greater range of information and receive instant personalised formative feedback.

F3. Using digital technologies can help students understand concepts and create knowledge. 


\section{Summary - case study descriptions}

Each of the case studies reflect different contexts and the diversity that exists amongst the beginning teachers with the experiences and attitudes they bring to teaching. The teachers all used digital technologies in their teaching practice, and this was able to be illustrated within a logic model. The digital age learning matrix was found to be a useful tool to evaluate learning activities and the variety of experiences has led to a range of assertions emerging from the individual case studies. 


\section{Chapter 5. Analysis and findings across the case studies. \\ The whole is more than the sum of the parts. (Aristotle, $384 \mathrm{BC}$ to $322 \mathrm{BC}$ )

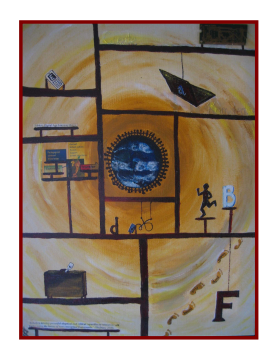

The case studies described in Chapter 4 illustrate the complexities that exist in each of the contexts. The findings in Chapter 4 were deduced by examining each case study independently and the key aspects of the beginning teacher in his or her context. A second analysis of the data involved examining data and findings across the case studies. The assertions emerging from individual case studies were examined across all the cases to ascertain their wider relevance and limitations. Secondly, the interview data were examined for variables of interest or emerging key ideas; with relevant statements from interviews being grouped together in an Excel spreadsheet. This was found to be a useful step in the analysis as it synthesised evidence from the data around a concept or variable of interest, which then allowed for thoughtful analysis. There were ideas that emerged from the data which had not been identified as a variable of interest in the research questions. These included personalising learning, the sense of power or influence a teacher had and the reality of being a beginning teacher

An analysis of the synthesised data included examining each of the research questions across the cases. Within each of the research questions the variables of interest were examined individually alternating between a detailed analysis of the quotes and the holistic implications.

This chapter begins by examining the assertions emerging from the individual case studies by exploring their relevance to the other case studies. The chapter then moves to looking at findings for each of the research questions, applying the evidence that emerged from the case studies in context and the generic inductive qualitative analysis. The themes from the generic inductive qualitative analysis that were not linked directly to the research questions are then discussed. 


\section{Comparison of assertions}

The assertions which emerged from each case study were compared across the case studies to ascertain their transferability. The results are included in Table 15 where each assertion was noted as significant (the case study they emerged from), relevant to the case study (the assertion can be applied to the findings of another case study) or were contradicted in a case study. The assertions fitted into three orientations assertions about the teacher (their beliefs and experiences), the context in which they were teaching, and the learning.

\section{The teachers}

Assertion A1 (the first assertion from case study A) emerges from the reported lack of sense of power felt by Ana. Dayna was in a similar situation where she was unable to get the access she wanted when the power points in her room did not work and were not fixed, though she had also successfully been assertive about her need for a laptop. Fiona was assertive and successful in gaining the access she wanted. Barry also had access problems though he did not see this as a source of frustration, possibly because he was able to gain the support he needed through actively nurturing his connections, and the context was different in that he was not the only teacher in the subject. This suggests that a beginning teacher's disposition and their teaching context will influence their sense of power and hence their ability to access and use digital technologies with their students for creating knowledge. The sense of power to access the digital technologies a beginning teacher wants appears to be influenced by their disposition and the context in which they are working i.e., whether they know the process to ask for a change and think that it is an appropriate thing to do and are able to ask for what they need.

Assertion $\mathrm{C} 1$ is also about the beginning teacher's perceptions. Cath, a competent user of digital technologies in the eyes of experienced teachers, felt that she was not competent when compared to the students she taught. This was not reported in any of the other case studies.

Assertion $\mathrm{A} 3$ and $\mathrm{F} 1$ reflect on the impact that experience has on the way that a beginning teacher uses digital technologies in their teaching and learning. It appears that the beginning teacher transfers their knowledge and understanding of the learning 


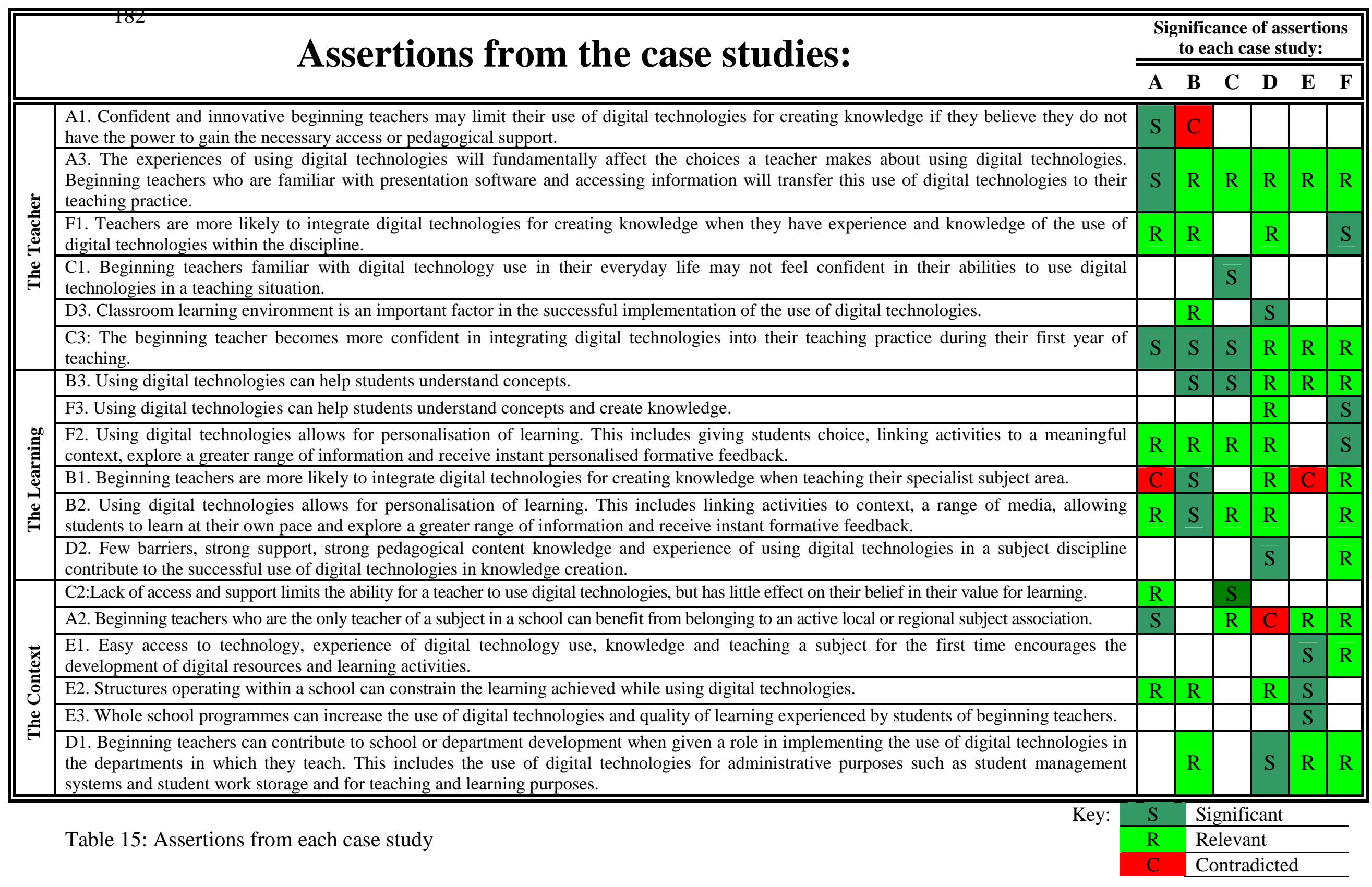


they have to the teaching situation. Where the teacher had experience of presentation software and accessing information this was used generically in the teacher's practice. Where experience includes subject specific software for creating knowledge as reported by Barry, Dayna and Fiona the teaching activities tend to aim for a greater depth of understanding and personalising learning. This is discussed further in the next chapter.

At the start of the year Cath was hesitant about using digital technologies with her students. She was afraid that they would know more than she did. By the end of the first year this was no longer expressed as a concern, and she identified a range of ways that she would use digital technologies with her students. Her confidence grew as she became more experienced in her pedagogical approaches. Ana was similar in that at the start of the year all she seemed to see was barriers that prevented her from using digital technologies. By the end of the year she was becoming more innovative in the ways she was choosing to use digital technologies and becoming more confident in how she could make it happen. Ana's growth in confidence appeared to be as she was learning the ropes, the culture of the school in which she was teaching, whereas Cath's confidence was directly about her position as a teacher in the classroom. Barry became more confident as he developed his ability to engage students in learning and as he established himself as a teacher. Assertion C3 can be applied to all the case studies, in that they all seemed to become more confident over the year of the study, but the source of the confidence seemed to vary according to each teacher's concerns at the start of the year. It was not recognised as an assertion in the case studies during individual examination, but once it was apparent in case study $\mathrm{C}$ it also became apparent as an important feature in case studies $\mathrm{A}$ and $\mathrm{B}$.

The classroom learning environment was a priority for Dayna; assertion D3 noted how she placed priority on having a positive learning environment as an important factor in successfully teaching with digital technologies. This was also an important consideration for Barry. While it was not directly reported by the other case studies, classroom behaviour was mentioned by Erina, Fiona and Ana, therefore likely to be a consideration if it was found to need to be a focus.

\section{The learning}

The use of digital technologies was found to help students learn. The students in case studies B and F were able to clearly articulate how the technologies were helping 
them to learn through the think alouds. The students in case study E were not able to explain how the learning activity using digital technologies was helping them to learn. Hence this assertion is not always true. The learning activity in case study $\mathrm{E}$ was part of a unit that all the health teachers taught, it was not designed by the teacher herself. The teacher was not familiar with Photoshop, the programme used in this lesson, having quickly been shown how to use the programme that morning. It could be that in this example the teacher's pedagogical content knowledge was lacking, hence the focus of the teacher moved from student learning to doing the activity, compounded by the lack of time available to the students.

Significant assertions (F2 and B2) concerned the teachers personalising learning for their students through the use of digital technologies. The personalising of learning in a classroom is a significant move away from a one size fits all industrial model of teaching. It appears that the digital technologies were used in this way to a greater or lesser extent by all the teachers in the study.

The teachers were more likely to integrate digital technologies into students' learning when they were teaching in their specialist subject. A number of the teachers in the study had been employed to teach at least one class in a secondary subject area. The use of digital technologies in the secondary subject tended to be for presenting information or accessing information, where as the use in a specialist subject area tended to be more likely to include interactive technologies and focus on students actively creating knowledge. The contradiction to this was found in case study A where Ana was teaching in her specialist areas and unable to use digital technologies beyond occasional presentation or accessing information. This assertion needs to be refined to reflect the situations where this does not occur. Erina was initially teaching in her secondary subject area of geography and because she had excellent access to a data projector, DVD and video players in her classroom she used presentation software with her students. When it came to the students creating knowledge as in their inquiry projects, digital technologies were used as a source of information rather than as a place to create knowledge and share it. An exception was the Romans activity which did include the students finding information and emailing it to each other.

Knowledge creation, which is a high level of achievement for a learner in the digital age was recorded in case studies D and F. Assertions linked to the successful creation 
of knowledge included D2 (that digital technologies can help students to create knowledge) and F3 (the conditions included few barriers, strong support, strong pedagogical content knowledge and experience of using digital technologies in a subject discipline).

\section{The context}

A group of assertions focussed on the context in which the beginning teacher was teaching. The beginning teachers who were the only teachers in a specialist subject area in a school expressed how beneficial the local or regional subject associations were for pedagogical knowledge and support, including support when using digital technologies within the subject area. This was significant for Ana. It was relevant for Cath, Fiona and Erina in that they wanted access to such associations but had not been able to access this support. The assertion was contradicted by Dayna who was not the only teacher in a specialist area, but found the local subject associations to be a good source of support for her own professional learning.

Assertion E1 gives conditions in the context that were found to help Erina develop digital resources for teaching. These were similar to those experienced by Fiona, both having to teach outside their primary subject speciality.

The structures in the context were found to significantly restrict the effectiveness of the use of digital technologies by Erina. This included the length of lessons (timetabling) and the different teaching rooms allocated to her classes. Similar structural constraints were experienced by Barry, Dayna and Ana. A further constraint that was mentioned by Dayna was the restriction by NZQA.

Erina was teaching in a school which had a whole school approach to developing the teacher's and students' ability to integrate digital technologies into the learning. This was an example of how the contextual structures can impact positively on the beginning teacher's use of digital technologies as she used technologies while teaching prepared lessons, was not thought of as 'the digital expert' and did not have to teach the students basic programmes as they had already learnt these.

A beginning teacher can contribute to the school or department's development in the use of digital technologies. This was seen on the school level with Dayna being involved in a group exploring uses for digital technologies. At a department level Fiona, Dayna, Erina and Barry all reported being involved in working to develop 
department-wide use of digital technologies. This contrasts with the reported experiences of Cath, who found that without support and access, or having input into what was happening within the schools she was teaching, she had little opportunity to use or influence the use of digital technologies (assertion C3). However, it was also found that the beginning teachers who had expressed an interest in using digital technologies and faced significant barriers (Cath and Ana) retained their belief in the value, and determination to implement their ideas in the future (assertion C2). Furthermore, there was no discernable difference between their attitude as they discussed future use and that of the teachers who reported a higher level of support.

\section{The research questions}

The results from the data were collated and analysed to examine how beginning teachers used digital technologies during their first year of teaching. These results are outlined below by describing how digital technologies were used and the purpose of the use. This is followed by the results which focus on why digital technologies were or were not used by the beginning teachers.

\section{How do digitally able beginning teachers use digital technologies for teaching and learning?}

The six teachers in the study used a range of digital technologies. The technologies included cell phones, email, internet (Web 1.0 and Web 2.0), intranet, digital recording devices, presentation software, an interactive whiteboard, and various computer programmes. The reported use of technologies is summarised in Table 16.

Cell phone functions were used by most of the beginning teachers, more so than email. The students preferred to use cell phones to communicate:

Dayna: I use text messaging all the time. I text my kids. I tell them when they have to bring something in the next day when they are away. Just my seniors.

Researcher: Does it work well?

Dayna: Yes, they don't check their emails ever. They didn't even know that they had school emails until I told them this week. I tried emailing them. (Case study $\mathrm{D}$, Interview 1)

The researcher found that the teachers were more likely to respond to a text message through their cell phones than to an email message. Cell phones were also used for their organisational functionality: 
I get students to put notes in their cell phones like when they have to go to the computer room. I say to them get your phone out and put your homework in. (Erina)

The teacher who was based in England for six months reported using an interactive whiteboard. The teachers based in New Zealand reported that each of their schools had interactive whiteboards, or were in the process of getting them, but not in the classes they were teaching in, so these were not significant for this study. All of the teachers had used data projectors. The teachers routinely used digital technologies to plan and develop teaching resources.

I use word all the time in my teaching. All my lesson plans are done in Word. I use PowerPoint in history heaps. I don't write on the whiteboard, all my notes are in PowerPoint. (Erina)

Table 16 shows the variety of digital technologies which were reported as being used in the case studies. Nearly half of the reported uses involved students operating the digital technologies; the rest involved teacher use. There were no examples of students creating and sharing knowledge products online.

Five of the teachers had used digital recording equipment. This included using a digital camera or a digital video camera. The internet was used by all the teachers in the study. There was a variation in how often digital technologies were used by the teachers. Dayna, Erina and Fiona used some type of digital technology with students on a daily basis, whereas Ana, Barry and Cath used digital technologies for their own preparation and organisation, and less frequently with their students. The reasons for this variation are discussed later in this chapter when the factors which encouraged or impeded digital technology use are examined.

\section{The purpose of digital technology use}

Through an analysis of the teacher interview data, six different purposes for using digital technologies for teaching were identified. These included: to engage students in learning, to access information, to prepare students for a digital world beyond school, for efficiency, the teacher's own professional leaning, to save money, reduce the carbon footprint and for administration or management purposes. An analysis table is included as appendix 9. 
Table 16: Reported digital technology use

\begin{tabular}{|c|c|c|c|c|c|c|c|}
\hline \multirow{2}{*}{\multicolumn{2}{|c|}{ Type of technology: }} & \multicolumn{6}{|c|}{ Case Study } \\
\hline & & A & B & $\mathrm{C}$ & D & $E$ & $\mathbf{F}$ \\
\hline \multicolumn{2}{|r|}{ Cell phone } & $\begin{array}{l}\text { text parents } \\
\text { and as an } \\
\text { organiser }\end{array}$ & Calculator & & $\begin{array}{l}\text { Text } \\
\text { students }\end{array}$ & $\begin{array}{l}\text { Text } \\
\text { students }\end{array}$ & $\begin{array}{l}\text { As an } \\
\text { organiser }\end{array}$ \\
\hline & Email & parents & & & & $\begin{array}{l}\text { Student } \\
\text { photos }\end{array}$ & \\
\hline \multirow{4}{*}{ 岂 } & $\begin{array}{l}\text { Educational } \\
\text { sites } \\
\text { including } \\
\text { DLOs }\end{array}$ & $\begin{array}{l}\text { Teaching } \\
\text { resources. }\end{array}$ & $\begin{array}{l}\text { BBC- } \\
\text { muscles } \\
\text { Maths }\end{array}$ & mathematics & & $\begin{array}{l}\text { Sports } \\
\text { injuries }\end{array}$ & $\begin{array}{l}\text { Teacher } \\
\text { resources } \\
\text { DLOs- Hangi, } \\
\text { food safety }\end{array}$ \\
\hline & www general & $\begin{array}{l}\text { Moulin rouge } \\
\text { icebreaker }\end{array}$ & & & $\begin{array}{l}\text { Patterns } \\
\text { Artist models }\end{array}$ & $\begin{array}{l}\text { Geography } \\
\text { inquiry } \\
\text { project } \\
\text { Romans web } \\
\text { quest }\end{array}$ & \\
\hline & $\begin{array}{c}\text { Teacher } \\
\text { developed } \\
\text { sites }\end{array}$ & $\begin{array}{l}\text { Facebook } \\
\text { site }\end{array}$ & Protopage & & Moodle & & Art dept wiki \\
\hline & $\begin{array}{c}\text { Student } \\
\text { developed } \\
\text { sites }\end{array}$ & & & & & & \\
\hline \multicolumn{2}{|c|}{ LMS/ intranet } & & $\begin{array}{l}\text { Maths } \\
\text { resources }\end{array}$ & & Moodle & & F drive \\
\hline \multicolumn{2}{|c|}{ Digital camera } & $\begin{array}{l}\text { Food, clothes } \\
\text { moderation, } \\
\text { Wearable art } \\
\end{array}$ & & & $\begin{array}{l}\text { Clothes } \\
\text { moderation }\end{array}$ & $\begin{array}{l}\text { Images } \\
\text { Geography } \\
\text { assignment }\end{array}$ & moderation \\
\hline \multicolumn{2}{|c|}{ Video camera } & & & $\begin{array}{l}\text { Volleyball } \\
\text { technique }\end{array}$ & & $\begin{array}{l}\text { Dance/gymn } \\
\text { astics }\end{array}$ & \\
\hline \multicolumn{2}{|c|}{ Voice projection } & $\begin{array}{l}\text { Amplify } \\
\text { sound from } \\
\text { laptop }\end{array}$ & & & & & Food room \\
\hline \multicolumn{2}{|r|}{$\begin{array}{l}\text { Interactive } \\
\text { Whiteboard }\end{array}$} & & & $\begin{array}{l}\text { Rotational } \\
\text { symmetry }\end{array}$ & & & \\
\hline \multicolumn{2}{|c|}{$\begin{array}{l}\text { Photoshop/ } \\
\text { illustrator }\end{array}$} & & & & $\begin{array}{l}\text { Business } \\
\text { cards } \\
\text { superheroes }\end{array}$ & image & signs \\
\hline \multicolumn{2}{|r|}{ PowerPoint } & & & Present ideas & $\begin{array}{l}\text { Teaching } \\
\text { resources }\end{array}$ & Present ideas & Present ideas \\
\hline \multicolumn{2}{|r|}{ Word } & & & & Resources & & \\
\hline \multicolumn{2}{|r|}{ Excel } & & Graphing & & & & \\
\hline \multicolumn{2}{|r|}{ Adobe suite } & & & & & & $\begin{array}{l}\text { Available on } \\
\text { staff } \\
\text { computers }\end{array}$ \\
\hline & & & & Key: & $\begin{array}{l}\text { dents using } \\
\text { icher using } \\
\text { h teacher ar } \\
\text { hnology. }\end{array}$ & $\begin{array}{l}\text { digital techn } \\
\text { digital techno } \\
\text { tudents using }\end{array}$ & $\begin{array}{l}\text { gy } \\
\text { yy. digital }\end{array}$ \\
\hline
\end{tabular}

\section{Engage students in learning}

Digital technologies were in use or their use was planned to engage students in their learning. This included using digital technologies to focus students, provide variation, help establish an effective learning environment, provide a means for students to learn more and to present information to students in an engaging way.

Dayna reported using PowerPoint presentations to focus fashion students on learning at key stages of learning units: "There is no data projector in fashion. I use it [the data projector from the next room] for about 2 weeks of the term, the start the middle and the end just to refocus them." 
Fiona and Barry both reported that posters were not engaging to all students, and were looking to digital technologies as a way of providing variation and choice to students as they presented their developing knowledge:

The tried and true method seems to be 'make a poster'. The kids are just insanely over that. I don't believe that making a poster fills their desires I am thinking of finding some way of making movies for show and tell stuff... Instead of always making a poster I would like them to collectively work on something that they can construct. I think they are just bored. (Fiona)

Fiona observed that students were keen to use computers so she chose to engage them in learning by designing activities that required them to use digital technologies:

Any time I get them into the computer room even to watch a DVD I am always telling them to turn their screens off. They are just aching to muck around on the computer. Most will be surfing the net aimlessly. If they had the know how and an assignment, they would be working on that actively.

Helping students to understand a concept or idea through their use of interactive digital technologies was reported in four of the case studies. Barry had used a BBC site which allowed students to move muscles and bones shown in 3D to understand how these worked. Cath had students carrying out a detailed video analysis of volleyball shots. Erina had students using Photoshop to manipulate images of themselves to understand how the media pictures are not true representations and Fiona's students used a range of digital learning objects to understand about the nutritional value of fast food, how to create a hangi and how to stack a fridge correctly.

I have found an interactive website that has all the fast food places. They have the entire menus, and when you roll over the 'what to purchase' it has the nutritional value and the percentage of your calorie intake per day it is, your cholesterol and sodium levels. You can click the boxes and tally it up. You can add up breakfast lunch and dinner. It was quite amazing. It sort of freaked the kids out so it was quite good. (Fiona)

The use of digital technologies was not limited to teaching and learning activities; they were also used to create an effective learning environment to enhance students' ability to engage in learning:

Students bring in their ipods with their song lists. They have to edit them down so that I can tolerate them. I bought them a new chord so that they can hook them up to the speakers. The students all had their own ipods, but I said Na, I don't mind Ipods, I always work to music. It is so antisocial. Now they all have to put them away and we now have 20 minute slots when we have to listen to 3 people's music through a lesson. Now they just do it themselves, I don't have to orchestrate that part. (Dayna) 
The use of presentation software was used by the teachers to engage students in learning. All teachers reported using data projectors to present information to students. The most common way of doing this was by showing a PowerPoint developed by the teacher or a website shown to the whole class through a laptop and data projector:

PowerPoint - I do that quite a bit. I find kids tend to focus more when I put things on a PowerPoint with pretty colours and pictures. (Cath)

Barry did not report using PowerPoint as he did not have a classroom with a permanent data projector. The use of PowerPoint appeared to function as a lecture style teaching activity might have in the past, though, like with the use of overhead transparencies (OHTs), the teacher was able to prepare the presentation in advance and unlike OHTs or the whiteboard, the teacher was able to hyperlink and incorporate multimedia. For the teachers in the study it seemed to be more than just giving information - it was used for stimulating ideas, focusing at key points and helping students to make connections.

Cath used digital technologies with the purpose of helping students to make connections between information: "Just making connections between what is being talked about and then using a different medium to present it."

Information was also presented by showing DVD recordings such as excerpts from the Moulin Rouge movie to look at costumes in case study A, a rugby league game in case study B, DVD about Romans in case study E and art DVDs in case studies D and F. Websites were shown to students such as the Icebreaker site in case study A. These were chosen by the teachers as they were perceived to be of interest to the students, hence these are attempts to make the learning relevant to engage them in the learning process.

Using digital technologies to present information was not always to aid understanding or to show concepts. Fiona took the opportunity to use digital presentations as visual stimulations in her class, to engage the students in thinking: "I also have a DVD which is little snippets of adverts made from overseas for visual stimulus."

Through their experiences the beginning teachers believe that digital technologies could be used to engage students in the learning process. 


\section{Access information}

Digital technologies were used with the purpose of students being able to access a range of information from the internet. This included activities which involved the students carrying out an inquiry or web quest. Erina included a range of inquiry type activities in case study E:

History they have just finished a massive research unit on the Romans. They were in little groups researching topics like education, colosseum and religion. It involved going on the internet and finding out about it and then writing short notes on it like study notes that they gave to the rest of the class that they did via Word. They then sent them to me via the email system.

Erina's year 13 geography students researched urban planning decision making, using websites and physically visiting a site to take digital photographs. Her year 10 students explored Roman lifestyles, sharing their results through email; she had her physical education students researching a sporting injury and used web quests to guide students as they look for information.

Ana's students downloaded images from the internet; the purpose was to gain colour pictures to present in a research project. The reason for this was that Ana did not have access to the school's coloured photocopier to find images from books, but she did have access to a colour printer.

Fiona used Google synchronously in class to find answers to questions raised during lessons:

I guess it is what you guys taught us at teachers college, if you don't know something, look it up in front of them don't be afraid to not have all the answers. I have a computer in front of me so if I need to Google something I just do it. If I need to find something I can say, hey, I will get back to you in five seconds, then I will just announce it in front of the whole class.

The purpose of digital technology use in this example was to access content knowledge as questions arose in class.

Dayna had her year 9 students researching symbols on the internet for a homework activity; a similar activity but at a more advanced level was set by Fiona for her year 12 students, though not for homework as she reported that her students did not have equitable internet access beyond school. Dayna had students examining sewing patterns on the internet that they could then purchase locally and use in her fashion design class. 
Teachers as well as the students used the internet to access information. The teachers also accessed information from school intranets. The subject departments had shared drives from which the teachers could upload and download resources. Barry found that having a shared drive with teaching resources meant that he had access to a range of resources he did not need to print off and carry home, yet could access from home for planning his lessons:

There are activity worksheets, games, worksheets for games, other explanations how to play the games. Everything is there and it is in one place. It is accessible from anywhere. If I am at home I can get hold of all the mathematics stuff at school and I don't have to carry stuff home. So that is the biggest thing I do for planning. (Barry)

Using digital technologies for accessing information and resources helped the beginning teachers in their lesson planning and connecting students to a wide range of information.

\title{
Preparation for the world beyond school
}

The ubiquitous nature of digital technologies and the role of the secondary school teacher in preparing students for the world beyond school was reported as a purpose for using digital technologies for teaching and learning in case studies B and F:

\begin{abstract}
If they wanted to research something, find something out, you could spend a lot of time teaching them how to find things rather then looking through text books The reality is when they leave school they are not going to have access to the text books, they are not going to have access to that information. Whereas if they learnt to find that information on the internet they will be able to use it when they go out whether it be through journals or through wikipedia or through Google. All these different ways you can find information that you often don't learn until you go to university, but if you had that opportunity that would be ideal. (Barry)
\end{abstract}

The essential place of digital technologies within subjects was a purpose for using digital technologies identified by Fiona: "We are an art design class so it is completely relevant for them in this subject to be working with digital technologies."

Both Barry and Dayna brought up the idea of redundancy of skills no longer necessary in the digital world. Dayna noted that maximum time should be spent focussing on learning:

Anything and everything that is going to assist them and push them further, If it makes it faster, they will produce more and experience more. There are lots of things that are labour intensive like redrawing stuff in art. OK, it might help them become a better drawer, but sometimes it is just unnecessary. The photocopier and the scanner are brilliant. Just like bare basic technologies that can speed up a 
process and move along so that they spend more time on the learning side of it rather than the labour intensive.

Like Dayna, Barry noted that digital technologies have made some skills less important to learn to succeed in the digital world:

I still see a lot of spelling tests and things. To tell the truth I am a terrible speller, but everything I have had to write formally has been word processed so I have been able to get through. Spell-check is brilliant with I think is a metaphor for everything. As we become more reliant on technology we less and less need the skills to get by without it...

Learning and digital technology use beyond school helped to inform decisions made by beginning teachers.

\section{Time and efficiency}

Using time efficiently was another consideration. Barry saw that digital technologies served the purpose of helping him use his time effectively in a lesson. This was important to Barry who was changing classrooms each lesson and focussed on establishing effective learning environments within his classes:

Ideally I would like to have like a projector and be able to have my starter and things preplanned, I don't have to come in and write it on the board, I can come in and just bang it up on the screen it is ready to go. It would give me more time because it is pre prepared I would move onto the next thing, the example, put that onto the board and you can work through it more efficiently, without having to spend that time writing.

Fiona also considered the efficient use of time. She found that to use a computer room she had to book it for a whole lesson, then it took time to take her students to the room and get them started on the learning activity. Therefore one purpose of using digital learning objects was to ensure that there was no down time when students were in the computer rooms.

\section{Save money, save the world}

Having information and work stored in digital format can save money in printing costs. By having electronic submission of work, Erina and Dayna used electronic submission of work for this purpose:

Kids send in their assignments via email into an assignment box. Like I have just done PowerPoint presentations with my physical education class - they presented them in class and also sent them to me rather than printing them off and handing them in. (Barry) 
The environmental effect of consumerism was important to Fiona:

As an environmental thing it has plusses and minuses - it saves paper but the actual computers themselves aren't environmentally friendly. We live in a world where it is such a focal point, I have to make it important and relevant.

A teacher's beliefs in equity, social justice and the environment can impact on the teaching and resourcing decisions they make.

\section{Administration}

The teachers used digital technologies for the purpose of their own professional learning and this was done in different ways. Accessing teaching resources through a staff intranet helped teachers in case studies B, D and E. They were able to download worksheets or other resources and adapt them for use with their own students. It saved them time developing their own resources.

Ana used technologies to access information for her personal professional learning: "Well I mean I use it all the time to brush up on things I may have forgotten, just research only."

Dayna collated information she accessed from the internet with the purpose of expanding her knowledge and the resources she had available for students:

Word is used for my own learning when I am doing research it is so easy to just grab images off the internet then I will just write up what I think about it then I can use that as a resource when I go to use that with my kids, so I have built up a library of different artists and different information.

Teachers used digital technologies for the management and administration of records and student achievement. Storage of digital photos rather than keeping the original work for moderation and exemplar purposes was carried out by five of the case study teachers. Erina also reported that she used a system of digital submission for work that was to be assessed. Some of the teachers reported using an intranet for recording and reporting student achievement and absences; this was not reported by all teachers, though it was not a question that was asked directly as it was not about teaching and learning. It is likely that all the teachers did use the school intranet for this function.

The final purpose for using digital technologies noted in the analysis was for classroom management and student organisation. Students were encouraged to use their cell phones as organisers, noting in their cell phone reminder things they had to do, or deadlines to 
meet for the subject. Two of the teachers mentioned that they would text either their senior students or a sports team they coached with organisational details; more commonly students input the information themselves in class. Keeping in contact with parents of form students involved the use of text messages or email for two of the teachers: "I pretty much use cell phones for organizing teaching" (Erina).

Beginning teachers use digital technologies for administration purposes as schoolwide systems are digitised and this is a system in which they must operate. They also chose to use digital technologies for administration of their teachers and to help their students to organise themselves.

The technologies being used by beginning teachers for teaching and learning were rarely seen in New Zealand schools in the previous ten years. However, teaching decisions appear to be similar as those made ten years prior. Showing students information or guiding students through an inquiry were both dominant teaching methods from the past, so while the use of technology has changed, on the surface the way teaching occurs may have altered little.

The purpose of using digital technologies by the beginning teachers in this study varied within the theme of being an effective teacher. The teachers wanted to engage students in learning, teach efficiently and effectively to improve access to help students to learn, and live in a digital world.

\section{What factors impede or encourage the use of digital technologies by beginning teachers?}

The teachers in the case study joined the study as they were interested in using digital technologies in their teaching during their first year. At the initial interviews they each outlined how they would like to use digital technologies for teaching and for their own professional learning. During the year each of the teachers faced challenges as they attempted to use digital technologies. They also found there were additional opportunities or support that helped them to use digital technologies in the ways they had hoped, or in additional ways. The barriers and enablers were coded to five categories: access, experience, support, school structures and beliefs. Access, support and school structures were largely context dependent (external to the teacher). Experience and beliefs was teacher dependent (internal). The barriers are summarised in Table 17. Complexity theory suggests that looking for cause and 
effect leads to a reductionist view of the data. In examining the range of components it was hoped that the complexities of the aspects that impact on transfer of learning would be understood more clearly.

\section{Access}

Access to hardware such as laptops and data projectors, software, online sites and computers for students was, to some extent, a barrier to digital technology use in the case study schools. The case study schools all had digital student management systems that the teachers were expected to use, but a national policy meant that only teachers appointed to permanent teaching positions were given laptops. Fiona and Ana were the only teachers who were appointed to permanent positions when they started teaching. Ana was given a leased laptop when she started teaching which cost her \$6 a week. Fiona and Cath owned personal laptops that they used for their teaching. Erina was not given a laptop, but was teaching in a classroom which had computer and internet access. Dayna and Barry were appointed in positions until the end of the year and were not given access to a laptop which hindered their use of digital technologies for learning. Dayna and Barry's employment contracts were renewed for the following year, and though they were still in a temporary position they were each given a laptop. Barry was given a leased laptop for which he had to pay $\$ 7$ a week and Dayna, after being assertive about her needs, was given a laptop that did not have a battery in it:

No one here pays for their laptops. Do some people have to pay for their laptop?... I would pay \$7 a week to have a decent laptop. 
Table 17: Summary of barriers and enablers

\begin{tabular}{|c|c|c|c|c|c|c|c|}
\hline \multirow{2}{*}{\multicolumn{2}{|c|}{$\begin{array}{l}\text { Barrier or enabler: } \\
\text { (reported by teacher) }\end{array}$}} & \multicolumn{6}{|c|}{ Case study: } \\
\hline & & $\bar{A}$ & B & $\mathrm{C}$ & D & $\mathbf{E}$ & $\mathbf{F}$ \\
\hline \multirow{8}{*}{ 恣 } & $\begin{array}{l}\text { Laptop or computer } \\
\text { access (Teacher) }\end{array}$ & & $1 / 2 \longdiv { 2 / 2 }$ & & $1 / 2 \longdiv { 2 / 2 }$ & & \\
\hline & $\begin{array}{l}\text { Student access to } \\
\text { computers at school }\end{array}$ & & & & $\begin{array}{l}\text { seniors } \\
\text { juniors }\end{array}$ & & \\
\hline & Access to internet sites & & & & & & \\
\hline & Access to data projectors & & & & & & \\
\hline & Power supply access & & & & & & \\
\hline & Cell phone access & & & & & & \\
\hline & $\begin{array}{l}\text { Access to digital or } \\
\text { video camera }\end{array}$ & & & & & & \\
\hline & Access to programmes & surveys & & & & & \\
\hline \multirow{5}{*}{ 竞 } & PRT & & & & & & \\
\hline & Department & & & & & & \\
\hline & Informal within school & & & & & & \\
\hline & $\begin{array}{l}\text { Teaching support } \\
\text { beyond school }\end{array}$ & & & & & & \\
\hline & $\begin{array}{l}\text { Other support beyond } \\
\text { school }\end{array}$ & & & & & & \\
\hline \multirow{4}{*}{ 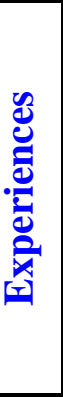 } & $\begin{array}{l}\text { Using digital } \\
\text { technologies in } \\
\text { University degree }\end{array}$ & & & & & & \\
\hline & $\begin{array}{l}\text { Digital technologies in } \\
\text { teaching diploma or seen } \\
\text { on teaching experience }\end{array}$ & & & & & & \\
\hline & Work & & & & & & \\
\hline & Personal & & & & & & \\
\hline \multirow{2}{*}{ 悉 } & $\begin{array}{l}\text { Effective learning } \\
\text { environment }\end{array}$ & & & & & & \\
\hline & $\begin{array}{l}\text { Have the power to get } \\
\text { access or support. }\end{array}$ & & & & & & \\
\hline \multirow{2}{*}{ 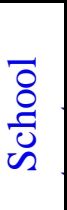 } & Timetabling & & & & & & \\
\hline & Time & & & & & & \\
\hline
\end{tabular}

Key:

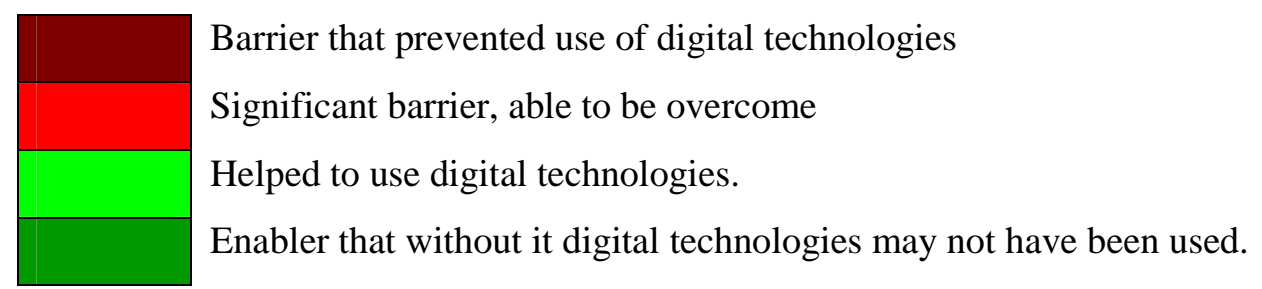


Erina was given a laptop when she was appointed to a one-year contract at the second school she taught in. The variation in access to school laptops is caused by differences in individual school-based management decisions on who is given a laptop, how and when laptops are allocated to teachers and whether an appointment is a permanent or a temporary teaching position. All the teachers had a laptop which enabled them to use digital technologies by the end of their first year of teaching.

The case study schools all had computer rooms that teachers could book when they were not being used by computing classes. Being able to book a computer room for many of the learning activities which involved year 9 and 10 students was thought to be important by the case study teachers. The number of rooms available, decisions about placement and numbers of computers was dependent on school-based management decisions and financial constraints. Understanding the procedures of accessing digital resources was up to the teacher.

For senior students there were pods of computers to which the teachers could send groups of students with limited supervision. Erina (in her first school), Fiona and Dayna all reported accessing pods of computers for their students to enable them to use digital technologies for their learning. This level of access enabled these teachers to have students self-pace their use of digital technologies to meet their personal learning needs, giving the teacher time to spend with individual students.

...upstairs there are five art computers so my year 12 class, I can have the class on computers, which I often do. I like to have half the class showing me what they have done and the other half on the computers. (Dayna)

Software which blocked access to certain websites made using the internet with students difficult for Ana and Fiona. The decision on what is blocked and procedures for accessing websites that have been blocked are part of a school's policy and procedures.

Access to data projectors was important for the teachers who wanted to show their students PowerPoints, multimedia presentations or websites, or to share student work in a visual way (as Ana did with photos of her students' food creations). Barry and Ana did not have easy access to a data projector as they began teaching. Dayna had to move her class to a nearby area to use the data projector and Fiona asked for a data projector and was given one. Cath and Barry could book a data projector if they needed to use one:

You have to book them, there is online booking which I have had issues booking them for the right time and day. But I think I am over it now. (Cath) 
Not having a data show limited the teacher's ability to have whole class discussions around a presentation, and access to a data projector made this possible.

Two of the teachers in the study had trouble with accessing a power supply. Ana did not have a power point that was situated in a place that enabled her to use a data projector without an extension as she began teaching, and she did not have an extension cord. One of the classes that Dayna taught in had three power points none of which worked:

In the art room none of the plugs work, there is a fuse blown and it has been like that for about 6 months. I called the computer technician as I thought there was a problem with my laptop. I had tried all three plugs in the art room. He came and plugged it into the office and it worked. I was so embarrassed. So I can't use my laptop in the computer room as it has no battery and it can't be plugged in. I asked at the start of the year if I can have the battery fixed and it hasn't happened.

This prevented both Dayna and Ana from using data projectors. These barriers could and should be easily remedied, so the factor is not so much the lack of power supply, but the lack of a sense of power, influence and knowledge that these beginning teachers had to get things changed or remedied. This is probably due to both being a beginning teacher and still learning the culture of the school they are in.

Cellphones are a ubiquitous item in secondary schools and this was utilised for organisational purposes by some of the teachers in the study. A barrier for some of the teachers was their privacy, not wanting to give out their personal cell phone number to parents and students. Barry in particular was careful about keeping a professional distance:

Researcher: so you don't have a Bebo page?

Barry: No way, I've decided, you know that up to $40 \%$ of job dismissals in the States are from information from pages like Facebook and Bebo. Plus I've always thought six degrees of separation...I would just rather not have one. I am pretty paranoid. (Barry)

This was not an issue for other teachers:

Dayna: I use text messaging all the time. I text my kids. I tell them when they have to bring something in the next day when they are away. Just my seniors.

Researcher: There are no issues with students being inappropriate or anything?

Dayna: No. I could change my number if it got like that I guess. I didn't really think about it. If it was an issue, I would deal with it. (Dayna) 
Having a personal cell phone enabled communication with students for Dayna and Erina. Students having cell phones enabled them to put organisational details and reminders into their cell phone and use the calculator function.

Access to other hardware such as digital and video cameras enabled the teachers and students to use the technology; conversely, having to share a digital camera with four other teachers made recording student achievement difficult for Ana.

Access to programmes was an important enabling factor. It seemed that the teachers would use programmes that were available and that they were familiar with. If a programme was not available it would not be considered for use and as new teachers, few had the knowledge of systems and/or the power to get a new programme installed.

There is awesome software out there. I spent a lot of time [at university] working on a software like silicon coach, it analyses all different types of techniques, it is biomechanical package. They have a school package, but it is still really expensive. (Barry)

Research has identified that access is an important factor that teachers consider when making decisions about how to teach (Moseley et al., 1999; Sandholtz et al., 1997; Webb \& Cox, 2004). In this study access remains important as both an enabling factor and a barrier to the beginning teachers.

\section{Experience}

Being a beginning teacher meant that the teachers in the study had limited experience of teaching, learning and school culture from a teacher's perspective. The experiences a teacher had appeared to impact on the way that they chose to use technologies. Ana had limited experience of digital technologies being used in a school setting or in her areas of expertise, though she did have experience of using digital technologies in her personal life. Ana used digital technologies for presenting information and accessing resources or information, reflecting her own experiences of how she had used digital technologies.

Barry had applied the use of digital technologies to his area of expertise (physical education). He was less familiar with the use of digital technologies in science and mathematics. This appeared to impact on his view of how digital technologies could be used in the different subjects that he taught. In the observed lesson the students were focussed on learning conceptual physiological information in an interactive environment. He was less confident about using digital technologies in mathematics, 
noting that he had used the available programmes less than his mathematics colleagues. He had not reported using mathematics specific digital technologies in his degree or having observed anyone else using them. In mathematics he believed that students:

...might be able to do it interactively but they can't do it back on paper and that's where most of the tests are, so they still have to be able to do it on paper.

This view was not expressed with regard to physical education, which also has written exams. This likely reflects a different level of thinking about applying digital technologies in the different subjects he was teaching which depends on the depth of understanding (as a result of experiences) of pedagogical content knowledge and the use of technology in a subject specific context.

Both Fiona and Dayna had experienced using digital technologies in their undergraduate degrees with Fiona using digital technologies as a key component in her subsequent industry experience. Both these teachers saw digital technologies as integral to their teaching subjects, graphic design and art.

Experience shaped the way that digital technologies were integrated into the teaching and learning programme and the opportunities sought by the teachers to integrate digital technologies. Experience of digital technologies being used to understand concepts or develop subject specific skills was an enabling factor for teachers using digital technologies to create knowledge. A lack of experience could be a barrier to their use.

\section{Support}

The teachers reported either strong support from the subject departments in which they worked, or strong support from educationalists beyond the school. Those teachers who did not report strong support from within their school were those who were the only specialist teacher in the school. These teachers commented on the importance of external support they received from local subject associations (groups of teachers teaching in the same specialist area) or, in case study E, support from a university lecturer she knew from her teaching diploma. Dayna was an exception, reporting strong support from both the department she was teaching in and from beyond the school (see Table 18). Cath reported receiving limited support within and beyond school while teaching in another country and in the first school that Cath 
taught she noted that she would have liked support to teach physical education to the higher levels of students, but had been unable to access this through the school she was in or through local networks.

The support reported by the beginning teachers and included in diagrams in the individual case studies is collated in the Table 18, where the level of support is indicated by S (strong), M (medium) or L (low).

Table 18: Level of support reported across case studies

\begin{tabular}{|c|c|c|c|c|c|c|c|c|c|}
\multicolumn{1}{|c|}{} & \multicolumn{7}{|c|}{ Case study } \\
\hline \multicolumn{1}{|c|}{ Support } & A & B & C1 & C2 & D & E1 & E2 & F \\
\hline \hline Formal school support & M & S & M & L & S & L & S & M \\
\hline Informal school support & M & S & L & M & S & L & S & S \\
\hline $\begin{array}{c}\text { School structures to support } \\
\text { beginning teachers }\end{array}$ & L & S & L & L & M & L & S & M \\
\hline $\begin{array}{c}\text { Regional teacher networks } \\
\text { Use of informal teacher } \\
\text { networks }\end{array}$ & S & L & L & L & S & L & L & M \\
\hline $\begin{array}{c}\text { Friends/support beyond } \\
\text { teaching. }\end{array}$ & L & M & M & L & $\begin{array}{c}\text { S- } \\
\text { M }\end{array}$ & L & L & L \\
\hline
\end{tabular}

Dayna, Barry, Fiona and Erina (at her second school) reported strong collegial support through a subject department where they could discuss their ideas about teaching and learning. This included discussions about using technologies:

I get support from everyone else in the physical education dept, informal support ..., Emma is really onto it with Kamar. Everyone just helps each other. Everyone else had used Photoshop before so they helped me with that. (Erina)

Technical support within the school was an important factor for the teachers to use computer rooms, gain access to data projectors or overcome barriers faced.

Support as a beginning teacher, while it varied in the different schools, did not seem to directly impact on the use of digital technologies by the teachers. Barry noted strong support enabled him to take students into a computer room:

One of the computer teachers has been quite supportive of me when I have gone in there with my class. A tough class, she has stayed and helped, supported me, made sure the students are aware of the rules and routines around the classroom. 
That has made it much easier for me. Not having to just go in there, remember it all and try to enforce it when I haven't actually seen it. So having someone who knows it and supports makes it a lot better.

Without that support he was unlikely to have attempted to use the technologies with that particular group of students.

Ana and Dayna mentioned the lack of support to get technologies working in their classrooms as a direct barrier to their use.

... I can't use my laptop in the computer room as it has no battery and it can't be plugged in. I asked at the start of the year if I can have the battery fixed and it hasn't happened. (Dayna)

The support of friends or people beyond teaching was noted by most of the teachers to some extent. Barry had been shown a website to use with his students by a friend:

Friends give me ideas, show me sites. A friend showed me the BBC anatomy site. Guys from [the organisation] that I used to work with, they are often looking at new training ideas, they send me sites and links to check out which is quite useful.

Dayna also noted the importance of the support of friends:

I have lots of friends who are travelling all over the world and looking at amazing stuff at the moment. They are on things like Bebo. And I have just joined Facebook which I am still learning how to use you know so that I can see what my friends are doing. I got sent a whole lot of pictures of artwork, photographs of amazing architecture from Greece. I have some coming in from all over the world as far as resources are concerned, just ideas.

Dayna noted that this support was diminishing through her first year of teaching as her friends were moving down new pathways.

Beginning teachers value support from teachers with expertise in their subject area. Where the beginning teacher was the only teacher of a subject in a school, the support of the subject association teachers or known experts in the subject pedagogy helped them develop their pedagogical content knowledge.

\section{Structures}

A significant barrier to the use of digital technologies identified by Erina, Barry, Cath and Ana was aspects of the school structures that they had to work within. School structures also enabled the use of digital technologies. Timetabling, room allocations, school curriculum and length of lessons could be a barrier or enable the use of digital technologies within their lessons. 
Erina and Barry had classes located in different rooms around the school. This meant that they had to move to meet the students in the classroom and had minimal preparation time before students arrived (or they arrived after the students). Barry was keen to use a data projector at the start of his lessons to minimise his time writing on a whiteboard and for a quick start to lessons. This was not possible as classrooms did not have data projectors set up in them so they had to be booked and carried to the classroom, then set up.

The reality is I will use them as much as is accessible and practical. If I have access to use those, to spend time doing computer workshops with them then I definitely will, if it fits in with the timetable. (Barry)

Erina was moving between classes which did have data projectors set up in them and did use them for her history students who were in the same room each lesson, but found it more difficult for her heath and physical education students who were in different rooms. An added consideration for Erina was the length of lessons. She found that the lessons were sometimes too short to accomplish learning activities which used digital technologies such as the observed body image lesson:

By the time I get everyone into the computer room and logged in it is half an hour max to complete the activity. They couldn't all work on their own image, not all were here when the photos were taken, they couldn't all download the image I sent them and the computer room doesn't have the capacity to have all the students working on a computer individually. There is one computer room with 30 computers. This is always booked with the IT classes. These are all barriers to the use of digital technologies in this example. (Erina)

School curriculum and rooming decisions could impact on the availability of suites of computers. This appeared to sometimes cause an access barrier for Dayna, Cath, Fiona and Ana who could not get the flexibility of using computers with their junior classes that they wanted. Conversely, school curriculum and rooming decisions made enabled digital technology use for Erina, Dayna and Fiona.

Erina had access to suites of computers, units of work that had digital technologies integrated prepared in advance and a school-based curriculum which included computer skills when students were in year 9. When Erina wanted to teach students about body image through a Photoshop activity, the activity was prepared for her in advance and the students were familiar with the programme, having been introduced to it the previous year. 
School policies and procedures were found to be a barrier to digital technology use in some schools. Blocked websites were hindering Fiona and Ana. Fiona used the technicians to gain access to the blocked sites she needed. Ana tried to use proxies to access blocked sites.

The school where Fiona taught had a policy of blocking students from accessing the computers for misdemeanours:

There are students here who come from homes with very little money. Students who don't have access at home get on the computers and they just want to play games. When they do that I shut them down quickly and they lose their licence. A loss of licence is a barrier that you come across - it means that students can't go on to the computers.

Students would also lose their licence for uniform infringements.

Dayna and Fiona both had access to a pod of computers next to their classroom. This enabled them to integrate computer use with their senior students. This contrasts sharply with Cath's experience in her second school where the school policies appeared to limit access to computer suites and interactive whiteboards (which were only available to the senior mathematics teachers).

Structural barriers were not limited to the school system; the qualifications system also held barriers to the use of digital technologies. Dayna identified one such barrier:

The closest I have got (to using digital portfolios) is digital submissions. The students think it is great - it saves them money. NZQA doesn't accept this for their final submission yet. Some kids do animations that must be turned into 2D images onto a board. It takes them ages then they have to flatten them for their final assessment. It is crazy. (Dayna)

Structures in schooling and the wider education system can inhibit or enhance the use of digital technologies by beginning teachers.

\section{Beliefs and attitudes}

The teachers' beliefs and attitudes or disposition could be an indirect barrier or enabler for the use of digital technologies in teaching and learning. Fiona was clear about what she aimed to accomplish in her teaching and learning and was assertive in getting what she needed to accomplish this: 
I currently don't have a data projector in the room I will be teaching in. But I have a bit of weight and I am going to push for it. I have been quite vocal. I get on quite well with the person in charge. He has even said to me 'Fiona, I forget that you are a beginning teacher'. And that is why you don't always come to mind for stuff.

Barry was proactive, being able to tap into the support he needed to be successful. He had a strong support network which he nurtured. Dayna had a can do attitude:

I got the computer at the end of last year as I asked for it - I said if you want me to do any work over the summer I need a laptop I am going to Auckland for the summer, so they gave me this one.

Ana did not believe that she had the power to gain access to digital technologies or change procedures:

Then again, how am I going to get them onto the computer - there is a room next door but how am I going to get them onto it. I would like to, but it is the story of my life. How am I going to get them to do it?

Cath, like Ana, did not have the support she needed, or the perceived ability to gain access to use digital technologies in the second school she taught in. This did not appear to impact on her belief in the importance of using digital technologies with students to enhance their learning.

The differences in attitude and context had an effect on the teachers' ability to overcome barriers to the use of digital technologies. Fiona and Dayna were able to find solutions to barriers they faced through innovation or by asking for help. Barry overcame barriers by accessing the support he needed. Ana found it difficult to overcome the barriers she faced.

The factors identified as barriers to enabling teachers to use their knowledge of digital technologies in their teaching practice overlapped. When they were present they were perceived as enablers and when they were absent they were barriers. The barriers and enablers were coded to two overlapping orientations: context based (including access, support and school structures) and personal based (experiences and beliefs). The teachers were innovative in overcoming barriers, especially where they had a sense of agency, and the presence of barriers did not deter them from aspiring to use digital technologies in the longer term. 


\section{How do beginning teachers connect and collaborate in their teaching and professional learning?}

The most common way that beginning teachers connected for the purpose of professional discussions was through face-to-face meetings with colleagues, other teachers or friends. Email was used between meetings or to keep in contact, though text message was found to be a preferred way of communication with the beginning teachers. The researcher found that keeping in contact by text message was more effective than through email, usually generating a response within 24 hours, whereas emails were sometimes left unanswered. The teachers stated that they preferred contact to be made through text message.

Professional discussions ranged from formally timetabled discussions to informal chats at a chance meeting. All the teachers were included in PRT support (except Cath when she was teaching in England) though the extent of the programmes varied greatly between the schools from one regional meeting with other PRTs and one observation by the head of department (in ten weeks) to structured weekly meetings where agenda items included latest research, behaviour management, pedagogy and supporting students.

Types of connections and collaborations included sharing resources, ideas and skills or knowledge about using digital technologies. Dayna reported sharing resources with the head of the art department. She shared boards she had made up and the head of art had shared teaching and assessment ideas. Barry had been shown the anatomy and physiology by a friend and the body image lessons that Erina was using were shared through the physical education and health department. Ideas were also shared between teachers. This could happen during informal meetings such as Dayna's lunchtime discussions with her head of department, or Barry's conversations with the

other physical education teachers. Knowledge about how to use programmes was also shared; Erina was shown the basics of Photoshop by a colleague and Fiona learnt about wikis from her head of department.

The beginning teachers reported learning or gaining ideas from their students. Cath was given the idea of video analysis, Barry was persuaded to allow the students to use the calculator function on their cell phones and Ana's students helped by finding the proxies or websites. All the beginning teachers gave examples of instances when they listened to their students, though they were not asked about this. The examples are spread through answers to different questions. Fiona was observed asking 
students for input into what to include in a class wiki; Dayna had the students involved in providing music for the classroom.

Beginning teachers did use digital technologies to access information and resources for teaching purposes, but not Web 2.0 social networking. Web 2.0 interactive technologies only impacts in the area of communicating with peers beyond teaching. Therefore digital technologies have not impacted significantly on the ways that beginning teachers connect and collaborate to engage in professional learning, beyond emailing information or organisational functions.

\section{What learning occurs in a beginning teacher's classroom as students use digital technologies?}

The digital age learning matrix was developed to examine the potential knowledge creation and connected sharing of the knowledge in learning activities used in a school setting (this is explained in Chapter 2). Interviews and observations included how learning activities fitted onto the matrix and within each case study description these were examined.

The intention of the learning was examined using the digital age learning matrix as a framework for part of the data collection and analysis. Through the use of the digital leaning matrix learning activities were examined for the inclusion of critique, connections, collaboration or creation of knowledge. The actual learning that occurred was not examined in detail as it appeared to be beyond the scope of this thesis, though in three of the case studies a sample of students shared how and what they were learning as they were using digital technologies and the teachers in interviews commented on the success of particular learning activities.

\section{Depth of learning activities in the digital age}

Each of the case study teachers had students physically using digital technologies at different times during their first year teaching. A sample of the activities is included in Table 19 including examples from the technology, arts, mathematics, physical education and social sciences curriculum areas. The examples in the table are explained further in the previous chapter in each of the case study descriptions. Table 19 was developed by examining a selection of learning activities that the case study teachers reported they had used during their first year of teaching. The learning activities where students used digital technologies were each designed for different 
Table 19: Summary of learning activities using digital technologies

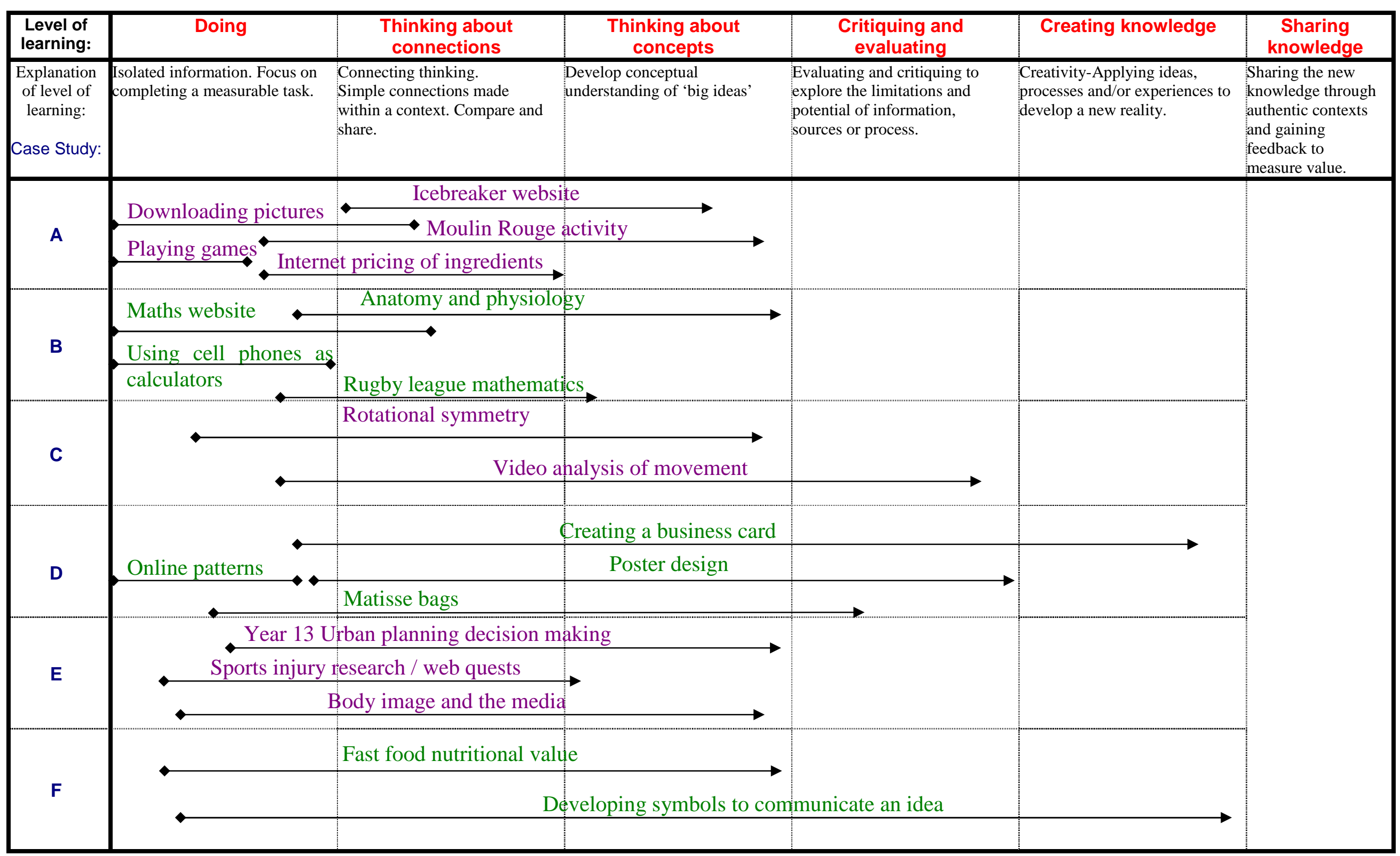


learning purposes. When the activities were examined for what the students were being asked to do (the learning intention), it was evident that some activities had the purpose of the students completing a measurable task, such as downloading pictures from the internet, and other tasks were requiring students to develop conceptual understanding, such as in the anatomy and physiology example discussed in case study B, and others were requiring students to create their own reality through applying concepts or processes, such as developing symbols to communicate an idea.

All of the teachers in the case study schools included at least one activity using digital technologies which focussed on students understanding concepts within the subject they were learning. Cath included a learning activity that explicitly included critiquing and evaluating digital video of physical movement in physical education. Two of the teachers, Dayna and Fiona, included an activity which involved the students creating knowledge with the use of digital technologies. Dayna applied the idea of creating knowledge to her teaching in art:

If they can get the conceptual and holistic view of what art can be - like artists models, how to use artist model - like I am going to use this person's techniques, how they apply the paint and I am going to use this person's composition. If they can understand how they can combine that and that they are pretty much sorted because they use that and that and it becomes their own work, even though they have copied other people's work, they have only taken a small part. That would be knowledge to me, understanding those concepts.

Most of the learning activities required students to make connections and aimed towards developing conceptual understanding. These tasks may have led to greater conceptual understanding through later learning activities; this research focussed on the learning activity using digital technology.

Learning activities from case studies D and F included critically evaluating ideas or concepts and then creating knowledge or intellectual property. The learning activities which included critique, evaluation or creating knowledge were all activities within the teachers' specialist field of pedagogical knowledge and experience. None of the teachers included sharing knowledge, the higher level of knowledge creation in a connected digital society.

\section{Engaging students}

But sir, I haven't figured out whether I am male or female yet. (Student comment at the end of a lesson, case study B) 
The use of digital technologies was found to engage the students in learning. This was observed and reported by the teachers and students.

Engagement was noted in the following forms:

Students who did not want to leave class, for example:

Autumn then takes over using the mouse and the technician guides her as she asks for help. The bell goes, but Autumn doesn't move until she has got the letters coloured about five minutes later. (Observation notes from case study F)

Students were enthusiastic about learning:

Researcher: Are you likely to go to this site again?

Student: Probably this afternoon to show my Mum: "Mum, look at what we did!"

Students who said they were likely to return to the learning activity in their own time later:

Researcher: Are you likely to access these websites beyond this class?

Student: Yes, definitely and for study and stuff. We will use this to revise from home. So it is pretty good.

Students observed to be on task during the lessons.

The students and the teachers did not make any negative comments about interest or motivation when using digital technologies, beyond a few students who were sidetracked by the topic of brain sex in case study B:

But really only two of the students got off task, they are the least mature in the class I expected that, they focused on the brain sex aspect, which is useful information, but not anatomy which they needed to focus on, so they did go back to the anatomy.

The engagement could be attributed to three factors: the multisensory nature of learning activities, the support they receive while learning, and the personalisation of the learning activity.

Cath noted that the use of multimedia presentation software increased engagement in her senior classes:

PowerPoint - I do that quite a bit. I find kids tend to focus more when I put things on a PowerPoint with pretty colours and pictures. I use this more for year 12-13. 
The engaging effect of the multimedia was also noted in case study B by a student:

It is pretty interesting. You understand it more. When I do this I know straightaway if I am wrong and I learn the right answer. I read it and it shows me pictures. It is quite interesting. I am aiming for a career in sports and this is something I really need to know.

The above quote includes a reference to other reasons for engaging in the learning; the learning activity was deemed to be interesting and relevant to the student's career path. Barry's carefully designed anatomy and physiology learning activity was an example of personalising learning to successfully engage his students:

The students did as hoped. I was worried that the students would get bored, the activities wouldn't sustain them and they would get off task.

He designed the learning activity to engage the students in learning by personalising it to meet their learning needs, building on what they had previously learnt, including a limited number of targeted websites connected through a home page and including links to how the learning might fit in with future careers and tertiary learning opportunities.

For the class of underachieving boys that Barry taught he personalised their learning by utilising their interest in rugby league:

The league hooked them in and they were able to watch it in class time, they like the competitive aspect and taking on the persona of a person.

Students reported engaging in learning because they could go at their own pace, they knew what they had to learn and were able to get immediate feedback on whether they had learnt it:

It is a good way to learn because you get to read about it and do the activities, learn about the stuff as you go, at your own pace. When I do the worksheets sometimes I don't understand them as I don't have all the information but here I can go and look at all the information. You can look at it then try and do the tests. (year 11 student, case study B)

The learning activities started from a basis of what was familiar to the students then moving them to the unfamiliar as a way of scaffolding student learning. Students were encouraged to engage in the unfamiliar through peer support and by being able to move at differing paces, depending on their own individual and group's learning needs. During an observed lesson, Barry spent time with every student in the class to discuss their learning progress: 
I watched all of them have a go at the muscle game. I watched at least half of them do the test on that. Which was good to see. They did look at the skeleton and I didn't mind them doing that as we have done this, we have looked at the bones, as this goes with the muscles. I have no problems going with the bones as we have done it.

Students interviewed in case studies B and F knew what they needed to learn and were able to find information they needed using the sites their teachers had directed them to on the internet:

[the internet is...] Better because it is easy to find what we want to learn. I find it a lot more easy, there were so many more (symbols) and it is so much easier to find things on the internet than a book. (year 12 student, case study F)

The students were able to get help through the website information when using interactive programmes or from their peers when they needed it:

$\ldots$ it is easier to learn because it is like one on one time, not waiting for the teacher to go round all the other students. (year 11 student, case study B)

The students felt they were in control of their learning and this was seen as a good thing:

The six teachers in the study were using digital technologies to personalise learning for their students to a greater or lesser extent, with the purpose of maximising their achievement through the students engaging in the learning. Examples of personalising learning included giving students some control over their learning through choice, pace and knowledge of expectations, linking learning activities to student interests and passions and by giving individuals targeted formative feedback on their learning progress.

In the observed classes the students were well supported in their learning both from peers and from their teachers. This support was likely to have helped engage students in learning through direct support and indirectly through the learning environment which had been created.

In all the observed classes the students worked together in informal groups of two or three and shared ideas and learning as they went. If they could not work out something in their small group they would turn to others in the class. Examples include a student calling out across the class to another group of students 'where is the voice box fellas?' (year 11 student, case study B) and in case study D a pair of 
students leaned back to ask for help from another group to make a bouffant hair style.

Three of Fiona's students noted her dedication and direct contribution to their learning:

I learnt how to trace that then how to make it like a blue outline then I could draw on top of it which I would never have known without (the teacher). She is really good because she will offer you one on one like in breaks and stuff.

Yeah definitely - she's real dedicated.

Yeah real dedicated. (three students talking about their learning, case study F)

Digital technologies were seen as a way of improving the ability of the teachers to personalise learning:

....as we move on to body image, definitely use it there. They have to design a poster. But I am going to say you have to do a presentation, they can do a poster if they want, but they could do a PowerPoint, a Protopage, a webpage, I found last year teaching in the classroom they didn't get the most out of the learning. I think I can do it better using the digital technologies.

There are huge amounts of information about body image on the internet. The information I can talk to them in class are quite limited in terms of the scope of what is out there. What it also does is allow them to express it in way that is relevant to them. When I just say bang, do a poster some of them it might appeal to, but a lot sigh. By giving choice and options and something new to try that they don't always get the opportunity to do then that gives them the opportunity to put in the effort to really give it a go. That is what I want with this class. I expect at least half the class to gain merit or excellence. They are working towards that now, but to achieve it I need to increase that interest.

In some of the contexts the students reported that they did not usually use digital technologies at school for learning:

We don't use computers in other subjects, except in geography. (year 11 student, case study B)

It could be expected that the students' engagement was due to the novelty factor of a different type of lesson, but this was not evident in the student think alouds where a range of reasons for engaging in the learning activity were reported, none of which could be directly attributed to the novelty factor.

The case study teachers used a range of learning activities for differing purposes. The lessons with digital technologies engaged students in the learning process, and this was not due to the novelty factor alone. The digital age learning matrix provided a framework to evaluate the depth of learning and it was evident that all teachers used 
digital technologies to help students to understand concepts. Some of the teachers went beyond this to have students critique and evaluate ideas, and two had students creating knowledge. None of the activities aimed to have students sharing their ideas and receiving critique beyond the classroom environment.

\section{Summary}

The beginning teachers in this study were using a range of digital technologies in their teaching practice. They used their cell phones more than email, presentation software to organise lessons and to present information to students, digital photos and video as an assessment tool and record keeping, and students were learning through the internet, software programmes and subject specific technologies. The purpose for using digital technologies included engaging students in learning, accessing information, preparing students for the world beyond school to complete administration tasks, using time effectively, saving money and saving the world by reducing the school's carbon footprint.

They chose to use digital technologies in their teaching practice due to their aspirations, support they received and the access they had. Each teacher brought a unique disposition, knowledge set and range of experiences to teaching which influenced their aspirations to use digital technologies. The access, structures and support afforded by the context in which they were teaching made it possible or difficult to use digital technologies, along with the learning environment they were able to establish. The support varied within the context that the teachers were based though common to all the teachers was an appreciation of technical and pedagogical support. Schooling structures, policies and procedures influenced decisions made about the use of digital technologies including: timetabling, location of digital technologies, exam requirements and school policies such as consequences for student misbehaviour that all impacted on how and if the teachers used digital technologies. The access that the teachers had to digital technologies also varied and was influenced by cost, school policies and procedures, sense of agency, support and time. Irrespective of the difficulties faced, the teachers became increasingly confident in their ability to integrate digital technologies into their practice over their first year of teaching. 
How the beginning teachers chose to use digital technologies was influenced by their own experience of using digital technologies. Experience of generic technologies and programmes led to the use of presentation software and internet inquiry type projects. Alongside other factors were the teacher's disposition, which influenced their ability to build and maintain their personal learning networks, their resilience when facing setbacks and their sense of agency. Beginning teachers did use digital technologies to access information and resources for teaching purposes and for communication with peers, but were not utilising Web 2.0 functionality for professional learning.

The students were engaged in learning while using digital technologies; the engagement was due to sound teaching practices and the dedication of the teachers. When using digital technologies the teachers were able to personalise learning, allowing students to go at their own pace and to have choice in their learning, which engaged the students in learning. The digital age learning matrix emerged by applying ideas of connectivism and creativity to measure the learning potential of teaching activities which use digital technologies. Using this tool for analysis resulted in the identification of a pattern that reflected a correlation; the learning activities which included critique, evaluation and creating knowledge were within the subjects of the teachers' undergraduate degree majors and what they had experienced using concept specific digital technologies, which appears to have extended their pedagogical content knowledge.

Large scale surveys and quantitative data to examine beginning teachers' experiences of using digital technologies was considered at the research design phase of the thesis, but a quantitative study would not have resulted in the examination of the complexities faced by teachers. The complex influences that impact on the beginning teacher as they seek to transfer their knowledge to use digital technologies with their students was examined through multiple case studies. Then the findings from the case studies were compared so that each case study was understood further, and conclusions were able to be drawn as the sum was more than the parts. 


\section{Chapter 6. Discussion}

\section{Nā tō rourou, nā taku rourou ka ora ai te iwi}

With your food basket and my food basket the people will thrive

This study aimed to ascertain how digitally able beginning teachers use digital technologies in their teaching practice. This chapter draws together the findings from the case studies with existing understandings from research literature about learning and beginning teaching in the digital age. It begins by examining the knowledge that the beginning teachers brought with them to their teaching context and whether the teachers were able to apply their knowledge to their teaching practice within the complexities of a school. The content and learning intention when using digital technologies are evaluated and discussed. Complexity theory is revisited and how secondary schooling could be categorised as complex systems is explored, including aligning the pedagogical reasoning and action model developed by Shulman (1987) with ideas about knowledge creation, teaching and learning in the digital age. The chapter concludes by examining the context of beginning teachers and how this influenced the research, the implications of the research and future research.

The research was conducted through a complexity theory conceptual framework on the ideas of theorists such as Davis and Sumara (2006), Morrison (2002), and Waldrop (1992). The constructs are visually presented in Figure 31. A complex system (in this study a school) has a number of aspects which make it unique (for example, its structures, history, processes, data or information, and people). These aspects are interconnected (as shown with random black lines) and change over time, but the integrity of the system (yellow octagon) remains in tact. The boundaries of the complex system are open so that information and ideas can pass between the parts of the system (black lines) and systems or aspects beyond (a-f). The connections between the parts are where knowledge emerges as the system evolves due to change within or from beyond the organisation. The system changes as new ideas, processes, or practices are introduced and developed (diversity) or become redundant. The emerging knowledge is not predictable. This knowledge development is underpinned by connectivist learning theory (Siemens, 2004). 


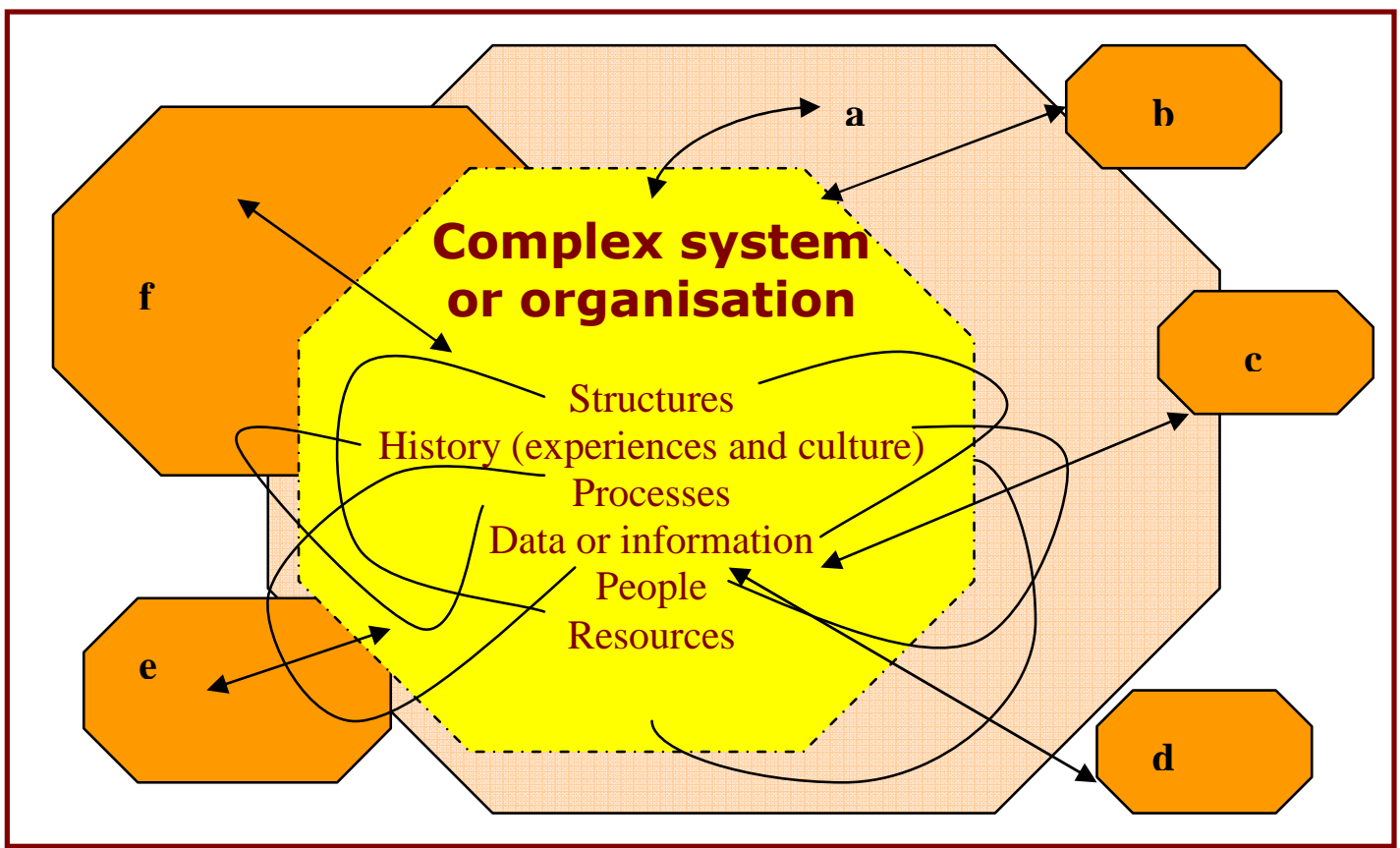

Figure 31: Model of ambiguously bound complex system with connections within and beyond its boundaries.

\section{The people- the beginning teachers.}

Teachers in New Zealand secondary schools make decisions about how they will teach their students within the boundaries set by school and national policies and procedures. Applying the model in Figure 31, the complex system would be the school. The beginning teacher would be a subset of the people in the school. The school would be a nested structure (Davis and Sumara, 2006) of the New Zealand education system ('a' in the above diagram) which includes national policies and procedures that the school system must follow. The way teachers make decisions is illustrated in Figure 32. The beginning teachers made teaching decisions about using digital technologies with their students by transferring their learning; by drawing on their pedagogical content knowledge, their experiences in using digital technologies and by considering what was feasible in the context in which they were teaching. 


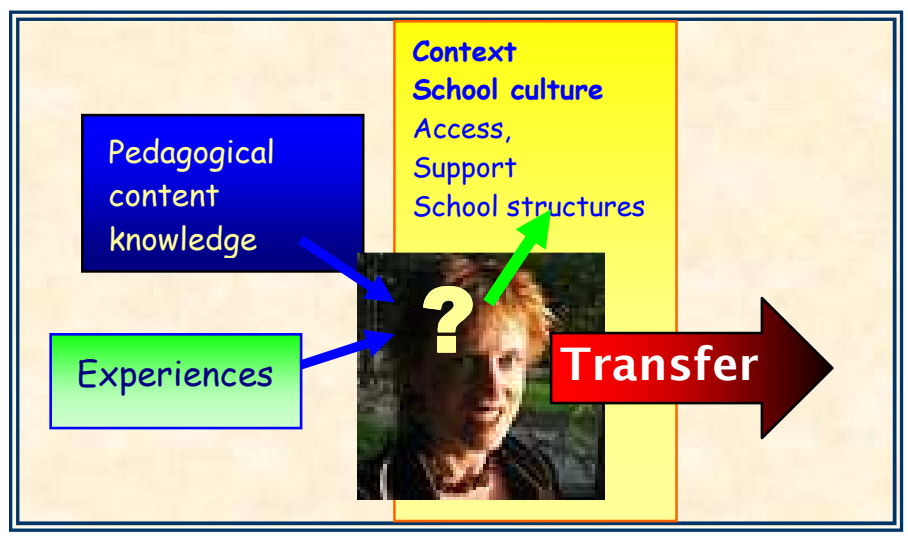

Figure 32: Transferring learning: considering whether to use digital technologies

\section{Base knowledge brought to teaching}

Differing types of transfer of learning are identified in the literature. The cognitive approach to transfer of learning involves complex and dynamic processes likely to be appropriate for transferring knowledge or experiences in a digital era. A cognitive approach recognises that when a learner is in a new context or situation they bring with them their beliefs and experiences which includes four types of knowledge: conceptual knowledge, procedural knowledge, strategic knowledge and tacit knowledge (Bransford \& Schwartz, 1999).

The way that the case study teachers transferred their learning followed a cognitive approach as outlined in Figure 33. Their conceptual knowledge included concepts and methodologies learnt through academic and informal study of their specialist subjects and the preservice teacher education diploma programme, procedural knowledge gained through informal and formal learning of how to use of digital technologies, strategic knowledge linked to curriculum implementation and tacit knowledge such as techniques to engage students and keep them focussed on learning. These four types of knowledge together contributed to the teachers' knowledge, and align with Shulman's (1987) base knowledge for teaching which includes pedagogical content knowledge, conceptual knowledge, pedagogical knowledge, contextual knowledge and knowledge of educational purposes and values. By applying their existing knowledge (base teaching knowledge) to the new situation of using digital technologies in a learning context with their students, the teachers in the study were applying a cognitive approach to transferring learning. Figure 33 illustrates how the types of knowledge and experiences of the beginning teacher interact to form the basis of knowledge that could be transferred to the teaching situation. 


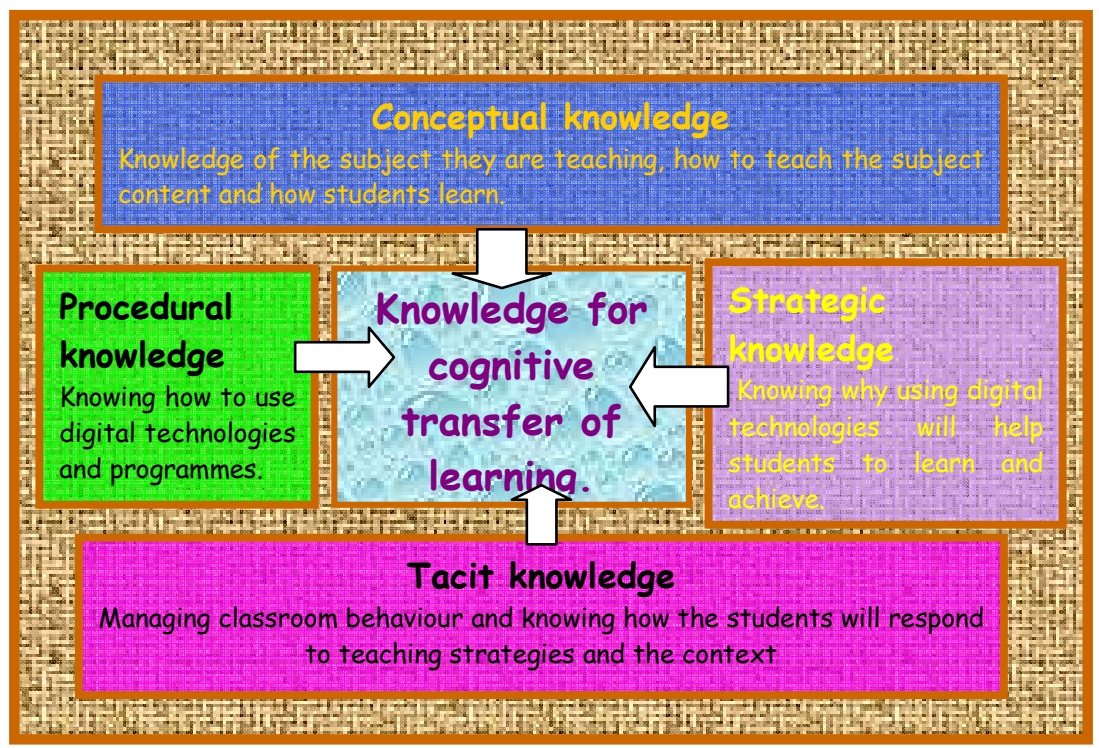

Figure 33: Base knowledge for cognitive transfer of learning

The base knowledge transferred was found to include a complex range of factors. Clifford et al. (2005) had found that student teachers who were confident in the use of digital technologies in their personal use were not necessarily confident in decision making in planning and implementation of digital technologies in their teaching practice. If the beginning teachers were not able to make the cognitive connections between their pedagogical content knowledge and their procedural knowledge of using digital technologies, then it is understandable that they would lack the confidence to integrate and transfer their knowledge to the classroom situation.

Researchers have identified the importance of teaching philosophy on the willingness of experienced teachers to introduce digital technologies to their teaching and the way that they use digital technologies (Becker, 1999; Clifford, 2004; Cuban, 2001). Studies have noted the importance of teacher beliefs in the use of digital technologies (Ertmer, 2005; Goos et al., 2003; Hernández-Ramos, 2005; Moseley et al., 1999). The general conclusion drawn from these studies is that teachers use digital technologies in ways that align with their beliefs. For example, teachers with a transmission approach to teaching saw digital technologies as learning with technical tools (Levin \& Wadmany, 2005) or teachers with constructivist beliefs used digital technologies in constructivist compatible ways (Becker \& Riel, 2000). The initial intention of this research was to explore the types of beliefs that may be relevant to transferring learning in the digital era, but this was found to be problematic. The teachers in this study were able to explain what they believed the role of the teacher in the learning process should be to a greater or lesser 
extent through terminology and ideas commonly used in the teaching qualification that they had recently completed. Being recent graduates they knew how they had been taught to teach using a range of teaching strategies to scaffold student learning, building on their prior knowledge and giving frequent formative feedback to students on their progress towards identified learning outcomes. The practice they had observed, the way they had experienced being taught and the way they taught themselves may not align to their expressed beliefs therefore it was difficult to put their beliefs into their pedagogical practice. Such a result was found by Chen (2008). As exploring beliefs was problematic, it was decided to focus on the way that the teachers approached teaching and their intended learning outcomes through the use of an evaluation tool which was developed and applied. Examples of teaching using digital technologies were aligned to the digital age learning matrix to evaluate the potential learning.

Karsenti et al. (2002) found five factors behind the motivation of student teachers to integrate ICT into their teaching. These included:

- the integration of ICT in their placement classrooms

- the student teacher's level of computer literacy

- the pedagogical integration in the teacher education programme

- the future teacher's expectations of success in integrating ICT

- the value placed on ICT by future teachers.

The first three in this list were found in this research to contribute towards developing the student teacher's pedagogical content knowledge, though on a superficial level unless awareness was being raised through explicit discussions connecting ideas about digital technologies and pedagogical content knowledge. A factor not included in the research by Karsenti et al. (2002) and identified in this thesis was the importance of knowledge and experiences from undergraduate degrees and work experience.

The type of knowledge that seemed to significantly influence how the beginning teachers in the case studies used digital technologies was their pedagogical content knowledge. The greater this knowledge within the field that the teacher was teaching, the more likely they were to use digital technologies with students in a way that encouraged critique, evaluation and knowledge creation as outlined in the digital age learning matrix. 


\section{Pedagogical content knowledge}

Shulman (1986) developed a framework for teacher education in which he introduced three content knowledge bases essential for teaching: subject matter content knowledge, pedagogical content knowledge and curricular knowledge. Subject matter content knowledge is the academic knowledge of the subject including the substantive knowledge (concepts and principles) and the syntactic knowledge (subject methodologies). Pedagogical content knowledge is how to make the subject comprehensible to others, to help learners construct an understanding of the subject. Shulman (1987) suggested that pedagogical content knowledge was essential knowledge for teachers:

The key to distinguishing the knowledge base of teaching lies at the intersection of content and pedagogy, in the capacity of a teacher to transform the content knowledge he or she possesses into forms that are pedagogically powerful and yet adaptive to the variations in ability and background presented by the students. (p. 15)

Pedagogical content knowledge is unique to teachers and separates a subject expert from a subject teacher, for example, an historian from a history teacher. Curricular knowledge varies depending on the nation's policy about control and resourcing of the curriculum. Shulman includes software, text books and other resources as curricular knowledge. In New Zealand curricular knowledge is more commonly associated with knowledge of implementing curriculum documentation, department schemes and teaching aims as developed by the state, school or department. Teaching resources and tools including digital technologies are selected by the teacher or teaching department, so therefore they would be categorised as pedagogical content knowledge.

Pedagogical content knowledge was found to be an important influence in how and whether the beginning teachers used digital technologies. When teachers in this study were teaching a subject in which they had transferred strong pedagogical content knowledge, the learning activities that they had designed for students that included digital technologies had a greater depth of learning on the digital age learning matrix. Activities where students were critiquing, evaluating and creating knowledge were where the beginning teacher had a thorough grasp of the subject content and methodologies in the subject being taught. Learning activities which had been designed by the teachers where they had strong pedagogical content knowledge were reported and observed to engage students in the learning process, showing strong evidence of personalising learning for the students. 
Effective teaching practices (pedagogical knowledge) were evident where the teachers designed learning activities which included the use of digital technologies within a topic in which the teacher had strong pedagogical content knowledge. This included developing learning relationships with students, having students active in the learning process, giving formative feedback to students on their learning progress, having the content meaningful to the students, differentiating learning so that students can learn at a different pace to peers, having choice within constraints and the teachers having high academic expectations of the students. These features were seen in lessons such as Barry's anatomy and physiology example and align with effective teaching practices outlined in the best evidence synthesis for quality teaching (Alton-Lee, 2003).

In a meta-analysis of research findings about the effectiveness of using ICT for teaching and learning, Cox et al. (2004) concluded that teachers need a range of knowledge about the affordances of digital technologies, including how digital technologies can help students to understand concepts and develop skills within the subject disciplines; this infers not only a knowledge of potential digital technologies but also pedagogical content knowledge. This is an area where beginning teachers are different to experienced teachers. Barry, Cath, Dayna, Erina and Fiona each reported they had encountered digital technologies infused in their undergraduate degrees (and workplace experience for case studies B and F) which informed their substantive and syntactic content knowledge, establishing a knowledge base that can be transferred to integrate technologies into their classrooms. They did not start from a base of pedagogical knowledge then add digital technologies to it as an experienced teacher with limited experience of digital technologies in their subject might.

The knowledge for cognitive transfer of learning is integrated in Figure 34, shown in green, blue and pink/violet to match the types of knowledge identified in Figure 33. This knowledge, which tends to be specific to the individual teacher, is transferred within the context in which the teacher is teaching and is subject to influences from within that context. The result is that digital technologies are or are not used in the teaching and learning process. 


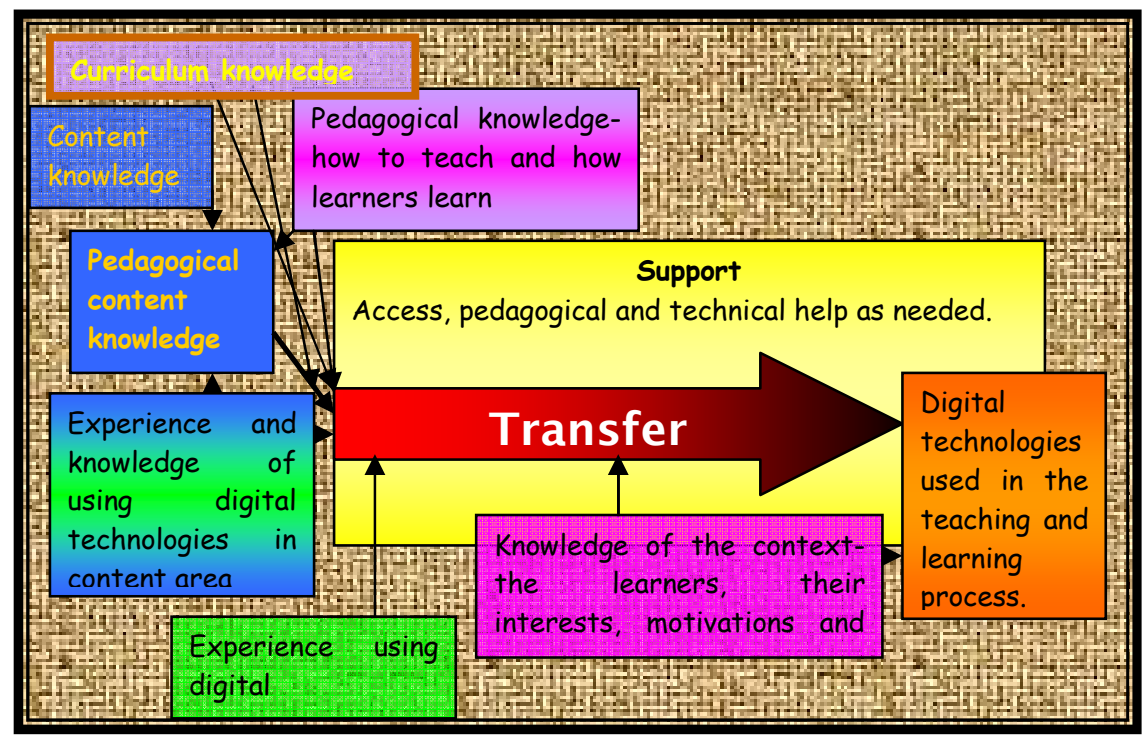

Figure 34: Complexity of transferring knowledge

\section{Transferring base knowledge to the school context.}

There is a range of complex interrelationships in the model outline in Figure 34, and every context will yield unique results. However, the key elements of the teachers in the case studies as they transferred learning have been captured in the model and these align with Shulman's (1987) base knowledge for teachers. During transfer, the relationships and support the beginning teachers had were found to be important and closely connected to the context of the teacher and their disposition.

The teachers in the case studies transferred their pedagogical content knowledge and their experiences using digital technologies to their teaching practice, enabled or restricted by their disposition and the support and access available in their teaching and the broader context. As a specific example to illustrate how this transfer occurred, Figure 35 illustrates how Barry taught his students about the role of muscles and bones in body movement applying strategic, conceptual, procedural and tacit knowledge. 


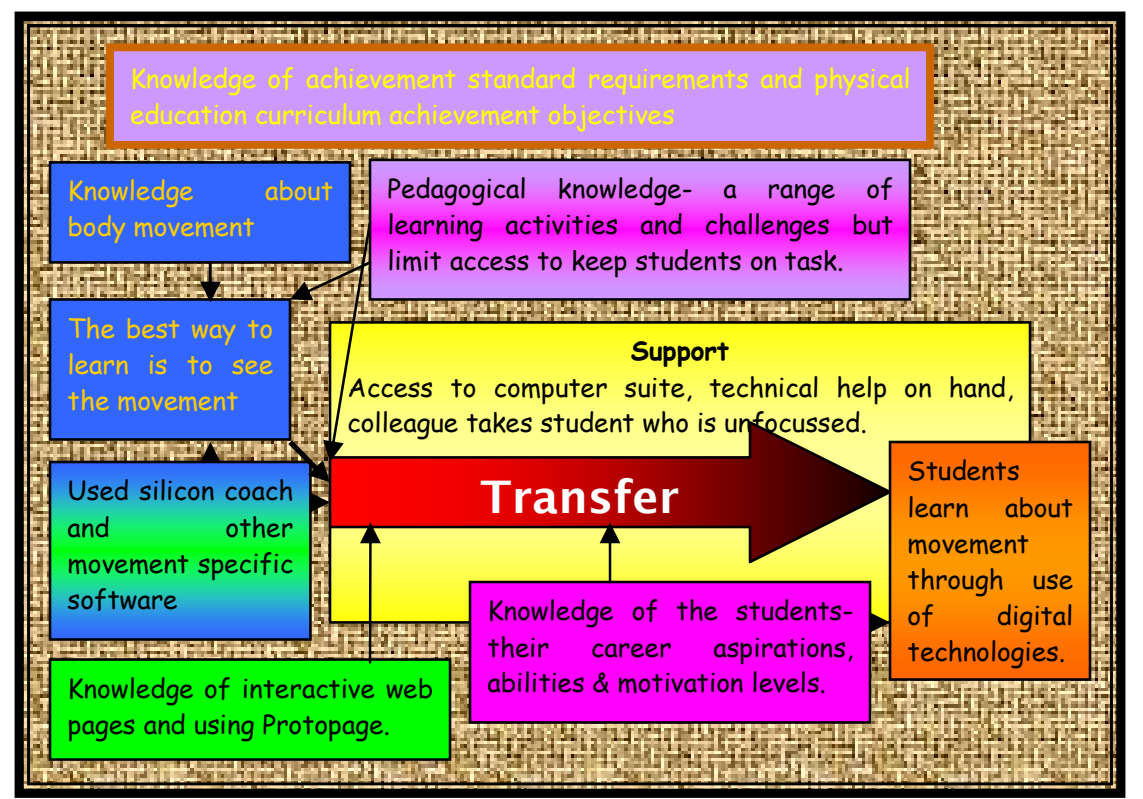

Figure 35: Complex cognitive transfer of learning, case study $B$

A failure to transfer has been found to be due to a lack of a knowledge base in young children (Brown, Kane, \& Long, 1989). It appears that where the knowledge base of the use of digital technologies in the specialist teaching areas was strong, the transfer and the resulting learning activity were also strong. Where the beginning teacher lacked experience and knowledge of digital technology use in their teaching subject, the learning experiences were unlikely to involve critique, evaluation or knowledge creation.

\section{The school- the complex organisation}

The schools in which the beginning teachers were employed are complex organisations. As such each had unique, though sometimes similar processes, culture, history, resources and people. The beginning teachers became part of the complex organisation and faced barriers and enablers as they sought to use digital technologies in their teaching practice through transferring or applying their base knowledge.

Established teachers have been found to have high expectations of young, digitally literate beginning teachers, also known as 'digital saviours' (Cowie et al., 2008; Karsenti et al., 2002). However, beginning teachers do not have the depth of pedagogical content knowledge that experienced teachers have, so to be the saviours they will need nurturing.

The context in which a beginning teacher was teaching influenced their use of digital technologies through the school's policies, procedures and culture which impacted 
on the access, support and expectations of the students. Research into experienced teachers' use of digital technologies has found a number of contextual and teacher knowledge factors which influenced their use.

Becker (1999) identified eight factors that facilitated greater levels of internet use by teachers. These are compared with findings from the beginning teachers' use of digital technologies in 2007/8, and are included in Table 20 and the findings from this study are compared alongside it.

Table 20: Comparison of Becker's enabling factors with findings from this research

\begin{tabular}{|c|c|}
\hline $\begin{array}{l}\text { Becker (1999)-factors which } \\
\text { facilitated greater levels of } \\
\text { internet use }\end{array}$ & $\begin{array}{l}\text { Comparative relevance of Becker's factors to } \\
\text { beginning teachers, } 2007 / 8 \text { using digital } \\
\text { technologies }\end{array}$ \\
\hline $\begin{array}{l}\text { High levels of classroom } \\
\text { connectivity: (meaning internet } \\
\text { connection) }\end{array}$ & $\begin{array}{l}\text { Easy access and knowing how to gain access to digital } \\
\text { technologies was important. }\end{array}$ \\
\hline Computer expertise: & $\begin{array}{l}\text { Experience of using subject specific digital technologies for } \\
\text { learning }\end{array}$ \\
\hline Constructivist pedagogy: & $\begin{array}{l}\text { Depth of pedagogical content knowledge appeared to influence } \\
\text { innovation in teaching practice }\end{array}$ \\
\hline $\begin{array}{l}\text { Participation in staff } \\
\text { development: }\end{array}$ & All teachers were involved in professional development \\
\hline $\begin{array}{l}\text { High frequency of informal } \\
\text { contacts with other teachers; }\end{array}$ & $\begin{array}{l}\text { High frequency of informal and formal contacts with other } \\
\text { teachers }\end{array}$ \\
\hline $\begin{array}{l}\text { Involvement in professional } \\
\text { leadership activities: }\end{array}$ & $\begin{array}{l}\text { While Dayna, Barry, Fiona and Erina were all involved in decision } \\
\text { making about the use of digital technologies in their department } \\
\text { or school, it did not seem to impact on their own use of digital } \\
\text { technologies. }\end{array}$ \\
\hline Being a young teacher; and & $\begin{array}{l}\text { The teachers in this study were aged } 21-35 \text {, experiences } \\
\text { appeared to be more relevant than age }\end{array}$ \\
\hline $\begin{array}{l}\text { Not being a mathematics } \\
\text { teacher. }\end{array}$ & $\begin{array}{l}\text { Maths teachers used subject specific digital technologies rather } \\
\text { than generic internet based technologies } \\
\text { Teaching and designing learning activities in their major subject, } \\
\text { where they have in-depth pedagogical content knowledge was } \\
\text { more important than the subject being taught. }\end{array}$ \\
\hline
\end{tabular}

Becker's enabling factors included ideas about the teacher (computer expertise, constructivist pedagogy, being young and not teaching mathematics) and contextual factors (classroom connectivity, staff development and leadership) and dispositional factor (frequency of informal contacts with other teachers). The findings from the case studies have highlighted that rather than general computer expertise, it is experience using digital technologies in the subject specific area that enables beginning teachers to enhance student learning, and more important than 'constructivist pedagogy' was the depth of pedagogical content knowledge, which 
would include knowledge of how to enable students to construct knowledge by building on their prior learning in the particular subject being taught. The contextual factors were found to be less specific, with access rather than connectivity being important. Connectivity would be part of the access, though in 2008 most classrooms had broadband connections. Teacher disposition, though not specifically identified, would have underpinned the informal contacts, and is discussed later.

Access to digital technologies was an issue, particularly at the start of the first year of teaching for Ana, Barry and Cath. This could be related to the enculturation process that teachers undergo as they begin teaching (Feiman-Nemser, 2003). 'Learning the ropes' to enable a teacher new to a school to use digital technologies could include; how and when to book digital technologies (e.g., cameras, computer rooms); how to access technician help; how to navigate through website blocking software; and finding out who you need to persuade to get digital technologies put into your teaching space(s). How teachers learn the ropes depends on school systems, people within the context and the relationship the teacher has with colleagues which is dependent on the teacher's own disposition.

Gaining access to the digital technologies required sometimes depended on dispositional characteristics such as being able to identify and persuade the person or people with decision making capability that having digital technologies in the classroom was worthwhile. To do this required a sense of agency, the belief that you held the power and the right to ask. A sense of agency was found to be powerful in overcoming a number of factors that beginning teachers faced in a study of graduates from Te Wananga O Aotearoa as they entered their first year of teaching (Stucki, Kahu, Jenkins, Bruce-Ferguson, \& Kane, 2006). This appears to be the case with beginning teachers as they aspire to use digital technology. Ana did not feel that she had the ability to get what she felt she needed to integrate digital technologies as she began teaching, although her sense of agency increased during the year. In contrast to Ana, Fiona had a sense of agency and was assertive when she needed resources for her teaching practice and was able to overcome barriers she faced. The sense of agency was not only dispositional; it was also influenced by the context in which the beginning teachers were teaching.

Support is dependent on the connections and relationships the beginning teacher could draw upon. It is through connections and relationships that knowledge emerges within a 
complex system (Davis and Sumara, 2006). For experienced teachers in previous research the support has been about learning to integrate digital technologies and technical support (Becker, 2000; Cuban, 2001; Ham et al., 2002; Lai, 2005). For the beginning teachers in this study the support that was reported as most helpful empowered the teacher and directly focussed on developing pedagogical content knowledge. Teachers were empowered by being included in professional conversations with colleagues where their knowledge and experience were recognised. Such examples of empowerment were reported by Barry, Dayna, Erina and Fiona. Pedagogical support that was most valued was received from teachers with strong pedagogical content knowledge in the same subject as the beginning teacher. Where there was no support available at the school they were teaching in, the teachers accessed this support through regional networks or through contacts they initiated; the extent they were able to do this depended on the disposition of the teacher.

The schools in which the teachers were based provided support. Examples of ways that the teachers reported receiving formal and informal support included:

- an experienced teacher working alongside a beginning teachers the first time the teacher took junior students to the computing room

- having technical assistance available on hand or by phone, teacher aid with computing expertise

- school policy of integrating digital technologies into learning and prepared lessons

- an introduction to computing programmes given to all year nine students

- classrooms set up with easy access to relevant digital technologies

- sets of computers available on hand

- regular meetings with a mentor with strong pedagogical content knowledge

- opportunities to discuss pedagogical and digital technology ideas with colleagues

- being included in lead groups examining how digital technologies can be integrated and

- 'browse weeks' where all classes are open for teachers to pop in to see how colleagues are teaching.

Each of these examples were either reported by one or more of the teachers, or identified as something that would have helped them (Table 21). 
The examples identified in Table 21 are those that were specifically mentioned by one or more of the teachers in the identified case studies. Teachers individually respond to and prioritise professional learning opportunities in different ways. There may have been further features which enhance their opportunities that were not recognised by the researcher or that the teachers did not mention. A school which included the features outlined in Table 21 would be an exemplary school as it would be supporting the teachers as they use digital technologies. Such a school would contrast with a school where digital technologies are rarely used and teachers are mainly teaching to a transmission one size fits all model. In such a school culture the introduction of a different way of learning by an individual teacher can result in resistance from the students as they are being expected to learn in a different way to that which they associate with school learning (Starkey \& McCarthy, 2008).

Table 21: Contextual factors that help beginning teachers integrate digital technologies

\begin{tabular}{|c|c|c|c|c|c|c|c|c|}
\hline \multirow{2}{*}{$\begin{array}{l}\text { School practices which helped beginning teachers } \\
\text { integrate digital technologies into their teaching }\end{array}$} & \multicolumn{8}{|c|}{ Case study: } \\
\hline & $\mathbf{A}$ & $\mathbf{B}$ & C1 & $\mathrm{C2}$ & $\mathbf{D}$ & E1 & $\mathbf{E 2}$ & $\mathbf{F}$ \\
\hline \multicolumn{9}{|l|}{ Formal school based support for beginning teachers } \\
\hline \multicolumn{9}{|l|}{$\begin{array}{l}\text { Having technical assistance available on hand or by } \\
\text { phone }\end{array}$} \\
\hline \multicolumn{9}{|l|}{$\begin{array}{l}\text { Opportunities to discuss ideas about teaching with } \\
\text { digital technology with colleagues }\end{array}$} \\
\hline \multicolumn{9}{|l|}{$\begin{array}{l}\text { Opportunities to discuss pedagogical practice with } \\
\text { colleagues with same from same specialist area }\end{array}$} \\
\hline \multicolumn{9}{|l|}{$\begin{array}{l}\text { Classrooms set up with easy access to relevant digital } \\
\text { technologies }\end{array}$} \\
\hline \multicolumn{9}{|l|}{ Sets of computers available on hand } \\
\hline \multicolumn{9}{|l|}{ A mentor with strong pedagogical content knowledge } \\
\hline \multicolumn{9}{|l|}{ Teacher aid with computing expertise } \\
\hline \multicolumn{9}{|l|}{$\begin{array}{l}\text { Beginning teachers included in lead groups examining } \\
\text { how digital technologies can be integrated }\end{array}$} \\
\hline \multicolumn{9}{|l|}{$\begin{array}{l}\text { School policy of integrating digital technologies into } \\
\text { learning }\end{array}$} \\
\hline \multicolumn{9}{|l|}{$\begin{array}{l}\text { Introduction to computing programmes given to all year } \\
\text { nine students }\end{array}$} \\
\hline \multicolumn{9}{|l|}{$\begin{array}{l}\text { Browse weeks where all classes are open for teachers to } \\
\text { pop in to see how colleagues are teaching }\end{array}$} \\
\hline \multicolumn{9}{|l|}{0.8 workload in first year, 0.9 in second year } \\
\hline $\begin{array}{l}\text { Teacher working alongside a beginning teachers the first } \\
\text { time the teacher took junior students to the computing } \\
\text { room }\end{array}$ & & & & & & & & \\
\hline
\end{tabular}

Key:

\begin{tabular}{|l|l|}
\hline Identified as important in the case study \\
\hline Identified as 'would have helped' \\
\hline
\end{tabular}

Mentoring was a way of supporting the professional learning of teachers. The mentoring needs to be appropriate if it is to allow for innovation (Becker \& Riel, 2000; Clifford et 
al., 2005; Hargreaves \& Fullan, 2000). What appeared to be appropriate in this study was mentoring by someone in the same field of teaching who could focus conversations and feedback to include pedagogical content knowledge and encourage the beginning teachers to develop their own ideas. This type of mentoring was sometimes found in the same school as the beginning teacher and sometimes accessed externally to the school.

Each of the teachers was in a different context, with two teachers experiencing two schools each. The teachers were teaching in a variety of types of schools reflecting the community that they serve. Some schools were situated in relatively wealthy environments, some in poorer neighbourhoods, most had a mixture. It included rural and urban schools, small and large size schools. The school context appeared to impact on the teachers' experiences as they used digital technologies, a finding that aligns with the complexity theory notion of a school being a complex organisation.

Auld et al. (2008) examined a selection of schools from Australia, identified as exemplary in their use of digital technologies. The researchers argue that there are not exemplary schools; rather there are exemplary teachers in their practice using digital technologies. The results of this research suggest that schools can have exemplary practices which increase the likelihood of teachers successfully integrating digital technologies during their first year of teaching. This includes the way that they support and encourage beginning teachers as they seek to use digital technologies.

The examples of contextual factors which help beginning teachers to integrate digital technologies in their teaching and learning are the result of the culture and leadership within the departments and the schools in which the teachers work. While I agree with Auld et al. (2008) in that it is the teacher who will demonstrate the exemplary practice when using digital technologies within student learning, I believe that this research shows that it is possible for policies, attitudes and practices in schools to be exemplary when it comes to supporting and encouraging beginning teachers to integrate digital technologies. For example, the school in case study E2 had digital technology use embedded in learning across the curriculum, the students were aware of how to use applications through being taught generic skills and Erina was in a department where the teachers supported each other in their developing understanding and use of digital technology. The school in case study E2 had similar characteristics to the school in Tearle's (2003) study of an exemplary ICT school. 
The 'training' was available to staff members, but this was low key and the department's support was strong. This contrasts with the other school in the study with aspects of exemplary practice where the support was focussed on the beginning teacher rather than the school-wide use of digital technologies. Complexity theory suggests that exemplary practices in one school may not be appropriate for a different context and two teachers in the same school may report differences in their experiences and the practices they found to support them.

The level and type of support that the teachers reported receiving in their schools varied and appeared to be unrelated to the wealth of the school community and more dependent on the relationships between the teacher and his or her colleagues, which was related to the culture of the school and the department and the disposition of the teacher. The schools in case studies B and E2 appeared to offer the strongest level of support to the beginning teachers. B was a decile 2 school $^{3}$ and E2 was a decile 10 school. The type of support received was an important influence on the beginning teachers' use of digital technologies, with the most effective support focussing on pedagogical content knowledge from a head of department who also encouraged the use of digital technologies. This aligns with the notion of the importance of connections within the complex organisation espoused in complexity theory and connectivist learning theory.

The relative wealth of the community in which the case study schools were located did not appear to affect whether and how the teachers used digital technologies, or the professional learning opportunities of the teachers. This finding contradicts ideas put forward by Hargreaves (2003) who cited research by Leadbetter (2001) and Baumann (1998) to describe a type of apartheid he believed was happening in schools where the wealthier schools' teachers connect and collaborate in their professional learning and students are being prepared to take the high end jobs in society, and the schools in poorer communities are preparing their students for service industry jobs and the teachers have little opportunity to have professional discussions. The schools that offered limited pedagogical or professional discussions to the beginning teachers included case studies A (decile 5), C (decile 6) and the first school in case study E (decile 4). Of these, school A in particular appeared to be a school that was facing difficulties with high staff turnover and the teacher feeling

\footnotetext{
${ }^{3}$ decile 10 schools are situated in wealthier neighbourhoods, decile 1 in the least affluent
} 
powerless. The strongest school or department support was reported in case studies B (decile 2), D (decile 10), E2 (decile 10) and F (decile 5). What did appear to happen is when the support was not available or forthcoming in a school, the beginning teachers themselves would gather the pedagogical support they needed by connecting to professional learning communities beyond the school, either through experienced teachers in the same subject area or contacts made while at university or socially. This aligns with research by Slaouti and Barton (2007) who found that beginning teachers in their study found a way to gather support and achieve their aims when they were faced with barriers.

In a 2005 evaluation of laptop use in New Zealand secondary schools, almost half of teachers said they were paying personally for a proportion of the lease of their laptop under the TELA scheme (Cowie et al., 2008). A school's board of trustee's decision on whether to support teachers by paying for the laptops or asking the teachers themselves to pay for their laptops reflects variation in support across different schools or in different contexts the support varies. The relative wealth of a school did appear to affect the beginning teachers' access to laptops. The boards of trustees' in the higher decile schools paid for the lease of a laptop to the teacher; the poorer schools passed the weekly charge on to the teacher. This did not seem to be an issue for the beginning teachers whose focus was on the practicalities of teaching - as Dayna (who was in a decile 10 school) noted: No-one here pays for their laptops. Do some people have to pay for their laptop? I would pay \$7 a week to have a decent laptop.

Laptop lease policy limits provision to those who are employed in a permanent position, which included two out of the six case study teachers, though by the end of the year each of the teachers had a laptop either that they owned themselves (Fiona and Cath), for which they paid a lease (Barry and Ana), or the school owned or leased (Dayna and Erina).

Differences in digital technology use exist between teaching subjects. John and Baggott la Velle (2004) examined the subcultures of teacher subject identity and their pedagogical beliefs and how this influenced aspirations for ICT use and the reality of how teachers use ICT, and found variety between subjects and within subjects. A beginning teacher would have a less well developed rhetoric on the pedagogy of the subjects that they teach than an experienced teacher, especially in their secondary subject. Passey et al. (2004) found that in four of their English case 
study schools, the use of ICT in design and technology practice was resulting in higher attainment levels than in other schools. The authors of the research linked this to the explicit design and technology process in the curriculum which aligns with the way that teachers were supporting students in the subject as they used ICT. Dayna's teaching included art design and Fiona taught graphic design, both had integrated digital technologies in a similar way as outlined by Passey et al. Ana who was teaching fashion design and fabric technology had not, indicating that it is not a simple cause-effect relationship, a finding which aligns with Prigogin's (1997) notion that complexity theory is non-deterministic and can not predict future outcomes.

\section{Teaching using digital technologies}

All the beginning teachers in the study did transfer their pedagogical content and procedural knowledge (how to use digital technologies) resulting in their students using digital technologies in their learning programmes. Through the process of using digital technologies in the teaching programmes, the teachers were personalising learning.

\section{Student centred approach}

The teachers in the study reported and/or were observed to spend most of the class teaching time working with individual or small groups of students while using digital technologies. This was the way that these teachers appeared to prefer to teach and is a way that allowed for personalised feedback to students about their learning progress. In case study B students said that they appreciated that the use of digital technologies allowed for them to be less dependent on the teacher and were therefore able to go at their own pace which was different to the way the teacher taught when away from the computers. The teacher reported that he was able to spend time with every student in the class and check their understanding of concepts. A report by Hennessy et al. (2003) proposed that as teachers increased their use of digital technologies in their teaching practice, interactions with individuals and small groups increased. This research found that when the digitally literate beginning teacher has adequate access to digital technologies in their teaching practice, interactions with individuals and small groups occur which aligns with research that has found that digital technologies may be enabling teachers who want to take a more student-centred approach to teaching to develop their practice in this way (Webb \& Cox, 2004). 


\section{Measuring learning in the digital age}

The development of the digital age learning matrix was in response to a lack of models available to measure learning in the digital age, models that included the importance of a flexible curriculum, collaboration, making connections, students creating knowledge, critique and evaluation. It does assume that students will be developing ideas and knowledge and having their creations evaluated through the wider community as might happen in an informal setting through Web 2.0 (Lenhart \& Madden, 2007a). It was applied to the learning activities using digital technologies that the beginning teachers reported using.

The activities that the beginning teachers were using varied according to their intended purpose. The majority of activities involved the students thinking about connections, with all teachers including activities that aimed to have students developing conceptual understanding. These results suggest that most of the teachers were aiming to have students understanding key concepts in their subjects, which reflects the dominant constructivist/transmission model of teaching in an outcomes-based model of education. The teachers were teaching the students to understand the sets of knowledge that they believed they needed to learn. Critiquing and evaluating were included by half the teachers in their teaching using digital technologies and in art design and graphic design students were creating knowledge. The created knowledge was not being shared beyond the classroom environment, though this was something the teachers said they would like to include in the future. As the teachers in the study become more experienced, developing their pedagogical content knowledge, their teaching may continue to move towards a more connectivist approach to student learning.

While the digital age learning matrix was designed as a tool to measure the type of learning within a teaching activity, it has been used as a basis for conversations between teachers about learning activities and conceptions about teaching and learning.

The beginning teachers in this study were making use of the ubiquitous cell phone. Nearly every teenager has this digital era 'coming of age' status symbol, used as an organiser and for communications with family and friends (Vincent, 2004). The beginning teachers represented the first generation of teachers who had owned cell 
phones since their own teenage years, hence recognising the importance that these have in teenage lives. Cell phones were used for texting students about organisational aspects (sports team meetings, things needed for class when a student is away) and for the calculator function (in a mathematics class). Not all beginning teachers were comfortable using their personal cell phone to contact students; two teachers said they would not do this. None of the teachers was given access to school funded cell phones.

The young people (students) in this study appeared to be motivated to learn as they were using digital technologies. In some cases this could have been for the novelty factor of what they were doing - for example, using Photoshop to change their personal image. For others, while there was a novelty factor, the students talked about their learning and how their learning was helped by using the digital technologies, which suggests that the students will continue to engage in this type of learning activity. The novelty factor occurs when digital technologies are introduced and as the learning is different or novel, motivation increases. The motivation drops again when the novelty wears off (Moss et al., 2002). It appears that where the purpose of digital technology use is on appropriate student learning rather than doing the longer term decline in motivation is negated.

A learning strategy that students commonly used when using digital technologies was a trial and error strategy. Typically this involved the student trying out something (guessing where a bone should go, adding in a colour in a graphics class or morphing the hair using Photoshop in a health lesson), then evaluating the results. If they could not do what they were aiming to do they would either look for online help within what it was they were using or ask a peer. The students in the classes were set up well for this type of learning, with a range of resources or options, but not too many that it was overwhelming. For example Barry used one web site to put together the relevant links for the students to explore to learn about bones, muscles and movement. This allowed the students to browse and explore a range of places without getting lost in cyberspace or drifting too far from the topic. Included were some self-assessments so that the students could check their progress in learning. This helped keep them focussed as did Barry's teaching strategy of spending time with every student in the class to assess their learning progress. As with previous studies, good teaching practices were found to be the key to engaging students in learning. Active engagement, participation in groups, frequent interaction, gaining feedback and connections to real-world contexts have been found to enhance how children learn while using computer-based applications (Roschelle et al., 2000). 


\section{Learning in the digital age}

The way that digital technologies are used in schools has been found to be causing a disconnection between formal and informal learning where the learner in school is placed in a passive role and informal learning has the learner in an active role (Becta, 2007). This has meant that students do not always want to engage with digital technologies in school the way that teachers may envisage learning with digital technologies happening. This could be reflected in the way that students who rarely get access to computers behave when given access at school: "Students who don't have access at home get on the computers and they just want to play games" (Fiona).

This disconnection between formal and informal learning may not be new to the digital age - to some extent young people have always learnt informally through active engagement. What is new is the wealth of information they can easily access anywhere, anytime.

The use of digital technologies in their teaching practice enabled the case study teachers to focus on student learning. Due to the variety of teachers' conceptions about learning, sometimes the focus was on having the students internalise knowledge (as with case study B learning about bones and muscles) or externalise knowledge (case study E making PowerPoints of injury prevention), or a focus on internal cognitive processes (comparing, evaluating, connecting) such as video analysis of a volleyball movement (case study C). In a study by Passey et al. (2004) it was found that teachers were using digital technologies within the context of students internalising or externalising learning, a dominant teaching focus in transmission style of teaching. This was the focus for some, but not all, of the learning activities using digital technologies by the beginning teachers in this study.

In the digital age, secondary school learning could include the students creating and sharing new knowledge through critique, evaluation and connections rather than being limited to learning existing prescribed knowledge. This would require a flexible curriculum and an approach to teaching underpinned by an appropriate theory of learning and knowledge construction such as connectivism. The beginning teachers in this study, while interested in teaching in a connectivist way, lacked the theoretical models to guide their teaching decisions. 
The approach that students have to the use of digital technologies has been found to be influenced by their experiences of using digital technologies outside the classroom (Sutherland et al., 2004) it appeared to be linked to aspects of peer socialisation. Fiona found that students without computers at home focussed on playing games on the computer at school during lessons. Her students' conception of how youth should be using computers focused on gaming through their social learning. Students were found to adopt a 'trial and error/ask a friend' approach to learning with digital technologies. This is likely what happens beyond the classroom environment when there are few people to explain how to do something (parents are unlikely to be on hand, or maybe unable to help each time a young person is stuck in a game).

\section{Complexity theory applied to secondary schools}

Complexity theory has been a lens through which to view secondary school in this study. Beginning teachers in the study are part of a complex phenomenon of secondary schooling. According to Davis and Sumara (2006) the key concepts in complexity theory include the recognition that complex organisations or systems are; self-organising, bottom-up emergent, have short range relationships, nested structure, ambiguously bound, organisationally closed systems, structurally determined and far from equilibrium. Using examples from the case studies, secondary schooling does appear to meet these categories of complexity, though some interpretations I have made below may be tenuous.

- Self-organising - Teachers are autonomous agents who, through a socio-cultural perspective, are interlinked, co-dependent and develop knowledge and practice through their networks. While they are organised to a certain extent through externally imposed structures, those structures are only effective when they help the teachers to meet their own goals. For example, Ana was unable to access some websites due to school web-blocking procedures; she became subversive, getting the students to help her access the sites. The teachers in this study to differing extents, depending on their need self-organised their support structures.

- Bottom-up emergent - Emerging knowledge and resulting organisational structures within and across schools are being shaped as teachers and students use digital technologies, learning from their experiences and sharing their knowledge through the relationships they have with colleagues and friends. The application of digital technologies within their teaching context is part of the 
bottom-up emergent phenomenon. The students in the classroom influence the emerging knowledge (Wink, 2000); for example in case study $\mathrm{C}$, the students initiated video analysis of volleyball moves, and in case study B students introduced cell phones as calculators. While at a national level there are policies which state that digital technologies should be integrated into teaching and learning, the reality of how this is done and evolving learning about how to do this is emerging from the experience and learning of teachers in the classroom. This finding fits a model that links the policy developments to the classroom teacher as proposed by Starkey et al. (2009).

- Short range relationships - Professional learning is situated in formal and informal communities of practice. Much of the information exchanged about the use of digital technologies in schools is through relationships between teaching colleagues, mentors, friends of the beginning teachers and teachers and their students. Relationships are the glue for complexity theory and connectivism in a digital learning environment.

- Nested structure - Beginning teachers belong to different structures including their classroom environments, the school community, regional teaching networks and the secondary education community which is on a national and global scale. Each of these groups are connected through dynamic networks. Beginning teachers are 'centrally networked'. They are part of their classroom environment, the school community, regional groups such as beginning teachers and subject associations and part of the broader secondary education community. All of the aspects of secondary schooling identified in Figure 33 exist at different levels as part of nested structures. For example, policies about digital technologies exist in classrooms, departments, school wide and nationally.

- Ambiguously bound and organisationally closed systems each of the different organisational structures that the beginning teachers belong to are closed systems with ambiguous boundaries. For example, the regional teaching networks can have ambiguous 'regional' boundaries, may or may not include people not teaching, and the members may change from month to month and the core purpose will change over time. 
- Structure determined - Teachers and schools change structures as they adapt to maintain viability within dynamic contexts. However, the structures that exist within schools will often determine the processes that occur.

- Far from equilibrium teaching and learning is constantly changing as policies develop, ideas change and technology develops. Many forces in the digital age move secondary schooling from a state of equilibrium to a state in which teachers, students, policy makers, educators and researchers seek to understand and develop knowledge of the situation, to establish equilibrium. This will in turn be upset by the emerging knowledge that is caused by being far from equilibrium.

One important concept in complexity theory when applied to the social sciences not identified by Davis and Sumara (2006) is that emerging knowledge will draw upon the history of the organisation or system (Buchanan, 2000). Perhaps not explicitly explored in the literature to date is the culture of an organisation which is related to the history but is not the same.

- Have a history. Each school has a unique history and culture which has emerged through the events, people, time and community in which it exists. This in itself is dynamic and changes over time.

Secondary schooling is a complex phenomenon (Davis \& Sumara, 2006). Figure 36 illustrates the complexity of secondary schooling, and the aspects that have been identified in this research. The introduction of digital technologies into society has had an effect on communication networks, youth culture and the nature of knowledge. This is resulting in emerging knowledge as different aspects interact. 


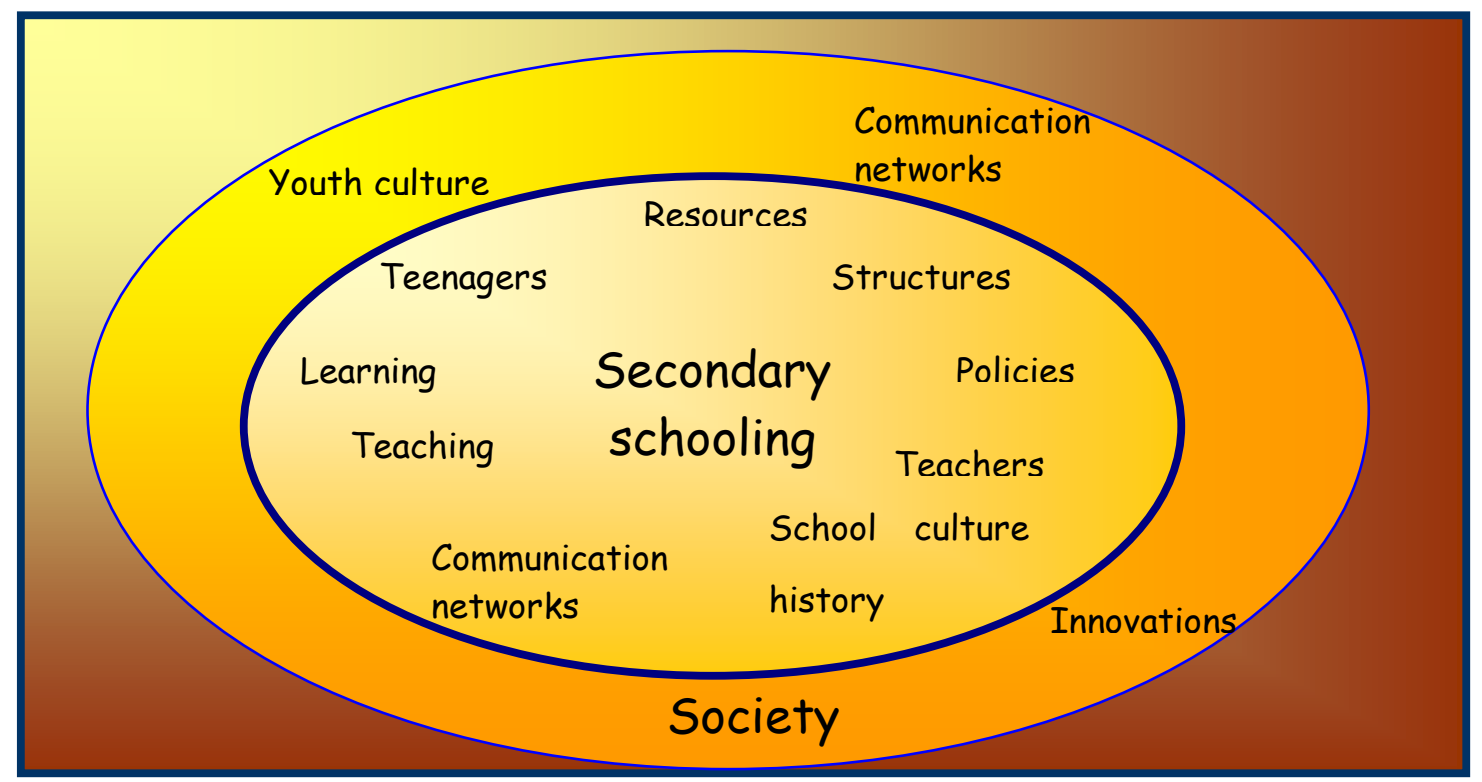

Figure 36: Partial representation of the complex phenomenon of secondary schooling

Thus beginning teachers as part of society, secondary education, schools, regions and classrooms at the start of the digital age are part of a complex phenomenon.

If it is accepted that secondary schooling is a complex phenomenon and the digital age is changing access to and development of knowledge, then connectivism is a logical learning theory. The beginning teachers were not prepared or ready to teach in a connectivist way which would require being able to approach the curriculum with flexibility, and encourage connections not only between information and knowledge, but also beyond the classroom and to ultimately have students creating knowledge within a connected environment. The digital age learning matrix captures the features of learning that a connectivist teacher in the digital age would incorporate in their teaching over an extended sequence of learning activities. The teachers who included knowledge creation in their lessons had strong pedagogical content knowledge and technopedagogical knowledge. This suggests that to be a teacher implementing a flexible curriculum that encourages knowledge development requires strong pedagogical content knowledge which includes technopedagogical knowledge and understanding of learning in the context of the digital age.

\section{Using complexity theory as a conceptual framework.}

The constructs underpinning complexity theory formed the conceptual framework of this thesis (Table 22). There were a number of methodological approaches available to examine how a digitally able beginning teacher may or may not use digital 
technologies in their first year of teaching practice. The research could have taken a quantitative approach such as surveying all first year teachers across New Zealand. This would have yielded statistics which could be generalisable for New Zealand in 2007. Through a quantitative approach it would have been difficult to explore the complexities that exist from teaching in a unique school culture, and how knowledge emerges through the connections that the beginning teacher had.

Table 22. Complexity theory conceptual framework.

\begin{tabular}{|l|l|l|}
\hline $\begin{array}{l}\text { Constructs underpinning } \\
\text { complexity theory } \\
\text { conceptual framework. }\end{array}$ & $\begin{array}{l}\text { Complexity theory } \\
\text { perspective of schooling. }\end{array}$ & $\begin{array}{l}\text { Complexity theory } \\
\text { perspective of research. }\end{array}$ \\
\hline $\begin{array}{l}\text { A complex system is } \\
\text { multileveled, ambiguously } \\
\text { bound and can not be } \\
\text { examined as isolated parts } \\
\text { (Waldrop, 1992) }\end{array}$ & $\begin{array}{l}\text { Connections which bind a } \\
\text { system are ambiguous and } \\
\text { occur within schools, } \\
\text { departments, regional and } \\
\text { national structures and } \\
\text { networks. }\end{array}$ & $\begin{array}{l}\text { Research design considers } \\
\text { the context in which } \\
\text { knowledge is emerging. } \\
\text { There are likely to be } \\
\text { multiple contexts at } \\
\text { differing levels. }\end{array}$ \\
\hline $\begin{array}{l}\text { The connections between } \\
\text { the parts of a system are } \\
\text { where knowledge } \\
\text { emerges. Human } \\
\text { relationships are an } \\
\text { important connection in an } \\
\text { education context (Stacey, } \\
\text { 2001) }\end{array}$ & $\begin{array}{l}\text { The parts of the schooling } \\
\text { system that influence } \\
\text { emerging knowledge } \\
\text { include the people, } \\
\text { history, culture, processes } \\
\text { and resources. Schools are } \\
\text { contextually unique. }\end{array}$ & $\begin{array}{l}\text { Examining connections } \\
\text { within and beyond a } \\
\text { system can help to gain an } \\
\text { understanding of how } \\
\text { knowledge emerges. The } \\
\text { literature review situates } \\
\text { the research in a historical } \\
\text { context. }\end{array}$ \\
\hline $\begin{array}{l}\text { Knowledge emerges } \\
\text { through redundancy and } \\
\text { diversity (Davis and } \\
\text { Sumara, 2006). }\end{array}$ & $\begin{array}{l}\text { New ideas, practices and } \\
\text { beliefs develop and some } \\
\text { are applied within schools } \\
\text { or teaching, others become } \\
\text { redundant. }\end{array}$ & $\begin{array}{l}\text { The theories and models } \\
\text { developed from and } \\
\text { applied to research will be } \\
\text { constantly evolving, } \\
\text { reflecting diversity and } \\
\text { redundancy of ideas. }\end{array}$ \\
\hline $\begin{array}{l}\text { Change is not predictable, } \\
\text { but the balance between } \\
\text { randomness and } \\
\text { deterministic order } \\
\text { (Cilliers, 1998). }\end{array}$ & $\begin{array}{l}\text { The result of change in } \\
\text { one part of a complex } \\
\text { system is not predictable } \\
\text { due to complexity of } \\
\text { connections. }\end{array}$ & $\begin{array}{l}\text { Instead of a predict/control } \\
\text { paradigm, models, } \\
\text { frameworks and } \\
\text { considerations are } \\
\text { developed that can be } \\
\text { applied to specific } \\
\text { contexts. }\end{array}$ \\
\hline
\end{tabular}

The literature review informed the study by giving a historical perspective over the timeframe that digital technologies have been researched in the schooling context. Examining the history is an important aspect of complexity according to Buchanan (2000). The literature reflected the changing emphasis and conceptions of how digital technologies can and are being used in schools and by young people. The literature is underpinned by the assumptions and epistemological beliefs of the authors, such as examining the alignment between constructivism and use of digital 
technologies (Becker \& Riel, 2000) or counting the ratios of computers in schools (Johnson et al, 2005). From the review variables of interest were developed.

Complexity theory underpinned this thesis and informed the conceptual framework. The overall focus was to examine a small group of beginning teachers in their first year of teaching. To understand the complexities of their experiences and contexts a case study approach was adopted. The case studies included the positioning of the school as a complex organisation in which knowledge is emerging. Research questions were developed with consideration of the features of a complex organisation. Data collection and individual case studies were framed through the use of a logic model and variables of interest (rather than propositions as recommended by Yin, 2003) reflected the concept of being unable to predict the findings due to the complex influences. Analysis of the data was designed to examine key features of a complex organisation in which the beginning teachers work. Assertions from each case study were compared and a generic inductive qualitative analysis across the case studies aimed to find any themes. Analysis was carefully organised to avoid a prediction/control methodology.

A key tenet of complexity theory is the importance of the connections and how the parts of a complex system (such as school) influence and control the emerging knowledge and practices of the system. The people with whom the beginning teachers interacted with, through connections, to help develop their understanding of teaching using digital technologies were identified by the research participants who also explained the nature of their knowledge development. The formal and informal supporting people were an important aspect within this research as it is through these connections that knowledge is likely to emerge.

This thesis attempts to examine the use of digital technologies in a schooling context at the start of a digitally connected era. Complexity theory offered a framework to examine the context and learning of the beginning teachers. It seemed appropriate to examine and apply theories aligned with the digital era. Connectivism theory had been developed with this in mind and is underpinned by complexity theory offering a consistency to this study. Evaluating the teaching activities to identify how relevant these are to the digital age required a tool that was not available through the literature, probably due to the emerging nature of the research and practice in this area, hence the development of the digital age learning matrix. 


\section{Implications}

Given that one of the findings emerging from this research is that the beginning teachers in the study made pedagogical decisions about the use of digital technologies in a different way to experienced teachers, there could be implications for both teacher preparation and for supporting teachers during their first year of teaching.

\section{Teaching preparation}

How teacher education programmes can help student teachers to design learning environments that effectively integrates digital technologies was a challenge identified by Clifford et al. (2005). Past studies have suggested that the integration of digital technologies into teacher education programmes should be grounded in pedagogy. Emphasis on professional learning for using digital technologies should be on the learning process rather than how to teach digital technology use (Becker \& Riel, 2000; Clifford et al., 2005; Ofsted, 2005; Sandholtz \& Reilly, 2004). This study takes this further; the teachers in this study who included experience of digital technologies within their pedagogical content knowledge were able to integrate digital technologies to encourage creative knowledge construction and collaboration in their classes. Therefore teacher education programmes should consider integrating subject specific uses of digital technologies into pedagogical content papers and where possible student teachers should experience how teachers in the same subject specialist area plan, teach and reflect as their students use digital technologies for learning. This should include the opportunity to discuss with them what the students are learning, how and why. Choosing appropriate mentors would be a consideration. In a study of student teachers and their mentors in schools, Cuckle and Clarke (2002) found that the mentors who did not see a need for computers in education did not encourage student teachers to integrate digital technologies in their teaching.

A teacher's disposition appeared to have an effect on their relationships with colleagues which ultimately has an impact on the support received. Beginning teachers in this study were most likely to engage students in learning activities with digital technologies that required critique, evaluation and knowledge creation where they had strong pedagogical content knowledge. Support from experienced teachers in the same subject area was helping the teachers to develop their pedagogical content knowledge. Having an awareness of personal disposition and how to build 
and maintain professional relationships benefit the beginning teachers and their students. It would therefore be useful to the teachers if this was included in their preteaching programme.

There is a gap between the development of learning theories and the application in the classroom. The teachers in this study demonstrated application of behaviourism, socio-cognitivism and constructivism in the learning activities using digital technologies. Through the use of digital technologies learning activities were personalised to meet the individual learning needs of students, a teaching approach encouraged in teacher education. The beginning teachers were therefore applying learning theories and ideas from their preservice teacher education programme. While the teachers wanted to use Web 2.0 technologies, they appeared to lack the theoretical model in which to base their use. For example, Ana was keen to use Facebook or social software with her students but was unsure how to have students learning through it. This was probably because she was teaching to an outcomesbased model where the teacher is the 'knower'. Had Ana been applying a connectivist learning model she may have developed her idea to include developing learning networks creating, sharing and critiquing knowledge collaboratively. An understanding of connectivism and applying the digital age learning matrix to their learning activities could be a way of preparing teachers for teaching secondary students in the digital age.

Shulman (1987) developed a model of teacher pedagogical reasoning and action to reflect how teachers decide what and how to teach within a professional teaching context. The model reflects the time in which it was written. From the digital age perspective on learning as outlined in this thesis, the concepts underpinning the transformation action are problematic. The "capacity of a teacher to transform the content knowledge he or she possesses (Shulman, 1987, p.15) infers that the teacher learns or knows the content then repackages it to teach it to students, which appears to be a transmission perspective of the teaching process. Transforming the content knowledge is one method of teaching under the action of 'enabling connections' and not the only way of teaching. An alternative model of pedagogical reasoning, cognisant of the features of teaching and learning in the digital age as outlined in this thesis is represented in Figure 37. 
The differences between the original developed by Shulman in 1987 and Figure 37 is the underpinning idea of students creating knowledge in the digital era through connections in an open and flexible curriculum, rather than the teacher transmitting the 'truths' and methodologies of a subject according to a prescribed curriculum. Both models assume that the students will construct an understanding of the content through a variety of pedagogical approaches to build on their existing knowledge.

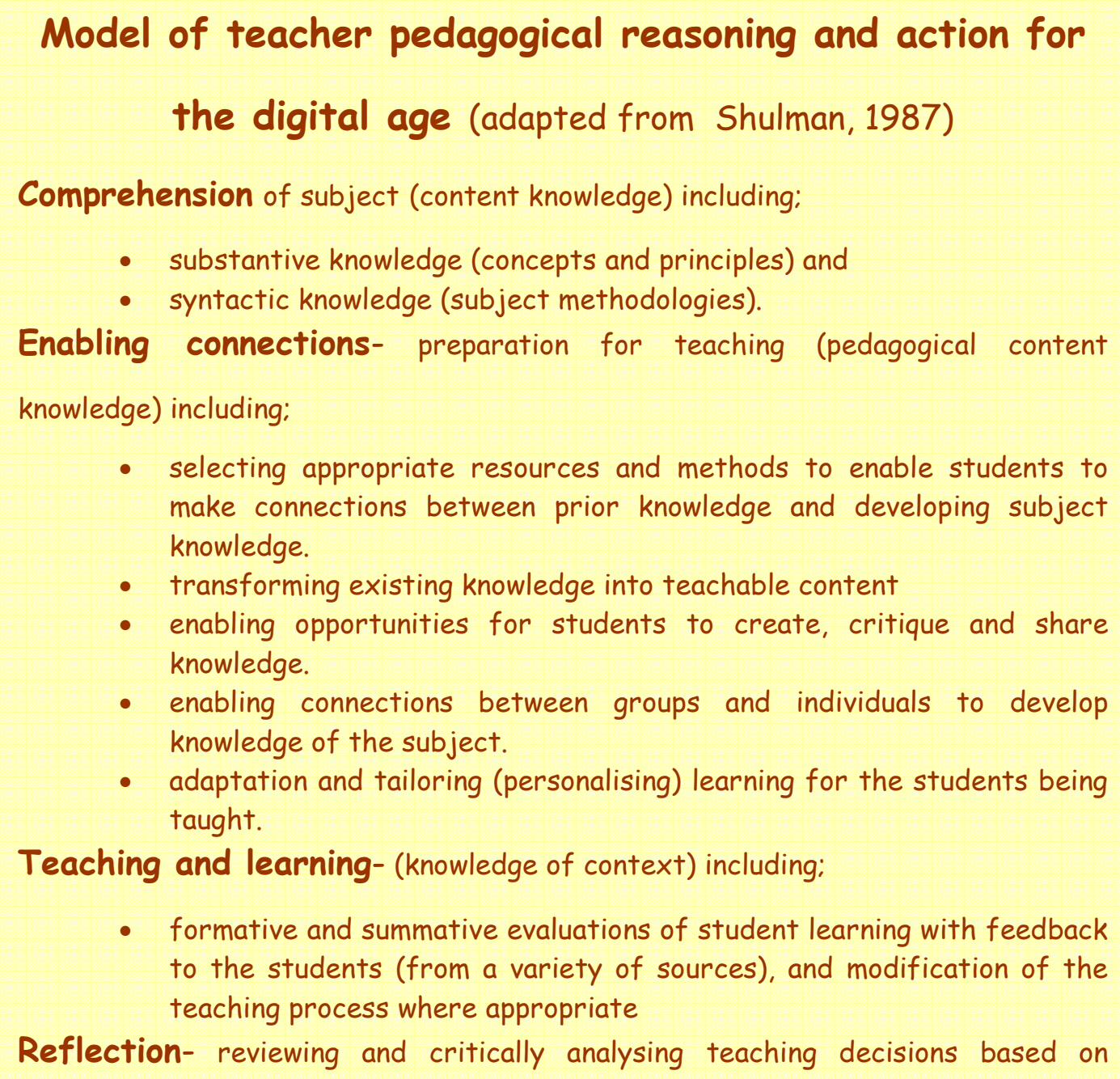
make connections between prior knowledge and developing subject knowledge.

- transforming existing knowledge into teachable content

- enabling opportunities for students to create, critique and share knowledge.

- enabling connections between groups and individuals to develop knowledge of the subject.

- adaptation and tailoring (personalising) learning for the students being taught.

Teaching and learning- (knowledge of context) including;

- formative and summative evaluations of student learning with feedback to the students (from a variety of sources), and modification of the teaching process where appropriate

Reflection- reviewing and critically analysing teaching decisions based on

Figure 37: Model of teacher pedagogical reasoning and action for the digital age

\section{Supporting teachers in their first year}

The subject that the beginning teacher was teaching appeared to impact on their use of digital technologies. When teaching a subject they had the most experience of using digital technologies through academic studies and employment they were more likely to personalise learning and encourage students to create knowledge. This is in line with Shulman's (1987) findings. A teacher with limited pedagogical content knowledge is more likely to teach in a transmission way, with limited cognisance of 
their students' prior knowledge even when their pedagogical beliefs indicate otherwise. When Barry was teaching mathematics or science he was using the department's units of work and was focussed on student behaviour. When teaching physical education with digital technologies he was focussed on personalising learning to get the students to achieve the best they could. There were other factors influencing the different focus besides pedagogical content knowledge such as the different age levels of the students. However, it is likely that where a teacher has a clear understanding of the pedagogical content knowledge they are more likely to be able to pinpoint student misunderstandings of concepts, or gaps in knowledge and address these in pedagogically appropriate ways (Bransford et al., 2000; Grossman \& Schoenfeld, 2005). The importance of developing strong pedagogical content knowledge has implication for both preservice teacher learning and support for the beginning teacher in their first year of teaching.

The research into the use of digital technologies in schools in the past has focussed on experienced teachers learning how to use programmes or applications, and then applying this knowledge to their teaching practice (Knezek \& Christensen, 1999). This is not appropriate for beginning teachers who are familiar and confident with the use of digital technologies in their subject specialism and everyday life.

In a complex organisation the knowledge emerges through interactions between the people, processes and structures within and beyond the organisation (Morrison, 2002). The beginning teachers in this study were more likely to be innovative and contribute to the emerging knowledge within a school when they felt they were supported by the structures, processes, colleagues and management.

Support was found to be important to help the beginning teachers develop their pedagogical content knowledge and use digital technologies with their students. Examples of ways that the teachers reported receiving effective formal and informal support included: an experienced teacher working alongside a beginning teacher the first time the teacher took junior students to the computing room; having technical assistance available on hand or by phone; teacher aid with computing expertise; regular meetings with a mentor with strong pedagogical content knowledge; opportunities to discuss pedagogical and digital technology ideas with colleagues; being included in lead groups examining how digital technologies can be integrated; 'browse weeks' and belonging to teacher networks beyond the school context. Each 
of these examples either helped the teacher to think about their pedagogical practice or offered direct assistance with the digital technologies.

Clifford et al. (2005) noted that traditional modelling systems are no longer appropriate in teacher education, and asks how can emerging teachers be mentored in a way that allows them to be innovative? Research by Slaouti and Barton (2007) found that self esteem of newly qualified teachers was boosted as their contributions about the use of digital technologies were acknowledged by other teachers. This research suggests that innovation can be encouraged by allowing the beginning teacher the flexibility to apply their teaching ideas. By giving them confidence by being included in professional discussions about pedagogy in their specific teaching area, contributing to decisions about the use of digital technologies at a department and school level, and by being an active participant in a community of learners, schools are likely to reap the benefits of employing the digitally aware beginning teacher. Ma te huruhuru, ka rere te manu me whakahoki mai te mana ki te whanau, hapu, iwi. The beginning teachers in this study benefited from having a mentor with strong pedagogical content knowledge in the same subject as them with whom they could share innovative ideas.

The way that schools organised their timetables impacted on the beginning teachers as they sought to use digital technologies. Erina found that 40 minute lessons were too short to take students to a computer suite and carry out an activity using Photoshop. Barry and Erina found that moving between classrooms each lesson prevented them from setting up activities using a digital projector, which compared with Erina's first school where she was based in one classroom that had digital technologies set up in the classroom and suites of computers nearby. From this study it appears that policies and procedures that support beginning teachers to access and use digital technologies include:

- Timetabling beginning teachers to teach in one classroom in which digital technologies are readily available.

- Lesson length is adequate to include changing classrooms, a learning activity and student reflection time.

- Ensuring that each beginning teacher is provided with a laptop, including teachers who are employed on a temporary basis. 
- Having groups of computers that students can access close to or in their base classroom and where the computers are next to the classroom the teacher can easily monitor student behaviour and learning.

The school culture and leadership can impact on the way that beginning teachers use digital technologies through direct encouragement or indirect messages. In a study by Johnson et al. (2005) $76 \%$ of secondary principals said that the integration of ICT was making major improvements to the quality of curriculum delivery in their school. This suggests that at a leadership level there is a perception that the use of digital technologies improves the quality of teaching. Leadership attitudes influence the culture and direction of a school (Fullan, 2005; Hargreaves, 2003). Therefore beginning teachers are likely to be supported and encouraged in their use of digital technologies in teaching and learning. Currently inequalities exist between schools with regards to beginning teacher access to laptops, where some teachers are expected to pay to lease a laptop (an essential tool for their work) and other schools supply a laptop, though it does not necessarily work effectively (e.g., no battery). To feel valued and to be able to carry out administration tasks, this access needs to be given to all teachers.

The employment of the beginning teachers can affect their acculturation and their feeling of being valued. Out of the six teachers in the case study two began in permanent teaching positions, two changed schools after six months to other temporary positions and the remaining two teachers had their contracts renewed. It appears that the beginning teachers (and perhaps this is new teachers to the school) are given the classes that are available, without matching their teaching to their pedagogical content knowledge. Given the clear importance of pedagogical content knowledge in the outcome for the students, I would suggest that students would benefit from a policy of ensuring that beginning teachers were teaching in the subject where they have the strongest pedagogical content knowledge.

\section{Teaching students in the digital age}

The students' preferred approach to learning using digital technologies in the case studies was a 'trial and error, ask a friend' approach. This was encouraged and managed by the teachers in the study in the following ways:

- Students were encouraged to share their learning and questions within the learning environment. 
- Erina had students work in pairs for an observed learning activity; she had selected the pairs to help broaden students' knowledge of their peers.

- Fiona's students worked in small groups where they discussed their learning.

- The activities used allowed students to explore and make mistakes.

- The teachers circulated within the classes spending time with each student.

- Barry included a 'test yourself quiz' for the students to access to allow them to self-check their progress.

- Barry set up a webpage with links to the relevant sites to keep students focussed within the learning intention.

Teachers in the study were able to have their students actively participating in the learning process; students were trying things out unafraid of making mistakes with digital technologies as they collaborated, connected, critiqued, and sometimes created knowledge. This aligns with the construct of diversity (developing and applying new processes and ideas) and redundancy (when things don't work out) creating the condition for emerging knowledge in complex organisations, which is a feature of complexity theory (Davis \& Sumara, 2006)

\section{Phases of First-Year Teaching}

The initial interviews of beginning teachers were carried out after the teachers had been teaching for 8-10 weeks in their first teaching position. The teachers had minimal time to prepare for the particular classes they were teaching, with as little as one week between being offered a position and commencement date. At the initial interviews the teachers identified a range of barriers to their use of digital technologies which reflects their 'survival' mode as identified by Moir (2008). The final interviews were undertaken towards the end of their first year, a time Moir identified as when teachers reflect. This is likely to have accounted for the increased optimism about using digital technologies in the later interviews - the respondents were still feeling very busy but had moved out of the survival mode. Ana reflects this change. At the start of the year her frustration was evident: "I would like a data projector - is that too much to ask for in 2007?" but by the end of the year she felt she had the digital technologies she needed and was looking forward to the things she was setting up for the future, including a Facebook site as a place for students to reflect and share information: 
In the future I will add wearable arts photos, add in homework, notes, links to websites, for example, we are doing knitting at the moment and one of the students just came in and showed us a good website. Another student found a good website for ball dresses. She wrote it on the board. A link in Facebook would be more useful.

The phases of first year teaching is an important aspect in this study as it aligns with a complexity theory underpinning the research as outlined in the methodology section of this dissertation - a range of contextual factors should be taken into account when constructing knowledge of a phenomenon.

\section{Further research}

This study has shown that learning theory for the digitally able beginning teachers need to be developed and included in preservice teacher education. The models suggested in this research (the digital age learning matrix and modified pedagogical reasoning and action model) could be used to put the theory into practice, and the process and results should be the subject of further research and refinement.

Further research into the use of complexity theory as a conceptual framework would help future researchers in this field.

\section{Summary}

The complex interrelations between a teacher's experiences, beliefs, the context in which they teach (which includes the access to resources and technology) and the support they access have been found to influence whether experienced teachers will use digital technologies (Becker, 1999; Sime \& Priestley, 2005). Similar influences were found in the case studies, with the teacher's disposition and their level of pedagogical content knowledge influencing their aspirations to have students using digital technologies within their learning programmes.

Pedagogical content knowledge was the most significant aspect of the base knowledge in the process of transferring knowledge to the teaching context for the beginning teachers in the study. This included digital technology knowledge and experiences from undergraduate degrees and work experience, and the greater this knowledge within the field that the teacher was teaching, the more likely they were to use digital technologies with students in a way that encouraged critique, evaluation and knowledge creation as identified through the digital age learning matrix. This finding had not been found recorded in the digital technology or teaching in the digital age research literature. 
Young teachers entering the teaching profession take a different pedagogical reasoning pathway to experienced teachers when making decisions about using digital technologies with their students. The beginning teachers in this study applied a cognitive approach to transfer their learning when making decisions about teaching and learning using digital technologies. The base knowledge that was transferred included experiences and understandings of digital technologies for general purposes and subject specific functions. Whether transfer occurred depended on contextual and personal attributes including the access and support they have in the context in which they are teaching and through their networks, and their sense of agency. The result of the transfer of learning is the personalising of learning, and the students being actively engaged in learning; commonly using an approach that involves trial and error, then asking a friend or peer.

Secondary schooling is a complex phenomenon. Pedagogical reasoning and action in the digital age should reflect that complexity and mirror ideas from connectivism learning theory which includes the idea of students creating knowledge. The beginning teachers in the study drew on a range of learning theories in the design of learning activities but connectivism was notably absent. The implications of this research points to knowledge, experiences and support that would help beginning teachers to be innovative in their use of digital technologies within their teaching practice. This includes: (a) familiarity with teaching students using the 'trial and error, ask a friend' approach to learning, (b) teacher experiences of the use of digital technologies in specific subject specialist areas, (c) support from people with pedagogical content expertise, (d) access to digital technologies, and (e) preservice teacher education programmes which include digital age learning theories and models. The digital age learning theories and models include complexity theory, connectivism, pedagogical reasoning and action for the digital age and the digital age learning matrix.

Johnson (2001) writing about digital technologies noted that:

Emergent behaviours, like games, are all about living within boundaries defined by the rules, but also using that space to create something greater than the sum of the parts (p.181).

This sentiment is applicable to emergent knowledge in schools and education. In this study the beginning teachers faced barriers caused by structures, rules and processes 
and in many cases were able to work within those restrictions to expand the knowledge of using digital technologies for the teaching and learning processes.

Complexity theory was a logical choice to underpin a thesis that examined teaching and schooling at the start of the digital age. The emerging knowledge of how schools and the education system operate as complex organisations framed the research processes, underpinning the design and interpretation of results. Through this approach a digital age learning matrix was developed, Shulman's (1987) model of pedagogical reasoning and action was updated for the digital age, and considerations for school leaders aiming to support teachers in their first year of teaching have been developed. 


\title{
Chapter 7. Conclusion
}

\author{
Ma te huruhuru, ka rere te manu \\ Me whakahoki mai te mana ki te \\ whanau, hapu, iwi \\ Adorn the bird with feathers so it can fly \\ and bring pride to its' family
}

Secondary schooling is a complex phenomenon from which knowledge emerges at the edge of chaos. This thesis focuses on digitally able beginning teachers and contributes to the emerging knowledge of teaching and learning in the digital age, a time when making connections and networking through information and communication technologies enables access to information and people. The enhanced access changes the way that knowledge is developed and perceived in society. A function of secondary schools is to produce knowledgeable graduates; hence if the nature of knowledge changes, the implications will reach across the complex, connected schooling system affecting learning theories, policies, communications and teaching practices.

This research began with four research questions, the answers to which can be summarised within Figure 38. The logic model which guided the data gathering process was used to summarise the key findings for each aspect of the research. It unpacks the complexity of the experiences of the beginning teachers in their first year of teaching.

The first research question was: how do digitally able beginning teachers use digital technologies for teaching and learning? The beginning teachers in this study were using a range of digital technologies in their teaching practice. In making a decision about how to use digital technologies, teachers drew on their experiences and pedagogical content knowledge. The purpose for using digital technologies included to engage students in learning, access information, prepare students for the world beyond school, complete administration tasks, use time effectively, save money and save the world by reducing the school's carbon footprint.

The second research question required examining the factors that impede or encourage the use of digital technologies by beginning teachers. The factors were contextual and/or personal and where a factor was present it enabled the use of digital technologies and where it was absent it became a barrier. Support and access 
were important factors. It was mainly within the teaching context that support and digital technologies were accessed. This varied between contexts and was influenced by cost, school policies, procedures and culture. How the teachers chose to use digital technologies was influenced by their own personal experiences of using them. For example, experience of generic technologies and programmes led to the use of presentation software and internet inquiry type projects. Alongside other factors were the teachers' disposition, which influenced the ability to build and maintain personal learning networks, resilience when facing setbacks, and a sense of agency.

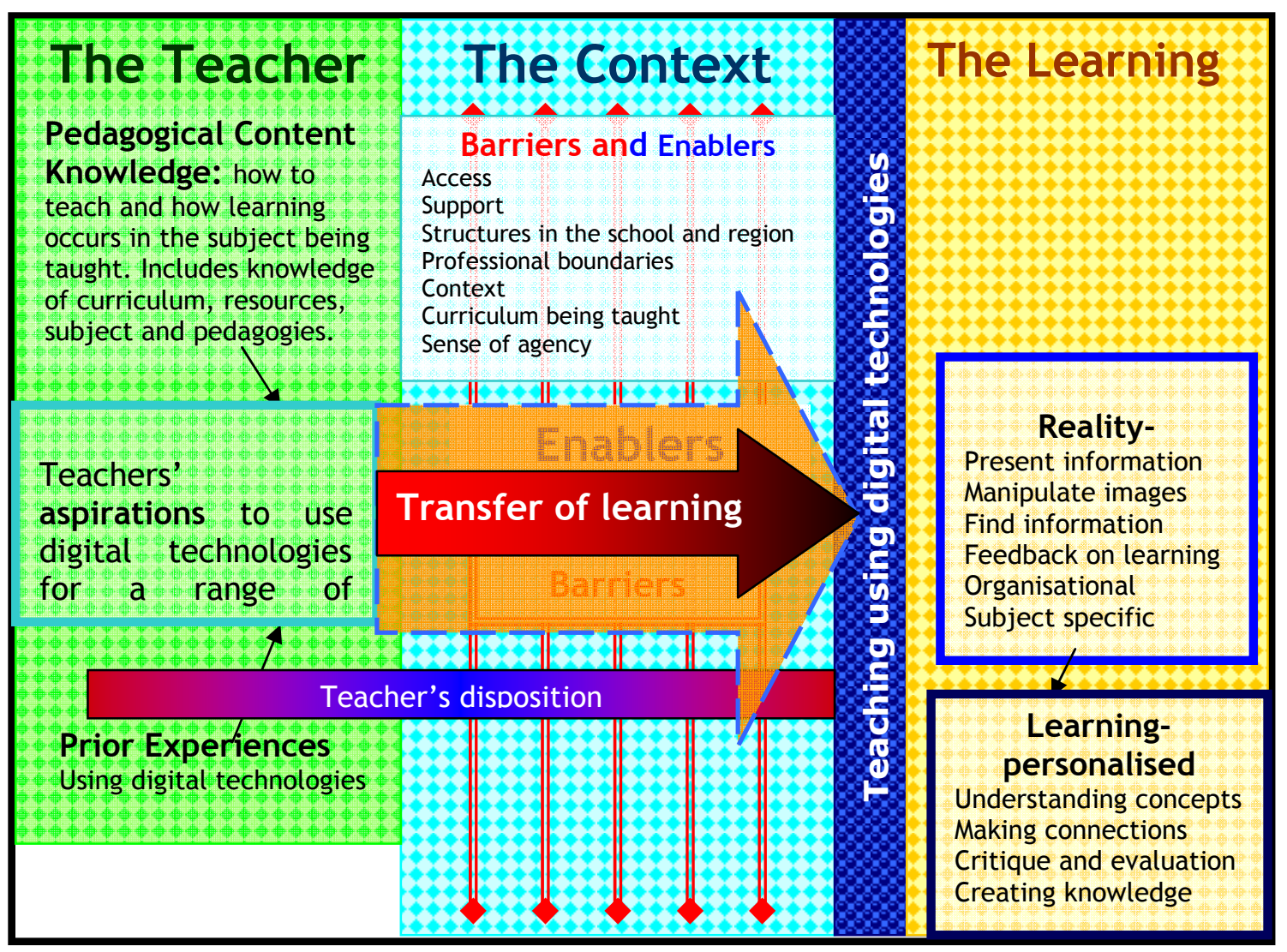

Figure 38: The pathway towards digital technology use for beginning teachers

The third research question asked about the learning that occurs in a beginning teacher's classroom as students use digital technologies. The learning varied depending on the teaching activity. The depth of the learning was measured against the digital age learning matrix and a correlation was found between the depth of the teacher's pedagogical content knowledge and the depth of learning. The learning activities which included critique, evaluation and creating knowledge were within the subjects of the teachers' undergraduate degree majors and those who had experience 
using concept-specific digital technologies, which appears to have extended their pedagogical content knowledge.

The students engaged in learning while using digital technologies; the engagement was due to sound teaching practices and the dedication of the teachers. When using digital technologies the teachers personalised learning, allowing students to go at their own pace and to have choice.

The final research question asked how beginning teachers connect and collaborate in their teaching and professional learning. Collaboration and mutual support was important for the beginning teachers in the study. They used digital technologies to access information and resources for teaching purposes, but not Web 2.0 social networking. Web 2.0 interactive technologies were being used to communicate with peers beyond teaching. Therefore digital technologies have not impacted significantly on the ways that beginning teachers connect and collaborate to engage in professional learning, beyond accessing information or organisational functions.

While the research questions guided the study, the findings went beyond the questions to the heart of learning theory and pedagogical reasoning in the digital age. The complex interrelations between a teacher's experiences, beliefs, the complex context in which they teach (which includes the access to resources and technology) and the support they access have been found to influence whether experienced teachers will use digital technologies (Becker, 1999; Sime \& Priestley, 2005). Similar influences were found to impact on whether and how a beginning teacher uses digital technologies in their teaching practice, with additional influences, the teacher's sense of agency, and their level of pedagogical content knowledge.

The digital age has increased access to information and enabled the connecting of people, ideas and creative product through networks which impacts on the way society creates, accesses and shares collective knowledge (Friedman, 2006; Gilbert, 2005; Tapscott \& Williams, 2006). Secondary schools are complex organisations, through which knowledge emerges in response to changes such as the ubiquitous presence of digital technologies in society. The underpinning change is a move from a positivist position where the teacher is the 'knower' of knowledge and transmits prescribed knowledge to their students who must reflect this back to achieve, to one where students think critically, make connections and create and evaluate knowledge. Connectivism is a learning theory that reflects this development. 
Connectivism reflects how knowledge is created in this digital era where tools such as Web 2.0 functions are available. The digital age learning matrix was developed to explore how teachers might use a range of digital technologies, matching the use with depth of learning when connectivist theory was applied. When the digital age learning matrix was applied to learning activities used by beginning teachers it became clear that the majority of the learning activities focussed on students constructing knowledge to prescribed learning outcomes or existing knowledge, to encourage constructivist learning. While a few activities involved critiquing, evaluating or creating knowledge, the sharing of knowledge beyond the classroom was not recorded in any of the activities. The beginning teachers were applying the theories of constructivism, social-cognitivism and behaviourism to the learning activities, reflecting the dominant curriculum of their preservice education. The teachers were not able to clearly articulate the learning purpose of activities that used technologies which enabled collaborative knowledge creation, and were unsure how to integrate Web 2.0 in meaningful ways into their teaching practice suggesting a lack of familiarity of appropriate learning theory to underpin the application.

Using digital technologies with students at the start of the digital age requires teachers to transfer their learning. Experienced teachers and beginning teachers approach this in different ways. Experienced teachers appear to add digital technologies to their existing knowledge of teaching and learning while beginning teachers have a range of experiences of learning with digital technologies which informs their developing pedagogical content knowledge. Beginning teachers transfer their experiences and pedagogical knowledge to their teaching practice through cognitive transfer of learning.

Figure 38 summarises the transfer of learning process that the beginning teachers took. The assertions that emerged from the individual case studies were divided into three categories: the teacher, the context and the learner. The summary of the transfer of learning has a similar division where the teacher held the base knowledge, experiences and aspiration for using digital technologies with students, the context in which they were placed influenced if and when the use of digital technologies would occur, and the learning is the product of the transfer.

This research has implications for the professional education and support of beginning teachers in the digital age. This includes: (a) familiarity with teaching students using the 'trial and error, ask a friend' approach to learning, (b) teachers 
experienced in the use of digital technologies in specific subject specialist areas, (c) support from people with pedagogical content expertise, (d) access, and (e) preservice teacher education programmes which include digital age learning theories and models. The digital age learning theories and models include complexity theory, connectivism, pedagogical reasoning and action for the digital aged and the digital age learning matrix.

\section{Summary}

Beginning teachers are entering the profession with an understanding of digital technologies in their subject area, and knowledge of a range of theoretical models they apply to their teaching practice. Where the beginning teachers had extensive pedagogical content knowledge they were personalising learning as their students used digital technologies for learning. There was limited focus on the students creating, critiquing and sharing their knowledge through connections which are aspects of learning in the digital age and reflect key elements of connectivist learning theory. This gap between the educational tools being used and the conceptual understanding of learning and knowledge creation in the digital age, or the gap between theoretical models and the reality in classrooms is understandable as clearly a time lag occurs as theoretical models are developed, debated and integrated into teacher education programmes such as connectivism. The beginning teachers in this study were working from theoretical models which predate the digital era.

The current generation of young graduating teachers has been identified as digital saviours (Cowie et al., 2008; Karsenti et al., 2002). They have grown up with digital technologies more so than any beginning teachers in the past; most had cell phones as teenagers, Google for information, and keep in constant contact with friends through Facebook and texts. This generation of teachers may be part of a revolution within the teaching profession at a time when baby-boomer generation teachers are retiring which aligns with the whakatauki in the first chapter (set the old net aside while the new net goes a-catching). In this study the professional relationships the beginning teachers had with their colleagues was important as they developed pedagogical content knowledge and attempted to integrate digital technologies into their teaching practice. The old net should not be set aside, instead it is important for beginning teachers to be connected and supported, given wings to help them to fly, possibly higher than the previous generation (as in the whakatauki in the final chapter). 
258 


\section{References}

Alton-Lee, A. (2003). Quality teaching for diverse students in schooling: Best evidence synthesis iteration Wellington: Ministry of Education.

Anderson, C. (2006). The long tail. London: Random House.

Anderson, H. H. (Ed.). (1959). Creativity and its cultivation. New York: Harper \& Brothers.

Anderson, L. W., \& Krathwohl, D. R. (Eds.). (2000). A taxonomy for learning, teaching, and assessing: A revision of Bloom's taxonomy of educational objectives: Allyn \& Bacon.

Attewell, J. (2004). Mobile technologies and learning: A technology update and mlearning project summary. London: Learning and Skills Development Agency.

Auld, G., Holkner, B., Fernando, A., Henderson, M., Romeo, G., Russell, G., et al. (2008). Exemplar schools using innovative learning technologies. Paper presented at the Australian Computers in Education Conference, Canberra, Australia.

Bandura, A. (1977). Social learning theory. Englewood Cliffs. NJ: Prentice-Hall.

Becker, H. J. (1999). Internet use by teachers. Irvine: Center for Research on Information Technology and Organisations.

Becker, H. J. (2000). Findings from the teaching, learning and computing survey: Is Larry Cuban right? Retrieved 18 March, 2006, from http..www.crito.uci.edu/tlc/findings/ccsso.pdf

Becker, H. J., \& Riel, M. M. (2000). Teacher professional engagement and constructivist-compatible computer use. Teaching, learning, and computing: 1998 National Survey. Report \#7. Retrieved 28 March, 2006, from www.crito.uci.edu/tlc/findings/report_7/startpage.html

Becta. (2007). Harnessing technology review 2007: Progress and impact of technology in education. Coventry: Becta.

Bereiter, C. (2002). Education and mind in the knowledge age. Mahwah, N.J:Lawrence Erlbaum.

Bereiter, C., \& Scardamalia, M. (1998). Beyond Bloom's taxonomy: Rethinking knowledge for the knowledge age. In Hargreaves, A., Lieberman, M., Fullan 
M. and Hopkins D. (Eds.), International Handbook of Educational Change (pp. 675-692). Dordrecht: Kluwer Academic Publishers.

Berg, B. L. (2004). Qualitative research methods for the social sciences (5th ed.). Boston: Pearson.

Biggs, J., \& Collis, K. (1982). Evaluating the quality of learning: the SOLO taxonomy. New York: Academic Press.

Bishop, R., \& Glynn, T. (1999). Culture counts: changing power relations in education. Palmerton North: Dunmore Press.

Bloom, B.S. (1956). Taxonomy of educational objectives: Handbook I: The cognitive domain. New York: David McKay.

Bolstad, R., Gilbert, J., Vaughan, K., Darr, C., \& Cooper, G. (2006). Zooming in on learning in the digital age (ZILDA); Report 1: Zooming in on "digital age" learners. Wellington: NZCER.

Bransford, J. D., Brown, A. L., \& Cocking, R. R. (2000). How people learn: Brain, mind experience and school. Washington, D.C.: National Academy Press.

Bransford, J. D., \& Schwartz, D. L. (1999). Rethinking transfer: A simple proposal with multiple implications. Review of Research in Education, 24, 61-100.

Brown, A. L., Kane, M. I., \& Long, C. (1989). Analogical transfer in young children: Analogies as tools for communication and exposition. Applied Cognitive Psychology, 3, 275-293.

Brown, M. (2004). The study of wired schools: A study of Internet-using teachers., Doctoral thesis, Massey University; Palmerston North.

Brown, M. (2005). Telling tales out of school: The political nature of the digital landscape. In K.-W. Lai (Ed.), e-Learning Communities: Teaching and Learning with the Web (pp. 23-38). Dunedin: University of Otago Press.

Brown, T. H. (2006). Beyond constructivism: navigationism in the knowledge era. On the Horizon, 14(3), 108-120.

Bruner, J. (1966). Toward a Theory of Instruction. Cambridge, MA: Harvard University Press.

Buchanan, M.(2000). Ubiquity : Why catastrophes happen. Three River Press: NewYork.

Campbell, N., \& Yates, R. (2005). e-Learning and pre-service teacher education. In K.-W. Lai (Ed.), e-Learning communities: Teaching and learning with the web (pp.39-50). Dunedin: University of Otago Press. 
Cassady, J. C. (2002). Learner outcomes in the Cognitive Domain. In J. Johnston and L. Toms Baker (Eds.), Assessing the Impact of Technology in Teaching and Learning: A source book for evaluators. (pp.35 -65 ) Michigan: University of Michigan.

Castells, M. (1996). The rise of network society. Oxford: Blackwell.

Castells, M. (2001). The internet galaxy. Oxford: Oxford University Press.

Chen, C. H. (2008). Why do teachers not practice what they believe regarding technology integration? The Journal of Educational Research, 102(1), 65-75.

Christensen, R., \& Knezek, G. (2001). Profiling teacher stages of adoption for technology integration. Computers in New Zealand Schools, 13(3), 53-60.

Chui, G. (2000). 'Unified theory' is getting closer, Hawking predicts. San Jose Mercury News. Sunday, Jan. 23. p29. Retrieved Feb 52007 from www.mercurynews.com.

Cilliers, P. (1998). Complexity and Postmodernism: Understanding Complex Systems, Routledge: London.

Clifford, P. (2004). Where's the beef: Finding literacy in computer literacy. Retrieved 9 January, 2006, from http://www.galileo.org/research/LTL/LTL_presentation.pdf.

Clifford, P., Friesen, S., \& Lock, J. (2005). Coming to teaching in the 21 st century:

Study conducted by the Galileo Network. Retrieved 7 November 2005, from www.galileo.org/research/publications/ctt.pdf

Cohen, L., Manion, L., \& Morrison, K. (2000). Research methods in education (Fifth ed.). London: RotledgeFalmer.

Cowie, B., Jones, A., Harlow, A., McGee, C., Cooper, B., Forret, M., et al. (2008). Tela: Laptops for teachers evaluation: Final report years 9-13. Wellington: Ministry of Education.

Cox, M., Webb, M., Abbott, C., Blakeley, B., Beauchamp, T., \& Rhodes, V. (2004). ICT and pedagogy: A review of the research literature. London: Department for Education and Skills.

Creswell, J. W., \& Clark, V. L. P. (2007). Designing and conduction mixed methods research. Thousand Oaks: Sage.

Cuban, L. (2001). Oversold and underused: Computers in the classroom. Cambridge, Mass: Harvard University Press.

Cuban, L., Kirkpatrick, H., \& Peck, C. (2001). High access and low use of technologies in high school classrooms: Explaining an apparent paradox. American Educational Research Journal, 38(4), 813-834. 
Cuckle, P., \& Clarke, S. (2002). Mentoring student-teachers in schools: Views, practices and access to ICT. Journal of Computer Assisted Learning, 18(3), 330.

Darwin, C. (1869). On the Origin of Species by Means of Natural Selection, or the Preservation of Favoured Races in the Struggle for Life (5th ed.), London: John Murray.

Davis, B., \& Sumara, D. J. (2006). Complexity and education: Inquiries into learning, teaching and research. Mahwah, NJ: Lawrence Erlbaum Associates.

Dewar, S., Kennedy, S., Staig, C., \& Cox, L. (2003). Recruitment and retention in New Zealand secondary schools. Wellington: Ministry of Education.

Dewey, J. (1920). Democracy and education: An introduction to the philosophy of education. New York: Macmillan.

Downes, S. (2007). Half an Hour: Creativity Retrieved 10 August 2007, from http://halfanhour.blogspot.com/2007/08/creativity.html

Downes, S. (2008a). Half an hour [Electronic Version]. Retrieved 13 October 2008 from http://www.downes.ca/cgi-bin/page.cgi?post=45919.

Downes, S. (2008b). Places to go: Connectivism and connective knowledge. Innovate, 5(1).

Dye, J. (2007). Meet Generation C: Creatively Connecting Through Content [Electronic Version]. EContent magazine, 30, 38-43. Retrieved September 2007 from www.econtentmag.com.

Education Review Office. (2005a). E-learning in secondary schools Wellington: Education Review Office.

Education Review Office. (2005b). Voices. Beginning teachers' experience during their first two years of teaching. Wellington: Education Review Office.

Ericsson, K. A. (2006). Protocol analysis and expert thought: Concurrent verbalizations of thinking during experts' performance on representative tasks. In K. A. Ericsson, N. Charness, P. J. Feltovich \& R. R. Hoffman (Eds.), The Cambridge Handbook of Expertise and Expert Performance. (pp. 223241). New York: Cambridge University Press.

Ertmer, P. A. (2005). Teacher pedagogical beliefs: The final frontier in our quest for technology integration? Educational Technology, Research and Development, 53(4), 25-40. 
Falloon, G. W. (2004). An analysis of the impact of an E-classroom environment on athe social, cognitive and affective elements of student work practices. Curtin University of Technology, Perth.

Feiman-Nemser, S. (2003). What new teachers need to learn. Educational Leadership, 60 (8), 25-29.

Friedman, T. L. (2006). The world is flat. The globalized world in the twenty-first century. (rev. ed.) Victoria: Penguin.

Fritze, P.A. (2003). Innovation in university computer facilitated learning systems: Product, workplace experience and the organisation. Unpublished doctoral thesis. RMIT: Faculty of Education, Language and Community Services.

Fullan, M. (2005). Learning communities writ large. In R. DuFour, R. Eaker \& R. DuFour (Eds.), On common ground (pp. 209-223). Bloomington, Indiana: National Education Service.

Gilbert, J. (2005). Catching the knowledge wave? The knowledge society and the future of education. Wellington: NZCER Press.

Glassett, K. F. (2008). Technology and pedagogical beliefs of teachers: A cross case analysis. Paper presented at the American Educational Research Association Annual Meeting, New York.

Gonzalez, C. (2004). The role of blended learning in the world of technology. Retrieved 30 March, 2006, from www.unt.edu/benchmarks/archives/2004/september04/eis.htm.

Goos, M., Galbraith, P., Renshaw, P., \& Geiger, V. (2003). Perspectives on technology mediated learning in secondary school mathematics classrooms. Journal of Mathematical Behavior, 22(1), 73-89.

Gordon, L. (1997). Tomorrow's schools' today: School choice and the education quasi-market. In M. Olssen \& K. M. Matthews (Eds.), Education policy in New Zealand: the 1990s and beyond (pp. 65-82). Palmerston North: Dunmore Press.

Gratch, A. (2001). The culture of teaching and beginning teacher development. Teacher Education Quarterly, Fall 2001.

Green, H., \& Hannon, C. (2007). Their Space: Education for a digital generation. London: Demos.

Grossman, P., \& Schoenfeld, A., with Lee, C.. (2005). Teaching subject matter. In L. Darling-Hammond \& J. Bransford (Eds.), Preparing Teachers for a 
Changing World: What teachers should learn and be able to do. San

Fransisco: Jossey-Boss.

Guba, E., \& Lincoln, Y. (1989). Fourth generation evaluation. Beverly Hills, CA: Sage.

Guskey, T. R. (2000). Evaluating professional development. California: Corwin Press.

Ham, V., Gilmore, A., Kachelhoffer, A., Morrow, D., Moeau, P., \& Wenmoth, D. (2002). What makes for effective teacher professional development in ICT? An evaluation of the 23 ICTPD school clusters programme 1999-2001 Christchurch: Ministry of Education.

Hargreaves, A. (1995). Realities of teaching. In L. W. Anderson (Ed.), International encyclopedia of teaching and teacher education (2nd ed., pp. 80-87).

Cambridge: Pergamon.

Hargreaves, A. (2003). Teaching in the knowledge society: Education in the age of insecurity. Maidenhead: Open University.

Hargreaves, A., \& Fullan, M. (2000). Mentoring in the new millennium. Theory into Practice, 39(1), 50-56.

Haskell, R. E. (2001). Transfer of learning: Cognition, instruction and reasoning. New York: Academic Press.

Hennessy, S., Deaney, R., \& Ruthven, K. (2003). Pedagogic strategies for using ICT to support subject teaching and learning: an analysis across 15 case studies. Cambridge: University of Cambridge.

Heppell, S. (1999). Computers, creativity, curriculum and children. Times Educational Supplement, London.

Hernández-Ramos, P. (2005). If not here, where? Understanding teachers' use Of technology in Silicon Valley schools. Journal of Research on Technology in Education, 38(1), 39.

Hood, J.C. (2007). Orthodoxy vs power: The defining traits of grounded theory. In Bryant A. \& Chernaz, K (eds) The Sage Handbook of Grounded Theory,. London:Sage

Hook, P. (2008). Artichoke [Electronic Version]. Retrieved 13 October 2008 from http://artichoke.typepad.com/.

Horrigan, J. B. (2007). A typology of Information and Communication Technology Users. Washington DC: Pew Internet \& American Life Project. 
infoDev. (2005). Knowledge maps: ICTs in education. Washington: The International Bank for Reconstruction and Development.

Jenkins, H., Clinton, K., Purushotma, R., Robinson, A. J., \& Weigel, M. (2007). Confronting the challenges of participatory culture: media education for the 21st century. Chicago: The MacArthur Foundation.

Jesson, J. (1997). Teacher education for supply or quality: Politics, problems, probabilities and predictions. a cloudy crystal ball. In M. Olssen \& K. M. Matthews (Eds.), Education policy in New Zealand: the 1990s and beyond (pp. 346-357). Palmerston North: Dunmore Press.

John, P. D., \& Baggott la Velle, L. (2004). Devices and desires: subject sub-cultures, pedagogical identity and the challenge of ICT Technology, Pedagogy and Education, 13(3), 307-327.

Johnson, M., Kazakov, D., \& Švehla, M. (2005). ICT in schools report 2005. Wellington.: 2020 Communications Trust.

Johnson, S. (2001). Emergence: the connected lives of ants, brains, cities, and software. New York: Scribner.

Jonassen, D., Peck, K., \& Wilson, B. (2000). Learning with technology: A constructivist approach. Upper Saddle River, NJ: Prentice Hall.

Karsenti, T., Brodeur, M., Deaudelin, C., Larose, F., \& Tardif, M. (2002). Integrating ICTs in teacher tr@ining: A challenging balance. Pan-Canadian Education Research Agenda Symposium, Information Technology and Learning Retrieved 12 January, 2006, from www.cmec.ca/stats/pcera/RSEvents02/Tkarsenti_TEN.pdf

Kennedy, G. E., Judd, T. S., Churchward, A., Gray, K., \& Krause, K.-L. (2008). First year students' experiences with technology: Are they really digital natives? . Australasian Journal of Educational Technology, 24(1), 108-122.

Kirkpatrick, D. (1994). Evaluating Training Programs San Francisco: BerrettKoehler Publishers.

Kitchen, S., Finch, S., \& Sinclair, R. (2007). Harnessing technology schools survey 2007. Coventry: Becta.

Knezek, G., \& Christensen, R. (1999). Stages of Adoption for Technology in Education. Computers in New Zealand Schools, 11(3), 25-29.

Kozma, R. B. (2003). Technology and classroom practices: An international study. Journal of Research on Technology in Education, 36(1), 1-14.

Kvale, S. (1996). Interviews: An introduction to qualitative research. London: Sage. 
Lai, K.-W. (2005). e-Learning Communities: Teaching and Learning with the Web. Dunedin: University of Otago Press.

Leberman, S., McDonald, L., \& Doyle, S. (2006). The transfer of learning: Participants' perspectives of adult education and training. Aldershot: Gower.

Lenhart, A., Hitlin, P., \& Madden, M. (2005). Teens and technology: Youth are leading the transition to a fully wired and mobile nation. Washington DC: Pew Internet and American Life Project.

Lenhart, A., \& Madden, M. (2005). Teen Content Creators and Consumers: More than half of online teens have created content for the internet; and most teen downloaders think that getting free music files is easy to do. Washington DC: Pew Internet and American Life Project.

Lenhart, A., \& Madden, M. (2007a). Social networking websites and teens: An overview. Washington DC: Pew Internet and American Life Project.

Lenhart, A., \& Madden, M. (2007b). Teens, privacy and online social networks: How teens manage their online identities and personal information in the age of MySpace. Washington DC: Pew Internet and American Life Project.

Lenhart, A., Madden, M., Macgill, A. R., \& Smith, A. (2007). Teen Content Creators. Washington DC: Pew Internet and American Life Project.

Levin, D., Arafeh, S., Lenhart, A., \& Rainie, L. (2002). The digital disconnect: The widening gap between Internet-savvy students and their schools. Washington DC: Pew Internet and American Life Project

Levin, T., \& Wadmany, R. (2005). Changes in educational beliefs and classroom practices of teachers and students in rich technology-based classrooms. Technology, Pedagogy and Education, 14(3), 281-307.

Lincoln, Y. S., \& Guba, E. G. (2002). Judging the quality of case study reports. In A. M. Huberman \& M. B. Miles (Eds.), The Qualitative Researchers' Companion (pp. 205-215). Thousand Oaks: Sage.

Ling, R., \& Yttri, B. (2002). Hyper-coordination via mobile phones in Norway. In J. E. Katz \& M. Aakhus (Eds.), Perpetual contact: Mobile communication, private talk, public performance. Cambridge: Cambridge University Press.

Ling, R., \& Yttri, B. (2003). Control, emancipation and status: The mobile telephone in the teen's parental and peer group control relation-ships. Retrieved 18 June 2007 from www.privateline.com/Ling/2004Ling.doc.

Loertscher, D. (2007). Children, teens and the construction of information spaces. Teacher librarian, 35(2), 14-17. 
Loveless, A. (2002). Literature review in creativity, new technologies and learning. Report 4: A report for NESTA Futurelab. Retrieved 24 May 2005, from www.nestafuturelab.org/research/reviews/cr01.htm

Lowther, D., Strahl, J. D., Inan, F. A., \& Ross, S. M. (2008). Does technology integration "work" when key barriers are removed? Paper presented at the AERA annual meeting, New York.

Macgill, A. R. (2007). Parents, Teens and Technology. Washington DC: Pew Internet and American Life Project

Miles, M. B., \& Huberman, A. M. (1994). Qualitative data analysis: An expanded source book (second edition). Thousand Oaks, CA: Sage.

Ministry of Education. (1993). The New Zealand curriculum framework. Wellington: Learning Media.

Ministry of Education. (2006). Enabling the 21st Century Learner; an e-learning action plan for schools 2006-2010. Wellington: Learning Media.

Ministry of Education. (2007). The New Zealand Curriculum. Wellington: Learning Media

Mishra, P., \& Koehler, M. J. (2008). Introducing technological pedagogical content knowledge. Paper presented at the AERA annual meeting, New York.

Mitra, S., Dangwal, R., Chatterjee, S., Jha, S., Bisht, R. S., \& Kapur, P. (2005). Acquisition of computer literacy on shared public computers: Children and the "Hole in the wall". Australasian Journal of Educational Technology 21(3), 407-426.

Moir, E. (2008). Phases of first-year teaching [Electronic Version]. Retrieved 15 October 2008 from http://www.teachersupportprograms.org/phases_first_year_teaching/.

Morrison, K. (2002). School Leadership and Complexity Theory. London \& New York: Routledge Falmer.

Moseley, D., Higgins, S., Bramald, R., Hardman, F., Miller, J., Mroz, M., et al. (1999). Ways forward with ICT: Effective pedagogy using information and communications technology for literacy and numeracy in primary schools. Newcastle: Newcastle University.

Moss, G., Jewitt, C., Levacic, R., Armstrong, V., Cardini, A., \& Castle, F. (2002). The interactive whiteboards, pedagogy and pupil performance evaluation: An evaluation of the Schools Whiteboard Expansion (SWE) London: DfES. 
Muir-Herzig, R. G. (2004). Technology and its impact in the classroom. Computers \& Education, 42(2), 111-131.

NACCCE. (1999). All our futures: Creativity, culture and education. Retrieved 17 August 2007, from www.dfes.gov.uk/naccee/index1.shtml

Nisbet, J., \& Watt, J. (1984). Case study. In J. Bell, T. Bush, A. Fox, J. Goodey \& S. Goulding (Eds.), Conducting Small-Scale Investigations in Educational Management. London: Harper \& Row.

Ofsted. (2005). Embedding ICT in schools - a dual evaluation exercise. (Publication.

Retrieved 14 April 2007, from www.ofsted.gov.uk/Ofsted-

home/Publications-and-research/Education/Curriculum/Information-andcommunication-technology/Secondary/Embedding-ICT-in-schools-a-dualevaluation-exercise

Oppenheimer, T. (1997). The computer delusion. The Atlantic Monthly, 280(1), 4562.

Papert, S. (2004). Technology in Schools: To support the System or Render it Obsolete. Retrieved 8 January, 2006, from http://www.mff.org/edtech/article.taf?_function=detail\&Content_uid1=106

Passey, D., Rogers, C., Machell, J., \& McHugh, G. (2004). The motivational effect of ICT on pupils. Retrieved 15 November, 2005, from http://www.dfes.gov.uk/research/data/uploadfiles/RR523new.pdf

Pedretti, E., Mayer-Smith, J., \& Woodrow, J. (1998). Technology, text, and talk: Students' perspectives on teaching and learning in a technology-enhanced secondary science classroom. Science Education, 82(5), 569-589.

Plato. (360 BCE). Symposium [Electronic Version].eBooks@Adelaide. Retrieved 2 August 2007 from http://etext.library.adelaide.edu.au/p/plato/p71sy/.

Prensky, M. (2001, October). Digital Natives, Digital Immigrants. On the Horizon Retrieved 15 November, 2005, from http://www.marcprensky.com/writing/Prensky\%20\%20Digital\%20Natives,\%20Digital\%20Immigrants\%20-\%20Part1.pdf

Prensky, M. (2005a). "Engage me or enrage me" - What today's learners demand. Educause Review, 40(5), 60.

Prensky, M. (2005b). Listen to the Natives. Educational Leadership, 63(4), 8-13. Prigogine, I. (1997). The End of Certainty. The Free Press: New York.

Radford, M. (2008). Prediction, control an the challenge to complexity. Oxford Review of Education. 34 (5), 505-520. 
Reeves, T. C. (1995). Questioning the questions of instructional technology research. Paper presented at the Annual conference of the association for educational communications and technology, research and theory division, Anaheim, CA.

Reeves, T. C. (1997). Established and emerging evaluation paradigms for instructional design. In C. R. Dills \& A. J. Romoszowski (Eds.), Instructional development paradigms (pp. 163-178). Englewood Cliffs: Educational Technology Publications.

Ritchie, J., \& Spencer, L. (2002). Qualitative data analysis for applied policy research. In A. M. Huberman \& M. B. Miles (Eds.), The Qualitative Researcher's Companion (pp. 305-329). Thousand Oaks: Sage.

Robinson, K. (2006). Do schools kill creativity? Ted Talks Retrieved 13 May 2007, 2007, from http://www.ted.com/index.php/talks/view/id/66

Rosa, C. D., Cantrell, J., Hawk, J., \& Wilson, A. (2005). College Students' Perceptions of Libraries and Information Resources. Dublin, Ohio: Online Computer Library Center.

Roschelle, J. M., Pea, R., Hoadley, C. M., Gordin, D. N., \& Means, B. M. (2000). Changing how and what children learn in school with computer-based technologies. The Future of Children, 10(2), 76-101.

Rowlands, I., Nicholas, D., Huntington, P., Gunter, B., Withey, R., Dobrowolski, T., et al. (2008). Information behaviour of the researcher of the future. from http://www.jisc.ac.uk/whatwedo/programmes/resourcediscovery/googlegen.a $\underline{\mathrm{spx}}$

Sandholtz, J. H., \& Reilly, B. (2004). Teachers, not technicians: Rethinking technical expectations for teachers. Teachers College Record, 106(3), 487-512.

Sandholtz, J. H., Ringstaff, C., \& Dwyer, D. C. (1997). Teaching with technology: Creating student-centered classrooms. New York: Teachers College Press.

Scardamalia, M., \& Bereiter, C. (2006). Knowledge building: Theory, pedagogy, and technology In R. K. Sawyer (Ed.), The Cambridge Handbook of the Learning Sciences. New York: Cambridge University Press.

Schwartz, D. L., Varma, S., \& Martin, L. (2007). Dynamic transfer and innovation [Electronic Version]. Handbook of Conceptual Change from http://aaalab.stanford.edu/papers/Dynamic\%20Transfer\%20and\%20Innovatio n.pdf.

Scott, D., \& Usher, R. (1996). Understanding educational research. London: Routledge. 
Senge, P., Cambron-McCabe, N. Lucas, T., Smith, B., Dutton, J. and Kleiner, A. (2000) Schools That Learn. A Fifth Discipline Fieldbook for Educators, Parents, and Everyone Who Cares About Education. New York: Doubleday.

Sessums, C. D. (2007). Toward a theory of discontent: What can learning theory contribute to education? [Electronic Version]. Retrieved 14 February 2007 from http://eduspaces.net/csessums/weblog/152933.html.

Shaw, L. (2004). The Effect of Practicum Experience on Ideas and Attitudes Towards ICT-use by Pre-service Teacher Education Students. Computers in New Zealand Schools, 16(1), 11-17.

Shulman, L. S. (1986). Those who understand: Knowledge growth in teaching. Educational Researcher, 15(2), 4-14.

Shulman, L. S. (1987). Knowledge and teaching: Foundations of the new reform. Harvard Educational Review, 57(1), 1-22.

Shulman, L. S. (2008). Stewards of change. Change, 40 (3), 6-7.

Siemens, G. (2004). Connectivism: A learning theory for the digital age. Retrieved 15 March, 2006, from http://www.elearnspace.org/Articles/connectivism.htm

Siemens, G. (2006, November 18). Knowing Knowledge. Retrieved November 18, 2006, from http://ltc.umanitoba.ca/KnowingKnowledge/index.php/Main_Page

Siemens, G. (2008). University of Manitoba 2008 online connectivism conference. Retrieved 14 November, 2008, from http://docs.google.com/View?docid=anw8wkk6fjc_14gpbqc2dt

Sime, D., \& Priestley, M. (2005). Student teachers' first reflections on information and communications technology and classroom learning: implications for initial teacher education. Journal of Computer Assisted Learning, 21(2), 130142.

Slaouti, D., \& Barton, A. (2007). Opportunities for practice and development: Newly qualified teachers and the use of information and communications technologies in teaching foreign languages in English secondary school contexts. Journal of In-service Education, 33(4), 405-424.

Somekh, B., Underwood, J., Convery, A., Dillon, G., Jarvis, J., Lewin, C., et al. (2007). Evaluation of the ICT Test Bed project. Nottingham: Becta.

Stacey, R. D. (2001). Complex responsive processes in organisations: Learning and knowledge creation. New York: Routledge.

Stake, R. E. (1995). The art of case study research. Thousand Oaks: Sage. 
Stake, R. E. (2006). Multiple case study analysis. New York: Guilford Press.

Starkey, L. (2008). Evaluating learning in classroom activities using digital technologies. Paper presented at the ACEC 2008, Canberra.

Starkey, L., \& McCarthy, A. (2008). Integrating Web 2.0 into a geography classroom. Paper presented at the Australian Computers in Education Conference, Canberra.

Starkey, L., \& Stevens, K. (2007). Three stages in the digital integration of New Zealand schools New Zealand Annual Review of Education(16), 105-118.

Starkey, L., Yates, A., Meyer, L.H., Hall, C., Taylor, M., Stevens, S. et al. (2009). Professional development design: Embedding educational reform in New Zealand. Teaching and Teacher Education, 25(1), 181-189.

Stucki, P., Kahu, A., Jenkins, H., Bruce-Ferguson, P., \& Kane, R. (2006). Narratives of beginning Maori teachers: Identifying forces that shape the first year of teaching. Wellington: Teaching and Learning Research Initiative.

Sutherland, R., Armstrong, V., Barnes, S., Brawn, R., et al. (2004). Transforming teaching and learning: Embedding ICT into everyday classroom practices. Journal of Computer Assisted Learning, 20(6), 413.

Tapscott, D. (1998). Growing up digital: The rise of the Net Generation. New York: McGraw-Hill.

Tapscott, D., \& Williams, A. D. (2006). Wikinomics: How mass collaboration changes everything. New York: Portfolio.

Tearle, P. (2003). ICT implementation: what makes a difference? British Journal of Educational Technology, 34(5), 567-583.

Twining, P., Broadie, R., Cook, D., Ford, K., Morris, D., Twiner, A., et al. (2006). Educational change and ICT: An exploration of Priorities 2 and 3 of the DfES e-strategy in schools and colleges. The current landscape and implementation issues. Coventry: Becta.

Vincent, J. (2004). ‘11 16 Mobile’: Examining mobile phone and ICT use amongst children aged 11 to 16. Guildford: Digital World Research Centre, University of Surrey.

Waldrop, M. M. (1992). Complexity; the emerging science at the edge of order and chaos. New York: Simon and Schuster.

Webb, M., \& Cox, M. (2004). A review of pedagogy related to information and communications technology. Technology, Pedagogy and Education, 13(3), 235-286. 
Wenglinski, H. (1998). Does it compute? The relationship between educational technology and student achievement in mathematics. Princeton, NJ: ETS.

Wikipedia. (2007). Definitions of creativity. Retrieved 17 August 2007, from http://en.wikipedia.org/wiki/Creativity\#Definitions_of_creativity

Williams, J. S. (2003). Why great teachers stay. Educational Leadership, 60(8), 7174.

Wink, J. (2000). Critical pedagogy: Notes from the real world. Boston: Allyn \& Bacon.

Yin, R. K. (2003). Case study research: Design and methods (3 ed. Vol. 5).

Thousand Oaks: Sage. 


\section{Appendices}

Appendix 1: Glossary of terms.

Appendix 2: Information sheet for participants.

Appendix 3: Information about the "Digital beginning teachers" research project for parents/ caregivers of students aged 15 and over.

Appendix 4: Consent form "Digital beginning teachers" research project for parents/students.

Appendix 5: Teacher Interview 1.

Appendix 6a: Interview 2 - observation of teaching using digital technologies.

Appendix 6b: Student think alouds.

Appendix 7: Interview 3 - after teaching using digital technologies/ end of first year teaching.

Appendix 8: Refining the research questions after initial research stage.

Appendix 9: Cross case synthesis - the purpose of reported digital technology use across the case studies.

Appendix 10: Generic inductive qualitative analysis. Theme: purpose or reasons given for using digital technologies. 


\section{Appendix 1: $\quad$ Glossary of terms.}

\begin{tabular}{|c|c|}
\hline Blogosphere & A community of bloggers. \\
\hline $\begin{array}{l}\text { Digital } \\
\text { technologies }\end{array}$ & $\begin{array}{l}\text { Digital technology is a generic term for all hardware and } \\
\text { software with a digital component. Examples include: } \\
\text { computers, calculators, cell phones, heart rate monitors } \\
\text { and ICTs. }\end{array}$ \\
\hline ERO & 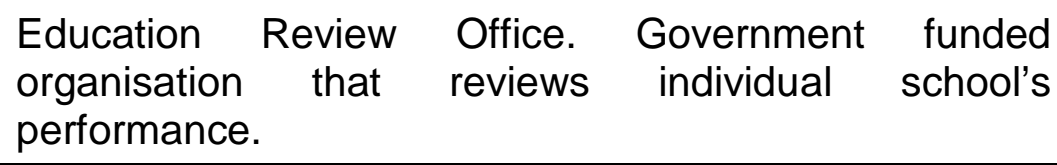 \\
\hline HOD & $\begin{array}{l}\text { Head of a subject department, position with curriculum } \\
\text { and teacher leadership. }\end{array}$ \\
\hline ICT & Information communication technology \\
\hline PD & Professional development of teaching staff. \\
\hline PRT & $\begin{array}{l}\text { Provisionally registered teacher. Most teachers become } \\
\text { fully registered after two years initial teaching practice. }\end{array}$ \\
\hline Technopedagogy & $\begin{array}{l}\text { Knowledge of teaching and learning using digital } \\
\text { technologies }\end{array}$ \\
\hline Web 2.0 & Interactive internet programmes \\
\hline Whakatauki & A proverb. \\
\hline Year 10 & $\begin{array}{l}\text { A student who has been at school for } 10 \text { years usually } \\
\text { aged } 14 / 15 \text {. }\end{array}$ \\
\hline LMS & Learning management system \\
\hline SMS & Student management system \\
\hline TELA & Laptops for teachers scheme \\
\hline NCEA & National Certificate in Educational Achievement \\
\hline
\end{tabular}


Appendix 2: Information sheet for participants.

How do beginning teachers use digital technology in teaching and learning?

Louise Starkey is working towards a $\mathrm{PhD}$ and would like six beginning teachers from a range of curriculum areas to work with.

Would you give you permission for:-

$\square$ Louise to visit you at your school over the next year and

$\square$ Talk with you about how you are choosing to use digital technologies in your classroom and professional learning,

$\square$ talk with your school based mentor about the support you are receiving to use digital technologies

$\square$ observe your students using digital technologies

talk with your students about what they are thinking about/learning as they use digital technologies

If you would give your permission for this, then read on...........

\section{About the research:}

Each year teachers joining the teaching profession have increased familiarity of digital technologies in their everyday life and through their studies. The digital technologies that are available and easy to use have also changed. This means that information is no longer sourced mainly from books or from listening to experts in the field. Students and teachers can access information and interact online to construct and develop knowledge and understanding. This research aims to examine how beginning teachers use digital technologies in their professional lives, for both their professional learning and as they support and guide students' learning. This study will inform a $\mathrm{PhD}$ thesis.

\section{Method of research:}

Louise aims to follow six teachers as case studies. Each case study will include a beginning teacher during their first year of teaching. This study has approval from the Human Ethics Committee at Victoria University of Wellington.

\section{Research questions:}

Main research question:

How do beginning teachers use digital technology in teaching and learning? Subquestions:

What factors impede or encourage the use of digital technologies by beginning teachers?

How do beginning teachers experience the use of digital technologies to connect and collaborate in their teaching and professional learning?

How do beginning teacher beliefs influence their use of digital technology in teaching and professional learning?

What are appropriate pedagogical beliefs/ learning theory in the digital era? How are beginning teachers mentored as they use digital technologies?

\section{Becoming a participant:}

If you want to volunteer to become one of the teacher participants in the research, please complete the attached consent form. Out of all the students who volunteer to take part in this study, six will be selected (the selection will aim to get a range of experiences and schools). You can withdraw from participating at any stage up to the end of data gathering (June 2008). If you have Louise as one of your lecturers in any course your initial indication of interest in participating in this research will be held 
by a third party until your grade for that particular course (or part of a course) is finalised. This is to ensure that participation or non-participation in this research does not influence your relationship with your lecturer in any way.

\section{What being a participant involves:}

In July 2007, once selection of the teachers is made, you will interviewed by Louise to explore your philosophy of teaching, confidence using digital technologies and hopes for the upcoming year. This interview should take up to 40 minutes. The interview will be recorded and the results summarised and given to you to check for accuracy.

Between July 2007 and July 2008 Louise will organise at least two further face-toface meetings with you (ideally one meeting per term). The duration of these meetings will be approximately 1 hour. During these meetings, the results and progress of previous term and plans for the following term will be recorded. Notes taken at these meetings will be checked with you for accuracy at the conclusion of each meeting. During one of your teaching sequences Louise will observe you with a class (if appropriate) and interview a sample of your students about their learning and use of digital technologies in the class. The student interviews will be recorded, be approximately 10 minutes each and may be digitally remastered into a presentation linked with samples of student work if student, teacher and school confidentiality can be maintained.

During the final term of the study, in 2008, Louise will interview you. She will also interview your mentor at school (if you have one) to examine the type of support you have had for introducing digital technologies into your teaching.

\section{How the results will be shared:}

The data will be collated and analysed, then included in a $\mathrm{PhD}$ thesis that will be available through Victoria University of Wellington library. You will be sent a summary of these results. The results will be shared with the education and teaching community through journal articles and conference presentations.

\section{Confidentiality:}

Your identity and the school in which you teach will remain confidential. You will be asked to choose a pseudonym for the thesis/ journal articles and presentations. Any aspect that may identify you will be changed in the thesis and any presentations. You will be asked to keep your schools', mentors' and students' participation in this research confidential.

All notes and raw data will be destroyed one year after the thesis is finalised. You can withdraw your offer to participate any time before the end of the data gathering phase (June 2008).

\section{Any questions or want to know more?}

Researcher:
Louise Starkey
MA001
Victoria University of Wellington,
College of Education.
louise.starkey@ vuw.ac.nz
Ph: 044639768

Supervisor:

Janice Wearmouth

Victoria University of Wellington,

College of Education.

janice.wearmouth@vuw.ac.nz

Ph: 044639532 


\title{
Appendix 3: Information about the "Digital beginning teachers" research project for parents/ caregivers of students aged 15 and over.
}

\section{Dear parent/caregiver}

(teacher) is taking part in a research project that is exploring how teachers use digital technology in teaching and learning. The research includes examining how the use of digital technologies helps the students to learn (or doesn't help them to learn). The research includes observing (class name) as they use digital technologies in their learning and talking to a sample of students in the class about their learning.

\begin{abstract}
About the researcher:
Louise Starkey has a background in secondary teaching and research. She has taught and been involved in senior management in New Zealand schools before joining Victoria University in 2005. This research is part of her $\mathrm{PhD}$ study.
\end{abstract}

\section{About the research:}

Each year teachers joining the teaching profession have increased familiarity of digital technologies in their everyday life and through their studies. They use this experience and ideas to integrate digital technologies into their classroom teaching practices. This research examines how teachers integrate the digital technologies into the classroom and the impact this has on student learning.

\section{Method of research:}

Louise is using case study methodology, following five teachers as they use digital technologies.

This study has approval from the Human Ethics Committee at Victoria University of Wellington, and Louise is under the supervision of Dr Lex McDonald and Professor Ken Stevens (Victoria University).

What being a part of this research involves:

During____ month/year___ Louise would like to observe xxxxx's xxxxx class as they use digital technologies to learn. Louise will interview a sample of students from this class (individually or in a group) what and how they are learning and how they are using the digital technologies in the class. The interviews will take approximately 10 minutes and take place during class time (this needs to be negotiated with the teacher, confirmed closer to time of research) Prior to interviewing any student, the purpose and methods of the research as outlined here will be explained and the individual students will be given the option of taking part in the interview or not. Interviews with students will be (voice) recorded. If the student agrees, it is possible that some voice recordings may be digitally remastered into a presentation that links the student voice with samples of student work, but only if student, teacher and school confidentiality can be maintained. Any student whose recording is used in such a way will be given a personal copy of the presentation and be asked again for permission for it to be used as part of this research (if the student doesn't want it to be used, then it will be deleted). The purpose of this is to illustrate the way that digital technologies are being used in schools, and the learning that occurs when the digital technologies are used. 


\section{How the results will be shared:}

The data will be collated and analysed, then included in a $\mathrm{PhD}$ thesis that will be available through Victoria University of Wellington library, and a summary of the thesis will be available through the school. Results will be shared with the education and teaching community through journal articles and conference presentations.

\section{Confidentiality:}

The participants and the school in which they attend will remain confidential. Pseudonyms will be used for the thesis/ journal articles and presentations. Any aspect that may identify students or the school will be changed or omitted in the thesis and presentations. All raw data including recordings will be destroyed at the conclusion of the research.

\begin{tabular}{|l|l|}
\hline Researcher: & Supervisor: \\
Louise Starkey & Dr Lex McDonald \\
MA001 & Victoria University of Wellington, \\
Victoria University of Wellington, & College of Education. \\
College of Education. & lex.mcdonald@ vuw.ac.nz \\
louise.starkey@ vuw.ac.nz & Ph: 044635173 \\
Ph: 044639768 & \\
\hline
\end{tabular}




\section{Appendix 4: Consent form "Digital beginning teachers" research project for parents/students.}

\section{Consent form: How do teachers use digital technology in teaching and learning?}

I, agree to take part in an interview the research examining how teachers use digital technology in teaching and learning.

\section{By taking part in an interview I understand that:-}

$\square$ My identity will remain confidential.

$\square$ Louise might talk to and digitally record a conversation with me as I explain what I have learnt.

$\square$ Parts of the interview might be included in a presentation about students using digital technologies to learn.

$\square$ Louise might develop a presentation using your interview and samples of class work to illustrate the use of digital technologies (only if the school, teacher and student identities remain confidential and the students involved agree to this).

$\square$ All notes and raw data will be destroyed one year after the thesis is finalised

$\square$ I can withdraw my offer to participate up until data gathering has finished (June 2008).

$\square$ Louise will check with me that what she records is what I meant to say after the interview.

$\square$ If Louise and I agree, Louise might match some of my recording with a sample of the work I show her. If this happens, I will be given a copy and will make the decision whether this can be shown to anyone else.

$\square$ I will keep the identity of participants in this research confidential including; students, the school and the teacher.

Or:

I do not want to take part in this research at this time.

Signed

Date

If under 15 years old - (Louise Starkey will remove this part for over 14s version)

Parent/guardian please sign to show you give permission for your son/ daughter to take part in an interview.

Or:

I do not want my child to take part in this research at this time.

Signed

Date

Contact information:

\begin{tabular}{|l|l|}
\hline Researcher: & Supervisor: \\
Louise Starkey & Dr Lex McDonald \\
Victoria University of Wellington, & Victoria University of Wellington, \\
College of Education. & College of Education. \\
louise.starkey@ vuw.ac.nz & lex.mcdonald@ vuw.ac.nz \\
Ph: 044639768 & Ph: 044635173 \\
\hline
\end{tabular}




\section{Appendix 5: Teacher Interview 1.}

Participant copy-

Name:-

1. Your experience of using digital technologies:

\begin{tabular}{|c|c|c|c|c|c|c|c|c|c|}
\hline $\begin{array}{l}\text { Technology or programme } \\
\text { (add any others that you use } \\
\text { or would like to use) }\end{array}$ & $\begin{array}{l}\text { I don't } \\
\text { know } \\
\text { what } \\
\text { this is }\end{array}$ & $\begin{array}{l}\text { know } \\
\text { what } \\
\text { this is }\end{array}$ & $\begin{array}{l}\text { I have } \\
\text { seen } \\
\text { someone } \\
\text { else use } \\
\text { it }\end{array}$ & $\begin{array}{l}\text { I saw } \\
\text { this } \\
\text { being } \\
\text { used } \\
\text { on TE }\end{array}$ & $\begin{array}{l}\text { I have } \\
\text { used it } \\
\text { myself }\end{array}$ & $\begin{array}{l}\text { I use it } \\
\text { regularly } \\
\text { (at least } \\
\text { once a } \\
\text { month) }\end{array}$ & $\begin{array}{l}\text { I have } \\
\text { used it } \\
\text { for my } \\
\text { own } \\
\text { learning }\end{array}$ & $\begin{array}{l}\text { I have } \\
\text { used it } \\
\text { for } \\
\text { teaching }\end{array}$ & $\begin{array}{l}\text { I would like } \\
\text { to use this } \\
\text { for } \\
\text { teaching or } \\
\text { my own } \\
\text { learning }\end{array}$ \\
\hline \multicolumn{10}{|c|}{ PC based data presentation and manipulation. } \\
\hline \multicolumn{10}{|l|}{ Word } \\
\hline \multicolumn{10}{|l|}{ Excel } \\
\hline \multicolumn{10}{|l|}{ Access } \\
\hline \multicolumn{10}{|l|}{ Moviemaker/ imovie } \\
\hline \multicolumn{10}{|l|}{ Powerpoint } \\
\hline & & & & & & & & & \\
\hline & & & & & & & & & \\
\hline \multicolumn{10}{|c|}{$\begin{array}{l}\text { Web based access to } \\
\text { information }\end{array}$} \\
\hline \multicolumn{10}{|c|}{$\begin{array}{l}\text { Learning mastery } \\
\text { games - e.g., Fling } \\
\text { your teacher, Hot }\end{array}$} \\
\hline \multicolumn{10}{|l|}{ Websites } \\
\hline & & & & & & & & & \\
\hline \multicolumn{10}{|c|}{$\begin{array}{l}\text { Digital communication } \\
\text { tools }\end{array}$} \\
\hline \multicolumn{10}{|l|}{ Text messaging } \\
\hline \multicolumn{10}{|l|}{ SMS via internet } \\
\hline \multicolumn{10}{|l|}{ Email } \\
\hline & & & & & & & & & \\
\hline & & & & & & & & & \\
\hline \multicolumn{10}{|c|}{$\begin{array}{l}\text { Social networking tools (or Web } \\
\text { 2.0) }\end{array}$} \\
\hline \multicolumn{10}{|c|}{\begin{tabular}{l|l|l} 
My Space, Ning, & & \\
Facebook, Bebo & & \\
\end{tabular}} \\
\hline \multicolumn{10}{|l|}{ Blogging } \\
\hline \multicolumn{10}{|l|}{ Wiki } \\
\hline \multicolumn{10}{|l|}{ Podcast } \\
\hline \multicolumn{10}{|l|}{ Video podcast } \\
\hline \multicolumn{10}{|l|}{$\begin{array}{l}\text { Second life or other } \\
\text { virtual worlds }\end{array}$} \\
\hline & & & & & & & & & \\
\hline \multicolumn{10}{|l|}{ Games } \\
\hline & & & & & & & & & \\
\hline & & & & & & & & & \\
\hline & & & & & & & & & \\
\hline & & & & & & & & & \\
\hline \multicolumn{10}{|c|}{ Digital learning environments } \\
\hline \multicolumn{10}{|l|}{$\begin{array}{l}\text { Online learning } \\
\text { communities }\end{array}$} \\
\hline \multicolumn{10}{|l|}{ Smartboards } \\
\hline videoconferencing & & & & & & & & & \\
\hline & & & & & & & & & \\
\hline
\end{tabular}




\section{How confident are you?}

Put an $\mathrm{X}$ on the following continuum for how confident you feel about successfully integrating digital technologies into your teaching practice.

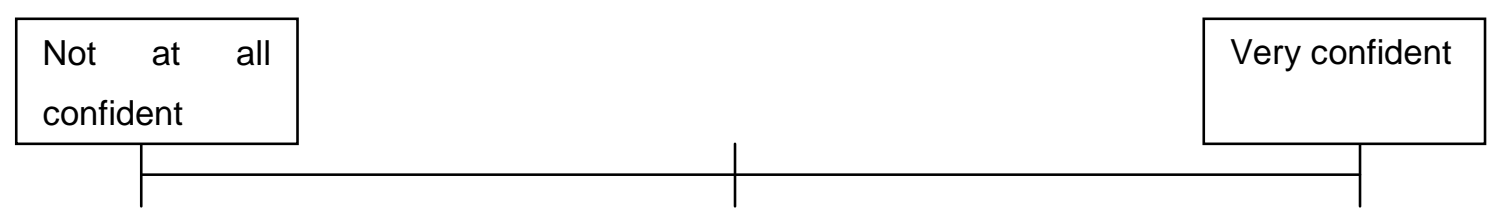

\section{How innovative do you consider yourself?}

Put an $\mathrm{X}$ on the following continuum for how confident you are at developing new ways of using digital technologies in your teaching and learning.

Highly innovative. I feel confident

developing new ways of using

the digital technologies.

\begin{tabular}{l}
\hline I don't feel confident \\
developing new ways of \\
using digital technologies.
\end{tabular}

\section{How important is it to use digital technologies?}

Put an $\mathrm{X}$ on the following continuum for how important you believe it is to integrate digital technologies into schools.

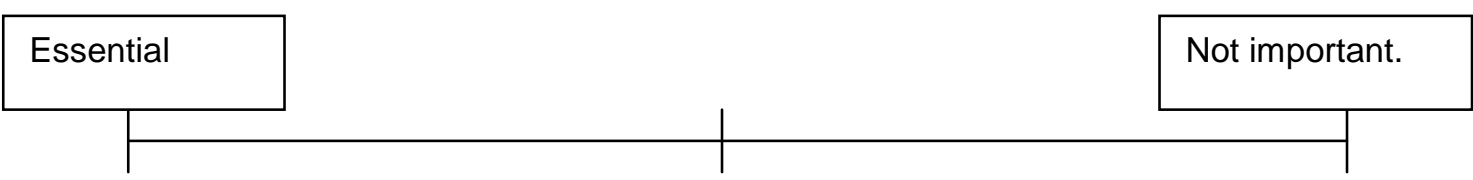

7. How would you like to use digital technologies with the classes you teach?

8. How do you think you will use digital technologies with the classes you teach?

9. Do you intend to or currently use digital technologies for your own professional learning? (if so, explain how)

10. What do you believe the role of the teacher should be in the learning process?

11. What do you understand 'knowledge' to be?

12. What role should digital technologies have in student learning? 
Appendix 6a: Interview 2 - observation of teaching using digital technologies.

\section{Background demographic information:}

Pseudonym:

Age of teacher:

Previous work/life experiences which give confidence or hesitancy to the use of DIGITAL TECHNOLOGIES in teaching/learning:

\section{Learning activity using digital technologies:}

Why are you using digital technology in this lesson/activity?

The context/unit:

The students - age, subject, level, chx...

Learning intention: Through using digital technologies, it is intended that the students will learn...

Digital technologies used:

How (what the students do):

Barriers and enablers encountered when setting up the learning activity and carrying it out:

Knowledge/experience and skill you needed to be successful using this digital technology: 


\section{Appendix 6b: Student think aloud}

Student interviews - semistructured "Think alouds" - with either groups who have worked together or individuals - during their class time...I will sit with students and ask them to explain the learning - show me what they have been doing and through the use of prompts, find out how the students might have used digital technologies to construct knowledge and the nature of any knowledge construction.

Possible prompts:

Show me what you have been learning.

What have you learnt?

What sort of decisions have you made in the learning process?

Who did you learn with?

(How) did the (digital technology(ies)) help you to learn?

Who has helped you to understand (this learning...)

How are you sharing this with other people?

Can you talk me through what you have been doing?

Could you have learnt this without using (the digital technology)?

What sort of things made it easier/difficult to use (the digital technology)?

How did you know to do this? 
Appendix 7: Interview 3 - after teaching using digital technologies/ end of first year teaching.

Teacher's reflection on the lesson/learning/ technology use:

\section{General:}

Technologies available for you to teach with: (could be owned privately or provided by the school)

Uses of DIGITAL TECHNOLOGIES in teaching/learning in the last year:

Barriers and enablers, learning outcomes for students, reflections...

Professional learning as a teacher - connections, communities and support including who supports you within school, outside of school and the type of support you have.

How your beliefs and experiences have (or not) helped you as a beginning teacher aiming to use digital technologies in your teaching 


\section{Appendix 8: Refining the research questions after initial research} stage.

\begin{tabular}{|c|c|c|}
\hline $\begin{array}{l}\text { Proposed } \quad \text { Research } \\
\text { Questions: }\end{array}$ & $\begin{array}{l}\text { Findings from the initial stages } \\
\text { of research: }\end{array}$ & $\begin{array}{ll}\text { Refined } & \text { research } \\
\text { questions: } & \end{array}$ \\
\hline $\begin{array}{l}\text { How do beginning teachers } \\
\text { use digital technology in } \\
\text { their professional practice? }\end{array}$ & $\begin{array}{l}\text { Beginning teachers were aged } \\
\text { between } 20 \text { and } 60 \text { years. It was } \\
\text { young teachers who had digital } \\
\text { technologies integrated into their } \\
\text { lives that were to be the focus of } \\
\text { the study. }\end{array}$ & $\begin{array}{l}\text { How do digitally able } \\
\text { beginning teachers use } \\
\text { digital technologies for } \\
\text { teaching and learning? }\end{array}$ \\
\hline $\begin{array}{l}\text { What factors impede and } \\
\text { encourage the use of digital } \\
\text { technologies by beginning } \\
\text { teachers and how can these } \\
\text { be overcome? }\end{array}$ & $\begin{array}{l}\text { Focussing on the factors which } \\
\text { impede or encourage use was the } \\
\text { key area of interest, so this was } \\
\text { narrowed to reflect that focus. How } \\
\text { the barriers have been overcome } \\
\text { and in what situation would be } \\
\text { included along with other aspects. }\end{array}$ & $\begin{array}{l}\text { What factors impede or } \\
\text { encourage the use of } \\
\text { digital technologies by } \\
\text { beginning teachers? }\end{array}$ \\
\hline $\begin{array}{l}\text { How do beginning teacher } \\
\text { beliefs about student } \\
\text { learning influence their use } \\
\text { of digital technologies in } \\
\text { teaching and professional } \\
\text { learning? }\end{array}$ & $\begin{array}{l}\text { Beliefs were one of the factors } \\
\text { identified in the initial interview as } \\
\text { enabling or impeding the use of } \\
\text { digital technologies, so this became } \\
\text { an aspect of the previous question. }\end{array}$ & \\
\hline $\begin{array}{l}\text { How do beginning teachers } \\
\text { experience the use of Web } \\
2.0 \text { to connect and } \\
\text { collaborate with their peers? }\end{array}$ & \multirow{2}{*}{$\begin{array}{l}\text { The support that the teachers have } \\
\text { appeared to affect their use of } \\
\text { digital technologies, so this } \\
\text { question was broadened to } \\
\text { encompass examining support } \\
\text { (which included mentor) rather } \\
\text { than Web 2.0, which was not being } \\
\text { reported as being used. } \\
\text { The mentoring aspect was taking } \\
\text { away from the key focus of the } \\
\text { research so this was culled out. }\end{array}$} & \multirow[t]{2}{*}{$\begin{array}{l}\text { How do beginning } \\
\text { teachers connect and } \\
\text { collaborate in their } \\
\text { teaching and professional } \\
\text { learning? }\end{array}$} \\
\hline $\begin{array}{l}\text { How can emerging teachers } \\
\text { be mentored in a way that } \\
\text { allows them to be } \\
\text { innovative? }\end{array}$ & & \\
\hline $\begin{array}{l}\text { What are appropriate } \\
\text { pedagogical beliefs/ } \\
\text { learning theory in the digital } \\
\text { era? }\end{array}$ & $\begin{array}{l}\text { To answer this question through } \\
\text { the research I needed to first } \\
\text { develop a framework then identify } \\
\text { what learning is occurring in the } \\
\text { case studies. }\end{array}$ & $\begin{array}{l}\text { What is the potential } \\
\text { learning and the actual } \\
\text { learning that occurs in a } \\
\text { beginning teacher's } \\
\text { classroom as students use } \\
\text { digital technologies? }\end{array}$ \\
\hline
\end{tabular}


Appendix 9: Cross case synthesis - the purpose of reported digital technology use across the case studies.

To engage students/ to help with their learning.

\begin{tabular}{|c|}
\hline Purpose: \\
\hline Using digital technology \\
for showing students \\
information/ to engage \\
students
\end{tabular}

As a resource - place to find information

Using interactive digital technologies to help students understand an idea or concept

Create products

Tool for reflection

Entertain students

Storage and display of exemplars of work

\section{Classroom} management/ organisation

\begin{tabular}{|c|c|c|c|c|c|}
\hline \multicolumn{6}{|c|}{ Case Study: } \\
\hline $\mathbf{A}$ & B & C & D & $\bar{E}$ & $\mathbf{F}$ \\
\hline $\begin{array}{l}\text { Moulin rouge DVD } \\
\text { Icebreaker } \\
\text { website }\end{array}$ & Rugby game & & PowerPoint & PowerPoint & $\begin{array}{l}\text { PowerPoint } \\
\text { Art DVD }\end{array}$ \\
\hline \multirow[t]{3}{*}{$\begin{array}{l}\text { Moulin rouge } \\
\text { Innovative textiles } \\
\text { products (pictures) }\end{array}$} & & & $\begin{array}{l}\text { Kiwi signs } \\
\text { Access patterns }\end{array}$ & $\begin{array}{l}\text { Roman activity } \\
13 \text { geo planning }\end{array}$ & web quest \\
\hline & $\begin{array}{l}\text { Calculator } \\
\text { Bones and } \\
\text { muscles }\end{array}$ & $\begin{array}{l}\text { Video analysis of } \\
\text { volleyball } \\
\text { Maths activity }\end{array}$ & & Photo images & \\
\hline & & & Business cards & $\begin{array}{l}\text { Photos for yr } 13 \\
\text { geo } \\
\text { Photo images }\end{array}$ & Create signs \\
\hline \multicolumn{6}{|l|}{ Facebook } \\
\hline \multicolumn{6}{|l|}{$\begin{array}{l}\text { Study and form } \\
\text { time } \\
\text { boggle }\end{array}$} \\
\hline $\begin{array}{l}\text { Food pictures, } \\
\text { Facebook site with } \\
\text { wearable arts. } \\
\text { moderation }\end{array}$ & & & moderation & Gym activities & moderation \\
\hline $\begin{array}{l}\text { Entertain students } \\
\text { Text or email } \\
\text { parents } \\
\text { Taking the roll }\end{array}$ & $\begin{array}{l}\text { Organization of } \\
\text { internet activity. } \\
\text { Would like to use } \\
\text { PowerPoints. }\end{array}$ & & $\begin{array}{l}\text { Text parents } \\
\text { Students who are } \\
\text { away }\end{array}$ & Text hockey team. & $\begin{array}{l}\text { Reading notices } \\
\text { Taking the roll }\end{array}$ \\
\hline
\end{tabular}


Appendix 10: General inductive qualitative analysis. Theme: purpose or reasons given for using digital technologies.

\begin{tabular}{|c|c|c|c|}
\hline Source & Quote & code & concept \\
\hline d3 & $\begin{array}{l}\text { It was really cool as when I went to call parents last night I found I could type in the student, bring up all their information - all their } \\
\text { report comments so that I could see if there was consistency across the subjects and over time before I spoke to parents. }\end{array}$ & \multirow{2}{*}{$\begin{array}{l}\text { access info easy } \\
\text { admin }\end{array}$} & \multirow{5}{*}{$\begin{array}{l}\text { Administrative } \\
\text { purpose }\end{array}$} \\
\hline d1 & I have to use excel for teaching as all our marking is done in excel. I use it for the budget & & \\
\hline d3 & $\begin{array}{l}\text { In textiles we have a classroom digital camera. It sits on my desk and as part of the process they have to record everything. Because } \\
\text { it is a practical subject I have to sign it off and physically see it and also at the end of the projects they have to sign it off. }\end{array}$ & $\begin{array}{|ll|}\begin{array}{l}\text { moderation } \\
\text { recording } \\
\text { achievements }\end{array} \\
\end{array}$ & \\
\hline a1 & $\begin{array}{l}\text { When you text message them, what would be the purpose? I was thinking that it could be reminders to bring stuff to class, or } \\
\text { reminders for homework, of deadlines. }\end{array}$ & student organisation & \\
\hline f1 & It would be good also as a promotional thing for when we have open days & promoting subject & \\
\hline d1 & $\begin{array}{l}\text { Bebo ...I don't know. I was thinking about this the other day because they are all into it. As far as getting dialogues to happen that are } \\
\text { related to learning, rather than what you did in the weekend }\end{array}$ & \begin{tabular}{|l|} 
dialogues about \\
learning
\end{tabular} & \multirow[t]{11}{*}{$\begin{array}{l}\text { Engaging students } \\
\text { in Learning }\end{array}$} \\
\hline $\mathrm{f1}$ & $\begin{array}{l}\text { We could have potentially the programmes that future students will be doing through the year so that they can see what they will be } \\
\text { working on through the year. }\end{array}$ & exemplars & \\
\hline $\mathrm{c} 1$ & $\begin{array}{l}\text { PowerPoint }- \text { I do that quite a bit. I find kids tend to focus more when I put things on a PowerPoint with pretty colours and pictures. } \\
\text { Use this more for year } 12-13 \text {. }\end{array}$ & engage in learning & \\
\hline c2 & Students seem to take more away from the lesson when digital technologies are being used. & students learn more & \\
\hline d3 & There is no data projector in fashion. I use it for about 2 weeks of the term, the start the middle and the end just to refocus them. & focus students & \\
\hline f2 & I also have a DVD which is little snippets of adverts made from overseas for visual stimulus, & stimulus & \\
\hline B3 & $\begin{array}{l}\text { There is huge amounts of information about body image on the internet. The information I can talk to them in class are quite limited in } \\
\text { terms of the scope of what is out there. What it also does is allow them to express it in way that is relevant to them. When I just say } \\
\text { bang, do a poster some of them it might appeal to, but a lot sigh. By giving choice and options and something new to try that they } \\
\text { don't always get the opportunity to do then that gives them the opportunity to put in the effort to really give it a go. That is what I want } \\
\text { with this class. I expect at least half the class to gain merit or excellent. They are working towards that now, but to achieve it I need to } \\
\text { increase that interest. }\end{array}$ & $\begin{array}{l}\text { Interest and learn } \\
\text { more }\end{array}$ & \\
\hline c2 & Just making connections between what is being talked about and then using a different medium to present it. & presentation & \\
\hline c2 & I enjoy learning about new ways of presenting information to students. & presentation & \\
\hline d3 & $\begin{array}{l}\text { There is one in the room by the art room. If I want to present anything it goes up in here, it is a matter of moving them from the } \\
\text { classroom }\end{array}$ & presentation & \\
\hline D1 & $\begin{array}{l}\text { Students bring in their ipods with their song lists. They have to edit them down so that I can tolerate them. I bought them a new chord } \\
\text { so that they can hook them up to the speakers. The students all had their own ipods, but I said Na, I don't mind Ipods, I always work } \\
\text { to music. It is so antisocial. Now they all have to put them away and we now have } 20 \text { minute slots when we have to listen to } 3 \\
\text { people's music through a lesson. Now they just do it themselves, I don't have to orchestrate that part. }\end{array}$ & Learning environment & \\
\hline
\end{tabular}




\section{Source Quote}

Powerpoint - I am going to use it for students learning, like they are going to have to create their own powerpoints next semester because we have just had exams and there was a massive section that my year 12s, which I went over and over and over with them and not all of them, but the majority of them crashed and burned on that one question. So I am going to break them up into small groups and get them to investigate a small section each and they are to present it back to class with resources.

Instead of always making a poster I would like them to collectively work on something that they can construct. I think they are just bored. Any time I get them into the computer room even to watch a DVD I am always telling them to turn their screens off. They are just aching to muck around on the computer. Most will be surfing the net aimlessly. If they had the know how and an assignment, they would be working on that actively.

The tried and true method seems to be make a poster. The kids are just insanely over that. I don't believe that making a poster fills their desires I am thinking of finding some way of making movies for show and tell stuff

b1

Every class I think it doesn't have to be the whole of every class, but to have some aspect of it, whether it is interactive whiteboards, powerpoints or....they all relate, it might not necessarily be sitting in a computer in every class, long term it is where it is going to go, no doubt about it.

f1 For student survival for the world in which they live in I think extremely, but I think a balance is essential. I have always been surrounded by people who are to the extreme of being too techy. I live in a graveyard of computers which is a bone of contention

\begin{tabular}{|c|c|}
\hline b1 & $\begin{array}{l}\text { I guess as we become more reliant and focused on the use of technology outside of school in the community and in the work force } \\
\text { digital technology should play more of a part in student learning. because most people, spelling tests. I still see a lot of spelling tests } \\
\text { and things. To tell the truth I am a terrible speller, but everything I have had to write formally has been word processed so I have been } \\
\text { able to get through. Spell-check is brilliant with I think is a metaphor for everything. As we become more reliant on technology we less } \\
\text { and less need the skills to get by without it, but in saying that I think it is important that we still teach the skills so that we can get by } \\
\text { without technology. I think technology in student learning will increase. I think that's what needs to happen to prepare them for life in a } \\
\text { technologically advanced world where they will be using computers every day. Their jobs in the future will be largely technology } \\
\text { based. It doesn't matter what you do these days. Even a builder or a tradesman is not working just physically with their hands a lot of } \\
\text { it is working with managing accounts and bookings. anything, it is all online. }\end{array}$ \\
\hline b1 & $\begin{array}{l}\text { again it is the access thing, ideally it comes down being able to access it all the time. If they wanted to research something, find } \\
\text { something out, you could spend a lot of time teaching them how to find things rather then looking through text books The reality is } \\
\text { when they leave school they are not going to have access to the texts books, they are not going to have access to that information. } \\
\text { Whereas if they learnt to find that information on the internet they will be able to use it when they go out whether it be through journals } \\
\text { or through wikipedia or through google. all these different ways you can find information that you often don't learn until you go to } \\
\text { university, but if you had that opportunity that would be ideal. }\end{array}$ \\
\hline f2 & $\begin{array}{l}\text { We are an art design class so it is completely relevant for them in this subject to be working with digital technologies. We use it all the } \\
\text { time to generate imagery - they are quite familiar with it, but not necessarily as a research tool. }\end{array}$ \\
\hline a1 & I may have forgotten, just research only \\
\hline
\end{tabular}

code

concept

.

$\begin{array}{lll}\text { En } & \\ \text { tec }\end{array}$

tec

\section{variation}

future includes digital technologies

world beyond school

world beyond school
rce sts

Work - use digital
technologies beyo

technologies beyond

school

\begin{tabular}{|l|l|} 
& \\
\hline $\begin{array}{l}\text { future, access } \\
\text { information. }\end{array}$ & \\
\hline $\begin{array}{l}\text { integral part of the } \\
\text { subject }\end{array}$ & ? \\
\hline $\begin{array}{l}\text { professional learning } \\
\text { learning }\end{array}$
\end{tabular}




\begin{tabular}{|c|c|c|c|}
\hline Source & Quote & code & concept \\
\hline $\mathrm{F} 1$ & Powerpoint - yes. I use it all the time, use it for my own learning, & presentation & \\
\hline d1 & $\begin{array}{l}\text { Word is used for my own learning when I am doing research it is so easy to just grab images off the internet then I will just write up } \\
\text { what I think about it then I can use that as a resource when I go to use that with my kids, so I have built up a library of different artists } \\
\text { and different information. }\end{array}$ & $\begin{array}{l}\text { develop } \quad \text { own } \\
\text { resources }\end{array}$ & \\
\hline a1 & $\begin{array}{l}\text { To actually research the place, the Moulin Rouge. To see how many acts, how many scenes to see how many costume changes } \\
\text { there are. You don't really get that from the DVD, as the DVD is so different. The screen is different to the stage show. It is easier for } \\
\text { them to see, they look at the DVD for the inspiration for the costumes, then the internet for the technical things like the change in } \\
\text { scenes and the costume changes. }\end{array}$ & range of information & access information \\
\hline $\mathrm{f1}$ & I think as a tool to discover and learn. & access to information & \\
\hline b1 & $\begin{array}{l}\text { Ideally I would like to have like a projector and be able to have my starter and things preplanned, I don't have to come in and write it } \\
\text { on the board, I can come in and just bang it up on the screen it is ready to go. It would give me more time because it is pre prepared I } \\
\text { would move onto the next thing the example, put that onto the board and you can work through it more efficiently, without having to } \\
\text { spend that time writing. If it is pre prepared even with OHTs. }\end{array}$ & $\begin{array}{l}\text { routines, organising } \\
\text { the lessons }\end{array}$ & \multirow{4}{*}{ time, efficiency } \\
\hline d1 & $\begin{array}{l}\text { Anything and everything that is going to assist them and push them further, If it makes it faster, they will produce more and experience } \\
\text { more. There are lots of things that are labour intensive like redrawing stuff in art. OK, it might help them become a better drawer, but } \\
\text { sometimes it is just unnecessary. The photocopier and the scanner are brilliant. Just like bare basic technologies that can speed up a } \\
\text { process and move along so that they spend more time on the learning side of it rather than the labour intensive. }\end{array}$ & redundancy & \\
\hline $\mathrm{f1}$ & $\begin{array}{l}\text { I would use these as a filler of after watching a DVD because I don't have computers in my class so I have to book the computer room } \\
\text { then I want to make the most of it. }\end{array}$ & time & \\
\hline b1 & Being able to present things to cut down time. & time & \\
\hline a1 & Like using the internet to get a whole lot of pictures really cheaply. Because is obviously prohibitive for the students & save money & \multirow{5}{*}{$\begin{array}{l}\text { save money, save } \\
\text { the world }\end{array}$} \\
\hline d3 & The closest I have got is digital submissions the students think it is great - it saves the students money. & save money & \\
\hline$f 1$ & $\begin{array}{l}\text { As an environmental thing it has plusses and minuses - it saves paper but the actual computers themselves aren't environmentally } \\
\text { friendly. We live in a world where it is such a focal point, I have to make it important and relevant.. }\end{array}$ & paper saving & \\
\hline e3 & $\begin{array}{l}\text { vKids send in their assignments via email into an assignment box. Like I have just done powerpoint presentations with my physical } \\
\text { education class - they presented them in class and also sent them to me rather than printing them off and handing them in. }\end{array}$ & $\begin{array}{l}\text { save money and } \\
\text { paperwork. }\end{array}$ & \\
\hline b1 & $\begin{array}{l}\text { There are activity worksheets, games, worksheets for games, other explanations how to play the games. Everything is there and it is } \\
\text { in one place. It is accessible from anywhere. If I am at home I can get hold of all the mathematics stuff at school and I don't have to } \\
\text { carry stuff home. So that is the biggest thing I do for planning. }\end{array}$ & $\begin{array}{l}\text { easy access save } \\
\text { paper/ carrying things }\end{array}$ & \\
\hline
\end{tabular}


